\title{
JAM-A: Junctional Adhesion Molecule-A or Janus Acting Mediator in atherosclerosis
}

Citation for published version (APA):

Schmitt, M. (2014). JAM-A: Junctional Adhesion Molecule-A or Janus Acting Mediator in atherosclerosis. [Doctoral Thesis, Maastricht University]. Uitgeverij BOXPress. https://doi.org/10.26481/dis.20140630ms

Document status and date:

Published: 01/01/2014

DOI:

10.26481/dis.20140630ms

Document Version:

Publisher's PDF, also known as Version of record

\section{Please check the document version of this publication:}

- A submitted manuscript is the version of the article upon submission and before peer-review. There can be important differences between the submitted version and the official published version of record.

People interested in the research are advised to contact the author for the final version of the publication, or visit the DOI to the publisher's website.

- The final author version and the galley proof are versions of the publication after peer review.

- The final published version features the final layout of the paper including the volume, issue and page numbers.

Link to publication

\footnotetext{
General rights rights.

- You may freely distribute the URL identifying the publication in the public portal. please follow below link for the End User Agreement:

www.umlib.nl/taverne-license

Take down policy

If you believe that this document breaches copyright please contact us at:

repository@maastrichtuniversity.nl

providing details and we will investigate your claim.
}

Copyright and moral rights for the publications made accessible in the public portal are retained by the authors and/or other copyright owners and it is a condition of accessing publications that users recognise and abide by the legal requirements associated with these

- Users may download and print one copy of any publication from the public portal for the purpose of private study or research.

- You may not further distribute the material or use it for any profit-making activity or commercial gain

If the publication is distributed under the terms of Article $25 \mathrm{fa}$ of the Dutch Copyright Act, indicated by the "Taverne" license above, 



\section{JAM-A: \\ Junctional Adhesion \\ Molecule-A}

\section{or}

\section{Janus Acting Mediator in Atherosclerosis}

\section{Dissertation}

to obtain the Degree of Doctor at Maastricht University and RWTH Aachen University on the authority of Rector Magnifici, Prof. dr. L.L.G. Soete and

Univ.-Prof. dr.-Ing. Ernst Schmachtenberg; in accordance with the decision of the Board of Deans of Maastricht University, in accordance with the Faculty of Mathematics, Computer Sciences and Natural Sciences of RWTH Aachen University.

to be defended in public in Maastricht on $30^{\text {th }}$ of June $2014,10.00 \mathrm{~h}$

by

Dipl. Biol. Martin Schmitt

born 5th of May 1983 in Düren, Germany 


\section{JAM-A: \\ Junctional Adhesion \\ Molecule-A}

\section{or \\ Janus Acting Mediator in Atherosclerosis}

Von der Fakultät für Mathematik, Informatik und Naturwissenschaften der RWTH Aachen University zur Erlangung des akademischen Grades eines Doktors der Naturwissenschaften genehmigte Dissertation

vorgelegt von

Diplom-Biologe

Martin Schmitt

aus Düren in Nordrhein-Westfalen, Deutschland

Berichter:

Univ.-Prof. dr. med. Christian Weber

Univ.-Prof. dr. rer. nat. Marc Spehr

Prof. Tilman Hackeng, PhD

Univ.-Prof. dr. rer. nat. Jürgen Bernhagen

Tag der mündlichen Prüfung: 18.06.2014 


\section{Supervisors:}

Prof. dr. Tilman M. Hackeng (Maastricht University)

Univ.-Prof. dr. Christian Weber (Maastricht University)

Univ.-Prof. dr. Nikolaus Marx (RWTH Aachen)

Co-Supervisor:

Dr. Rory R. Koenen (Maastricht University)

\section{Assessment Committee (Maastricht):}

Prof. dr. Mark J. Post (chairman)

Prof. dr. Eric A.L. Biessen

Univ.-Prof. dr. Jürgen Bernhagen (RWTH Aachen)

Univ.-Prof. dr. Fabian Kiesling (RWTH Aachen)

Prof. dr. Jaap J. Zwaginga (LUMC, Leiden University)

Assessment Committee (Aachen):

Univ.-Prof. dr. Christian Weber (LMU Munich)

Univ.-Prof. dr. Marc Spehr

Univ.-Prof. dr Jürgen Bernhagen

Prof. dr. Tilman M. Hackeng (Maastricht University) 


\title{
Euregio Cardiovascular (EuCAR) \\ International Research Training Group (IRTG) 1508 \\ 'Arterial remodeling'
}

at

\section{RWTH Aachen University}

\author{
Spokesperson: \\ Univ.-Prof. dr. rer. nat. Jürgen Bernhagen \\ Institute of Biochemistry and Molecular Cell Biology
}

and

\section{Maastricht University}

Spokesperson:

Prof. dr. Tilman Hackeng, PhD

School for Cardiovascular Diseases (CARIM) 
Layout: Martin Schmitt

Cover design: Martin Schmitt

(Cover picture was taken in Bregenz, Austria, and depicts the bifurcation of a carotid artery)

Printed by: Proefschriftmaken.nl || Uitgeverij BOXPress

Published by: Uitgeverij BOXPress, s'Hertogenbosch

ISBN: 978-90-8891-903-9

(C) 2014 Martin Schmitt, Munich 


\section{Contents}

Chapter 1 General Introduction

Chapter 2 Endothelial JAM-A guides monocytes into flow-dependent predilection sites of atherosclerosis

Chapter 3 Atherogenic mononuclear cell recruitment is facilitated by 72 oxidized lipoprotein-induced endothelial junctional adhesion molecule-A redistribution

Chapter 4 TNF- $\alpha$ and IFN- $\gamma$ promote lymphocyte adhesion to endothelial junctional regions facilitating transendothelial migration

Chapter 5 Hyperreactivity of junctional adhesion molecule A-deficient 124 platelets accelerates atherosclerosis in mice

Chapter 6 General Discussion

Summary 164

Zusammenfassung 169

Samenvatting 173

Curriculum Vitae / List of Publications 178 List of Abbreviations 184 Acknowledgement 


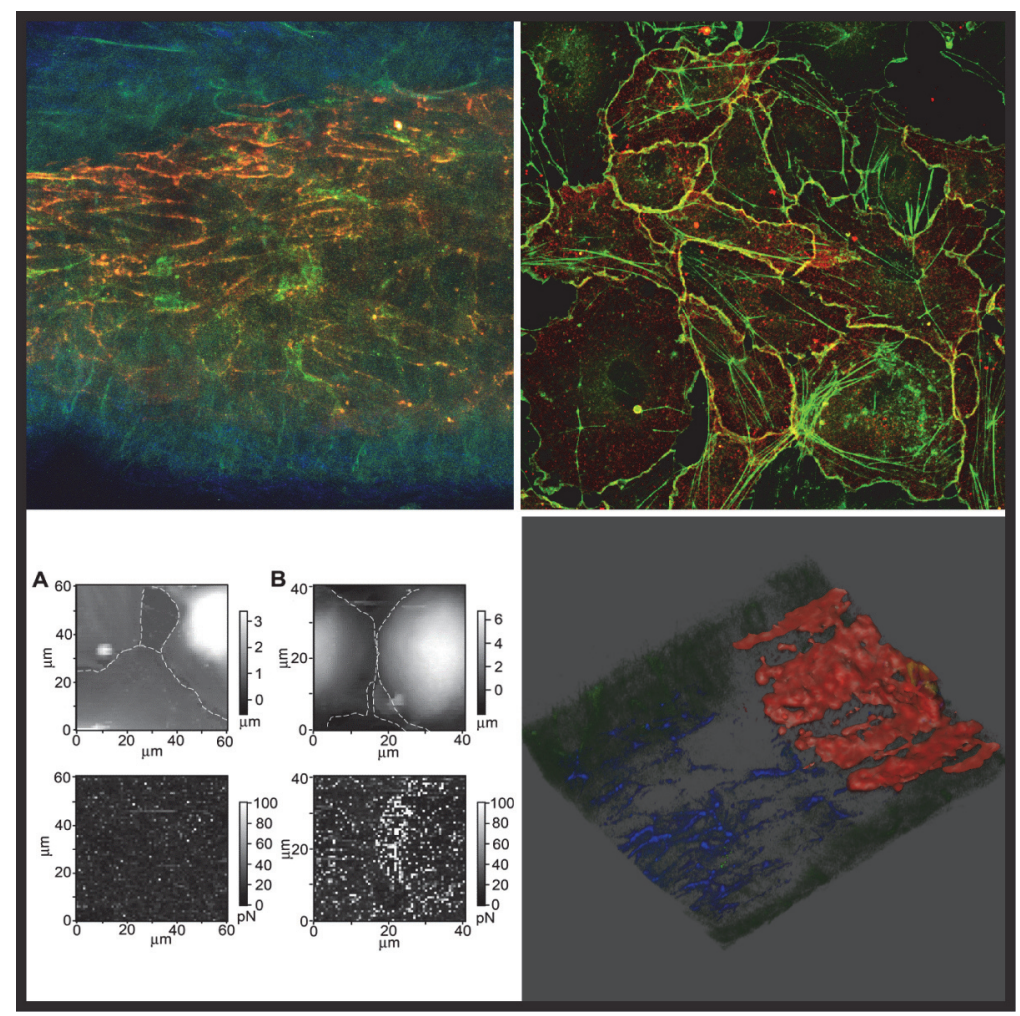

Chapter 1 
General

Introduction 


\section{Atherosclerosis}

Atherosclerosis is a chronic inflammation of the arterial wall and causes inter alia rearrangement of cellular and subcellular components. Besides some other diseases like thromboembolic disease, rhythm disorders and hypertension, atherosclerosis is the main contributor to cardiovascular diseases. Atherosclerotic lesions are mediated by modified low density lipoproteins (LDL) triggered immune cell influx, accumulation of dead mononuclear and vascular cells, reorganization of smooth muscle cells (SMC) as well as deposition of extracellular matrix like collagen. Most atherosclerotic lesions cause luminal narrowing comprising altered shear stress conditions, until unstable lesion rupture releases prothrombotic material into the lumen, initiating coagulation and causing occlusion. Dependent on the site of occlusion this may lead to myocardial infarction or stroke, two of the most important sources for illness and death in developed countries ${ }^{1-3}$.

The onset of atherosclerosis is represented by the formation of a "fatty streak", an accumulation of highly lipid-laden macrophages ${ }^{4}$. In a classification of plaque stages by Virmani and colleagues those intimal xanthomas still count for the non-atherosclerotic intimal lesions without necrotic core or fibrous depositions covering the lipid core, often referred to as fibrous cap ${ }^{5}$. Intimal macrophages phagocytose excess lipids, transform into "foam cells" and contribute together with activated endothelial cells and further intimal immune cells to the inflammatory milieu by secreting a great variety of cytokines, like Interleukin (IL)-1 and -6 , and tumor necrosis factor (TNF)- $\alpha^{6}$, chemokines and proteases. Progressive atherosclerotic lesions finally evolve from this enhanced secretion of atherogenic factors. Those lesion stages were categorized by Virmani et al. as pathological intimal thickening comprising SMCs in a proteoglycan-rich matrix and extracellular lipid accumulations and as fibrous cap atheroma containing a well-formed necrotic core and a covering fibrous cap. Finally, matrix-metallo protease mediated weakening of the fibrous cap results in a higher susceptibility to plaque rupture followed by vessel occlusion.

\section{The role of disturbed flow in atherogenesis}

Besides the generally accepted notion that hyperlipidemia induced excess of modified LDL in the vessel wall is responsible for activation of the endothelial cell layer and thus increasing mononuclear cell recruitment ${ }^{1,3}$, also alterations in laminar shear stress, preferentially occurring at branching points or curvatures activate the endothelium and cause enhanced mononuclear cell extravasation into the vessel wall ${ }^{7,8}$. First evidence for shear stress dependent mononuclear cell extravasation was found in the mid-eighties by differently localizing 
atherosclerotic plaques in areas of low shear stress ${ }^{9,} 10$ and later, plenty of evidence was found correlating shear stress mediated changes in expression pattern of chemokines, adhesion molecules, and microRNA (miR) to atherogenesis $^{11-13}$. Recently, Harrison and colleagues were able to show that endothelial borne platelet-endothelial cell adhesion molecule (PECAM)-1, a transmembrane protein of the immunoglobulin superfamily (Ig-Sf), is responsible for a decreased susceptibility for atherosclerotic lesion formation at vascular sites exposed to high shear stress but shows atherogenic effects in areas of low shear stress ${ }^{14}$.

Mononuclear cell recruitment thus is aggravated by an early activation of endothelial cells by both altered shear stress and modified LDL, accompanied by enhanced expression of adhesion molecules and chemokines. As atherosclerotic lesions contain a large number of effective immune cells, particularly monocytes and $\mathrm{T}$ lymphocytes ${ }^{15-17}$ the inflammatory recruitment of mononuclear cells is a process of central importance in initiation and progression of human atherosclerotic plaques, and has become a therapeutic target in the prevention and treatment of atherosclerosis.

\section{The leukocyte adhesion cascade}

The leukocyte adhesion cascade with its molecular effectors governs mononuclear cell extravasation into the vessel wall and is thus a complex and crucial mechanism mediating atherosclerotic lesion formation. It embraces a vast quantity of soluble and cell-bound molecular players orchestrating consecutive and defined steps of mononuclear cell infiltration ${ }^{18-21}$. Identifying molecular targets for therapeutic intervention would lead to new and powerful anti-inflammatory drugs ${ }^{22}$.

\section{Selectin mediated leukocyte tethering and slow rolling}

The initial step in the leukocyte adhesion cascade consists of tethering of leukocytes to the endothelium, which is mainly mediated by glycosylated Leukocyte-, Platelet- and Endothelial-selectin (CD62-L, -P, -E) and their binding partner Platelet-selectin glycoprotein ligand (PSGL)-123, 24 . Selectins are C-type lectin family members binding their ligands in a calcium-dependent manner. Additional to the interaction of leukocyte PSGL-1 with endothelial expressed Eand P-selectin, an interaction of L-selectin and PSGL-1 both expressed by leukocytes enables secondary leukocyte capture, thereby further assisting leukocyte binding to endothelial cell ${ }^{25}, 26$. P-selectin is also expressed by activated platelets, PSGL-1 is additionally expressed by endothelial cells ${ }^{27,28}$ and E-selectin also binds to glycosylated CD44 as well as E-selectin ligand $(E S L)-1^{29}$, overall increasing the number of interacting cell types. Intriguingly, 
$\mathrm{P}$ - and L-selectin mediated leukocyte tethering requires shear stress to support adhesion $^{30,31}$. Thus, adhesion strength grows while wall shear stress increases (catch bond), but with ever growing wall shear stress the adhesion strength decreases again (slip bond), possibly explaining why leukocyte tethering on selectins first increases and then decreases with rising wall shear stress ${ }^{32}$.

Subsequent to adhesion, leukocytes start to roll along the endothelium searching for suitable conditions like chemokine gradients or hot-spots of increased cell adhesion molecule (CAM) expression and meanwhile integrating different inflammatory signals which can activate numerous signaling pathways facilitating further steps in the leukocyte adhesion cascade like arrest or transmigration. The rapid ligand interaction and dissociation rate of selectins allow leukocytes to tether and roll along endothelial cells under shear flow ${ }^{33}$. Beside E- and P-selectin mediated rolling of leukocytes, also integrins participate in leukocyte rolling via $\alpha_{4} \beta_{7}$-integrin - mucosal vascular addressin cell-adhesion molecule (MADCAM)-1 interaction, very late antigen (VLA)-4 vascular cell-adhesion molecule (VCAM)-1 interaction ${ }^{34}$ and lymphocyte function-associated antigen (LFA)-1 - intercellular adhesion molecule (ICAM)-1 interaction $^{35}$. Integrins are cell surface receptors consisting of two type I transmembrane glycoproteins, one $\alpha$-subunit and one $\beta$-subunit, which are noncovalently linked. Various combinations of 18 different $\alpha$-subunits and 8 different $\beta$-subunits form at least 24 different heterodimers with diverse expression pattern, binding specificity and signaling properties ${ }^{36}$.

\section{The Arrest: Firm adhesion mediated by integrin - adhesion}

\section{molecule interaction}

Additional to the 3 classical steps of the leukocyte adhesion cascade, namely selectin-mediated rolling, chemokine-triggered activation and integrin-mediated firm adhesion ${ }^{37}$, nowadays the step of chemokine-triggered activation is expanded by 2 distinct processes that are arrest from leukocyte rolling and a post-binding phase of adhesion stabilization ${ }^{38}$. Both are governed by integrin activation increasing integrin affinity and attenuating integrin dissociation. Activation of LFA-1 and VLA-4 for example involves conformational changes from a bent low-affinity to an opened intermediate- and high-affinity conformation enabling integrins to bind to their specific interaction partners ICAM-1 and VCAM-1, respectively, which mediates arrest of rolling leukocytes $^{39,40}$. A rapid chemokine - G-protein coupled receptors (GPCR) interaction is needed to activate integrins via inside-out signaling. Quick activation/deactivation cycles mark GPCRs as particularly suitable for controlling rapid events like leukocyte arrest under shear stress conditions ${ }^{41-43}$. For easy accessibility and protection from proteolytic degradation, chemokines are deposited on glycosaminoglycans (GAG) of endothelial cells' luminal site by 
activated endothelial cells, mast cells and platelets. For example, chemokines like CXCL4 and CCL5 are deposited by platelets thereby triggering monocyte arrest, mediated by chemokine - GPCR interaction ${ }^{44,45}$. Moreover, not only an increase in ligand affinity subsequent to chemokine mediated activation, also the quantity of integrin molecules per cell determines the leukocyte adhesive strength $^{41,46,47}$.

Integrin clustering and allosteric conformational changes might trigger outside-in signaling and thus initiate activation of the full repertoire of signaling pathways $^{48}$. Absence of $\beta_{2}$ integrin mediated outside-in signaling or lack of guanine-nucleotide-exchange factors (GEF) important for outside-in signaling downstream-processes increased detachment of adherent leukocytes ${ }^{49}$, 50 , thus pointing clearly to a post-arrest phase of leukocyte adhesion stabilization.

Regulating integrin-mediated leukocyte adhesion activated by chemokines, at least 47 crucial proteins form a vast signaling network including at least 900 proteins and more than 6000 protein-protein interactions, thus representing a likely target for specificity and diversity in leukocyte adhesion ${ }^{38}$.

\section{Intraluminal crawling}

Subsequent to firm adhesion of leukocytes to the endothelium and in preparation of crossing the vessel wall, leukocytes start to crawl on the endothelium seeking preferred sites for transmigration in a macrophage 1 antigen (MAC-1)- and ICAM-1- dependent manner ${ }^{51,52}$. An inhibition in leukocyte extravasation and leukocytes preferring the transcellular route were observed when crawling was disabled ${ }^{52}$. Directly after leukocyte - endothelial cell binding triggered by adhesion molecule - integrin interaction, leukocytes start to form protrusions crawling into the endothelial cell body and junctions. This enhances the area of leukocyte and endothelial cell interaction and thus also the interaction area of adhesion molecules and integrins. Tetraspanin (CD9, CD151, CD81) mediated adhesion molecule clustering with subsequent binding to cytoplasmic molecules like ERM (ezrin, radixin, moesin) proteins and cytoskeletal components like vinculin, $\alpha$-actinin and talin-1 enables outside-in signaling, which is important for proceeding of the transmigration progress ${ }^{53,54}$. Endothelial cells form so-called transmigratory cups, ICAM-1 and VCAM-1 rich regions partly surrounding the leukocyte in order to initiate transendothelial migration ${ }^{53,55}$. In addition, binding of ICAM-1 to its integrin binding partner MAC-1 activates a p38 mitogen-activated protein kinase (MAPK) and RAS homologue (RHO) GTPase mediated signaling cascade leading to enhanced endothelial cell contraction and hence spreading of junctions of adjacent endothelial cells. Recently, an ICAM-1-activated endothelial nitric oxide (NO) synthase-dependent pathway was identified in the microvasculature of endothelial cells facilitating leukocyte transendothelial migration by modification 
of vascular-endothelial cell cadherin (VE-cadherin) phosphorylation ${ }^{56}$. VEcadherin is a crucial mediator of vascular permeability and tyrosine phosphorylation leads to loss of VE-cadherin mediated barrier function.

\section{Leukocyte transendothelial migration}

Crossing the vessel wall of postcapillary venules in order to reach the inflamed tissue underneath is the final step of the leukocyte adhesion cascade, which is part of a normal inflammatory reaction. Leukocyte transendothelial migration can be fast $(<2-5$ minutes), whereas passing the basement membrane can take much longer $(>5-15 \text { minutes })^{38}$. In pathological altered vessels leukocyte transendothelial migration also happens in arterioles, venules and even bigger arteries using a similar mechanism for leukocyte transendothelial migration through vascular endothelium. In general there are two distinct pathways of leukocyte extravasation, a paracellular route through the junctions of adjacent endothelial cells and a transcellular route where leukocytes prefer the thinnest site of the endothelial cell for crossing right through the cell body ${ }^{57}$. Carman and colleagues were able to provide evidence that transcellular migration occurs with an incidence of $5-20 \%$ in an in vitro model of MCP-1 activated HUVECs ${ }^{55}$, another model demonstrated $30 \%$ transcellular migration of T-lymphoblasts crossing TNF-stimulated human dermal microvascular endothelial cells ${ }^{58}$. Although transmigration rates are not consistent throughout different tissues stimulated by various triggers, the paracellular route seems to be the dominant one, likely due to the fundamental reorganization of cytoplasmic molecules necessary for transcellular migration.

\section{Paracellular transendothelial migration}

Leukocytes transmigrating on the paracellular route are guided through junctions of neighboring endothelial cells mainly by homophilic and heterophilic interactions of CAMs with integrins. Also re-localization of junctional CAMs away from cell-cell contacts to the luminal site of endothelial cells weakens the junctional barrier ${ }^{59}$ thus facilitating leukocyte transmigration on the paracellular route. In addition, re-localization of junctional CAMs increases their accessibility for leukocyte-borne interaction partners thus increasing firm adhesion ${ }^{60}$.

A number of CAMs are involved in guiding leukocytes through endothelial cell junctions. ICAM-1 and ICAM-2 interact with the integrin LFA-1 thus leading the leukocyte through the junction. PECAM-1 and CD99 mediate late stage transmigration via homophilic interactions ${ }^{20,21}$. Junctional adhesion molecule (JAM)-A, JAM-B, JAM-C and endothelial cell-selective adhesion molecule (ESAM) support transendothelial migration via both homophilic and heterophilic interactions with integrins ${ }^{60-62}$. Those adhesion molecules mediate leukocyte extravasation in a tissue-, stimulus- and leukocyte-specific manner. 
For example, in cremasteric venules PECAM-1, ICAM-1, and JAM-A mediate leukocyte extravasation in response to interleukin- $1^{63}$. An example for a leukocyte specific adhesion molecule is ESAM which mediates selectively neutrophil transmigration but does not influence T cell transmigration ${ }^{64}$.

\section{Transcellular transendothelial migration}

Leukocytes taking the transcellular route of transendothelial migration were shown in various inflammatory scenarios and in vitro models ${ }^{55,57,58,65,66}$. Intraluminal crawling constitutes the starting point of transcellular migration, where ICAM-1 mediated outside-in signaling triggers translocation of apical ICAM-1 to caveolae- and f-actin-rich regions and a potential caveolin-1 transport to the basal plasma membrane ${ }^{58,65}$. Actin and vimentin stabilize the endothelial-cell membrane, finally resulting in formation of channels through which leukocytes might pass. A lining of the cytoplasma/channel-lumeninterface with the same molecules facilitating paracellular migration is likely ${ }^{67}$.

\section{Crossing the basement membrane and pericyte layer}

The basement membrane is a network discontinuously surrounding endothelial cells of venules and capillaries being composed of laminins, such as laminin 411 ( $\alpha 4 \beta 1 \gamma 1$; laminin 8 ) and laminin $511(\alpha 5 \beta 1 \gamma 1$; laminin-10), and collagen type IV generated by endothelial cells and pericytes ${ }^{68}$. Laminins and collagen are interconnected by nidogen- 2 and the heparin sulphate proteoglycan perlecan ${ }^{69}$. In unstimulated murine cremasteric venules, regions of low expression of basement membrane matrix proteins could be detected and those low expression regions were even enlarged after IL-1 $\beta$ treatment ${ }^{70}$. Those low expression sites seem to be co-localized with gaps in the pericyte sheet, allowing leukocytes and chemoattractant molecules to pass through these areas of low hindrance ${ }^{70-72}$. Intriguingly, heparin-sulphate components of the basement membrane are able to bind chemokines and therefore accumulate those chemoattractant molecules ${ }^{73}$. After crossing the endothelial cell layer, an increased expression of laminin binding $\alpha_{6} \beta_{1}$ integrin activated by PECAM-1 interaction is likely, hence facilitating leukocyte migration through the basement membrane ${ }^{74}$. In addition to the concept of transmigration through physically permissive sites of the basement membrane, also transmigration due to biochemically permissive sites is under debate. Sites expressing laminin 511 are proposed to hinder transmigration, in contrast to promoted transmigration through laminin $411^{69}$. In detail, mice lacking a subunit of laminin 411 showed compensatory expression of a laminin 511 subunit, leading to reduced $T$ cell and neutrophil transmigration into inflamed central nervous system and into inflamed peritoneum, respectively ${ }^{75,76}$. In contrast, in vitro studies showed a 
higher ability to facilitate leukocyte transmigration of laminin $511^{77}$. In another study of mouse cremasteric venules, leukocyte permissive regions were deficient for both laminins ${ }^{72}$.

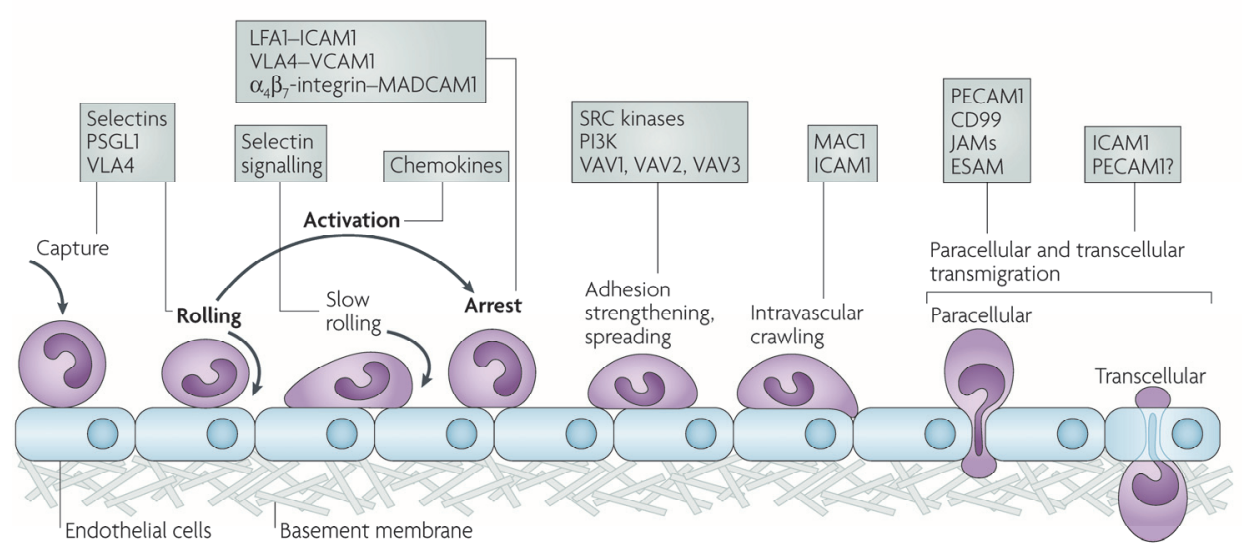

Figure 1: The updated leukocyte adhesion cascade.

The original three steps of the adhesion cascade are shown in bold: selectin-mediated rolling, chemokine-triggered activation and integrin-mediated adhesion. The figure has been extended by additional steps such as capture, slow rolling, adhesion strengthening and spreading, intravascular crawling and paracellular as well as transcellular transmigration. ESAM, endothelial cell-selective adhesion molecule; ICAM1, intercellular adhesion molecule 1; JAM, junctional adhesion molecule; LFA1, lymphocyte function-associated antigen 1; MAC1, macrophage antigen 1; MADCAM1, mucosal vascular addressin cell-adhesion molecule 1; PSGL1, P-selectin glycoprotein ligand 1; PECAM1, platelet/endothelial-cell adhesion molecule 1; PI3K, phosphoinositide 3-kinase; VCAM1, vascular cell-adhesion molecule 1; VLA4, very late antigen 4 (Ley et al. ${ }^{38}$ )

\section{Junctional Adhesion Molecules}

Junctional Adhesion Molecules (JAMs) are transmembrane proteins belonging to the Ig-Sf. The first JAM protein recognized was JAM-A (CD321, JAM-1 or F11-receptor) initially called F11-receptor, as it was identified as a receptor for the platelet activating antibody $\mathrm{F} 11^{78}$. Since initial studies were performed using endothelial and epithelial cells, the protein was named Junctional Adhesion Molecule based on its localization at cell-cell contacts. Later, further family members have been identified as JAM-B, JAM-C, JAM-4, ESAM and JAM-like (JAM-L) proteins. JAM-4, interacting with the PDZ domain (named after the first family members PSD-95, DLG, and ZO-1) of MAGI-1, is expressed at tight junctions (TJ) in epithelial cells ${ }^{79}$ and JAM-L is expressed by leukocytes and promotes adhesion to endothelial cells ${ }^{80}$ as well as coxsackie and adenovirus receptor (CAR) dependent neutrophil migration ${ }^{81}$. Detailed information on JAMA, JAM-B and JAM-C are to follow. 
All JAM family members share similar structural characteristics (JAM-A shown exemplary in Fig. 2), e.g. two extracellular Ig-like domains stabilized via disulfide bonds. The intracellular domain consists of a single-span transmembrane segment and a short cytoplasmic tail containing a phosphorylation site for protein kinase $\mathrm{C}$ (PKC) as well as a PDZ-binding motif (JAM-A: FLV) at the C-terminus.
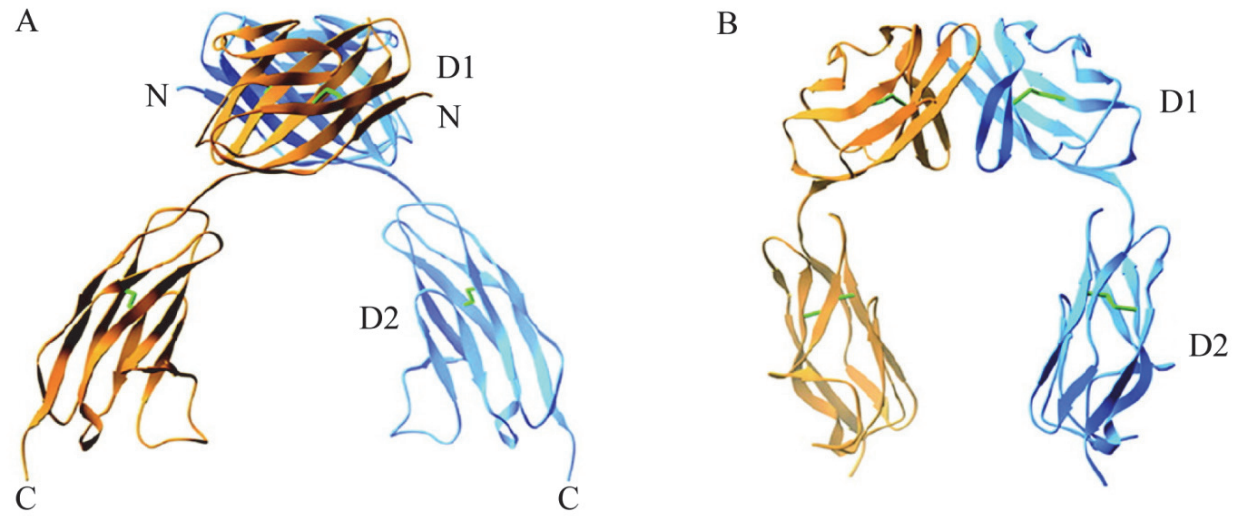

Figure 2: Structure of human JAM-A.

Ribbon drawing from human JAM-A dimer displaying one JAM-A molecule in blue and the other in orange. Disulfide bonds are shown in green. Two orthogonal views are shown (A/B). Immunoglobolin-like domain 1 (D1) is located distal, immunoglobulin-like domain 2 (D2) is located proximal to the C-terminus. (Prota et al. ${ }^{82}$ )

\section{Junctional Adhesion Molecule A}

The complete sequence of murine JAM-A was first identified in $1998^{83}$ followed by the identification of the human JAM-A in $1999^{84,85}$. JAM-A is highly conserved among mammals, with human, murine, bovine, and rodent JAM-A sharing about $70 \%$ amino acid identity ${ }^{83}, 86$. The crystal structures of the extracellular domain of murine JAM- $A^{87}$ and human JAM- $A^{82}$ (Fig.1) have been resolved, revealing two Ig-like domains being connected by a linker of 3 amino acids (VLV) resulting in a bent conformation with an angle of about $125^{\circ}$, which is stabilized by hydrogen bonding to both domains ${ }^{87}$. The membrane-distal D1 of JAM-A, containing a dimerization motif (RVE), facilitates homodimer formation (Fig. 2).

\section{Expression and localization}

JAM-A is mostly abundant in the tight junctions of cell-cell interfaces of endothelial and epithelial cells of various organs including liver, kidney, pancreas, heart, brain, lymph nodes, intestine, lung, placenta, and vascular tissue ${ }^{83,86,88,89}$; moreover it is expressed by nearly every cell-type of lymphoid 
and myeloid origin ${ }^{85,87}$. The junctional localization of JAM-A can be modified by inflammatory cytokines, as TNF- $\alpha$ and IFN- $\gamma$ treatment of endothelial cells causes re-localization of JAM-A from the intercellular junctions to the luminal surface $^{59,84}$, while expression levels were left unchanged ${ }^{59,84,90}$.

The re-localization of JAM-A might be facilitated by a TNF- $\alpha$ induced relieve of JAM-A from actin $^{91}$. In line with these findings, a MCP-1 facilitated JAM-A re-localization occurred also in brain endothelium. Internalization of JAM-A involving macropinocytosis is accompanied by Rho and Rho kinase as well as actin reorganization. JAM-A is transiently stored in endosomes and recruited to the apical site of endothelial cells ${ }^{92}$.

\section{Interaction partner and function}

An over-expression of JAM-A increases endothelial cell barrier-function as JAM-A interacts in a homophilic manner with neighboring molecules (in cis) and in dimeric state also with other dimers from adjacent cells (in trans) ${ }^{87}$, thus creating a tight, zipper-like structure (Fig. 3). The dimerization motif (RVE) responsible for homophilic binding obtains highly polar character and the competence to manage rearrangements being important for the transmigration process of leukocytes ${ }^{82}$. JAM-A homophilic interactions were shown to be essential for localization of JAM-A at TJs and for regulation of barrier function in epithelial cells ${ }^{93}$.

The heterophilic interaction of JAM-A with the $\alpha_{\llcorner} \beta_{2}$-integrin LFA-1 (CD11a/CD18) facilitates leukocyte adhesion and transmigration through the endothelial cell monolayer via integrin I-domain and JAM-A D2 interactions ${ }^{94,95}$. Homophilic JAM-A binding affinities were observed to be weaker than heterophilic JAM-A-LFA-1 interaction ${ }^{96}$. Remarkably, Wojcikiewicz and colleagues postulate that the more potent LFA-1-JAM-A interaction might have dual purpose: on the one hand it mediates leukocyte adhesion to endothelial cell junctions and on the other hand it weakens JAM-A homophilic interactions, thereby opening the TJ and helping the leukocyte to transmigrate. To be mentioned, the authors assume that the in vitro situation only corresponds to JAM-A homophilic interaction in trans by comparing JAM-A homophilic to JAMA-LFA-1 binding forces, meaning that both homophilic interactions in parallel might strengthen the binding forces ${ }^{96}$. Furthermore, JAM-A is a reovirus receptor ${ }^{97}$ which binds via D1 to the viral attachment protein $\sigma 1^{82}$.

Intracellular interactions of JAM-A take place with several different proteins containing PDZ domains. For example the junctional proteins zonula occludens-1 (ZO-1) and ALL-1 fusion partner from chromosome 6 (AF-6), both directly linked to the actin cytoskeleton ${ }^{98,99}$, bind to JAM-A with their diverse PDZ domains ${ }^{100}$. Those interactions anchor JAM-A to the actin filament system, enabling a quick actin-mediated re-localization of JAM-A. ZO-1 also may colocalize JAM-A with other TJ proteins like occluding and cingulin ${ }^{101}$. Another 
PDZ domain dependent anchoring protein is the multi-PDZ domain protein 1 (MUPP-1), which binds both JAM-A and claudin-1 by functioning as a multivalent scaffold protein recruiting various proteins to $\mathrm{TJs}^{102}$. Other PDZdomain dependent binding partners for JAM-A are calcium/calmodulindependent serine protein kinase (CASK) and atypical PKC isotype specific interacting protein $(A S I P)^{103-105}$, which may provide JAM-A with inside-out or outside-in signal transduction properties.

JAM-A additionally plays a role in angiogenesis. Key studies were able to show basic fibroblast growth factor (bFGF)-induced angiogenesis via dissociation of the JAM-A/ $\alpha_{V} \beta_{3}$ integrin complex thus allowing JAM-A signaling ${ }^{106}$. Moreover, bFGF induced inhibition of angiogenesis in JAM-A deficient mice was demonstrated ${ }^{107}$. Furthermore, JAM-A regulates the motility of epithelial ${ }^{93}$ and endothelial cells ${ }^{63,108}$, thus also playing a crucial role after mechanical injury of the vessel wall as conducted in stenting or in the inflammatory injury models like wire injury or ischemia/reperfusion injury. As angiogenesis and the formation of new blood vessels are of outmost importance for tumor growth, JAM-A is discussed as putative target for cancer therapy.

Recently, additional functions of JAM-A have been discovered, as JAMA mediated adhesion of $\mathrm{CD}_{3} 4^{+}$stem cells to the vascular wall after injury resulted in differentiation into endothelial progenitor cells, thus facilitating reendothelialization ${ }^{109}$.

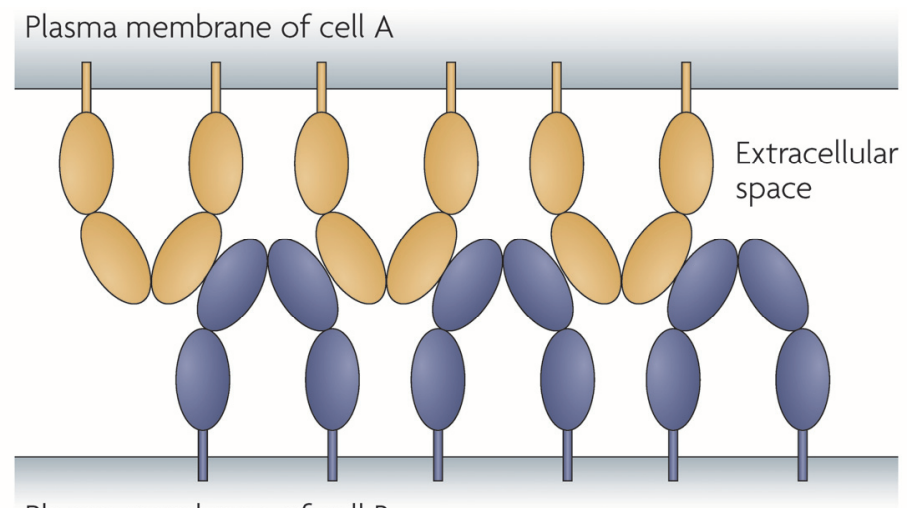

Plasma membrane of cell B

Figure 3: Homophilic JAM-A interactions in cis and in trans.

Neighboring JAM-A molecules form homophilic interactions in cis via binding of dimerization motifs located at the membrane-distal Ig domain. JAM-A dimers situated on two adjacent cells (orange and blue) form JAM-A homophilic interactions in trans, thus creating a zipper like structure. 


\section{Pathobiology of JAM-A expressed by different (immune) cell types}

Evidence for a differing impact of JAM-A deficiency in diverse cell types pertaining to inflammatory diseases and tumor angiogenesis is growing strongly. To delineate each effect JAM-A deficiency exerts on the different pathobiological mechanisms the following will provide a short introduction into this complex topic.

\section{Endothelial Cells:}

The first report of a role for endothelial JAM-A in monocyte transmigration demonstrated an inhibition of monocyte transmigration using a blocking monoclonal antibody against JAM-A on cultured endothelial cells ${ }^{83}$. Additionally, using this antibody in an air-pouch model, first in vivo evidence for JAM-A mediated monocyte transmigration arose. Furthermore, treatment with a monoclonal antibody against JAM-A significantly inhibited leukocyte accumulation in the cerebrospinal fluid and infiltration in the brain parenchyma $^{110}$.

First evidence for endothelial JAM-A facilitating atherosclerotic lesion formation came from Ostermann and colleagues (2005) and Babinska et al. (2007). They showed an increase of endothelial JAM-A mRNA and protein in early lesions of carotid arteries from apolipoprotein $E$ (Apoe) deficient mice after $\operatorname{diet}^{111}$ and in human atherosclerotic plaque biopsies ${ }^{112}$. The increase of endothelial JAM-A in human atherosclerotic plaque could also be validated by micro array technique ${ }^{113}$.

Additionally, a role for endothelial JAM-A in other inflammatory models could be proven. In ischemia/reperfusion (I/R) experiments of murine liver, JAM-A was upregulated in hepatic venular endothelium during reperfusion, accompanied by increased neutrophil recruitment rates. Accordingly, endothelial JAM-A deficiency resulted in a decreased neutrophil recruitment to hepatic tissue after $\mathrm{I} / \mathrm{R}$ in vivo ${ }^{114}$. Hyperplasia after wire injury of the carotid artery of Apoe deficient mice was significantly reduced in mice lacking JAM-A. Concomitantly, diminished neointimal macrophage content, decreased monocyte recruitment to injured eJAM- $\mathrm{A}^{-1}$ carotid arteries ex vivo and decreased transmigration of monocytes through JAM-A/Apoe deficient endothelial cells under flow conditions in vitro were found.

\section{Monocytes:}

Not much is known about the specific role of JAM-A in monocytes regarding inflammatory diseases. The only indication is reduced monocyte adhesion to an explanted carotid artery perfused with monocytes treated with soluble JAM-A.Fc ${ }^{111}$. This treatment blocks monocyte adhesion in a VLA-4 independent manner. 


\section{T cells:}

Like monocytes VLA-4 independent T cell adhesion to an ex vivo perfused carotid artery can be blocked by soluble JAM-A.F ${ }^{111}$. Additionally, a reduction of $T$ cell arrest under flow conditions and transendothelial chemotaxis towards SDF-1 after blocking JAM-A using antibody or soluble JAM-A.FC in in vitro assays were demonstrated.

\section{Dendritic cells:}

In in vitro assays JAM-A deficiency in dendritic cells caused an increased random motility and transmigration across lymphatic but not blood microvascular endothelial cells ${ }^{115}$. In vivo experiments using JAM-A deficient mice revealed increased dendritic cell migration to lymph nodes, whereas an endothelial JAM-A deficiency did not alter dendritic cell transmigration rates. Adoptive transfer experiments transferring JAM-A deficient dendritic cells to JAM-A wild type mice revealed increased contact hypersensitivity, thus linking JAM-A deficiency mediated increase of dendritic cell transmigration rates to contact hypersensitivity.

\section{Neutrophils:}

Neutrophils deficient for JAM-A showed defective uropod retraction and aberrant transendothelial migration in inflammatory models of peritonitis and heart ischemia/reperfusion as well as in adhesion and transmigration assays in vitro $^{116}$. In vivo, more $\mathrm{JAM}^{-\mathrm{A}^{--}}$neutrophils adhered to the endothelium or were trapped in between the endothelium and the basement membrane compared to JAM- $A^{+/+}$neutrophils, which was shown to be an endothelial JAM-A independent effect. Interestingly, morphologic analyses of JAM-A deficient neutrophils revealed long adhesive tails, a consequence of defective de-adhesion. Additionally, the motility of $\mathrm{JAM}^{-\mathrm{A}^{-/}}$neutrophils was significantly reduced compared to JAM-A ${ }^{+/+}$neutrophils, strongly hinting towards a defect in cell deadhesion.

An impaired interstitial migration of murine neutrophils lacking JAM-A has been shown in cremasteric venules after leukotriene B4 (LTB-4) treatment ${ }^{117}$. Furthermore, a co-internalization of $\beta_{1}$ integrins together with JAMA after inflammatory treatment could be demonstrated. As explanation for the decreased motility of neutrophils the authors suggest a JAM-A deficiency induced disruption of internalization of $\beta_{1}$ integrins expressed by neutrophils after treatment with $N$-formyl-1-1methionyl-1-1leucyl-1-phenylalanine (fMLP). This might be mediated by the small GTPase Rap-1, which plays a role in integrin internalization ${ }^{118}$ and which activity is reduced in JAM-A deficient neutrophils. Interestingly, Western blotting and FACS analysis demonstrated unaltered amounts of total $\beta_{1}$ integrin between JAM-A wild-type and deficient 
neutrophils, revealing no changes in expression level. The decrease of integrininternalization possibly causes the defect in directional migration and uropod retraction.

The mechanism of JAM-A-regulated $\beta_{1}$ integrin internalization and recycling mediated by Rap-1 activity could also be shown in epithelial cells ${ }^{119}$, ${ }^{120}$. Like in neutrophils also the motility of epithelial cells is influenced by $\beta_{1}$ integrin internalization, mediated by cis dimerization of JAM-A D2 Ig-like domains as well as PDZ-guanine nucleotide exchange factor (GEF) 2/Afadin interaction. Another study reported enhanced random motility of JAM-Adeficient endothelial cells, also providing data showing a role of JAM-A in endothelial cell motility through interactions with the junctional complex and the cytoskeleton via PSD95-Dlg-ZO-1 ${ }^{108}$.

\section{Platelets:}

The human F11 receptor was first cloned from platelet F11R cDNA in order to determine its structure ${ }^{121}$. Later, the human F11 receptor was determined as the homologue of murine Junctional Adhesion Molecule, leading to the uniform nomenclature of Junctional Adhesion Molecules for both species ${ }^{122}$. A monoclonal antibody against this platelet membrane protein, called Mab F11, caused platelet aggregation, granule secretion and phosphorylation of intracellular proteins ${ }^{78}$. Another study demonstrated JAM-A phosphorylation in thrombin and collagen activated platelets, thus initially hinting towards a physiological role ${ }^{121}$. The authors believed that thrombocytic JAM-A displays two distinct functions. On the one hand, JAM-A mediates integrin GPIIb/IIla dependent platelet aggregation, on the other hand JAM-A mediates platelet adhesion independent of integrins or fibrinogen receptors via homophilic JAM-A interactions with other cell types, thus playing a role in physiological processes important for platelet aggregation. Like murine JAM-A, cloning of human JAM-A into Chinese hamster ovary $(\mathrm{CHO})$ cells revealed JAM-A accumulations on the cell surface and enhanced localization between two adjacent cells ${ }^{122}$. Interestingly, the intracellular moiety of JAM-A co-localized with cortical f-actin, but not with cell-spanning stress fibers. Compared to JAM-A ${ }^{-/-} \mathrm{CHO}$ cells, more platelets adhered to immobilized JAM-A expressing $\mathrm{CHO}$ cells, contributing to the first evidence for JAM-A homophilic interactions. Definite indication for JAMA homophilic interaction came from Babinska and colleagues ${ }^{123}$. They were able to show specific adhesion of platelets to a matrix of immobilized JAM-A molecules or to activated HUVEC monolayers, which was inhibited by treatment with soluble JAM-A or JAM-A peptides mimicking N-terminal amino acid sequences. Recently, it was shown that thrombocytic JAM-A dampens integrin mediated outside-in signaling, thus decreasing platelets thrombotic potential by sustaining the inactive form therefor impairing platelet aggregation ${ }^{124}$. 


\section{Junctional Adhesion Molecule B}

JAM-B (VE-JAM, human JAM-2, murine JAM-3) shares the main part of the other JAM family members' structure, besides its dimerization motif (ALE) and an additional disulfide bridge in domain 1. In general the dimerization motifs are conserved features of JAMs, implying that heterophilic dimerization may also take part with JAM-B as one of the interaction partners. Additionally, JAM-B is not as prevalently expressed as JAM-A. Therefor JAM-B expression is restricted to endothelial cells and localizes mainly in the junctions of high endothelial venules ${ }^{125}$ and of the heart ${ }^{126}$. Contrary to JAM-A, the expression of JAM-B was not detected in leukocytes ${ }^{126}$. Heterophilic interaction partners of JAM-B were found in the leukocyte integrin VLA-4 and in JAM-C $C^{127,} 128$. Intriguingly, the JAM-B/VLA-4 interaction was shown to be JAM-C dependent, as $T$ cells lacking functional JAM-C did not show any JAM-B/VLA-4 interaction. Additional to endothelial cell expression, JAM-B is more abundant in tissues with chronic inflammatory diseases like asthma, bronchitis, interstitial nephritis, autoimmune hepatitis and alcoholic cirrhosis ${ }^{129}$. Using a model for murine allergic contact dermatitis, evidence was gathered that JAM-B also plays a role in leukocyte transmigration. After injection of neutralizing antibodies against JAM-B, mice showed reduced contact dermatitis as well as decreased leukocyte infiltration into the ear ${ }^{130}$. Summing up, the role of JAM-B in leukocyte transmigration and in vascular diseases seems not to be as crucial as JAM-A.

\section{Junctional Adhesion Molecule C}

Like its other family members, JAM-C (also known as JAM3, hJAM3 and mJAM-2) is expressed in endothelial cells, more precisely murine JAM-C was identified to be localized at high endothelial venules within lymph nodes and Peyer's patches ${ }^{131}$. Human JAM-C has been additionally detected on platelets, and lymphocytes such as monocytes, natural killer cells, dendritic cells, B cells and a T cell subset ${ }^{127,129,132,133}$. Dimerization (JAM-C dimerization motif: RIE) in homophilic manner via Ig domain 1 exists $^{134}$, but also in a heterophilic manner with JAM-B ${ }^{127}, M A C-1$ (alpha ${ }_{M}$ beta $_{2}$ integrin) and to a lesser extend alpha $a_{x}$ beta $_{2}$ integrin ${ }^{81,133}$. Intriguingly, binding affinity for JAM-C homodimers is weaker compared to JAM-C-JAM-B heterophilic interactions, possibly pointing towards a control mechanism for leukocyte adhesion through JAM-B expression ${ }^{135}$. First evidence for a role of JAM-C in human leukocyte transmigration was discovered when a blocking antibody against JAM-C or soluble JAM-C protein inhibited leukocyte transmigration across HUVECs ${ }^{132}$ additional to platelet-neutrophil interaction ${ }^{133}$. Later, an involvement of JAM-C in transmigration of leukocytes in different inflammation models like allergic dermatitis ${ }^{130}$, peritonitis ${ }^{136}$, acute pancreatitis $^{137}$, pulmonary inflammation ${ }^{138}$ and ischemia/reperfusion injury ${ }^{139}$ 
has been shown, where neutralizing antibodies or blockade with soluble JAM-C protein reduced leukocyte infiltration. Interestingly, endothelial JAM-C overexpression in the last three models mentioned resulted in increased leukocyte influx and exacerbated inflammation, which strongly indicates a role of JAM-C in leukocyte transmigration, but Bradfield and colleagues ${ }^{140}$ and Woodfin et al. ${ }^{141}$ found evidence that JAM-C rather regulates polarized leukocyte transmigration in such a way that it blocks leukocyte reverse endothelial transmigration. Further proof for a role of JAM-C in atherosclerosis was provided when an increase in JAM-C expression in atherosclerotic lesions of Apoe $^{-/-}$mice was shown ${ }^{142}$. Additionally, the authors were able to show an increase in JAM-C expression after oxidized as well as enzymatically modified LDL treatment of HUVECs together with a re-localization away from endothelial cell junctions to their apical site, thus increasing JAM-C's availability for its leukocyte counter-receptors. This inflammatory re-localization was also shown in vivo after ischemia/reperfusion injury ${ }^{139}$. More evidence for a role of JAM-C in atherosclerotic lesion formation came from Shagdarsuren and colleagues showing that JAM-C blockade decreased neointimal hyperplasia after wire injury of carotid arteries ${ }^{143}$ and from Langer et al. presenting a MAC-1/JAM-C mediated platelet-dendritic cell interaction leading to dendritic cell activation and recruitment to the injured vessel wall as well as platelet phagocytosis ${ }^{144}$. In contrast, one study was not able to detect differences in JAM-C expression pattern after inflammatory stimuli nor JAM-C dependent neutrophil adhesion and transmigration in in vitro flow assays ${ }^{145}$. Only when JAM-C blockade met blockade of PECAM-1, ICAM-1 and CD99 an effect on neutrophil transmigration became evident. 


\section{Aim of the study}

Preceding studies identified JAM-A as a crucial mediator for leukocyte adhesion as well as leukocyte transmigration in different inflammatory models, additionally to a JAM-A overexpression in atherosclerotic lesions of hyperlipidemic tissue of mice and human, but direct evidence for JAM-A facilitated mononuclear cell transmigration in hyperlipidemia and disturbed flow mediated atherosclerotic lesion formation is still missing. Furthermore, deficiency of leukocytic JAM-A has an impact on cell motility and integrin expression, but information on the consequences on atherosclerotic lesion formation is lacking yet. On molecular level, a re-localization of JAM-A after inflammatory stimuli was demonstrated, but deeper knowledge of re-localization sites in a atherogenic context and its causal mechanism remain elusive. By using $\mathrm{Apoe}^{--}$mice with a specific JAM-A deficiency in endothelial cells, leukocytes or platelets as well as deficiency of somatic JAM-A, we aimed to clarify the different roles of JAM-A originating from different cellular compartments on leukocyte transmigration and thus on hyperlipidemia mediated and flow-dependent atherosclerotic lesion formation additional to its net effect. As JAM-A re-localization seems to be an important prerequisite for leukocyte transmigration in inflammatory diseases, extensive fluorescent microscopy and atomic force microscopy studies shall add more information to JAM-A localization in inflammatory and atherogenic settings and its underlying mechanism. Targeting JAM-A localization might be a therapeutic strategy to interfere mononuclear cell transmigration in atherosclerotic vessels. The cholesterol-lowering lovastatin and the peroxisome proliferator activated receptor gamma-agonist pioglitazone are commonly used anti-atherosclerotic drugs, which have been shown to exert beneficial effects on oxLDL receptor expression and mononuclear cell recruitment ${ }^{146-151}$. Thus, the influence of lovastatin and pioglitazone on JAM-A localization and JAM-A mediated mononuclear cell recruitment shall be investigated. 


\section{References}

1. Hansson GK. Inflammation, atherosclerosis, and coronary artery disease. The New England journal of medicine. 2005;352:1685-1695

2. Hansson GK, Robertson AK, Soderberg-Naucler C. Inflammation and atherosclerosis. Annual review of pathology. 2006;1:297-329

3. Libby P. Inflammation in atherosclerosis. Nature. 2002;420:868-874

4. Weber C, Zernecke A, Libby P. The multifaceted contributions of leukocyte subsets to atherosclerosis: Lessons from mouse models. Nature reviews. Immunology. 2008;8:802815

5. Virmani R, Kolodgie FD, Burke AP, Farb A, Schwartz SM. Lessons from sudden coronary death: A comprehensive morphological classification scheme for atherosclerotic lesions. Arteriosclerosis, thrombosis, and vascular biology. 2000;20:1262-1275

6. Kishikawa $\mathrm{H}$, Shimokama $\mathrm{T}$, Watanabe $\mathrm{T}$. Localization of tymphocytes and macrophages expressing il-1, il-2 receptor, il-6 and tnf in human aortic intima. Role of cellmediated immunity in human atherogenesis. Virchows Archiv. A, Pathological anatomy and histopathology. 1993;423:433-442

7. Chiu JJ, Usami S, Chien S. Vascular endothelial responses to altered shear stress: Pathologic implications for atherosclerosis. Annals of medicine. 2009;41:19-28

8. Chiu JJ, Chien S. Effects of disturbed flow on vascular endothelium: Pathophysiological basis and clinical perspectives. Physiological reviews. 2011;91:327-387

9. Zarins CK, Giddens DP, Bharadvaj BK, Sottiurai VS, Mabon RF, Glagov S. Carotid bifurcation atherosclerosis. Quantitative correlation of plaque localization with flow velocity profiles and wall shear stress. Circulation research. 1983;53:502-514

10. Ku DN, Giddens DP, Zarins CK, Glagov S. Pulsatile flow and atherosclerosis in the human carotid bifurcation. Positive correlation between plaque location and low oscillating shear stress. Arteriosclerosis. 1985;5:293-302

11. Chen XL, Grey JY, Thomas S, Qiu FH, Medford RM, Wasserman MA, Kunsch C. Sphingosine kinase-1 mediates tnf-alpha-induced mcp-1 gene expression in endothelial cells: Upregulation by oscillatory flow. American journal of physiology. Heart and circulatory physiology. 2004;287:H1452-1458

12. Melchionna R, Porcelli D, Mangoni A, Carlini D, Liuzzo G, Spinetti G, Antonini A, Capogrossi MC, Napolitano M. Laminar shear stress inhibits cxcr4 expression on endothelial cells: Functional consequences for atherogenesis. FASEB journal : official publication of the Federation of American Societies for Experimental Biology. 2005;19:629-631

13. Hergenreider E, Heydt S, Treguer K, Boettger T, Horrevoets AJ, Zeiher AM, Scheffer MP, Frangakis AS, Yin X, Mayr M, Braun T, Urbich C, Boon RA, Dimmeler S. Atheroprotective communication between endothelial cells and smooth muscle cells through mirnas. Nat Cell Biol. 2012;14:249-256

14. Harrison M, Smith E, Ross E, Krams R, Segers D, Buckley CD, Nash GB, Rainger GE. The role of platelet-endothelial cell adhesion molecule-1 in atheroma formation varies depending on the site-specific hemodynamic environment. Arteriosclerosis, thrombosis, and vascular biology. 2013;33:694-701

15. Jonasson L, Holm J, Skalli O, Bondjers G, Hansson GK. Regional accumulations of $t$ cells, macrophages, and smooth muscle cells in the human atherosclerotic plaque. Arteriosclerosis. 1986;6:131-138

16. Hansson GK, Holm J, Jonasson L. Detection of activated t lymphocytes in the human atherosclerotic plaque. The American journal of pathology. 1989;135:169-175

17. Stemme S, Holm J, Hansson GK. T lymphocytes in human atherosclerotic plaques are memory cells expressing cd45ro and the integrin vla-1. Arteriosclerosis and thrombosis : a journal of vascular biology / American Heart Association. 1992;12:206-211

18. Woodfin A, Reichel CA, Khandoga A, Corada M, Voisin MB, Scheiermann C, Haskard DO, Dejana E, Krombach F, Nourshargh S. Jam-a mediates neutrophil transmigration in a stimulus-specific manner in vivo: Evidence for sequential roles for jam-a and pecam-1 in neutrophil transmigration. Blood. 2007;110:1848-1856

19. Woodfin A, Voisin MB, Imhof BA, Dejana E, Engelhardt B, Nourshargh S. Endothelial cell activation leads to neutrophil transmigration as supported by the sequential roles of icam2, jam-a, and pecam-1. Blood. 2009;113:6246-6257 
20. Schenkel AR, Mamdouh Z, Chen X, Liebman RM, Muller WA. Cd99 plays a major role in the migration of monocytes through endothelial junctions. Nature immunology. 2002;3:143-150

21. Lou O, Alcaide P, Luscinskas FW, Muller WA. Cd99 is a key mediator of the transendothelial migration of neutrophils. J Immunol. 2007;178:1136-1143

22. Mackay CR. Moving targets: Cell migration inhibitors as new anti-inflammatory therapies. Nature immunology. 2008;9:988-998

23. Kansas GS. Selectins and their ligands: Current concepts and controversies. Blood. 1996;88:3259-3287

24. McEver RP, Cummings RD. Perspectives series: Cell adhesion in vascular biology. Role of psgl-1 binding to selectins in leukocyte recruitment. The Journal of clinical investigation. 1997;100:485-491

25. Eriksson EE, Xie X, Werr J, Thoren P, Lindbom L. Importance of primary capture and Iselectin-dependent secondary capture in leukocyte accumulation in inflammation and atherosclerosis in vivo. The Journal of experimental medicine. 2001;194:205-218

26. Sperandio M, Smith ML, Forlow SB, Olson TS, Xia L, McEver RP, Ley K. P-selectin glycoprotein ligand-1 mediates I-selectin-dependent leukocyte rolling in venules. The Journal of experimental medicine. 2003;197:1355-1363

27. Rivera-Nieves J, Burcin TL, Olson TS, Morris MA, McDuffie M, Cominelli F, Ley K. Critical role of endothelial p-selectin glycoprotein ligand 1 in chronic murine ileitis. The Journal of experimental medicine. 2006;203:907-917

28. da Costa Martins P, Garcia-Vallejo JJ, van Thienen JV, Fernandez-Borja M, van Gils JM, Beckers C, Horrevoets AJ, Hordijk PL, Zwaginga JJ. P-selectin glycoprotein ligand-1 is expressed on endothelial cells and mediates monocyte adhesion to activated endothelium. Arteriosclerosis, thrombosis, and vascular biology. 2007;27:1023-1029

29. Hidalgo A, Peired AJ, Wild MK, Vestweber D, Frenette PS. Complete identification of eselectin ligands on neutrophils reveals distinct functions of psgl-1, esl-1, and cd44. Immunity. 2007;26:477-489

30. Finger EB, Puri KD, Alon R, Lawrence MB, von Andrian UH, Springer TA. Adhesion through I-selectin requires a threshold hydrodynamic shear. Nature. 1996;379:266-269

31. Lawrence MB, Kansas GS, Kunkel EJ, Ley K. Threshold levels of fluid shear promote leukocyte adhesion through selectins (cd62l,p,e). J Cell Biol. 1997;136:717-727

32. Marshall BT, Long M, Piper JW, Yago T, McEver RP, Zhu C. Direct observation of catch bonds involving cell-adhesion molecules. Nature. 2003;423:190-193

33. Alon R, Hammer DA, Springer TA. Lifetime of the p-selectin-carbohydrate bond and its response to tensile force in hydrodynamic flow. Nature. 1995;374:539-542

34. Berlin C, Bargatze RF, Campbell JJ, von Andrian UH, Szabo MC, Hasslen SR, Nelson $\mathrm{RD}$, Berg EL, Erlandsen SL, Butcher EC. Alpha 4 integrins mediate lymphocyte attachment and rolling under physiologic flow. Cell. 1995;80:413-422

35. Salas A, Shimaoka M, Kogan AN, Harwood C, von Andrian UH, Springer TA. Rolling adhesion through an extended conformation of integrin alphalbeta2 and relation to alpha $\mathrm{i}$ and beta i-like domain interaction. Immunity. 2004;20:393-406

36. Springer TA, Wang JH. The three-dimensional structure of integrins and their ligands, and conformational regulation of cell adhesion. Advances in protein chemistry. 2004;68:29-63

37. Springer TA. Traffic signals for lymphocyte recirculation and leukocyte emigration: The multistep paradigm. Cell. 1994;76:301-314

38. Ley K, Laudanna C, Cybulsky MI, Nourshargh S. Getting to the site of inflammation: The leukocyte adhesion cascade updated. Nat Rev Immunol. 2007;7:678-689

39. Campbell JJ, Qin S, Bacon KB, Mackay CR, Butcher EC. Biology of chemokine and classical chemoattractant receptors: Differential requirements for adhesion-triggering versus chemotactic responses in lymphoid cells. The Journal of cell biology. 1996;134:255-266

40. Campbell JJ, Hedrick J, Zlotnik A, Siani MA, Thompson DA, Butcher EC. Chemokines and the arrest of lymphocytes rolling under flow conditions. Science. 1998;279:381-384

41. Laudanna C, Kim JY, Constantin G, Butcher E. Rapid leukocyte integrin activation by chemokines. Immunological reviews. 2002;186:37-46

42. Constantin G, Majeed M, Giagulli C, Piccio L, Kim JY, Butcher EC, Laudanna C. Chemokines trigger immediate beta2 integrin affinity and mobility changes: Differential regulation and roles in lymphocyte arrest under flow. Immunity. 2000;13:759-769

43. Shamri R, Grabovsky V, Gauguet JM, Feigelson S, Manevich E, Kolanus W, Robinson MK, Staunton DE, von Andrian UH, Alon R. Lymphocyte arrest requires instantaneous 
induction of an extended Ifa- 1 conformation mediated by endothelium-bound chemokines. Nature immunology. 2005;6:497-506

44. von Hundelshausen P, Weber KS, Huo Y, Proudfoot AE, Nelson PJ, Ley K, Weber C. Rantes deposition by platelets triggers monocyte arrest on inflamed and atherosclerotic endothelium. Circulation. 2001;103:1772-1777

45. Huo Y, Schober A, Forlow SB, Smith DF, Hyman MC, Jung S, Littman DR, Weber C, Ley K. Circulating activated platelets exacerbate atherosclerosis in mice deficient in apolipoprotein e. Nature medicine. 2003;9:61-67

46. Arnaout MA, Mahalingam B, Xiong JP. Integrin structure, allostery, and bidirectional signaling. Annual review of cell and developmental biology. 2005;21:381-410

47. Kinashi T. Intracellular signalling controlling integrin activation in lymphocytes. Nature reviews. Immunology. 2005;5:546-559

48. Liu S, Kiosses WB, Rose DM, Slepak M, Salgia R, Griffin JD, Turner CE, Schwartz MA, Ginsberg $\mathrm{MH}$. A fragment of paxillin binds the alpha 4 integrin cytoplasmic domain (tail) and selectively inhibits alpha 4-mediated cell migration. The Journal of biological chemistry. 2002;277:20887-20894

49. Gakidis MA, Cullere X, Olson T, Wilsbacher JL, Zhang B, Moores SL, Ley K, Swat W, Mayadas T, Brugge JS. Vav gefs are required for beta2 integrin-dependent functions of neutrophils. The Journal of cell biology. 2004;166:273-282

50. Smith DF, Deem TL, Bruce AC, Reutershan J, Wu D, Ley K. Leukocyte phosphoinositide3 kinase gamma\} is required for chemokine-induced, sustained adhesion under flow in vivo. Journal of leukocyte biology. 2006;80:1491-1499

51. Schenkel AR, Mamdouh Z, Muller WA. Locomotion of monocytes on endothelium is a critical step during extravasation. Nature immunology. 2004;5:393-400

52. Phillipson M, Heit B, Colarusso P, Liu L, Ballantyne CM, Kubes P. Intraluminal crawling of neutrophils to emigration sites: A molecularly distinct process from adhesion in the recruitment cascade. The Journal of experimental medicine. 2006;203:2569-2575

53. Barreiro O, Zamai M, Yanez-Mo M, Tejera E, Lopez-Romero P, Monk PN, Gratton E, Caiolfa VR, Sanchez-Madrid F. Endothelial adhesion receptors are recruited to adherent leukocytes by inclusion in preformed tetraspanin nanoplatforms. The Journal of cell biology. 2008;183:527-542

54. Rohlena J, Volger OL, van Buul JD, Hekking LH, van Gils JM, Bonta PI, Fontijn RD, Post JA, Hordijk PL, Horrevoets AJ. Endothelial cd81 is a marker of early human atherosclerotic plaques and facilitates monocyte adhesion. Cardiovascular research. 2009;81:187-196

55. Carman CV, Springer TA. A transmigratory cup in leukocyte diapedesis both through individual vascular endothelial cells and between them. The Journal of cell biology. 2004;167:377-388

56. Martinelli R, Gegg M, Longbottom R, Adamson P, Turowski P, Greenwood J. Icam-1mediated endothelial nitric oxide synthase activation via calcium and amp-activated protein kinase is required for transendothelial lymphocyte migration. Molecular biology of the cell. 2009;20:995-1005

57. Feng D, Nagy JA, Pyne K, Dvorak HF, Dvorak AM. Neutrophils emigrate from venules by a transendothelial cell pathway in response to fmlp. The Journal of experimental medicine. 1998;187:903-915

58. Millan J, Hewlett L, Glyn M, Toomre D, Clark P, Ridley AJ. Lymphocyte transcellular migration occurs through recruitment of endothelial icam- 1 to caveola- and f-actin-rich domains. Nature cell biology. 2006;8:113-123

59. Shaw SK, Perkins BN, Lim YC, Liu Y, Nusrat A, Schnell FJ, Parkos CA, Luscinskas FW. Reduced expression of junctional adhesion molecule and platelet/endothelial cell adhesion molecule-1 (cd31) at human vascular endothelial junctions by cytokines tumor necrosis factor-alpha plus interferon-gamma does not reduce leukocyte transmigration under flow. Am J Pathol. 2001;159:2281-2291

60. Muller WA. Leukocyte-endothelial-cell interactions in leukocyte transmigration and the inflammatory response. Trends in immunology. 2003;24:327-334

61. Vestweber D. Regulation of endothelial cell contacts during leukocyte extravasation. Current opinion in cell biology. 2002;14:587-593

62. Weber C, Fraemohs L, Dejana E. The role of junctional adhesion molecules in vascular inflammation. Nat Rev Immunol. 2007;7:467-477 
63. Huang MT, Larbi KY, Scheiermann C, Woodfin A, Gerwin N, Haskard DO, Nourshargh S. Icam-2 mediates neutrophil transmigration in vivo: Evidence for stimulus specificity and a role in pecam-1-independent transmigration. Blood. 2006;107:4721-4727

64. Wegmann F, Petri B, Khandoga AG, Moser C, Khandoga A, Volkery S, Li H, Nasdala I, Brandau O, Fassler R, Butz S, Krombach F, Vestweber D. Esam supports neutrophil extravasation, activation of rho, and vegf-induced vascular permeability. The Journal of experimental medicine. 2006;203:1671-1677

65. Cinamon G, Shinder V, Shamri R, Alon R. Chemoattractant signals and beta 2 integrin occupancy at apical endothelial contacts combine with shear stress signals to promote transendothelial neutrophil migration. J Immunol. 2004;173:7282-7291

66. Nieminen M, Henttinen T, Merinen M, Marttila-Ichihara F, Eriksson JE, Jalkanen S. Vimentin function in lymphocyte adhesion and transcellular migration. Nature cell biology. 2006;8:156-162

67. Engelhardt B, Wolburg H. Mini-review: Transendothelial migration of leukocytes: Through the front door or around the side of the house? European journal of immunology. 2004;34:2955-2963

68. Stratman AN, Malotte KM, Mahan RD, Davis MJ, Davis GE. Pericyte recruitment during vasculogenic tube assembly stimulates endothelial basement membrane matrix formation. Blood. 2009;114:5091-5101

69. Hallmann R, Horn N, Selg M, Wendler O, Pausch F, Sorokin LM. Expression and function of laminins in the embryonic and mature vasculature. Physiological reviews. 2005;85:9791000

70. Wang S, Voisin MB, Larbi KY, Dangerfield J, Scheiermann C, Tran M, Maxwell PH, Sorokin L, Nourshargh S. Venular basement membranes contain specific matrix protein low expression regions that act as exit points for emigrating neutrophils. The Journal of experimental medicine. 2006;203:1519-1532

71. Sixt M, Engelhardt B, Pausch F, Hallmann R, Wendler O, Sorokin LM. Endothelial cell laminin isoforms, laminins 8 and 10, play decisive roles in t cell recruitment across the blood-brain barrier in experimental autoimmune encephalomyelitis. The Journal of cell biology. 2001;153:933-946

72. Voisin MB, Probstl D, Nourshargh S. Venular basement membranes ubiquitously express matrix protein low-expression regions: Characterization in multiple tissues and remodeling during inflammation. The American journal of pathology. 2010;176:482-495

73. Miyasaka M, Tanaka T. Lymphocyte trafficking across high endothelial venules: Dogmas and enigmas. Nature reviews. Immunology. 2004;4:360-370

74. Dangerfield J, Larbi KY, Huang MT, Dewar A, Nourshargh S. Pecam-1 (cd31) homophilic interaction up-regulates alpha6beta1 on transmigrated neutrophils in vivo and plays a functional role in the ability of alpha6 integrins to mediate leukocyte migration through the perivascular basement membrane. The Journal of experimental medicine.

2002;196:1201-1211

75. Wu C, Ivars F, Anderson P, Hallmann R, Vestweber D, Nilsson P, Robenek H, Tryggvason K, Song J, Korpos E, Loser K, Beissert S, Georges-Labouesse E, Sorokin LM. Endothelial basement membrane laminin alpha5 selectively inhibits t lymphocyte extravasation into the brain. Nature medicine. 2009;15:519-527

76. Wondimu A, Zhang T, Kieber-Emmons T, Gimotty P, Sproesser K, Somasundaram R, Ferrone S, Tsao CY, Herlyn D. Peptides mimicking gd2 ganglioside elicit cellular, humoral and tumor-protective immune responses in mice. Cancer immunology, immunotherapy: CII. 2008;57:1079-1089

77. Gorfu G, Virtanen I, Hukkanen M, Lehto VP, Rousselle P, Kenne E, Lindbom L, Kramer $\mathrm{R}$, Tryggvason K, Patarroyo M. Laminin isoforms of lymph nodes and predominant role of alpha5-laminin(s) in adhesion and migration of blood lymphocytes. Journal of leukocyte biology. 2008;84:701-712

78. Kornecki E, Walkowiak B, Naik UP, Ehrlich YH. Activation of human platelets by a stimulatory monoclonal antibody. The Journal of biological chemistry. 1990;265:1004210048

79. Hirabayashi S, Tajima M, Yao I, Nishimura W, Mori H, Hata Y. Jam4, a junctional cell adhesion molecule interacting with a tight junction protein, magi-1. Molecular and cellular biology. 2003;23:4267-4282

80. Moog-Lutz C, Cave-Riant F, Guibal FC, Breau MA, Di Gioia Y, Couraud PO, Cayre YE, Bourdoulous S, Lutz PG. Jaml, a novel protein with characteristics of a junctional 
adhesion molecule, is induced during differentiation of myeloid leukemia cells. Blood. 2003;102:3371-3378

81. Zen K, Liu Y, McCall IC, Wu T, Lee W, Babbin BA, Nusrat A, Parkos CA. Neutrophil migration across tight junctions is mediated by adhesive interactions between epithelial coxsackie and adenovirus receptor and a junctional adhesion molecule-like protein on neutrophils. Molecular biology of the cell. 2005;16:2694-2703

82. Prota AE, Campbell JA, Schelling P, Forrest JC, Watson MJ, Peters TR, Aurrand-Lions M, Imhof BA, Dermody TS, Stehle T. Crystal structure of human junctional adhesion molecule 1: Implications for reovirus binding. Proceedings of the National Academy of Sciences of the United States of America. 2003;100:5366-5371

83. Martin-Padura I, Lostaglio S, Schneemann M, Williams L, Romano M, Fruscella P, Panzeri C, Stoppacciaro A, Ruco L, Villa A, Simmons D, Dejana E. Junctional adhesion molecule, a novel member of the immunoglobulin superfamily that distributes at intercellular junctions and modulates monocyte transmigration. J Cell Biol. 1998;142:117127

84. Ozaki H, Ishii K, Horiuchi H, Arai H, Kawamoto T, Okawa K, Iwamatsu A, Kita T. Cutting edge: Combined treatment of tnf-alpha and ifn-gamma causes redistribution of junctional adhesion molecule in human endothelial cells. J Immunol. 1999;163:553-557

85. Williams LA, Martin-Padura I, Dejana E, Hogg N, Simmons DL. Identification and characterisation of human junctional adhesion molecule (jam). Molecular immunology. 1999;36:1175-1188

86. Liu Y, Nusrat A, Schnell FJ, Reaves TA, Walsh S, Pochet M, Parkos CA. Human junction adhesion molecule regulates tight junction resealing in epithelia. J Cell Sci. 2000;113 ( Pt 13):2363-2374

87. Kostrewa D, Brockhaus M, D'Arcy A, Dale GE, Nelboeck P, Schmid G, Mueller F, Bazzoni G, Dejana E, Bartfai T, Winkler FK, Hennig M. X-ray structure of junctional adhesion molecule: Structural basis for homophilic adhesion via a novel dimerization motif. The EMBO journal. 2001;20:4391-4398

88. Aurrand-Lions M, Johnson-Leger C, Wong C, Du Pasquier L, Imhof BA. Heterogeneity of endothelial junctions is reflected by differential expression and specific subcellular localization of the three jam family members. Blood. 2001;98:3699-3707

89. Liang TW, DeMarco RA, Mrsny RJ, Gurney A, Gray A, Hooley J, Aaron HL, Huang A, Klassen T, Tumas DB, Fong S. Characterization of hujam: Evidence for involvement in cell-cell contact and tight junction regulation. American journal of physiology. Cell physiology. 2000;279:C1733-1743

90. Gupta SK, Pillarisetti K, Ohlstein EH. Platelet agonist f11 receptor is a member of the immunoglobulin superfamily and identical with junctional adhesion molecule (jam): Regulation of expression in human endothelial cells and macrophages. IUBMB life. 2000;50:51-56

91. Martinez-Estrada OM, Manzi L, Tonetti P, Dejana E, Bazzoni G. Opposite effects of tumor necrosis factor and soluble fibronectin on junctional adhesion molecule-a in endothelial cells. Am J Physiol Lung Cell Mol Physiol. 2005;288:L1081-1088

92. Stamatovic SM, Sladojevic N, Keep RF, Andjelkovic AV. Relocalization of junctional adhesion molecule a during inflammatory stimulation of brain endothelial cells. Molecular and cellular biology. 2012;32:3414-3427

93. Mandell KJ, Babbin BA, Nusrat A, Parkos CA. Junctional adhesion molecule 1 regulates epithelial cell morphology through effects on beta1 integrins and rap1 activity. The Journal of biological chemistry. 2005;280:11665-11674

94. Ostermann G, Weber KS, Zernecke A, Schroder A, Weber C. Jam-1 is a ligand of the beta(2) integrin Ifa-1 involved in transendothelial migration of leukocytes. Nat Immunol. 2002;3:151-158

95. Fraemohs L, Koenen RR, Ostermann G, Heinemann B, Weber C. The functional interaction of the beta 2 integrin lymphocyte function-associated antigen-1 with junctional adhesion molecule-a is mediated by the i domain. $J$ Immunol. 2004;173:6259-6264

96. Wojcikiewicz EP, Koenen RR, Fraemohs L, Minkiewicz J, Azad H, Weber C, Moy VT. Lfa1 binding destabilizes the jam-a homophilic interaction during leukocyte transmigration. Biophysical journal. 2009;96:285-293

97. Barton ES, Forrest JC, Connolly JL, Chappell JD, Liu Y, Schnell FJ, Nusrat A, Parkos CA, Dermody TS. Junction adhesion molecule is a receptor for reovirus. Cell. 2001;104:441451 
98. Fanning AS, Jameson BJ, Jesaitis LA, Anderson JM. The tight junction protein zo-1 establishes a link between the transmembrane protein occludin and the actin cytoskeleton. The Journal of biological chemistry. 1998;273:29745-29753

99. Mandai K, Nakanishi H, Satoh A, Obaishi H, Wada M, Nishioka H, Itoh M, Mizoguchi A, Aoki T, Fujimoto T, Matsuda Y, Tsukita S, Takai Y. Afadin: A novel actin filament-binding protein with one pdz domain localized at cadherin-based cell-to-cell adherens junction. The Journal of cell biology. 1997;139:517-528

100. Ebnet K, Schulz CU, Meyer Zu Brickwedde MK, Pendl GG, Vestweber D. Junctional adhesion molecule interacts with the pdz domain-containing proteins af-6 and zo-1. J Biol Chem. 2000;275:27979-27988

101. Bazzoni G, Martinez-Estrada OM, Orsenigo F, Cordenonsi M, Citi S, Dejana E. Interaction of junctional adhesion molecule with the tight junction components zo-1, cingulin, and occludin. The Journal of biological chemistry. 2000;275:20520-20526

102. Hamazaki Y, Itoh M, Sasaki H, Furuse M, Tsukita S. Multi-pdz domain protein 1 (mupp1) is concentrated at tight junctions through its possible interaction with claudin-1 and junctional adhesion molecule. The Journal of biological chemistry. 2002;277:455-461

103. Martinez-Estrada OM, Villa A, Breviario F, Orsenigo F, Dejana E, Bazzoni G. Association of junctional adhesion molecule with calcium/calmodulin-dependent serine protein kinase (cask/lin-2) in human epithelial caco-2 cells. The Journal of biological chemistry. 2001;276:9291-9296

104. Ebnet K, Suzuki A, Horikoshi Y, Hirose T, Meyer Zu Brickwedde MK, Ohno S, Vestweber D. The cell polarity protein asip/par-3 directly associates with junctional adhesion molecule (jam). The EMBO journal. 2001;20:3738-3748

105. Itoh M, Sasaki H, Furuse M, Ozaki H, Kita T, Tsukita S. Junctional adhesion molecule (jam) binds to par-3: A possible mechanism for the recruitment of par-3 to tight junctions. The Journal of cell biology. 2001;154:491-497

106. Naik MU, Mousa SA, Parkos CA, Naik UP. Signaling through jam-1 and alphavbeta3 is required for the angiogenic action of bfgf: Dissociation of the jam-1 and alphavbeta3 complex. Blood. 2003;102:2108-2114

107. Naik MU, Naik UP. Junctional adhesion molecule-a-induced endothelial cell migration on vitronectin is integrin alpha $v$ beta 3 specific. Journal of cell science. 2006;119:490-499

108. Bazzoni G, Tonetti P, Manzi L, Cera MR, Balconi G, Dejana E. Expression of junctional adhesion molecule-a prevents spontaneous and random motility. Journal of cell science. 2005;118:623-632

109. Stellos K, Langer H, Gnerlich S, Panagiota V, Paul A, Schonberger T, Ninci E, Menzel D, Mueller I, Bigalke B, Geisler T, Bultmann A, Lindemann S, Gawaz M. Junctional adhesion molecule a expressed on human cd34+ cells promotes adhesion on vascular wall and differentiation into endothelial progenitor cells. Arteriosclerosis, thrombosis, and vascular biology. 2010;30:1127-1136

110. Del Maschio A, De Luigi A, Martin-Padura I, Brockhaus M, Bartfai T, Fruscella P, Adorini L, Martino G, Furlan R, De Simoni MG, Dejana E. Leukocyte recruitment in the cerebrospinal fluid of mice with experimental meningitis is inhibited by an antibody to junctional adhesion molecule (jam). The Journal of experimental medicine. 1999;190:1351-1356

111. Ostermann G, Fraemohs L, Baltus T, Schober A, Lietz M, Zernecke A, Liehn EA, Weber C. Involvement of jam-a in mononuclear cell recruitment on inflamed or atherosclerotic endothelium: Inhibition by soluble jam-a. Arteriosclerosis, thrombosis, and vascular biology. 2005;25:729-735

112. Babinska A, Azari BM, Salifu MO, Liu R, Jiang XC, Sobocka MB, Boo D, Al Khoury G, Deitch JS, Marmur JD, Ehrlich YH, Kornecki E. The f11 receptor (f11r/jam-a) in atherothrombosis: Overexpression of $\mathrm{f11} \mathrm{r}$ in atherosclerotic plaques. Thromb Haemost. 2007;97:272-281

113. Slevin M, Elasbali AB, Miguel Turu M, Krupinski J, Badimon L, Gaffney J. Identification of differential protein expression associated with development of unstable human carotid plaques. The American journal of pathology. 2006;168:1004-1021

114. Khandoga A, Kessler JS, Meissner H, Hanschen M, Corada M, Motoike T, Enders G, Dejana E, Krombach F. Junctional adhesion molecule-a deficiency increases hepatic ischemia-reperfusion injury despite reduction of neutrophil transendothelial migration. Blood. 2005;106:725-733

115. Cera MR, Del Prete A, Vecchi A, Corada M, Martin-Padura I, Motoike T, Tonetti P, Bazzoni G, Vermi W, Gentili F, Bernasconi S, Sato TN, Mantovani A, Dejana E. Increased 
dc trafficking to lymph nodes and contact hypersensitivity in junctional adhesion moleculea-deficient mice. J Clin Invest. 2004;114:729-738

116. Corada M, Chimenti S, Cera MR, Vinci M, Salio M, Fiordaliso F, De Angelis N, Villa A, Bossi M, Staszewsky LI, Vecchi A, Parazzoli D, Motoike T, Latini R, Dejana E. Junctional adhesion molecule-a-deficient polymorphonuclear cells show reduced diapedesis in peritonitis and heart ischemia-reperfusion injury. Proc Natl Acad Sci U S A. 2005;102:10634-10639

117. Cera MR, Fabbri M, Molendini C, Corada M, Orsenigo F, Rehberg M, Reichel CA, Krombach F, Pardi R, Dejana E. Jam-a promotes neutrophil chemotaxis by controlling integrin internalization and recycling. J Cell Sci. 2009;122:268-277

118. Cougoule C, Wiedemann A, Lim J, Caron E. Phagocytosis, an alternative model system for the study of cell adhesion. Seminars in cell \& developmental biology. 2004;15:679-689

119. Severson EA, Jiang L, Ivanov AI, Mandell KJ, Nusrat A, Parkos CA. Cis-dimerization mediates function of junctional adhesion molecule a. Molecular biology of the cell. 2008;19:1862-1872

120. Severson EA, Lee WY, Capaldo CT, Nusrat A, Parkos CA. Junctional adhesion molecule a interacts with afadin and pdz-gef2 to activate rap1a, regulate beta1 integrin levels, and enhance cell migration. Molecular biology of the cell. 2009;20:1916-1925

121. Sobocka MB, Sobocki T, Banerjee P, Weiss C, Rushbrook JI, Norin AJ, Hartwig J, Salifu MO, Markell MS, Babinska A, Ehrlich YH, Kornecki E. Cloning of the human platelet f11 receptor: A cell adhesion molecule member of the immunoglobulin superfamily involved in platelet aggregation. Blood. 2000;95:2600-2609

122. Naik UP, Naik MU, Eckfeld K, Martin-DeLeon P, Spychala J. Characterization and chromosomal localization of jam-1, a platelet receptor for a stimulatory monoclonal antibody. Journal of cell science. 2001;114:539-547

123. Babinska A, Kedees $\mathrm{MH}$, Athar $\mathrm{H}$, Ahmed $\mathrm{T}$, Batuman O, Ehrlich $\mathrm{YH}$, Hussain MM, Kornecki E. F11-receptor (f11r/jam) mediates platelet adhesion to endothelial cells: Role in inflammatory thrombosis. Thrombosis and haemostasis. 2002;88:843-850

124. Naik MU, Stalker TJ, Brass LF, Naik UP. Jam-a protects from thrombosis by suppressing integrin alphaiibbeta3-dependent outside-in signaling in platelets. Blood. 2012;119:33523360

125. Palmeri D, van Zante A, Huang CC, Hemmerich S, Rosen SD. Vascular endothelial junction-associated molecule, a novel member of the immunoglobulin superfamily, is localized to intercellular boundaries of endothelial cells. The Journal of biological chemistry. 2000;275:19139-19145

126. Cunningham SA, Arrate MP, Rodriguez JM, Bjercke RJ, Vanderslice P, Morris AP, Brock TA. A novel protein with homology to the junctional adhesion molecule. Characterization of leukocyte interactions. The Journal of biological chemistry. 2000;275:34750-34756

127. Arrate MP, Rodriguez JM, Tran TM, Brock TA, Cunningham SA. Cloning of human junctional adhesion molecule 3 (jam3) and its identification as the jam2 counter-receptor. The Journal of biological chemistry. 2001;276:45826-45832

128. Cunningham SA, Rodriguez JM, Arrate MP, Tran TM, Brock TA. Jam2 interacts with alpha4beta1. Facilitation by jam3. The Journal of biological chemistry. 2002;277:2758927592

129. Liang TW, Chiu HH, Gurney A, Sidle A, Tumas DB, Schow P, Foster J, Klassen T, Dennis K, DeMarco RA, Pham T, Frantz G, Fong S. Vascular endothelial-junctional adhesion molecule (ve-jam)/jam 2 interacts with $\mathrm{t}$, $\mathrm{nk}$, and dendritic cells through jam 3. J Immunol. 2002;168:1618-1626

130. Ludwig RJ, Zollner TM, Santoso S, Hardt K, Gille J, Baatz H, Johann PS, Pfeffer J, Radeke HH, Schon MP, Kaufmann R, Boehncke WH, Podda M. Junctional adhesion molecules (jam)-b and -c contribute to leukocyte extravasation to the skin and mediate cutaneous inflammation. The Journal of investigative dermatology. 2005;125:969-976

131. Aurrand-Lions M, Duncan L, Ballestrem C, Imhof BA. Jam-2, a novel immunoglobulin superfamily molecule, expressed by endothelial and lymphatic cells. The Journal of biological chemistry. 2001;276:2733-2741

132. Johnson-Leger CA, Aurrand-Lions M, Beltraminelli N, Fasel N, Imhof BA. Junctional adhesion molecule-2 (jam-2) promotes lymphocyte transendothelial migration. Blood. 2002;100:2479-2486

133. Santoso S, Sachs UJ, Kroll H, Linder M, Ruf A, Preissner KT, Chavakis T. The junctional adhesion molecule 3 (jam-3) on human platelets is a counterreceptor for the leukocyte integrin mac-1. The Journal of experimental medicine. 2002;196:679-691 
134. Santoso S, Orlova VV, Song K, Sachs UJ, Andrei-Selmer CL, Chavakis T. The homophilic binding of junctional adhesion molecule-c mediates tumor cell-endothelial cell interactions. The Journal of biological chemistry. 2005;280:36326-36333

135. Lamagna C, Meda P, Mandicourt G, Brown J, Gilbert RJ, Jones EY, Kiefer F, Ruga P, Imhof BA, Aurrand-Lions M. Dual interaction of jam-c with jam-b and alpha(m)beta2 integrin: Function in junctional complexes and leukocyte adhesion. Molecular biology of the cell. 2005;16:4992-5003

136. Chavakis T, Keiper T, Matz-Westphal R, Hersemeyer K, Sachs UJ, Nawroth PP, Preissner KT, Santoso S. The junctional adhesion molecule-c promotes neutrophil transendothelial migration in vitro and in vivo. The Journal of biological chemistry. 2004;279:55602-55608

137. Vonlaufen A, Aurrand-Lions M, Pastor CM, Lamagna C, Hadengue A, Imhof BA, Frossard $\mathrm{JL}$. The role of junctional adhesion molecule $\mathrm{c}(\mathrm{jam}-\mathrm{c})$ in acute pancreatitis. The Journal of pathology. 2006;209:540-548

138. Aurrand-Lions M, Lamagna C, Dangerfield JP, Wang S, Herrera P, Nourshargh S, Imhof $B A$. Junctional adhesion molecule-c regulates the early influx of leukocytes into tissues during inflammation. J Immunol. 2005;174:6406-6415

139. Scheiermann C, Colom B, Meda P, Patel NS, Voisin MB, Marrelli A, Woodfin A, Pitzalis C, Thiemermann C, Aurrand-Lions M, Imhof BA, Nourshargh S. Junctional adhesion molecule-c mediates leukocyte infiltration in response to ischemia reperfusion injury. Arteriosclerosis, thrombosis, and vascular biology. 2009;29:1509-1515

140. Bradfield PF, Scheiermann C, Nourshargh S, Ody C, Luscinskas FW, Rainger GE, Nash GB, Miljkovic-Licina M, Aurrand-Lions M, Imhof BA. Jam-c regulates unidirectional monocyte transendothelial migration in inflammation. Blood. 2007;110:2545-2555

141. Woodfin A, Voisin MB, Beyrau M, Colom B, Caille D, Diapouli FM, Nash GB, Chavakis T, Albelda SM, Rainger GE, Meda P, Imhof BA, Nourshargh S. The junctional adhesion molecule jam-c regulates polarized transendothelial migration of neutrophils in vivo. Nature immunology. 2011;12:761-769

142. Keiper T, Al-Fakhri N, Chavakis E, Athanasopoulos AN, Isermann B, Herzog S, Saffrich R, Hersemeyer K, Bohle RM, Haendeler J, Preissner KT, Santoso S, Chavakis T. The role of junctional adhesion molecule-c (jam-c) in oxidized Idl-mediated leukocyte recruitment. FASEB journal : official publication of the Federation of American Societies for Experimental Biology. 2005;19:2078-2080

143. Shagdarsuren E, Djalali-Talab Y, Aurrand-Lions M, Bidzhekov K, Liehn EA, Imhof BA, Weber C, Zernecke A. Importance of junctional adhesion molecule-c for neointimal hyperplasia and monocyte recruitment in atherosclerosis-prone mice-brief report. Arteriosclerosis, thrombosis, and vascular biology. 2009;29:1161-1163

144. Langer HF, Daub K, Braun G, Schonberger T, May AE, Schaller M, Stein GM, Stellos K, Bueltmann A, Siegel-Axel D, Wendel HP, Aebert H, Roecken M, Seizer P, Santoso S, Wesselborg S, Brossart P, Gawaz M. Platelets recruit human dendritic cells via mac$1 /$ jam-c interaction and modulate dendritic cell function in vitro. Arteriosclerosis, thrombosis, and vascular biology. 2007;27:1463-1470

145. Sircar M, Bradfield PF, Aurrand-Lions M, Fish RJ, Alcaide P, Yang L, Newton G, Lamont D, Sehrawat S, Mayadas T, Liang TW, Parkos CA, Imhof BA, Luscinskas FW. Neutrophil transmigration under shear flow conditions in vitro is junctional adhesion molecule-c independent. J Immunol. 2007;178:5879-5887

146. Li D, Chen H, Romeo F, Sawamura T, Saldeen T, Mehta JL. Statins modulate oxidized low-density lipoprotein-mediated adhesion molecule expression in human coronary artery endothelial cells: Role of lox-1. J Pharmacol Exp Ther. 2002;302:601-605

147. Matarazzo S, Quitadamo MC, Mango R, Ciccone S, Novelli G, Biocca S. Cholesterollowering drugs inhibit lectin-like oxidized low-density lipoprotein-1 receptor function by membrane raft disruption. Molecular pharmacology. 2012;82:246-254

148. Chiba Y, Ogita T, Ando K, Fujita T. Ppargamma ligands inhibit tnf-alpha-induced lox-1 expression in cultured endothelial cells. Biochemical and biophysical research communications. 2001;286:541-546

149. Mehta JL, Hu B, Chen J, Li D. Pioglitazone inhibits lox-1 expression in human coronary artery endothelial cells by reducing intracellular superoxide radical generation.

Arteriosclerosis, thrombosis, and vascular biology. 2003;23:2203-2208

150. Schramm R, Menger MD, Harder Y, Schmits R, Adam O, Weitz-Schmidt G, Schafers HJ. Statins inhibit lymphocyte homing to peripheral lymph nodes. Immunology. 2007;120:315324 
151. Grommes J, Morgelin M, Soehnlein O. Pioglitazone attenuates endotoxin-induced acute lung injury by reducing neutrophil recruitment. The European respiratory journal. 2012;40:416-423 
GENERAL INTRODUCTION 
Atherosclerosis is characterized by an immune cell driven narrowing and rupture of arterial vessel walls. Thus, leukocyte recruitment into the vessel wall is a crucial prerequisite for atherosclerotic lesion formation.

The underlying mechanism of leukocyte recruitment is represented by a multi-step cascade comprising leukocyte tethering, rolling, firm adhesion and transendothelial migration. Junctional adhesion molecules, especially JAM-A, have been shown to mediate adhesion and transmigration in various inflammatory models, but a comprehensive study comparing the roles of JAM-A in atherosclerotic lesion formation regarding their cellular context is still lacking.

In chapter 2, we strived to unravel the atherogenic potential of JAM-A expressed by endothelial cells or leukocytes as well as the atherogenic potential of somatic JAM-A. Additionally, we investigated recruitment rates of leukocytes transmigrating through endothelial cells, either with or without JAM-A deficiency under different inflammatory conditions in vivo and in vitro. Furthermore we aimed to localize endothelial JAM-A under different inflammatory and altered shear stress conditions in ex vivo and in vitro studies in order to elucidate the underlying mechanism. 


\section{Contribution to the manuscript (chapter 2):}

Martin Schmitt designed this study together with Dr. Rory Koenen and Prof. Christian Weber. Experiments were mainly accomplished and analyzed by Martin Schmitt. Martin Schmitt took care of animal husbandry and treatment of animals prior to sacrifice. For animal sacrifice, cutting paraffin sections and histology Martin Schmitt was assisted by Melanie Garbe and Roya Soltan. Moreover, Martin Schmitt performed evaluation and interpretation of all histology data. Martin Schmitt designed, conducted and evaluated the in vivo transmigration assay; for in vivo TPLSM imaging, Martin Schmitt was supported by Dr. Timo Rademakers. Martin Schmitt conducted murine carotid partial ligation with subsequent localization studies using TPLSM with initial support of Dr. Remco Megens. Evaluation of junctional protein pseudo-overlap was performed by Martin Schmitt with support of Prof. Marc Spehr. Ex vivo permeability assay was designed, conducted and evaluated by Martin Schmitt. Furthermore, Martin Schmitt designed, conducted and evaluated all in vitro transmigration, de-adhesion, redistribution and protein expression assays. Flow experiments were designed, conducted and evaluated by Martin Schmitt with initial support of Dr. Nynke van den Akker.

Data were discussed and interpreted by Martin Schmitt, Dr. Rory Koenen and Prof. Christian Weber. Martin Schmitt wrote the first draft of the manuscript. 


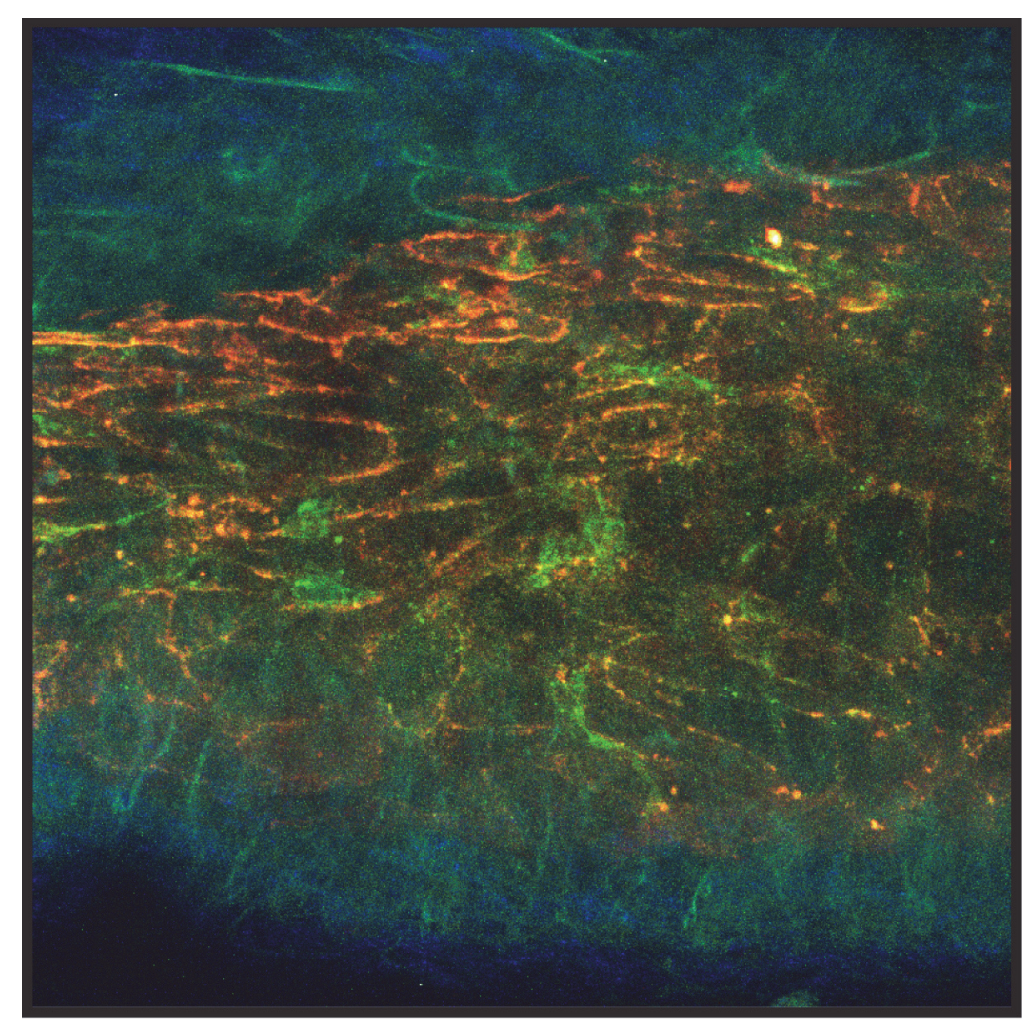

Chapter 2 


\section{Endothelial JAM-A guides monocytes into flow-dependent predilection sites of atherosclerosis}

Martin M.N. Schmitt, Remco T.A. Megens, Alma Zernecke, Kiril Bidzhekov, Nynke M. van den Akker, Timo Rademakers, Marc A. van Zandvoort, Tilman M. Hackeng, Rory R. Koenen* and Christian Weber*

* authors contribute equally

Circulation. 2014 Jan 7;129(1):66-76. 


\section{Abstract}

Background - Junctional Adhesion Molecule (JAM)-A expressed in endothelial, epithelial and blood cells can regulate permeability and leukocyte extravasation. Atherosclerosis develops at sites of disturbed flow in large arteries but the mechanisms guiding inflammatory cells into these predilection sites remain unknown.

Methods and Results - To characterize cell-specific functions of JAM-A in atherosclerosis, we employed apolipoprotein E-deficient mice with a somatic or endothelium-specific deficiency in JAM-A and bone marrow chimeras with JAM-A-deficient leukocytes. We show that impaired JAM-A expression in endothelial cells reduced mononuclear cell recruitment into the arterial wall and limited atherosclerotic lesion formation in hyperlipidemic mice. In contrast, JAM-A deficiency in bone marrow cells impeded monocyte de-adhesion, thereby increasing vascular permeability and lesion formation, whereas somatic JAM-A deletion revealed no significant effects. Regions with disturbed flow displayed a focal enrichment and luminal redistribution of endothelial JAM-A and were preferentially protected by its deficiency. The functional expression and redistribution of endothelial JAM-A was increased by oxidized low-density lipoprotein, but confined by athero-protective laminar flow through an upregulation of miR-145, which repressed JAM-A.

Conclusions - Our data identify endothelial JAM-A as an important effector molecule integrating atherogenic conditions to direct inflammatory cell entry at predilection sites of atherosclerosis. 


\section{Introduction}

Junctional Adhesion Molecule-A (JAM-A, also known as F11R), a member of the immunoglobulin ( $\mathrm{IgG}$ ) super-family, is located in the tight junctions of epithelial and endothelial cells but also expressed by leukocytes and CD34 ${ }^{+}$ cells, and exerts a wide variety of functions in cell polarity ${ }^{1}$ and barrier function via homophilic interactions ${ }^{2}$, stem cell adhesion and differentiation ${ }^{3}$, leukocyte trafficking and recruitment ${ }^{3-6}$. In particular, JAM-A mediates leukocyte adhesion and transmigration via heterophilic interactions with the $\alpha_{L} \beta_{2}$ integrin LFA-1 ${ }^{7-10}$.

Moreover, dendritic cell trafficking to the lymph nodes was increased in mice with somatic but not endothelial JAM-A deficiency, indicating a specific role in dendritic cell migration ${ }^{11}$. Additional findings revealed a crucial role of JAM-A on leukocytes in promoting de-adhesion ${ }^{12}$. In the absence of JAM-A, the directional motility of neutrophils was impaired, leading to incomplete transmigration with neutrophils being stuck between the endothelial cell layer and the basement membrane ${ }^{12}$. Whereas JAM-A on neutrophils promotes chemotaxis by regulating integrin internalization and recycling ${ }^{13}$, endothelial JAM-A has been implicated in mediating stimulus-specific neutrophil transmigration ${ }^{14}$. Upon co-stimulation with TNF- $\alpha$ and IFN- $\gamma$, endothelial JAM-A is redistributed to the luminal surface ${ }^{15,16}$ and specifically to the site of leukocyte transmigration as part of lateral border recycling compartments ${ }^{17}$.

Compelling evidence has emerged to indicate that JAM-A-mediated leukocyte transmigration plays an important role in inflammatory disease. For example, JAM-A-deficient mice displayed reduced leukocyte infiltration in models of peritonitis, hepatic and myocardial ischemia-reperfusion injury ${ }^{12,18}$, and in acute lung injury ${ }^{19}$. In models of vascular disease, somatic JAM-A deficiency was shown to protect against neointimal hyperplasia after wire-injury of the carotid artery in hyperlipidemic mice ${ }^{20}$. Accordingly, increased levels of JAM-A transcripts and protein have been demonstrated in human plaque biopsies and in plaque-prone aortas of mice ${ }^{21}$. The expression of JAM-A on inflamed and early atherosclerotic endothelium has been implicated in the recruitment of mononuclear cells through an inhibition with soluble JAM-A, suggesting a functional involvement in atherogenesis ${ }^{5}$.

Despite being strategically positioned at junctional entry ports of arterial endothelium, less is known about the cell-specific contributions and net effect of JAM-A in directing mononuclear cell migration during atherogenic recruitment and lesion formation. To dissect the functions of JAM-A in atherosclerosis, we employed apolipoprotein E-deficient $\left(A p o e^{-/}\right)$mice with a somatic or endothelial cell-specific deficiency in JAM-A and bone marrow (BM) chimeras with JAM-A-deficient leukocytes. Our data show that endothelial JAM-A promotes lesion formation by integrating effects of hyperlipidemia and disturbed flow, which result in its up-regulation, redistribution and subsequent function in 
promoting mononuclear cell influx into the artery wall, while limiting reverse transmigration. In contrast, leukocytic JAM-A is required for monocyte deadhesion and complete transmigration, thereby preventing vascular damage and protecting against atherosclerosis. 


\section{Methods}

\section{Mouse models of JAM-A-deficiency and plaque formation}

Somatic $J A M-A^{-/} \mathrm{Apoe}^{-/-}$were backcrossed for $>10$ generations into a C57BI/6 background ${ }^{20}$. Congenic Apoe ${ }^{-/}$mice were used as controls. Chimeric mice with a leukocytic JAM-A deficiency were obtained by reconstituting $A p e^{-/}$ recipients with $J A M-A^{-/} A p o e^{-/}$or control $A p o e^{-/-}$bone marrow (BM) $)^{22}$. Briefly, $\mathrm{BM}$ cells $\left(5 \times 10^{6}\right.$ in PBS) from donor mice were administered to recipient mice by tail vein injection, $24 \mathrm{~h}$ after an ablative dose of whole-body irradiation $(2 \times 6.5 \mathrm{~Gy})$.

A genetic reduction of endothelial JAM-A was achieved by crossing Apoe $^{-/}$mice with a loxP flanked (floxed) JAM-A gene $\left(J A M-A^{f / f f l}\right)$ with VeCad CreERT $T^{2}$ Apoe $^{-/-}$mice to obtain VeCad CreERT $T^{2} J_{A M}-A^{f / f t} A p o e^{--}$mice $(\mathrm{C} 57 \mathrm{BI} / 6)^{23}$. At an age of 3 weeks, 5 daily intraperitoneal injections of the estradiol analog tamoxifen ( $0.04 \mathrm{mg}$ per $\mathrm{g}$ mouse) dissolved in miglyol 810 (Caelo, Hilden, Germany) were administered to VeCad CreERT' ${ }^{2}$-positive or VeCad CreERT'-negative animals to obtain eJAM-A $A^{-/} A p o e^{-/}$or eJAM- $A^{+/+}$Apoe $^{-/}$mice, respectively. After 4-6 weeks, genetic depletion of JAM-A was confirmed by FACS analysis, resulting in $\sim 50 \%$ less endothelial JAM-A levels with no difference in leukocytic JAM-A levels compared to control mice. We chose a mouse model with an inducible endothelium-specific Crerecombinase, since constitutive expression of Cre-recombinase under the control of an endothelium-specific promotor (e.g. Tie2/Tek, VE-cadherin) has been shown to lead to a non-negligible amount of deletion of the floxed gene in hematopoietic cells ${ }^{24,25}$.

Plaque formation was induced in female littermates (aged 6-8 weeks, $\mathrm{n}=10-13$ ) by feeding a high-fat diet (HFD, $21 \%$ fat, $0.15 \%$ cholesterol, Altromin, Lage, Germany) for 12 weeks or by partial ligation of the carotid artery, resulting in altered shear stress due to reduced and partially retrograde blood flow ${ }^{26}$. In brief, $\mathrm{Apoe}^{-/}$mice $(\mathrm{n}=5)$ were anesthetized with ketamine $(80 \mathrm{mg} / \mathrm{kg})$ and xylazine $(10 \mathrm{mg} / \mathrm{kg}$ ), and left external and internal carotid, and occipital artery were ligated with 6-0 silk sutures, leaving only superior thyroid artery open. Mice were left on HFD for 2-8 weeks. Animal experiments were approved by local authorities and complied with German animal protection law (LANUV NRW, Recklinghausen, Germany).

\section{Quantification and immunohistochemical analysis of atherosclerosis}

The extent of atherosclerosis was assessed in aortic roots and on thoracoabdominal aortas by Elastica van Gieson (EVG) staining and for lipid depositions with Oil-red-O, respectively, and was quantified by computerized image analysis (Diskus Software, Hilgers, Königswinter, Germany) and Leica 
Qwin Imaging software (Leica Microsystems, Wetzlar, Germany)2. The relative content of macrophages and $\mathrm{CD}^{+} \mathrm{T}$ cells was determined by staining with antibodies against Mac-2 and CD3 (both AbD Serotec, Düsseldorf, Germany), and detection with FITC- and Cy3-conjugated antibodies (both Jackson ImmunoResearch Laboratories Inc., West Grove, PA). Nuclei were visualized with DAPI. Necrotic core areas were quantified in DAPI-stained slices of aortic roots. Images were recorded with a Leica DMLB fluorescence microscope and CCD camera. Stages of atherosclerotic lesions were determined by evaluation of EVG-stained aortic roots, as reported by Virmani et al. ${ }^{27}$.

\section{Stimulation of endothelial cells under static or flow conditions}

Human aortic endothelial cells (HAoECs) without genetic modification, and $J A M-A^{+/+}$Apoe $^{-/}$or JAM- $A^{-/}$Apoe ${ }^{-/}$SV40-large T antigen-immortalized mouse ECs were grown on collagenized glass slides or in specialized 48-well plates (IUL Instruments, Königswinter, Germany), respectively. HAoECs were treated with LDL, oxLDL (both $10 \mu \mathrm{g} / \mathrm{ml}, 16 \mathrm{~h}$ ), TNF- $\alpha$ and IFN- $\gamma(10 \mathrm{ng} / \mathrm{ml}$ and $20 \mathrm{ng} / \mathrm{ml}, 4 \mathrm{~h}$, respectively) or oxLDL plus JAM-A.Fc (10 $\mu \mathrm{g} / \mathrm{ml}, 15 \mathrm{~min})$. Mouse ECs were activated for at least $4 \mathrm{~h}$ with TNF- $\alpha(25 \mathrm{ng} / \mathrm{ml})$. For culture under flow conditions, HAoECs were harvested from static cultures and transferred to $0.4 \mu \mathrm{m} \mu$-slides (ibidi, Martinsried, Germany). After attachment, cell culture was continued under static or flow (both $48 \mathrm{~h}$ ) conditions, while shear stress was gradually increased to 5 or $20 \mathrm{dyn} / \mathrm{cm}^{2}$ using an ibidi pump system.

In vitro, ex vivo and in vivo monocyte adhesion and transmigration assays

$\mathrm{CD} 14^{+}$human monocytes and $\mathrm{CD} 115^{+}$mouse monocytes were freshly isolated from blood from healthy volunteers or from spleens of mice with the respective genetic modification, respectively, for every experimental series using the Monocyte Isolation Kit II or the CD115 mouse MicroBead Kit (Miltenyi, Bergisch Gladbach, Germany), which employ blocking reagents for the Fc-receptor. Human monocytes $\left(0.7 \times 10^{6} / \mathrm{ml}\right)$ were applied on HAoECs under shear stress $\left(1.5 \mathrm{dyn} / \mathrm{cm}^{2}\right)$ using a syringe pump (WPI, Berlin, Germany) in a laminar flow chamber for $5 \mathrm{~min}$ and flushed with assay medium for $30 \mathrm{~min}$, while time-lapse images were recorded (CellM system, Olympus, Tokyo, Japan). Mouse monocytes $\left(2 \times 10^{6} / \mathrm{ml}\right)$ were applied on stimulated mouse ECs under shear stress $\left(0.8 \mathrm{dyn} / \mathrm{cm}^{2}\right.$, BioFlux 200, IUL Instruments) for $10 \mathrm{~min}$ and flushed with assay medium for $30 \mathrm{~min}$, while time-lapse images were recorded. Monocytes showing complete, reverse and incomplete transmigration were counted and related to adherent or transmigrated monocytes. Human studies were approved by the institutional review board and informed consent was given by the subjects.

Carotid arteries of $\mathrm{Apoe}^{-/}$mice were explanted, mounted, pressurized at 80 $\mathrm{mmHg}$ and incubated with FITC-coupled CD31 antibody $(5 \mu \mathrm{g} / \mathrm{ml}$, 
BD Biosciences, San Jose, CA). After staining of monocytes with Rhodamine B $(1 \mu \mathrm{g} / \mathrm{ml}$, Sigma Aldrich, Carlsbad, CA) and stimulation of carotid arteries with TNF- $\alpha(10 \mathrm{ng} / \mathrm{ml}, 3 \mathrm{~h}$, eBioscience, San Diego, CA $)$, primary CD115 ${ }^{+}$ monocytes with and without JAM-A deficiency $\left(3 \mathrm{ml}\right.$ of $\left.2 \times 10^{5} \mathrm{cells} / \mathrm{ml}\right)$ were perfused in the mounted and pressurized vessel at $0.4 \mathrm{ml} / \mathrm{min}$, and monocytes were counted via 2-photon laser scanning microscopy (TPLSM).

The right carotid arteries of $e J A M-A^{-/}$and $e J A M-A^{+/+}$mice were challenged with IL-1 $\beta(2 \mu \mathrm{g} / \mathrm{ml}$, BioLegend, San Diego, CA) carried by a slowly degrading periarterial pluronic gel for $24 \mathrm{~h}$. In addition, Alexa Fluor (AF) 568-coupled anti-CD115 antibody (5 $\mu \mathrm{g} /$ mouse, eBioscience, San Diego, CA) was administered intravenously. On the next day, anaesthetized mice were injected intravenously with anti-CD31 FITC coupled antibody $(35 \mu \mathrm{g} / \mathrm{mouse}$ total, BD Biosciences, San Jose, CA) and subsequently prepared for in vivo TPLSM by surgically exposing the common carotid artery ${ }^{28}$.

\section{Measurement of vessel wall permeability}

Carotid arteries explanted from C57BI/6, Apoe ${ }^{-/}$with and without HFD, eJAM- $A^{-/}$, eJAM- $A^{+/+} A p o e-/-$ and BM-chimeric mice were mounted in a perfusion chamber and incubated with $70 \mathrm{kDa}$ dextran coupled to Rhodamine $\mathrm{B}$ $(0.35 \mathrm{mg} / \mathrm{ml})$, for $1 \mathrm{~h}$ at a pressure of $60 \mathrm{mmHg}$. Control carotid arteries were co-incubated with $50 \mu \mathrm{mol} / \mathrm{l}$ histamine. After subsequent washing of the vessels, z-stack images were taken with an Olympus FV1000MPE TPLSM system coupled to a BX61WI microscope.

\section{De-adhesion assay for mouse monocytes on SVEC monolayer or ICAM-1.FC}

Simian Virus 40 large $T$ antigen-transfected mouse endothelial cells (SVECs) were grown to confluence in $\mu$-slides ${ }^{0.4}$ (ibidi, Martinsried, Germany) under low shear stress $\left(<0.5 \mathrm{dyn} / \mathrm{cm}^{2}\right)$ over night. Alternatively, $\mu$-slides ${ }^{0.4}$ were coated with $2 \mu \mathrm{g} / \mathrm{ml}$ intercellular adhesion molecule (ICAM)-1.FC (R\&D Systems, Minneapolis, MN) or murine Fc control for $2 \mathrm{~h}$ at $37^{\circ} \mathrm{C}$ before blocking with $5 \%$ albumin/PBS for $2 \mathrm{~h}$. After stimulation of SVECs with TNF- $\alpha(10 \mathrm{ng} / \mathrm{ml}, 4 \mathrm{~h}$, eBioscience, San Diego, CA), JAM- $A^{+/+}$and JAM- $A^{-/} C D 115^{+}$monocytes $\left(10^{6}\right.$ cells $\left./ \mathrm{ml}\right)$ labeled with CFSE $(1 \mu \mathrm{g} / \mathrm{ml}$, Sigma Aldrich, Carlsbad, CA $)$ were perfused through $\mu$-slides ${ }^{0.4}$ and allowed to adhere at $0.75 \mathrm{dyn} / \mathrm{cm}^{2}$ for 3 minutes. Subsequently, flow rates were gradually increased up to $11.5 \mathrm{dyn} / \mathrm{cm}^{2}$ and monocytes remaining adherent were counted. 


\section{TPLSM of the carotid artery in vitro and in vivo}

TPLSM imaging was performed using a resonant scanning Leica SP5MP (in vivo, Mannheim, Germany) or an Olympus FV1000MP (Hamburg, Germany) with a pulsed Ti:Sapphire Laser tuned at $800 \mathrm{~nm}$ and a $20 \times N A 1.00$ (Leica) or $25 \times$ NA1.05 (Olympus) water immersion objectives. Emitted fluorescence signals were detected using photo-multiplier tubes (PMTs). Image processing was performed using Image-Pro Analyzer 7.0 (Media Cybernetics, Rockville, MD) and MetaMorph (Molecular Devices, Sunnyvale, CA).

In vivo image acquisition (Leica) was performed at $10 \mathrm{~Hz}$ with a field of view (FOV) of $435 \mu \mathrm{m}^{2}$ (voxel: $1.09 \times 1.09 \times 1.00 \mu \mathrm{m}^{3}$ ), including threefold line averaging. Directly after in vivo recording, image acquisition was continued in situ at $0.4 \mathrm{~Hz}$ with a FOV of $435 \mu^{2}$ (voxel: $0.85 \times 0.85 \times 1.00 \mu \mathrm{m}^{3}$ ) to examine the vessel without motion artefacts. Emitted fluorescence signal was detected using 2 non-descanned PMTs: 500-565 nm (FITC) and 565-620 nm (AF568).

Isolated plaque-prone carotid arteries including the bifurcation were mounted in a perfusion chamber and imaged ex vivo ${ }^{29}$. Subsequently, vessels were flushed with directly conjugated anti-JAM-A AF488 $(10 \mu \mathrm{gg} / \mathrm{ml}$, clone H202-106, AbD serotec, Düsseldorf, Germany) and anti-CD31-PE $(2 \mu \mathrm{g} / \mathrm{ml}$, clone MEC13.3, BD Pharmingen, San Diego, CA). Antibodies were incubated at physiological pressure $(60-80 \mathrm{mmHg})$ for $1 \mathrm{~h}$ and arteries were flushed prior to imaging. Emitted fluorescence signal was detected using 3 PMTs: $400-470 \mathrm{~nm}$ for second-harmonic generation (SHG); 500-565 nm (AF488); 565-605 nm (PI, PE). Three-dimensional datasets were acquired at $0.1 \mathrm{~Hz}$ including twofold frame averaging; FOV $=500 \mu^{2}$ (voxel: $0.49 \times 0.49 \times 1.00 \mathrm{\mu m}^{3}$ ).

For ex vivo perfusion assays, a total of $6 \times 10^{5}$ Rhodamine-B labeled CD115 monocytes were perfused through mounted carotids $(60-80 \mathrm{mmHg})$ at a flow rate of $0.5 \mathrm{ml} / \mathrm{min}$ for 6 minutes at $37^{\circ} \mathrm{C}$. Prior to perfusion, the endothelium was labeled with anti-CD31-FITC for 20 minutes. After perfusion, the number of leukocytes adherent to approximately $50 \%$ of the luminal surface was determined using TPLSM (as number of adherent leukocytes per $500 \times 500 \times 250 \mu \mathrm{m}^{3}$ ). The first $500 \mu \mathrm{m}$ adjacent to the pipettes were excluded because of potential handling damage. Emitted fluorescence signal was detected in 3 PMTs: $400-510 \mathrm{~nm}$ for second-harmonic-generation and autofluorescence; 510-525 nm (FITC); 560-660 nm (Rhodamine-B).

\section{Quantification of immunofluorescence}

HAoECs cultured under flow conditions were stained with an anti-JAM-A antibody $(10 \mu \mathrm{g} / \mathrm{ml}, 2 \mathrm{~h}$, clone M.Ab.F11, Hycult biotech, Uden, The Netherlands) followed by secondary antibody staining (anti-mouse IgG Alexa 594, $1 \mu \mathrm{g} / \mathrm{ml}, \quad 1 \mathrm{~h}$, Invitrogen, Carlsbad, $\mathrm{CA})$ and anti-CD31-FITC-antibodies $(10 \mu \mathrm{g} / \mathrm{ml}, 2 \mathrm{~h}$, clone 5.6E, Beckman Coulter, 
Krefeld, Germany). Slides were imaged using a High-Content Imager (BD Pathway 855, BD Biosciences, San Jose, CA) with a 20x objective. Per slide, 10 images were made. Using AttoVision-software (BD Biosciences, San Jose, $\mathrm{CA}$ ), cells were segmented and fluorescence intensity per cell was determined.

\section{Fluorescent bead assay}

HAoECs were treated as above and incubated with $3.3 \mu$ fluorescent microbeads $(\sim 1 \mu \mathrm{m}$ diameter, Polysciences Inc., Warrington, PA) coupled to JAM-A antibodies (clone 246) for 30 min. Nuclei were stained with HOECHST 33342 (Sigma Aldrich, Carlsbad, CA). After washing, bright field and fluorescent images were recorded. Bead numbers were related to nuclei count and normalized to binding of IgG-coupled control beads.

\section{MiR-145 and anti-miR-145 transfection of HAoECs}

HAoECs were grown to $80 \%$ confluence, before transfection with miR-145-3p or miR-145-5p mimics (75 pM, mirVana, Ambion Life Technologies, Darmstadt, Germany) or miR-145-3p or anti-miR-145-5p inhibitors (30 nM, mirVana, Ambion Life Technologies, Darmstadt, Germany) was performed using Lipofectamine 2000 (Invitrogen, Carlsbad, CA) following the supplier's recommendations. Quantitative (q)PCR analysis was performed after $24 \mathrm{~h}$.

\section{Quantitative real-time PCR}

Analysis of JAM-A mRNA and miR-145 levels in HAoECs was performed using established protocols ${ }^{5,30}$. In brief, cDNA was synthesized from freshly isolated total RNA $(1 \mu \mathrm{g})$ and mixed with TaqManTM Fast Universal PCR Master Mix (Applied Biosystems, Darmstadt, Germany) or SYBR Advantage qPCR Premix (Clontech, Mountain View, CA) and specific products were analyzed in duplicate by quantitative or comparative real time PCR. Primer sequences for JAM-A mRNA analysis after oxLDL/LDL treatment were 5'-TCGAGAGGAAACTGTTGTGC-3' and 5'-ACCAGTTGGCAAGAAGGTCA-3' (huJAM-A) and 5'-GCCTCAAGATCATCAGC-3' and 5'-ACCA CTGACACGTTGGC-3' (huGAPDH). For JAM-A mRNA analysis after HAoEC culture under flow or after transfection with miR-145 mimics, a predesigned TaqManTM assay (Hs00170991_M1:F11R) was performed using a $7900 \mathrm{HT}$ cycler (Applied Biosystems). Comparative analysis of target JAM-A mRNA or miR-145 copies was normalized to levels of actin or small nucleolar RNA RNU-44, respectively, and compared to static or transfection controls, respectively. For oxLDL/LDL-treated HAoECs, target JAM-A mRNA was quantified using a standard curve and normalized to levels of GAPDH. 


\section{Statistical Analysis}

Statistical analysis was performed using Prism 6.0 (GraphPad Software). Means were compared between 2 groups by 2-tailed, unpaired or paired Student's t-test, without or with Welch correction or among more than 2 groups by 1-way ANOVA with Tukey's or Bonferroni post-test or Kruskal-Wallis test with Dunn's post-test, as indicated. Differences with $\mathrm{P}<0.05$ were considered as statistically significant. 


\section{Results}

\section{Deficiency in endothelial JAM-A protects against atherosclerosis}

The inhibition of mononuclear cell recruitment by soluble JAM-A has implicated JAM-A in atherogenesis ${ }^{5}$, however, owing to its pleiotropic functions the overall and cell-specific effects of JAM-A have remained elusive. Notably, somatic JAM-A deletion did not significantly affect atherosclerotic lesion area in the thoraco-abdominal aorta and the aortic root of $\mathrm{Apoe}^{-/}$mice fed a high-fat diet
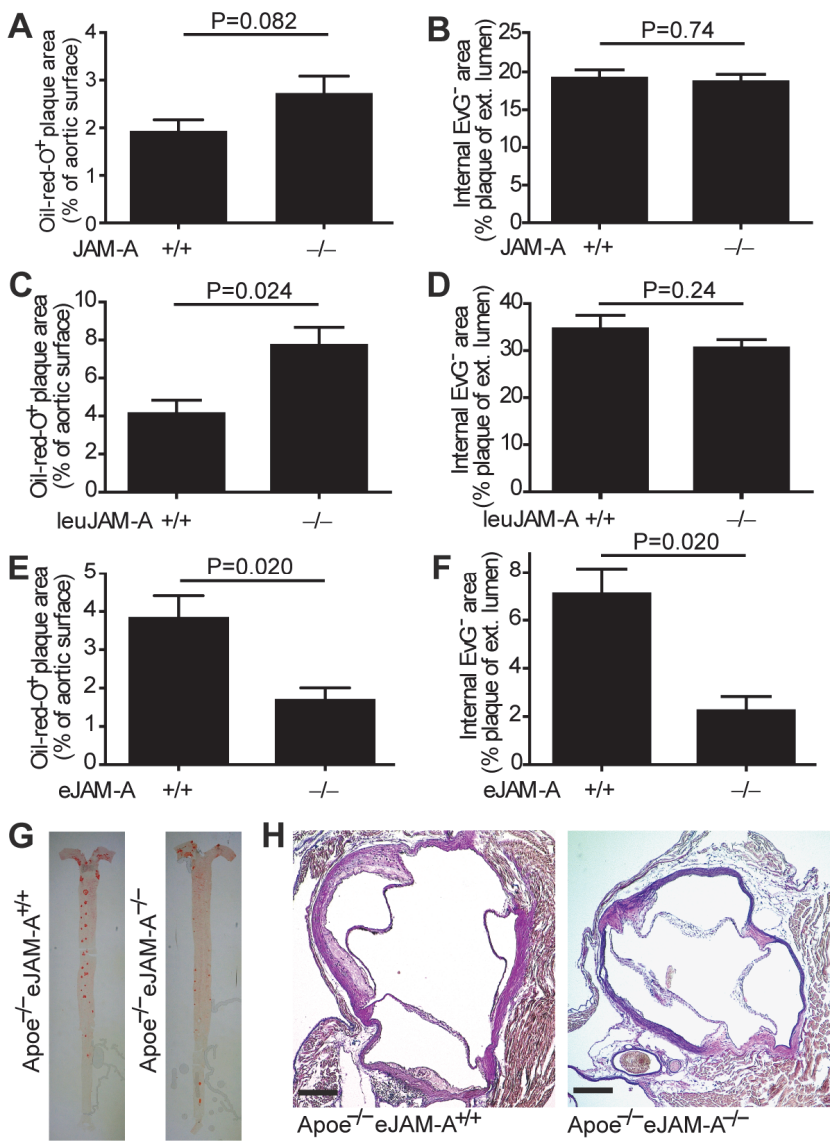

Figure 1: Cell-specific role of JAM-A deficiency in atherosclerosis.

$J A M-A^{+/+} A_{p o e^{-/}}$and $J A M-A^{-/} A p o e^{-\alpha}$ mice $(\mathbf{A}, \mathbf{B})$, leuJAM- $A^{+/+}$Apoe $^{-/-}$and leuJAM- $A^{-/}$Apoe $^{-/}$mice (C,D), eJAM- $A^{+/+} A p o e^{-/}$and eJAM- $A^{-/} A p o e^{-/}$mice (E,F) were fed a high-fat diet for 12 weeks. Atherosclerotic lesions were quantified in the thoraco-abdominal aorta after Oil-red-O staining $(\mathbf{A}, \mathbf{C}, \mathbf{E})$ and in the aortic root after EVG staining (B,D,F). Representative images depict the thoracoabdominal aortas (G) and aortic roots of eJAM- $A^{+/+} A p o e^{-/}$and $e J A M-A^{-/} A p o e^{-/}$mice $(\mathbf{H})$. Scale bar $=200 \mu \mathrm{m}$. Data represent mean \pm SEM $(n=10-13)$ and all $P$ values were calculated by 2-tailed $\mathrm{t}$ test. 
(HFD) for 12 weeks (Fig. 1A,B). In contrast, reconstitution of $A p o e^{-/}$mice with $J A M-A^{-/} A p o e^{-/}$BM (leuJAM- $A^{-/} A p o e^{-/}$) enhanced diet-induced lesion area in the thoraco-abdominal aorta but not in the aortic root, as compared to controls carrying $J A M-A^{+/+} A_{p o e^{-/}} \quad \mathrm{BM} \quad\left(\right.$ leuJAM- $\left.A^{+/+} A p o e^{-/}\right)$, indicating an atheroprotective function of JAM-A on BM-derived leukocytes (Fig. 1C,D). In turn, genetic deficiency in endothelial JAM-A reduced the diet-induced lesion area in the thoracoabdominal aorta and aortic root of tamoxifen-treated VeCad-CreERT $T^{2} J A M-A^{f / / f l} A p o e^{-/}\left(e J A M-A^{-/} A p o e^{-/}\right)$mice, as compared to their Cre- $\left(e J A M-A^{+/+} A p o e^{-/}\right.$) littermates (Fig. 1E-H), demonstrating a remarkable role of JAM-A on endothelial cells in promoting atherosclerosis.

\section{Endothelial JAM-A deficiency reduces lesional infiltration}

Immunohistochemistry in the aortic root revealed that the lesional content of Mac- $2^{+}$macrophages did not differ in somatic $J A M-A^{--} A p o e^{--}$mice versus $J A M-A^{+/+} A p o e^{-/}$controls (Fig. 2A). As compared to control chimeras, JAM-A deficiency in BM-derived cells reduced macrophage content (Fig. 2B). Likewise, deficiency in endothelial JAM-A markedly decreased macrophage content, as compared to controls with intact JAM-A (Fig. 2C,D). The infiltration with $\mathrm{CD}^{+} \mathrm{T}$ cells characterizing early lesion stages was unaffected by somatic deletion of JAM-A but markedly reduced in mice with JAM-A-deficient leukocytes or with an endothelial deficiency in JAM-A (Fig. 2E-G). As a hallmark for advanced lesions, necrotic core size was unaltered by somatic deletion of JAM-A, higher in mice with JAM-A-deficient BM-derived cells, indicative of increased macrophage turnover, and considerably reduced by endothelial deficiency in JAM-A (Fig. $2 \mathrm{H}-\mathrm{J}$ ). To evaluate the rate of lesion development in these mice, we performed a phenotypic classification ${ }^{27}$. Whereas JAM- ${ }^{-/-}$ $\mathrm{Apoe}^{-/-}$and leuJAM- $A^{-/-} \mathrm{Apoe}^{-/-}$mice developed lesions that were mainly in an advanced stage, eJAM- $A^{-/} A p o e^{-/}$mice almost exclusively bore lesions in initial or intermediate stages, displaying an increase in early lesion stages, as compared to controls (Fig. 2K). Whereas the preponderance of advanced lesions in chimeric mice is likely related to irradiation, a higher proportion of less advanced lesion stages in the eJAM- $A^{f / f l}$ lines could be due to tamoxifen treatment or residual differences in genetic background. Taken together, cell type-specific effects of leukocyte and endothelial JAM-A deficiency differentially modulate the inflammatory phenotype and stage of atherosclerotic plaques. 

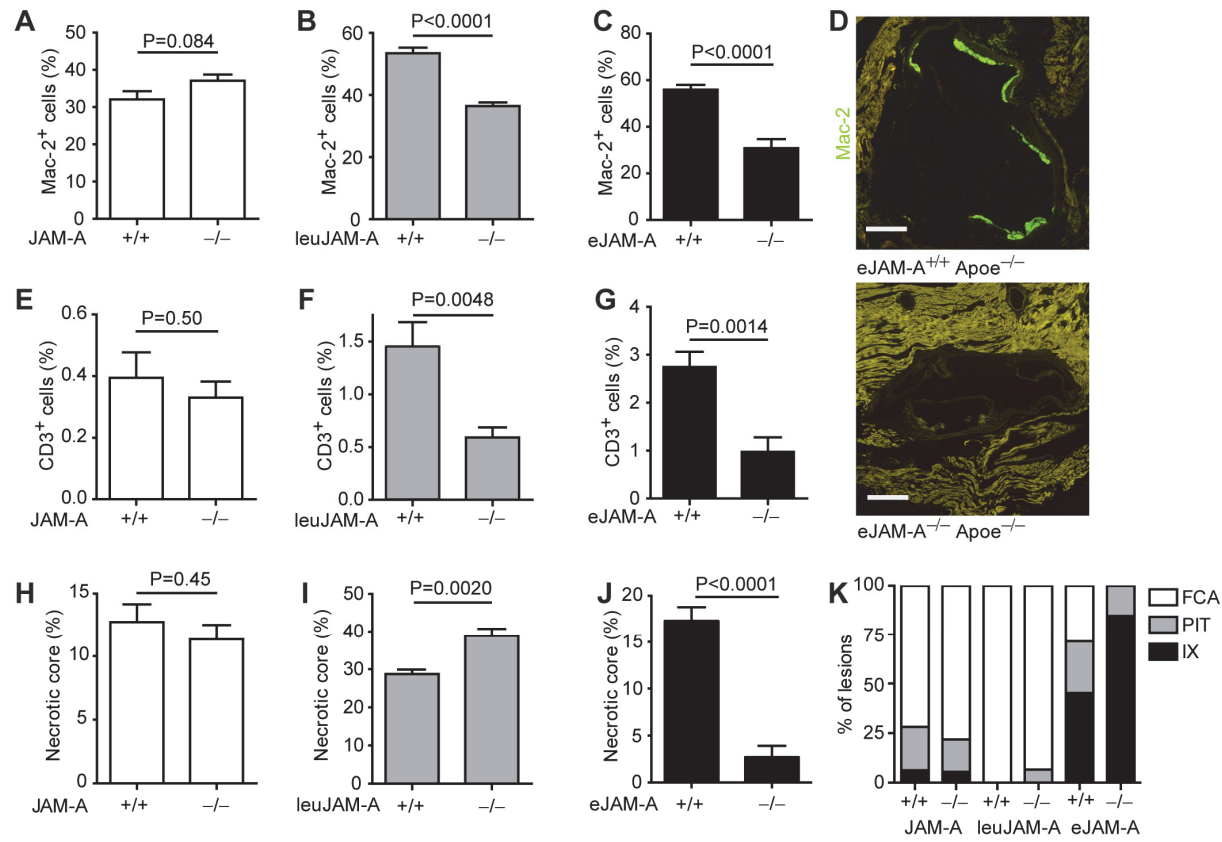

Figure 2: Phenotype of atherosclerotic lesions in JAM-A-deficient mice.

The relative content of Mac- $2^{+}$macrophages (A-D) and $\mathrm{CD}^{+}$T cells (E-G) in aortic root lesions was analyzed by quantitative immunofluorescence. Representative images of Mac-2-stained aortic roots isolated from eJAM- $A^{+/+} A p o e^{-/}$and $e J A M-A^{-/} A p o e^{--}$mice are shown (D). Scale bar $=200 \mu \mathrm{m}$. Necrotic core size in aortic root lesions was quantified following DAPI staining (H-J).

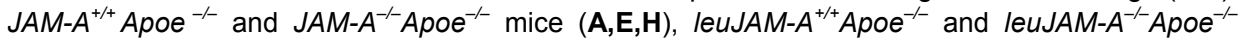
mice (B,F,I), and eJAM- $A^{+/ t} A p o e^{-/}$and eJAM- $A^{-/} A p o e^{-/}$mice $(\mathbf{C}, \mathbf{D}, \mathbf{G}, \mathbf{J})$ were fed a high-fat diet for 12 weeks. The lesions were phenotypically characterized according to the stage $(\mathbf{K})$. IX: intimal xanthoma, PIT: pathologic intimal thickening, FCA: fibrous cap atheroma. Data represent mean \pm SEM $(n=10-13)$ and all $P$ values were calculated by 2 -tailed $t$ test.

\section{Role of endothelial JAM-A in arterial leukocyte recruitment}

We used in vivo, ex vivo and in vitro adhesion and transmigration assays to mechanistically evaluate the role of endothelial and leukocytic JAM-A in arterial monocyte recruitment. Indeed, we found a lower number of wild-type CD115 monocytes that had crossed the endothelial layer of carotid arteries in eJAM- $A^{-\alpha}$ mice after treatment with IL-1 $\beta$, as compared to eJAM- $A^{+/+}$controls, both during in vivo recording (Fig. 3A) and in situ after sacrifice (Fig. 3B). Accordingly, the adhesion of wild-type monocytes to JAM-A-deficient endothelial monolayers stimulated with TNF- $\alpha / \mathrm{IFN}-\gamma$ was unaltered but their transmigration underneath JAM-A-deficient endothelial monolayers was markedly reduced, compared with JAM-A-bearing endothelial cells (Fig. 3C,D). The decreased transmigration of monocytes across JAM-A-deficient endothelial cells might also be explained by an increase in reverse transmigration, which 
was only observed when $J A M-A^{+/+}$leukocytes transmigrated across JAM-A-deficient endothelial cells (Fig. 3E).

Leukocytic JAM-A deficiency impairs de-adhesion and endothelial barrier function

As compared to wild-type monocytes, $J A M-A^{-/}$mouse monocytes showed a marked increase in firm adhesion to ex vivo perfused wild-type carotid arteries (Fig. 3G) and to JAM- $A^{+/+}$endothelial cells in a recruitment assay under flow conditions in vitro (Fig. $3 \mathrm{C}$ ). This was accompanied by reduced transmigration of $J A M-A^{-/}$monocytes (Fig. 3D), which may be attributable to a defect in deadhesion $^{12}$. JAM- $A^{-/}$monocytes showed a higher rate of incomplete transmigration (defined as cells that had entered endothelial junctions without exiting, thus being entrapped) across both JAM-A-expressing or JAM-A-deficient endothelial cells (Fig. 3F), explaining the overall decrease in complete transmigration (Fig. 3D).

To confirm defective de-adhesion of $J A M-A^{-/}$monocytes, we performed assays under variable flow conditions. Compared with $J A M-A^{+/+}$controls, adherent $J A M-A^{-/}$monocytes were more resistant to shear stress and detachment induced by gradually increasing flow rates both on stimulated SVEC monolayers (Fig. 4A) and the $\beta_{2}$ integrin ligand ICAM-1.FC (Fig. 4B). This clearly indicates that de-adhesion was impaired in $J A M-A^{--}$monocytes and that this effect was likely mediated by increased activity of $\beta_{2}$ integrins.

Because compromised endothelial integrity is a hallmark of early atherosclerosis ${ }^{31}$, we investigated the permeability of the carotid artery wall of Apoe $^{-/}$mice deficient in leukocytic and endothelial JAM-A fed with or without HFD for 6 weeks. As assessed by ex vivo TPLSM, the uptake of fluorescent dextran into the arterial media was not affected by HFD or endothelial JAM-A deficiency but increased by histamine-treatment or leukocytic JAM-A-deficiency (Fig. 4C). Altered vascular permeability in leuJAM- $A^{-/} A p o e^{-/}$mice may reflect the damage inflicted by impaired de-adhesion or transmigration of leuJAM- $A^{-/-}$ leukocytes and may explain increased lesion formation. 
A
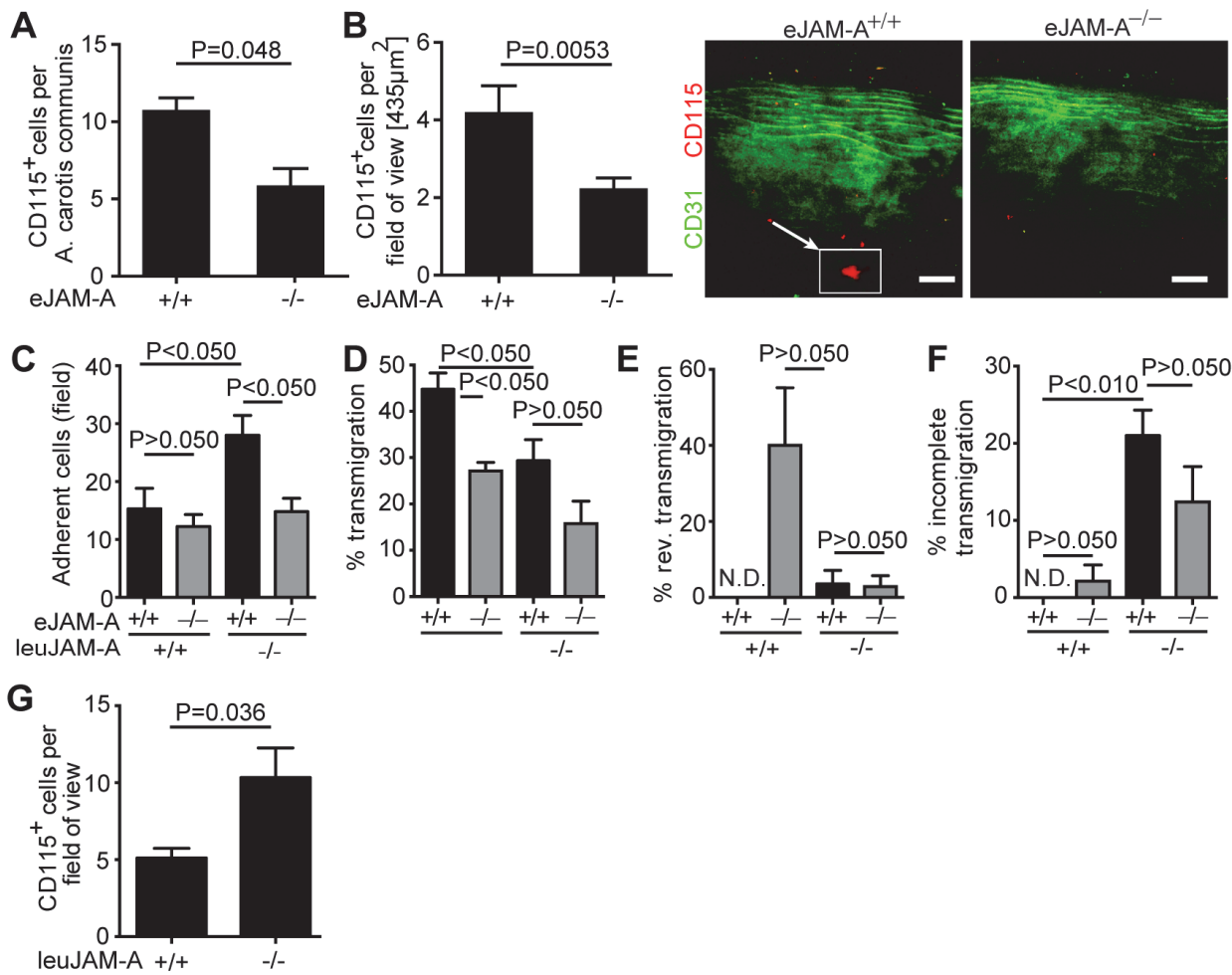

Figure 3: Cell-specific effects of JAM-A on transmigration.

$(\mathbf{A}, \mathbf{B})$ Numbers of $\mathrm{CD} 115^{+}$cells located in the vessel wall of common carotid arteries after incubation with IL-1 $\beta$ in a perivascular pluronic gel for $24 \mathrm{~h}$ were analyzed by in vivo (A) and post mortem in situ (B) 2-photon laser scanning microscopy (TPLSM) in eJAM- $A^{+/+}(n=3)$ and eJAM- $A^{-/}$mice $(n=7-9)$. Representative images depict $C D 115^{+}$monocytes (red; inset shows magnification) migrated into sub-endothelial regions, $\mathrm{CD} 1^{+}$endothelium and elastin autofluorescence in green (B, right panels). Scale bar $=40 \mu \mathrm{m}$. (C-F) Stable adhesion (C) completed (D), reverse $(\mathbf{E})$ and incomplete $(\mathbf{F})$ transendothelial migration of leuJAM- $A^{+/+}$or leuJAM- $A^{-/}$monocytes perfused on TNF- $\alpha /$ IFN- - -treated eJAM- $A^{+/+}$(black bars) or eJAM- $A^{-/}$ endothelial cells (grey bars) at $1.5 \mathrm{dyn} / \mathrm{cm}^{2}$ was analyzed by video microscopy $(n=3-5)$. (G) Adhesion of primary JAM-A $A^{+/+} A p o e^{-/-} \quad(n=6)$ and $J A M-A^{-/} A p o e^{-/-} \quad(n=7) \quad C D 115^{+}$mouse monocytes was determined using TPLSM after ex vivo perfusion of TNF- $\alpha$-activated carotid arteries $\left(J A M-A^{+/ t} A p o e^{-/}\right)$pressurized at $\left.80 \mathrm{mmHg}\right)$. Data represent mean $\pm \mathrm{SEM}$ and $\mathrm{P}$ values were calculated by one-way ANOVA with Bonferroni (Fig. 3C-F) multiple comparison test or 2-tailed test (Fig. 3A,B,G). 

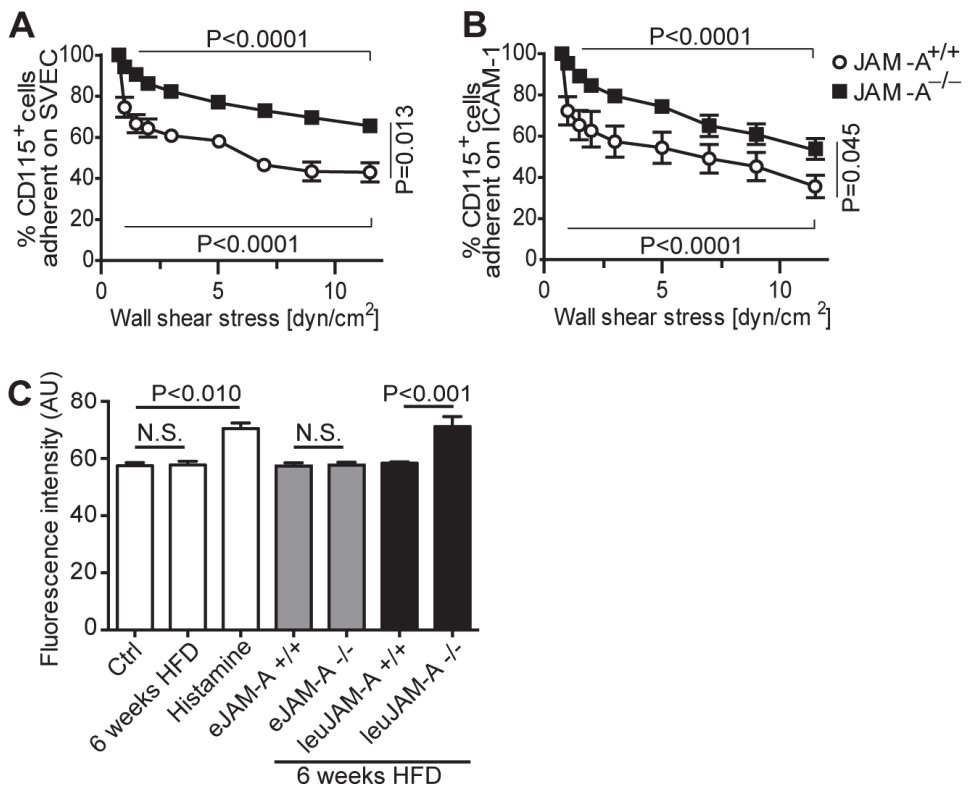

Figure 4: Cell-specific effects of JAM-A on de-adhesion and permeability.

$(\mathbf{A}, \mathbf{B})$ De-adhesion of primary $J A M-A^{+/+}$and $J A M-A^{-/}$CD $115^{+}$mouse monocytes was assessed by detachment of adherent cells at gradually increasing flow rates on TNF- $\alpha$-activated SVEC monolayers (A) or ICAM-1.FC (B) ( $n=12$ each). (C) Permeability was assessed by extravasation of $70 \mathrm{kDa}$ FITC-labeled dextran using TPLSM in carotid arteries ex vivo with or without (ctrl) histamine-treatment or after 6-weeks of HFD in $\mathrm{Apoe}^{-/-}$mice (open bars), with or without deficiency of endothelial $(n=5$, grey bars) or leukocyte $(n=5$, black bars) JAM-A. Data represent mean \pm SEM and $P$ values were calculated by one-way ANOVA with Tukey's multiple comparison test or 2-tailed $\mathrm{t}$ test.

\section{Focal redistribution of endothelial JAM-A in lesion-prone areas}

Analysis of atherosclerotic arteries and plaque tissue revealed an increase in JAM-A expression ${ }^{5,21}$. We used ex vivo 2-photon laser scanning microscopy (TPLSM) in unfixed and intact carotid arteries of $A_{p o e^{--}}$mice to label JAM-A and to determine its distribution in plaque-prone vessels as a potential mechanism underlying atherogenic leukocyte recruitment (Supplementary Fig. 1). The undiseased common part of the carotid artery explanted from 1 year-old $\mathrm{Apoe}^{-/}$mice on normal chow showed an organized mesh-like junctional pattern of JAM-A expression in luminal endothelial cells (Fig. 5A, left panel, Supplementary Video online). In contrast, segments near the bifurcation, which are prone to lesion formation owing to disturbed flow, displayed an apicoluminal redistribution and focal concentration of JAM-A away from endothelial 

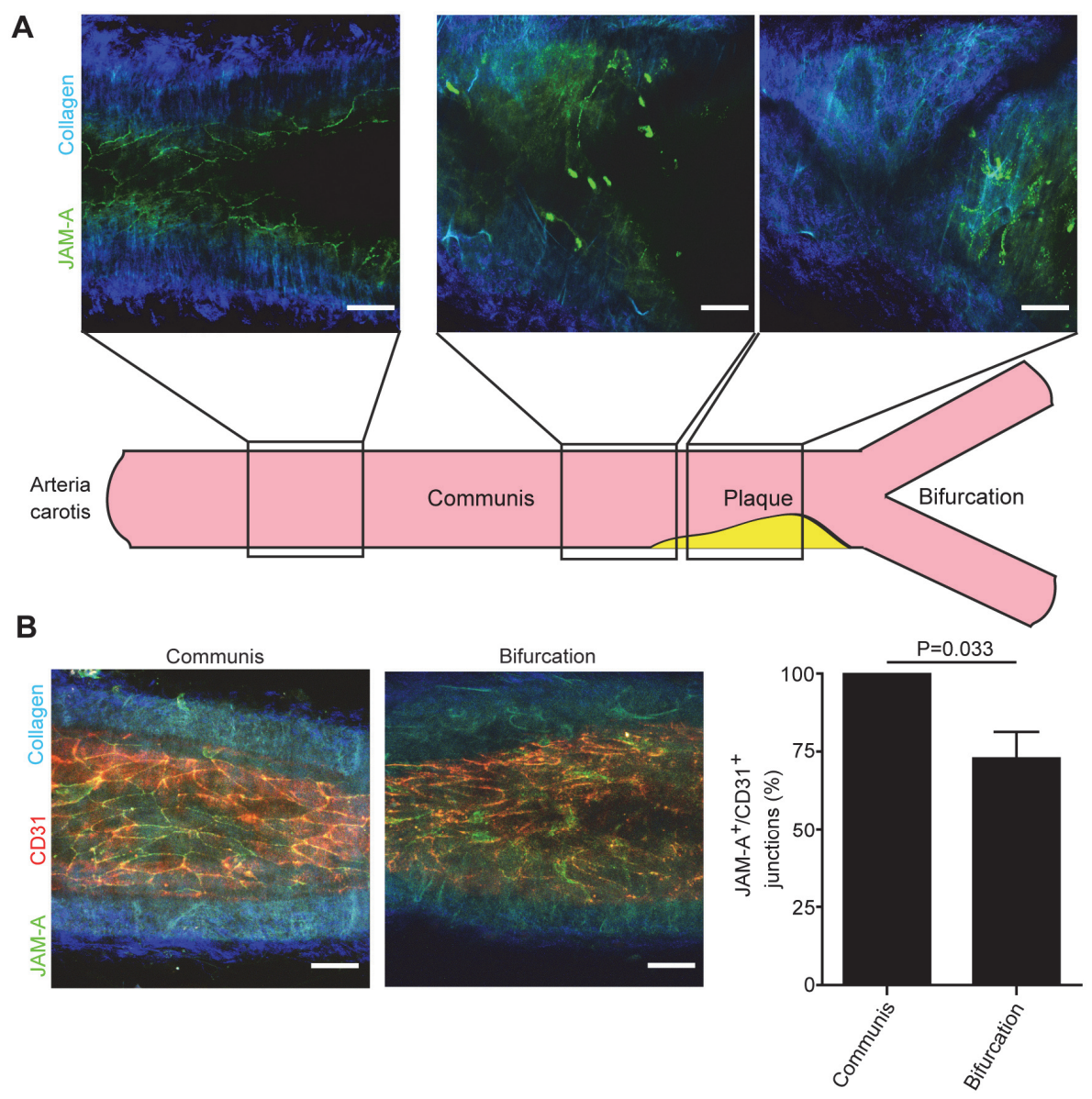

Figure 5: Arterial localization of JAM-A during atherogenesis.

(A) Visualization of JAM-A (green) and collagen (blue, SHG) in an explanted carotid artery of a 1 year-old $\mathrm{Apoe}^{-/-}$mouse fed normal chow. An organized junctional pattern of JAM-A staining is evident in the healthy part of the carotid artery (left panel), which changes into a focally enriched pattern in the shoulder (middle panel) and core (right panel) regions of the plaque. Images are total projections of z-stacks. A schematic drawing (lower part) depicts where images were taken. Scale bar $=40 \mu \mathrm{m}$. (B) Co-staining (left and middle panels) and semi-quantitative analysis (right panel) of CD31 (red) and JAM-A (green) in the carotid artery of an Apoe ${ }^{-/}$mouse fed a high-fat diet for 7 weeks revealed a decreased JAM-A/CD31 pseudo-overlap in the endothelial junctions at the diseased bifurcation, compared with the common part. Scale bar $=40 \mu \mathrm{m}$. Data represents mean $\pm \operatorname{SEM}(n=5)$ and $P$ value was calculated by 2 -tailed $t$ test.

cell junctions (Fig. 5A, middle and right panels). The middle panel shows the transition zone between undiseased segments with a normal junctional JAM-A pattern (left part) and focal enrichment of JAM-A in the shoulder region of a lesion (right part). To assess the propensity of JAM-A for early focal redistribution during lesion formation, we performed co-staining with PECAM-1 
(CD31) as another junctional protein expressed in endothelial cells (Fig. 5B and Supplementary Fig. 2). In carotid arteries of $A p o e^{-/-}$mice fed a HFD for 6 weeks, typical examples of co-staining for JAM-A and CD31 in the undiseased common part and the plaque-prone areas near the bifurcation are shown (Fig. 5B, left and middle panels). Using image analysis, we determined the pseudo-overlap of JAM-A and CD31 expression in undiseased areas for normalization (Fig. 5B, right panel). The bifurcation prone to nascent atherosclerotic lesion formation revealed a decrease in junctional colocalization of JAM-A and CD31 ( $72.8 \pm 8.4 \%$ of control, $n=5, P<0.05)$, implying a preferential redistribution of JAM-A.

\section{Oxidized LDL increases functional JAM-A expression}

To elucidate whether the focal accumulations of endothelial JAM-A in atherosclerotic lesions are caused by redistribution or increased de novo synthesis, we performed JAM-A antibody-coupled fluorescent bead assays,

A
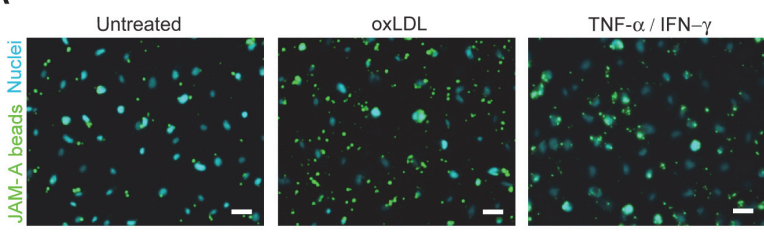

B
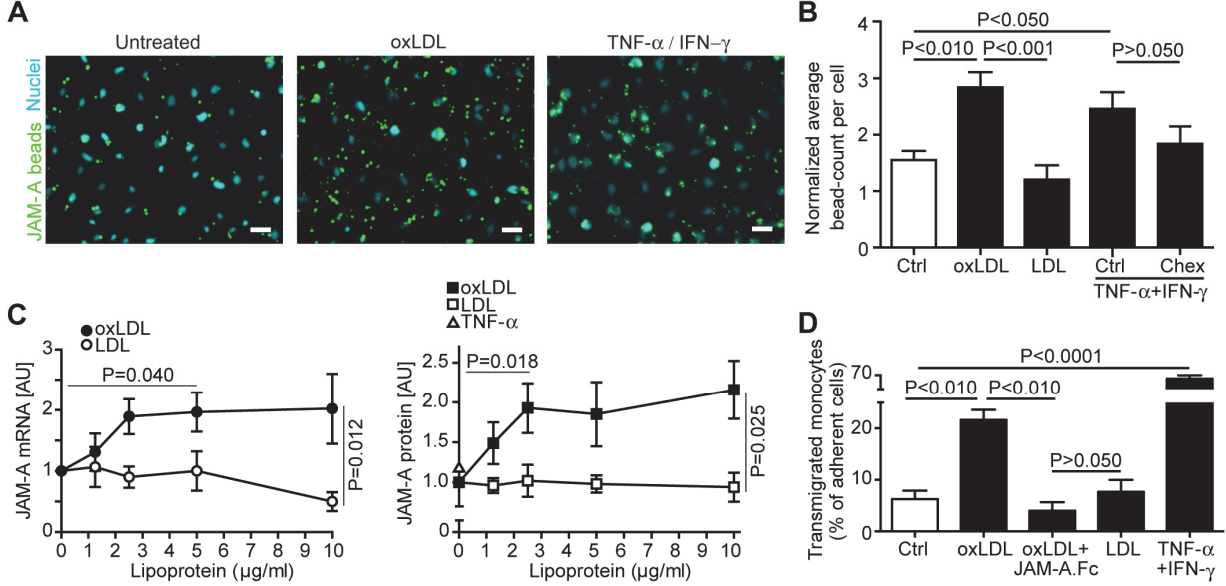

Figure 6: Expression and localization of JAM-A under atherogenic conditions.

$(A, B)$ Human aortic endothelial cells (HAoECs) were treated with or without LDL, oxLDL (16 h), TNF- $\alpha /$ IFN- $\gamma(4 \mathrm{~h})$ and/or cycloheximide (Chex, $1 \mathrm{~h}$ ), before incubation with fluorescent microbeads coupled to JAM-A antibodies (green). After washing, representative images were taken (A), beads were counted (B) and normalized to the number of endothelial cells (blue). Scale bar $=40 \mu \mathrm{m}$. Counts were corrected for unspecific binding using beads carrying isotype control. (C) HAoECs were treated with LDL (open symbols) or oxLDL (solid symbols) for $16 \mathrm{~h}$ at indicated concentrations. Quantitative real-time PCR normalized to GAPDH (left panel, $n=3$ ) and western blot analyses normalized to Ponceau staining (right panel, $n=5$ ) were performed. (D) Transendothelial migration of CD $14^{+}$monocytes across HAoECs treated with or without (open bar) LDL, TNF- $\alpha / \mathrm{IFN}-\gamma$ or oxLDL and with or without blocking JAM-A.Fc fusion protein (black bars) under flow conditions. Transmigrated cells were counted and normalized to the total number of adherent cells. Data represent mean \pm SEM of 3 independent experiments. $P$ values were calculated by one way ANOVA with Tukey's multiple comparison test (Fig. 6B,D) or 2-tailed t test (Fig. 6C). 
real-time PCR and western blot analysis. Similar to co-stimulation with TNF- $\alpha$ and IFN- $\gamma$, treatment with oxLDL but not with native LDL increased specific surface binding of anti-JAM-A microbeads to aortic endothelial cell monolayers (Fig. 6A,B). Blocking de novo protein synthesis with cycloheximide partially yet non-significantly reduced JAM-A surface levels, suggesting that both increased expression and redistribution contributed to the up-regulation of endothelial surface JAM-A. Treatment with oxLDL but not native LDL or TNF- $\alpha$ dose-dependently increased JAM-A transcript and protein expression in HAoECs, reaching a plateau at $2.5 \mu \mathrm{g} / \mathrm{ml}$ of oxLDL (Fig. 6C). To link JAM-A expression to atherogenic recruitment, we performed a transmigration assay using classical $\mathrm{CD}_{14}{ }^{+}$monocytes and HAoECs under shear flow conditions (Fig. 6D). Similar to co-stimulation with TNF- $\alpha$ and IFN- $\gamma$, treatment with oxLDL but not native LDL caused an increase in monocyte transmigration. Notably, blocking endothelial JAM-A with soluble JAM-A.Fc reduced the oxLDL-induced increase in transmigration to levels seen in untreated HAoECs, indicating that the effect of oxLDL on transmigration is mediated by JAM-A.

The expression and localization of JAM-A is governed by shear flow and miR145

Because the increased susceptibility to lesion formation in areas near bifurcations or branching points is related to altered flow conditions, e.g. low or oscillatory flow, we tested whether such aberrant flow conditions as induced by partial ligation of the carotid artery of $A p o e^{-/}$mice affects the localization of JAM-A. Indeed, co-staining for JAM-A and CD31 revealed a discontinuous pattern of JAM-A and redistribution from the junctions in the common part of partially ligated carotid arteries, as seen in the bifurcation of mice with established lesions (Fig. 7A and Supplementary Fig. 2). The redistribution of JAM-A was evident both in the common part and in the bifurcation, as early as 2 weeks after ligation (Fig. 7A). The pseudo-overlap of JAM-A with CD31 was markedly reduced in carotid arteries after 2 weeks and this reduction sustained for at least 8 weeks after partial ligation (Fig. 7B), indicating that JAM-A is preferentially redistributed from its junctional expression pattern under conditions of disturbed flow. Conversely, the control of JAM-A might be linked to atheroprotective laminar flow conditions. Hence, we assessed JAM-A expression in HAoECs cultured under static or flow conditions, revealing an inverse correlation of JAM-A expression with laminar shear flow (Fig. 7C,D; Supplementary Fig. 3A). To correlate this effect with a JAM-A-dependent local predilection for atherosclerosis, in vivo analysis confirmed that the reduction of atherosclerotic lesion formation in the descending aorta and the aortic arch between eJAM- $A^{+/+} A p o e^{-/-}$and eJAM- $A^{-/} A p o e^{-/}$mice was more prominent at regions of low/oscillatory shear stress, e.g. in the inner curvature of the arch or the descending aorta with branching points, as compared to regions with 
A
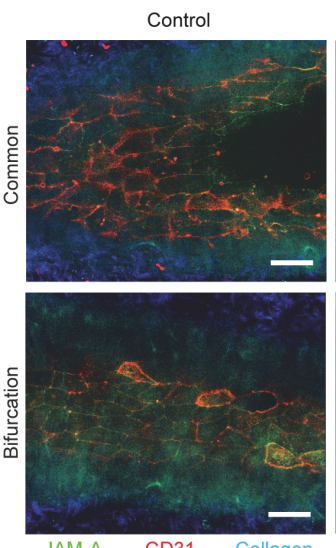

$\mathbf{E}$

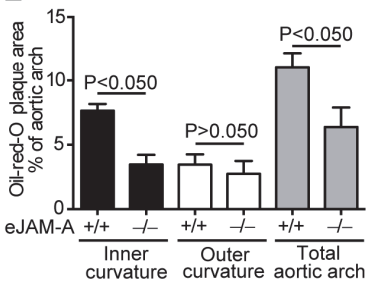

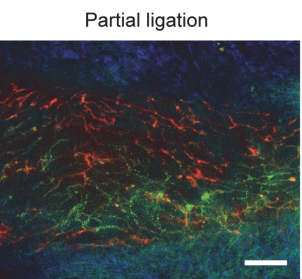

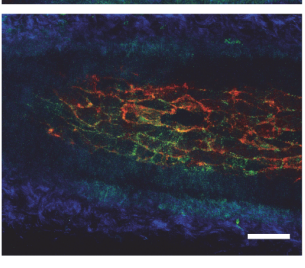

F

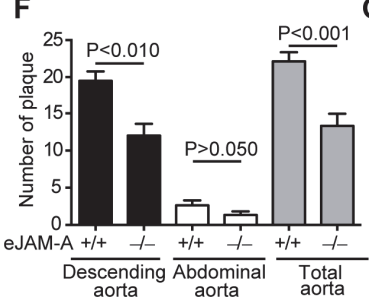

B
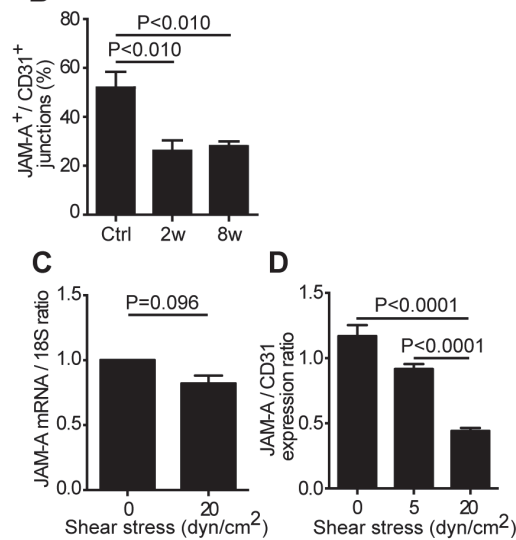

Shear stress $\left(\mathrm{dyn} / \mathrm{cm}^{2}\right)$

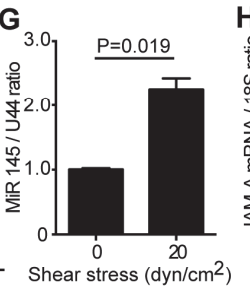

Figure 7: Expression and localization of JAM-A during altered flow conditions.

(A) Visualization of JAM-A (green), CD31 (red) and collagen (blue) in control (left panels) and treated carotid arteries (right panels) at the common part and the bifurcation, 2 weeks after partial ligation. Images are total projections of z-stacks. Scale bar $=40 \mu \mathrm{m}$. (B) Quantification of the percentage of junctions staining positive for both JAM-A and CD31 in controls and carotid arteries, 2 and 8 weeks after partial ligation $(n=4-6)$. (C,D) Expression of JAM-A mRNA relative to $18 \mathrm{~S}$ housekeeper, as analyzed by qRT-PCR (C), and expression of JAM-A protein relative to CD31, as quantified by immunofluorescence (D) in human aortic endothelial cells (HAoECs) cultured under static or flow conditions, as indicated $(n=19-32)$. $(\mathbf{E}, \mathbf{F})$ Quantification of Oil-red- $O^{+}$lesion surface in areas of low/oscillatory shear flow (inner curvature), high/laminar shear flow (outer curvature) or the total aortic arch $(\mathbf{E})$, and number of plaques in the descending, abdominal and total aorta $(\mathbf{F})$ of eJAM-A $A^{+/+} A_{p o e^{-/}}$and $e J A M-A^{-/} A p o e^{-/}$mice fed a high-fat diet for 12 weeks $(n=10-13)$. $(\mathbf{G}, \mathrm{H})$ Expression of miR-145 relative to U44 housekeeper in HAoECs cultured under static or flow conditions (G) and expression of JAM-A mRNA relative to $18 \mathrm{~S}$ housekeeper in HAoECs transfected with miR-145-3p, miR-145-5p mimics or control $(\mathbf{H})$, as analyzed by qRT-PCR $(n=3-4)$. Data represent mean \pm SEM and $P$ values were calculated by one-way ANOVA with Tukey's multiple comparison (Fig. 7B,E,F,H), Kruskal-Wallis with Dunn's post-test (Fig. 7D) or 2-tailed t test (Fig. 7C,G).

high/laminar shear flow, e.g. the outer curvature of the arch and the abdominal aorta (Fig. 7E,F).

Recent evidence has linked the expression of microRNA (miR)-145 in endothelial cells under shear flow conditions to the mechanosensitive transcription factor Krüppel-like factor $2(\mathrm{KLF} 2)^{32,33}$. Indeed, culture of HAoECs under shear flow conditions increased the expression of miR-145, as compared 
to static conditions (Fig. 7G). Notably, an analysis of miR target sequences revealed that the gene of JAM-A harbors at least two seed sequences for miR-145-3p and miR-145-5p (see Supplementary Fig. 4). To investigate whether JAM-A expression is regulated by a miR-145-dependent mechanism, we transfected HAoECs with miR-145-3p and miR-145-5p mimics. Notably, both the miR-145-3p and miR-145-5p strands reduced the copy number of JAM-A mRNA in HAoECs (Fig. 7H). Vice versa to verify those results we checked whether inhibition of miR-145-3p and miR-145-5p by transfection of appropiate miR inhibitors led to increased JAM-A mRNA copy numbers. Indeed, inhibitors against both miR-145-3p and miR-145-5p strands resulted in increased copy number of JAM-A mRNA (Supplementary Fig. 3B). These findings suggest that miR-145 is a flow-dependent regulator of JAM-A expression, which may protect against plaque formation by attenuating JAM-A mRNA levels under flow conditions. Taken together, endothelial JAM-A levels might serve to functionally integrate atherogenic risk factors, such as modified LDL and disturbed flow conditions. 


\section{Discussion}

Here we have unraveled the cell-specific effects and mechanisms exerted by JAM-A in diet-induced atherosclerosis, and the overall and context-dependent consequence of its genetic deficiency. Previous studies have reported differential or even contradictory effects of somatic and endothelial JAM-A deficiency in various models of tissue injury and inflammation ${ }^{14,17,34,35}$. This apparent inconsistency may be due to the use of heterogeneous models affecting different vascular beds. We employed diet-induced atherosclerotic lesion formation and arterial inflammation in $\mathrm{Apoe}^{-/}$mice and found that endothelial JAM-A promoted lesion formation and mononuclear cell infiltration. This effect was mediated by an elevated accessibility of JAM-A (through upregulation and redistribution) and its function in guiding monocyte recruitment, which was stimulated under atherogenic conditions. The expression and luminal enrichment of JAM-A was exacerbated by disturbed flow conditions, e.g. reduced shear flow, as encountered at predilection sites, whereas laminar shear flow induced miR-145 to repress JAM-A expression, in a mechanism that may contribute to limiting the susceptibility to atherosclerosis. Targeting endothelial JAM-A may thus serve as a feasible option to protect against atherogenic inflammation.

In contrast, we demonstrate that JAM-A deficiency in BM-derived leukocytes aggravates atherosclerotic lesion formation. Dendritic cells deficient in JAM-A display higher migratory capacity in lymphoid organs but not in blood vessels $^{11}$, while JAM-A-deficient polymorphonuclear cells show reduced diapedesis in peritonitis and ischemia-reperfusion injury, related to impaired de-adhesion and polarized motility ${ }^{12}$. We found that JAM-A-deficient monocytes indeed display defects in de-adhesion and complete transendothelial migration, likely due to persistently increased activity of $\beta_{2}$ integrins. Consequently, monocytes become entrapped between the endothelial cell layer and the basement membrane, and may thereby cause vascular damage. Our data thus indicate that the presence of leukocytic JAM-A may limit atherogenic damage by enabling physiological de-adhesion and migration of mononuclear cells.

No significant alterations of atherosclerotic lesion formation were found in mice with somatic JAM-A deletion, pointing towards an intermediate phenotype between the atherogenic influence of endothelial JAM-A and the protective functions of leukocytic JAM-A. Notably, the reduction in Mac- $2^{+}$and $\mathrm{CD}^{+}$cell content in mice with either endothelial or leukocytic deficiency in JAM-A was not recapitulated in JAM- $\mathrm{A}^{-1-}$ mice, where no difference could be observed. This may be due to counteracting effects of JAM-A deficiency in cells other than endothelial and bone-marrow derived cells, e.g. smooth muscle cells, pericytes or non-BM-derived resident macrophages. The intermediate phenotype was also reflected in the classification of lesion stages. In general, 
irradiation for BM reconstitution appeared to accelerate the development of more advanced stage plaques, whereas the deficiency in endothelial JAM-A delayed lesion progression and clearly favored a retention in early lesion stages.

We used various assays to assess the capacity of JAM-A-deficient leukocytes and/or endothelial cells to support recruitment in vivo, ex vivo and in vitro and we provide novel in vitro evidence that a deficiency in endothelial JAM-A might also allow for monocytes to reappear on the monolayer by passively permitting reverse migration, contributing to the overall decrease in complete transmigration. This retentive control exerted by JAM-A complements a reverse "gate-keeper" function revealed for JAM-C in a study, where blocking JAM-C reduced the number of monocytes in inflammatory tissue by increasing reverse transmigration ${ }^{36}$. Accordingly, a 'hesitant' or 'reverse' transmigration behavior has been identified for neutrophils during inflammation after ischemia-reperfusion injury in vivo, which was characterized by lower expression of JAM-C at endothelial junctions, enhanced by blockade or genetic deletion of $\mathrm{JAM}-\mathrm{C}^{37}$, and implicated in systemic dissemination of inflammation.

Mechanistically, the exacerbation of atherosclerotic lesion formation by endothelial JAM-A appears to be due to its redistribution from the intercellular junctions to the luminal surface, and to an up-regulated expression under atherogenic conditions, thus increasing the availability of luminal JAM-A. Previous work has addressed the redistribution of endothelial JAM-A, showing that JAM-A is re-localized to the apical surface in a cytokine-dependent manner under static or flow conditions in vitro ${ }^{15-17,35}$. We extend these findings by unveiling a focal up-regulation and redistribution of JAM-A expression in endothelial cells of carotid arteries under atherogenic conditions of hyperlipidemia. The increased luminal JAM-A availability could mediate enhanced recruitment and higher content of macrophages and $T$ cells in atherosclerotic plaques of hyperlipidemic mice. In vitro experiments confirmed that oxidized LDL increased expression of JAM-A and its redistribution to the apical surface.

Our data challenge the intuitive assumption that knocking-out a protein that is crucially involved in junctional barrier function, would cause a non-specific influx of leukocytes. Rather, the evidence presented in this study refutes a role of JAM-A in limiting transendothelial migration and points towards a specific role of JAM-A in leukocyte recruitment in the context of atherosclerosis. First, genetic deficiency in endothelial JAM-A decreased infiltration of plaques with macrophages and $T$ cells and reduced luminal monocyte extravasation in carotid arteries in vivo. Second, redistribution of JAM-A induced by oxLDL facilitated the transmigration of monocytes.

The increase in expression and focal redistribution of JAM-A in response to atherogenic stimulation with oxLDL reveals a striking similarity to JAM-C, a related JAM family member, which displays increased expression and 
redistribution to the apical surface after oxLDL treatment ${ }^{38}$. Like for JAM-A, JAM-C predominantly localized to interendothelial contacts under quiescent conditions, oxLDL induced a disorganized JAM-C localization that was no longer restricted to interendothelial junctions, and JAM-C supported both adhesion and transmigration upon oxLDL stimulation ${ }^{38}$.

The up-regulation and luminal redistribution of JAM-A is enhanced by aberrant shear flow conditions, e.g. after partial ligation or at predilection sites, whereas laminar shear flow appears to exert beneficial effects on JAM-A, limiting the susceptibility to atherogenesis. Accordingly, the reduction of atherosclerotic lesion formation in the aortic arch was more prominent in regions of low shear rather than high shear, e.g. the inner curvature of the arch and branching points of the descending aorta. Of note, KLF2-transduced or shear stress-stimulated human endothelial cells have been found to be enriched in miR-143/145, providing a mechanism for atheroprotective communication with neighboring SMCs via miR-145-containing microvesicles ${ }^{33}$. Our data confirmed that shear flow induces an increase in miR-145 expression in arterial endothelial cells, which is highly relevant and extends findings identifying JAM-A as a miR-145- target in tumor cells ${ }^{39}$. The overexpression or inhibition of miR-145 respectively suppressed or enhanced the expression of JAM-A in endothelial cells, which was mirrored by the flow-dependent reduction in JAM-A expression. Thus, miR-145 is a regulator of JAM-A in the setting of arterial remodeling.

Notably, platelet endothelial adhesion molecule-1 (PECAM-1), another Ig family adhesion molecule expressed on platelets, leukocytes and endothelial cell junctions, has recently been found to regulate atherosclerotic plaque formation in a cell- and site-specific manner ${ }^{40}$. In contrast to JAM-A, PECAM-1 on $\mathrm{BM}$ cells was atherogenic irrespective of the hemodynamic environment, whereas PECAM-1, like JAM-A, reduced lesion formation in areas of disturbed flow but was atheroprotective in high shear regions by mechanisms yet to be elucidated.

In the context of arterial denudation injury, the neointimal content of macrophages was reduced in mice with a somatic JAM-A deletion. This was likely due to a reduced JAM-A-dependent deposition of the chemokine CCL5 by platelets on the luminal surface of injured arteries ${ }^{20}$. Moreover, the phenotype of regenerating endothelial cells after wire-injury may differ, benefiting from increased JAM-A expression and its function in endothelial cell migration and shear resistance ${ }^{41}$.

Our study identifies the differential and cell type-specific contribution of JAM-A in atherosclerosis, namely a crucial involvement of endothelial JAM-A in atherogenic leukocyte recruitment in response to modified lipids and at predilection sites with disturbed flow. Increased expression and focal redistribution of JAM-A controlled by miR-145 establish a novel set of mechanisms to explain the higher susceptibility to atherosclerosis in regions 
with disturbed shear flow. Endothelial JAM-A may serve as a suitable marker for molecular imaging of early stages of lesion formation and may be developed as a therapeutic target to treat atherosclerosis 


\section{Supplementary Figures}

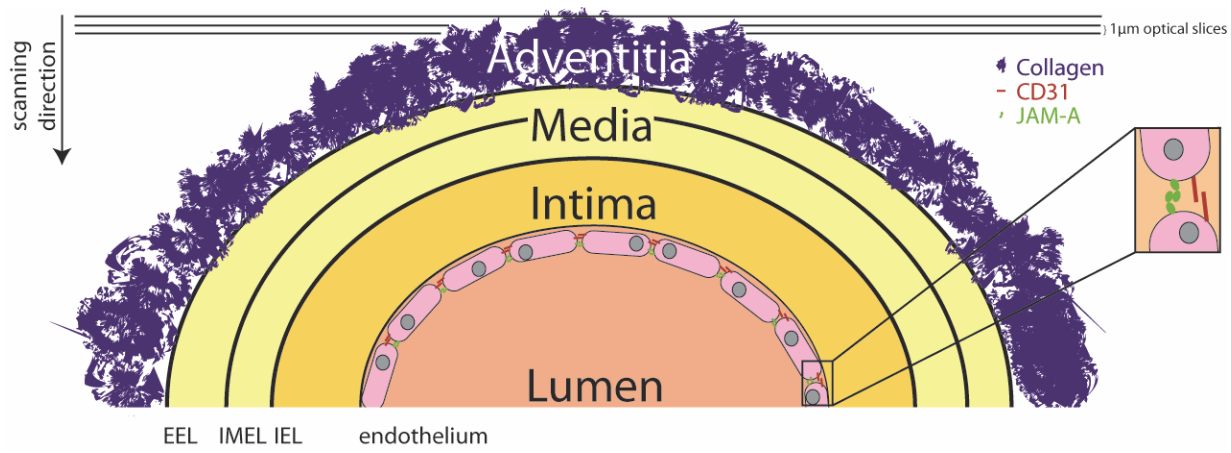

Supplementary Figure 1: Ex vivo TPLSM scanning mode of murine carotid arteries.

Scheme of TPLSM scanning mode for JAM-A (green) and CD31 (red) localization in murine carotid arteries under physiological pressure ex vivo. Z-stack record (1 $\mu \mathrm{m}$ optical slices) starts in the adventitia. Of note, CD31 is located distal to the lumen compared to JAM-A. Collagen is depicted blue due to Second Harmonic Generation. EEL: external elastic lamina; IMEL: intermediate elastic lamina; IEL: inner elastic lamina. 


\section{A}

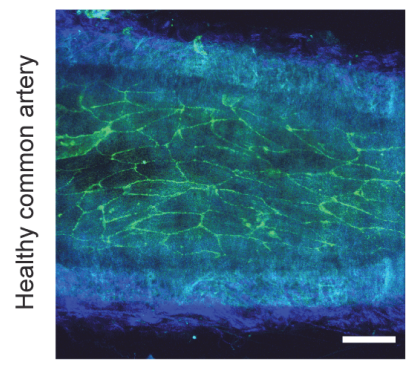

Collagen JAM-A

B

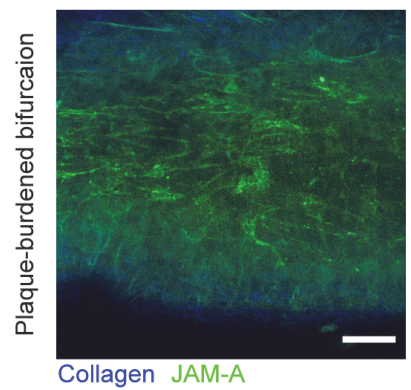

C

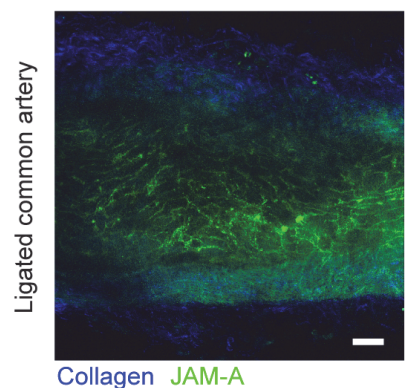

D

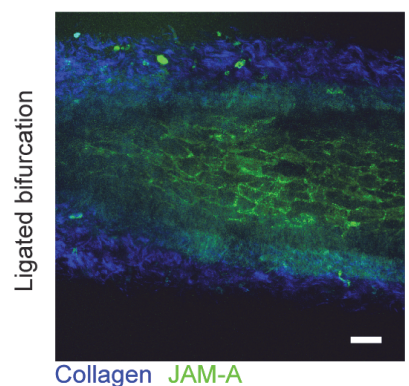

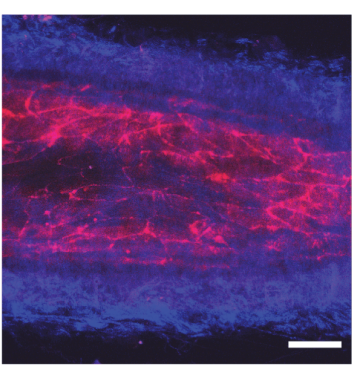

Collagen CD31

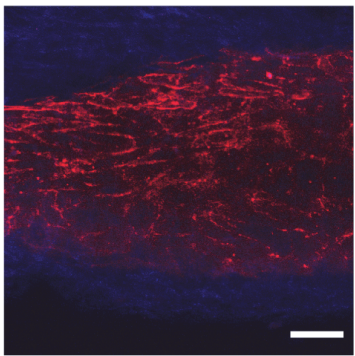

Collagen CD31

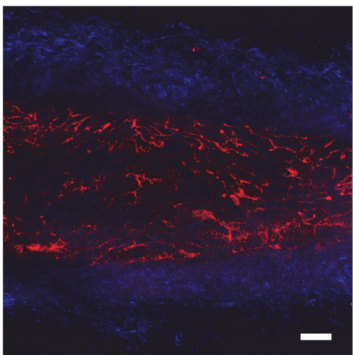

Collagen CD31

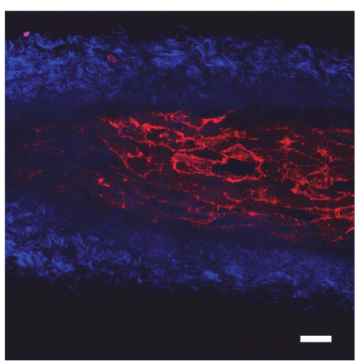

Collagen CD31
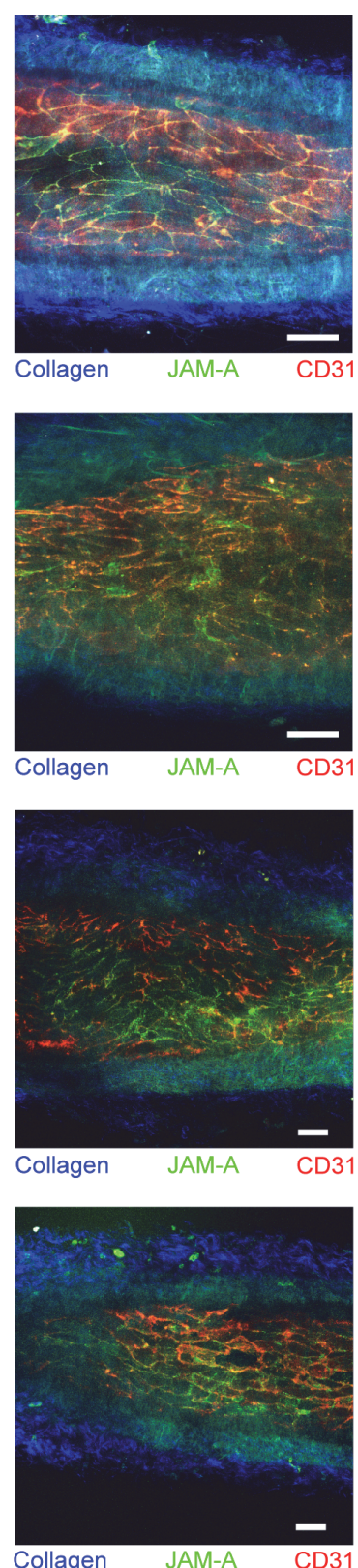

Supplementary Figure 2: TPLSM imaging of arterial JAM-A and CD31 expression

Individual visualization of JAM-A (green, left) and CD31 (red, middle) with collagen (blue, all panels) in control (A), atherosclerotic (B) and ligated carotid arteries at the common part (C) or the bifurcation (D). Right panels show merged images. TPLSM imaging was performed after 7 weeks of high-fat diet feeding or 2 weeks after partial ligation in $\mathrm{Apoe}^{-/-}$mice. Images are total projections of z-stacks. Scale bar $=40 \mu \mathrm{m}$. 
A

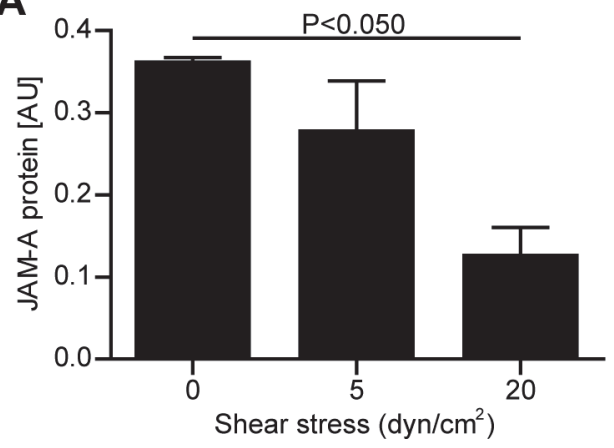

B

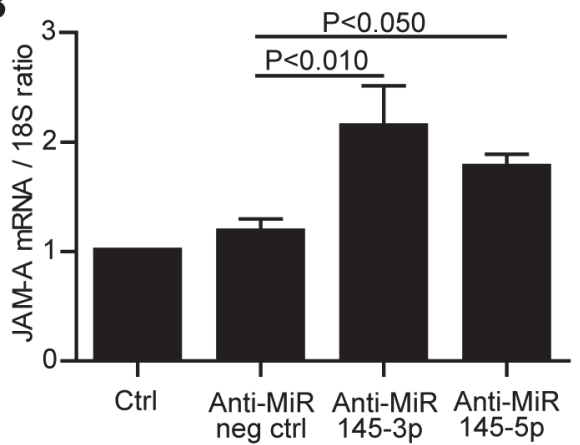

Supplementary Figure 3: Expression of JAM-A during altered flow conditions and miR 145 inhibition

(A) Expression of JAM-A protein relative to GAPDH housekeeper, as analyzed by western blotting in human aortic endothelial cells (HAoECs) cultured under static or flow conditions, as indicated $(n=3)$. (B) Expression of JAM-A mRNA relative to $18 \mathrm{~S}$ housekeeper in HAoECs transfected with miR-145-3p, anti-miR-145-5p inhibitors or control, as analyzed by qRT-PCR $(n=4)$. Data represent mean \pm SEM and $P$ values were calculated by one-way ANOVA with Tukey's multiple comparison post-test. 


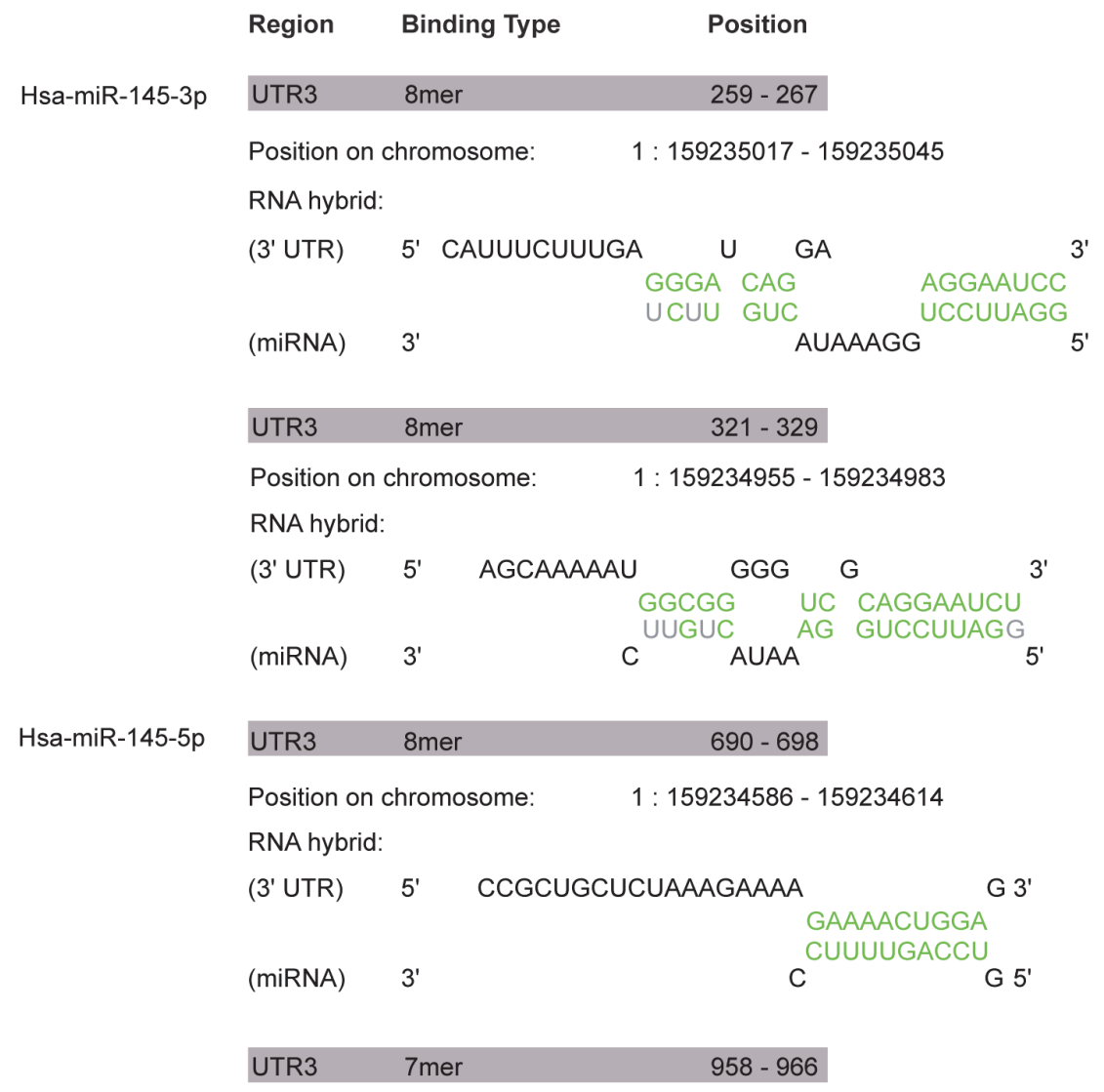

Position on chromosome: $\quad 1: 159234318-159234346$

RNA hybrid:

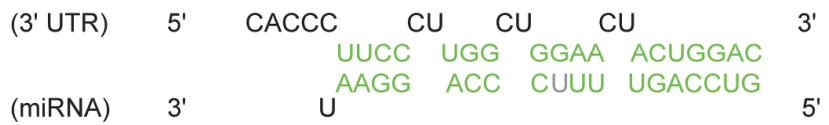

UTR3 $\quad 2598-2606$

Position on chromosome: $\quad 1: 159232678-159232706$

RNA hybrid:

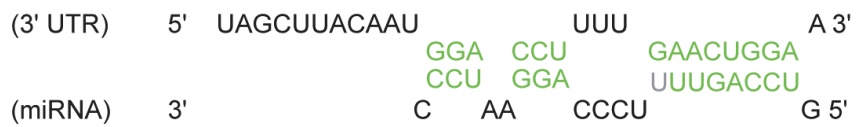

\section{Supplementary Figure 4: Seed sequences for miR-145 in JAM-A gene.}

The JAM-A gene contains 2 seed sequences for hsa-miR-145-3p and 3 seed sequences for has-miR-145-5p, thus being a putative target for both miR-145 strands. Complementary regions of JAM-A gene and miR-145 that are homologous are depicted in green, heterologous base-pairs in these regions are marked in grey. 


\section{Supplementary video file}

Supplementary video online

Link at:

http://circ.ahajournals.org/content/suppl/2013/09/24/CIRCULATIONAHA.113.00 4149.DC1/004149 Video 1.mov

Movie composed of z-stack imaging (1 $1 \mu \mathrm{m}$ depth) of a murine carotid artery mounted. Blue depicts SHG of collagen, green represents JAM-A and red illustrates CD31. 


\section{References}

1. Rehder D, Iden S, Nasdala I, Wegener J, Brickwedde MK, Vestweber D, Ebnet K. Junctional adhesion molecule-a participates in the formation of apico-basal polarity through different domains. Exp Cell Res. 2006;312:3389-3403

2. Liu Y, Nusrat A, Schnell FJ, Reaves TA, Walsh S, Pochet M, Parkos CA. Human junction adhesion molecule regulates tight junction resealing in epithelia. J Cell Sci. 2000;113 ( Pt 13):2363-2374

3. Stellos K, Langer H, Gnerlich S, Panagiota V, Paul A, Schonberger T, Ninci E, Menzel D, Mueller I, Bigalke B, Geisler T, Bultmann A, Lindemann S, Gawaz M. Junctional adhesion molecule a expressed on human cd34+ cells promotes adhesion on vascular wall and differentiation into endothelial progenitor cells. Arteriosclerosis, thrombosis, and vascular biology. 2010;30:1127-1136

4. Weber C, Fraemohs L, Dejana E. The role of junctional adhesion molecules in vascular inflammation. Nat Rev Immunol. 2007;7:467-477

5. Ostermann G, Fraemohs L, Baltus T, Schober A, Lietz M, Zernecke A, Liehn EA, Weber C. Involvement of jam-a in mononuclear cell recruitment on inflamed or atherosclerotic endothelium: Inhibition by soluble jam-a. Arteriosclerosis, thrombosis, and vascular biology. 2005;25:729-735

6. Bazzoni G. The jam family of junctional adhesion molecules. Curr Opin Cell Biol. 2003;15:525-530

7. Martin-Padura I, Lostaglio S, Schneemann M, Williams L, Romano M, Fruscella P, Panzeri C, Stoppacciaro A, Ruco L, Villa A, Simmons D, Dejana E. Junctional adhesion molecule, a novel member of the immunoglobulin superfamily that distributes at intercellular junctions and modulates monocyte transmigration. J Cell Biol. 1998;142:117127

8. Ostermann G, Weber KS, Zernecke A, Schroder A, Weber C. Jam-1 is a ligand of the beta(2) integrin Ifa-1 involved in transendothelial migration of leukocytes. Nat Immunol. 2002;3:151-158

9. Fraemohs L, Koenen RR, Ostermann G, Heinemann B, Weber C. The functional interaction of the beta 2 integrin lymphocyte function-associated antigen-1 with junctional adhesion molecule-a is mediated by the i domain. $J$ Immunol. 2004;173:6259-6264

10. Wojcikiewicz EP, Koenen RR, Fraemohs L, Minkiewicz J, Azad H, Weber C, Moy VT. Lfa1 binding destabilizes the jam-a homophilic interaction during leukocyte transmigration. Biophysical journal. 2009;96:285-293

11. Cera MR, Del Prete A, Vecchi A, Corada M, Martin-Padura I, Motoike T, Tonetti P, Bazzoni G, Vermi W, Gentili F, Bernasconi S, Sato TN, Mantovani A, Dejana E. Increased dc trafficking to lymph nodes and contact hypersensitivity in junctional adhesion moleculea-deficient mice. J Clin Invest. 2004;114:729-738

12. Corada M, Chimenti S, Cera MR, Vinci M, Salio M, Fiordaliso F, De Angelis N, Villa A, Bossi M, Staszewsky LI, Vecchi A, Parazzoli D, Motoike T, Latini R, Dejana E. Junctional adhesion molecule-a-deficient polymorphonuclear cells show reduced diapedesis in peritonitis and heart ischemia-reperfusion injury. Proc Natl Acad Sci U $S$ A. 2005;102:10634-10639

13. Cera MR, Fabbri M, Molendini C, Corada M, Orsenigo F, Rehberg M, Reichel CA, Krombach F, Pardi R, Dejana E. Jam-a promotes neutrophil chemotaxis by controlling integrin internalization and recycling. J Cell Sci. 2009;122:268-277

14. Woodfin A, Reichel CA, Khandoga A, Corada M, Voisin MB, Scheiermann C, Haskard DO, Dejana E, Krombach F, Nourshargh S. Jam-a mediates neutrophil transmigration in a stimulus-specific manner in vivo: Evidence for sequential roles for jam-a and pecam-1 in neutrophil transmigration. Blood. 2007;110:1848-1856

15. Ozaki H, Ishii K, Horiuchi H, Arai H, Kawamoto T, Okawa K, Iwamatsu A, Kita T. Cutting edge: Combined treatment of tnf-alpha and ifn-gamma causes redistribution of junctional adhesion molecule in human endothelial cells. J Immunol. 1999;163:553-557

16. Martinez-Estrada OM, Manzi L, Tonetti P, Dejana E, Bazzoni G. Opposite effects of tumor necrosis factor and soluble fibronectin on junctional adhesion molecule-a in endothelial cells. Am J Physiol Lung Cell Mol Physiol. 2005;288:L1081-1088

17. Mamdouh Z, Mikhailov A, Muller WA. Transcellular migration of leukocytes is mediated by the endothelial lateral border recycling compartment. J Exp Med. 2009;206:2795-2808

18. Khandoga A, Kessler JS, Meissner H, Hanschen M, Corada M, Motoike T, Enders G, Dejana E, Krombach F. Junctional adhesion molecule-a deficiency increases hepatic 
ischemia-reperfusion injury despite reduction of neutrophil transendothelial migration. Blood. 2005; 106:725-733

19. Lakshmi SP, Reddy AT, Naik MU, Naik UP, Reddy RC. Effects of jam-a deficiency or blocking antibodies on neutrophil migration and lung injury in a murine model of ali. Am J Physiol Lung Cell Mol Physiol. 2012;303:L758-766

20. Zernecke A, Liehn EA, Fraemohs L, von Hundelshausen P, Koenen RR, Corada M, Dejana E, Weber C. Importance of junctional adhesion molecule-a for neointimal lesion formation and infiltration in atherosclerosis-prone mice. Arteriosclerosis, thrombosis, and vascular biology. 2006;26:e10-13

21. Babinska A, Azari BM, Salifu MO, Liu R, Jiang XC, Sobocka MB, Boo D, Al Khoury G, Deitch JS, Marmur JD, Ehrlich YH, Kornecki E. The f11 receptor (f11r/jam-a) in atherothrombosis: Overexpression of f11r in atherosclerotic plaques. Thromb Haemost. 2007;97:272-281

22. Bernhagen J, Krohn R, Lue H, Gregory JL, Zernecke A, Koenen RR, Dewor M, Georgiev I, Schober A, Leng L, Kooistra T, Fingerle-Rowson G, Ghezzi P, Kleemann R, McColl SR, Bucala R, Hickey MJ, Weber C. Mif is a noncognate ligand of cxc chemokine receptors in inflammatory and atherogenic cell recruitment. Nat Med. 2007;13:587-596

23. Monvoisin A, Alva JA, Hofmann JJ, Zovein AC, Lane TF, Iruela-Arispe ML. Ve-cadherincreert2 transgenic mouse: A model for inducible recombination in the endothelium. Developmental dynamics : an official publication of the American Association of Anatomists. 2006;235:3413-3422

24. Priestley GV, Ulyanova T, Papayannopoulou T. Sustained alterations in biodistribution of stem/progenitor cells in tie2cre+ alpha4(f/f) mice are hematopoietic cell autonomous. Blood. 2007;109:109-111

25. Alva JA, Zovein AC, Monvoisin A, Murphy T, Salazar A, Harvey NL, Carmeliet P, IruelaArispe ML. Ve-cadherin-cre-recombinase transgenic mouse: $A$ tool for lineage analysis and gene deletion in endothelial cells. Developmental dynamics : an official publication of the American Association of Anatomists. 2006;235:759-767

26. Nam D, Ni CW, Rezvan A, Suo J, Budzyn K, Llanos A, Harrison D, Giddens D, Jo H. Partial carotid ligation is a model of acutely induced disturbed flow, leading to rapid endothelial dysfunction and atherosclerosis. Am J Physiol Heart Circ Physiol. 2009;297:H1535-1543

27. Virmani R, Kolodgie FD, Burke AP, Farb A, Schwartz SM. Lessons from sudden coronary death: A comprehensive morphological classification scheme for atherosclerotic lesions. Arteriosclerosis, thrombosis, and vascular biology. 2000;20:1262-1275

28. Rademakers T, Douma K, Hackeng TM, Post MJ, Sluimer JC, Daemen MJ, Biessen EA, Heeneman S, van Zandvoort MA. Plaque-associated vasa vasorum in aged apolipoprotein e-deficient mice exhibit proatherogenic functional features in vivo. Arteriosclerosis, thrombosis, and vascular biology. 2013;33:249-256

29. Megens RT, Reitsma S, Schiffers PH, Hilgers RH, De Mey JG, Slaaf DW, oude Egbrink MG, van Zandvoort MA. Two-photon microscopy of vital murine elastic and muscular arteries. Combined structural and functional imaging with subcellular resolution. $J$ Vasc Res. 2007;44:87-98

30. Nazari-Jahantigh M, Wei Y, Noels H, Akhtar S, Zhou Z, Koenen RR, Heyll K, Gremse F, Kiessling F, Grommes J, Weber C, Schober A. Microrna-155 promotes atherosclerosis by repressing bcl6 in macrophages. The Journal of clinical investigation. 2012;122:41904202

31. Simionescu M. Implications of early structural-functional changes in the endothelium for vascular disease. Arteriosclerosis, thrombosis, and vascular biology. 2007;27:266-274

32. Lee JS, Yu Q, Shin JT, Sebzda E, Bertozzi C, Chen M, Mericko P, Stadtfeld M, Zhou D, Cheng L, Graf T, MacRae CA, Lepore JJ, Lo CW, Kahn ML. KIf2 is an essential regulator of vascular hemodynamic forces in vivo. Dev Cell. 2006;11:845-857

33. Hergenreider E, Heydt S, Treguer K, Boettger T, Horrevoets AJ, Zeiher AM, Scheffer MP, Frangakis AS, Yin X, Mayr M, Braun T, Urbich C, Boon RA, Dimmeler S. Atheroprotective communication between endothelial cells and smooth muscle cells through mirnas. Nat Cell Biol. 2012;14:249-256

34. Shaw SK, Ma S, Kim MB, Rao RM, Hartman CU, Froio RM, Yang L, Jones T, Liu Y, Nusrat A, Parkos CA, Luscinskas FW. Coordinated redistribution of leukocyte Ifa-1 and endothelial cell icam-1 accompany neutrophil transmigration. J Exp Med. 2004;200:15711580 
35. Shaw SK, Perkins BN, Lim YC, Liu Y, Nusrat A, Schnell FJ, Parkos CA, Luscinskas FW. Reduced expression of junctional adhesion molecule and platelet/endothelial cell adhesion molecule-1 (cd31) at human vascular endothelial junctions by cytokines tumor necrosis factor-alpha plus interferon-gamma does not reduce leukocyte transmigration under flow. Am J Pathol. 2001;159:2281-2291

36. Bradfield PF, Scheiermann C, Nourshargh S, Ody C, Luscinskas FW, Rainger GE, Nash GB, Miljkovic-Licina M, Aurrand-Lions M, Imhof BA. Jam-C regulates unidirectional monocyte transendothelial migration in inflammation. Blood. 2007;110:2545-2555

37. Woodfin A, Voisin MB, Beyrau M, Colom B, Caille D, Diapouli FM, Nash GB, Chavakis T, Albelda SM, Rainger GE, Meda P, Imhof BA, Nourshargh S. The junctional adhesion molecule jam-c regulates polarized transendothelial migration of neutrophils in vivo. Nature immunology. 2011;12:761-769

38. Keiper T, Al-Fakhri N, Chavakis E, Athanasopoulos AN, Isermann B, Herzog S, Saffrich R, Hersemeyer K, Bohle RM, Haendeler J, Preissner KT, Santoso S, Chavakis T. The role of junctional adhesion molecule-c (jam-c) in oxidized Idl-mediated leukocyte recruitment. FASEB journal : official publication of the Federation of American Societies for Experimental Biology. 2005;19:2078-2080

39. Gotte M, Mohr C, Koo CY, Stock C, Vaske AK, Viola M, Ibrahim SA, Peddibhotla S, Teng YH, Low JY, Ebnet K, Kiesel L, Yip GW. Mir-145-dependent targeting of junctional adhesion molecule a and modulation of fascin expression are associated with reduced breast cancer cell motility and invasiveness. Oncogene. 2010;29:6569-6580

40. Harrison M, Smith E, Ross E, Krams R, Segers D, Buckley CD, Nash GB, Rainger GE. The role of platelet-endothelial cell adhesion molecule-1 in atheroma formation varies depending on the site-specific hemodynamic environment. Arteriosclerosis, thrombosis, and vascular biology. 2013;33:694-701

41. Li S, Huang NF, Hsu S. Mechanotransduction in endothelial cell migration. J Cell Biochem. 2005;96:1110-1126 
In chapter 2, we demonstrated a focal JAM-A re-localization away from the cell-cell borders to the apical site of endothelial cells after oxLDL or cytokine treatment, as well as in areas of disturbed flow. This re-localization increased recruitment rates of monocytes and thus might represent the reason for endothelial JAM-A exerting atherogenic effects.

Not much is known about the underlying molecular mechanism of endothelial JAM-A re-localization. Martinez-Estrada and colleagues found a TNF- $\alpha$ mediated re-localization of endothelial JAM-A and hypothesized that this re-localization was due to decreased interaction of JAM-A with cortical actin ${ }^{1}$. As their results were rather preliminary, additional data to determine the role of JAM-A/actin interaction on endothelial JAM-A localization is needed.

With the following chapter 3 , we aimed to further characterize the influence of endothelial JAM-A re-localization on atherogenic lymphocyte recruitment. Additionally, a potential pharmacologic intervention of endothelial JAM-A re-localization and leukocyte recruitment with atheroprotective drugs like lovastatin or pioglitazone shall be investigated. Moreover, we strived to further elucidate the molecular mechanism underlying endothelial JAM-A relocalization by studying actin localization as well as ZO-1/JAM-A interaction under atherogenic conditions as well as after actin (de-) stabilizing treatment. 
Contribution to the manuscript (chapter 3):

Martin Schmitt designed, conducted and evaluated transmigration assays, immuno-fluorescence imaging, permeability assay, bead assays, Western blotting and co-immunoprecipitation. Data were discussed and interpreted by Martin Schmitt and Dr. Rory Koenen. Furthermore, Martin Schmitt and Dr. Rory Koenen wrote the manuscript. 


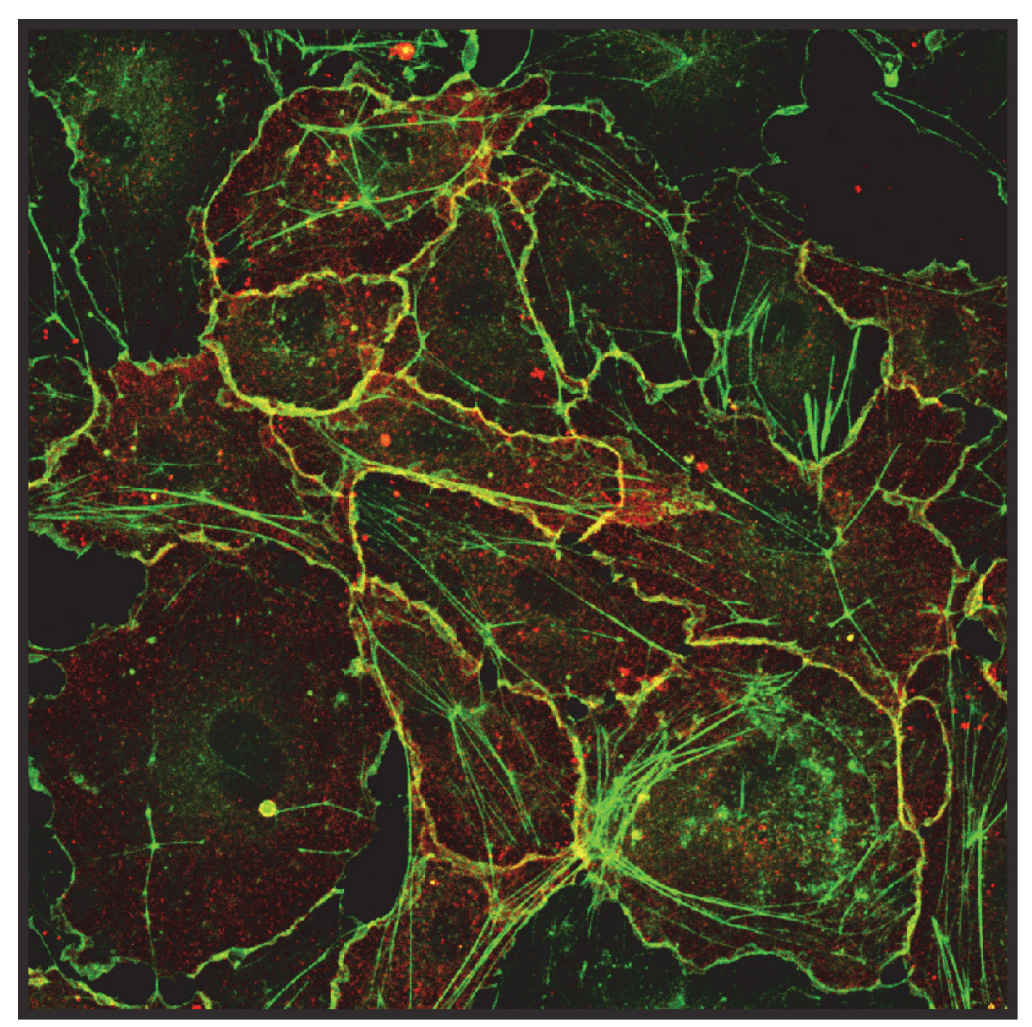

Chapter 3 


\section{Atherogenic mononuclear cell recruitment is facilitated by oxidized lipoprotein-induced endothelial junctional adhesion molecule-A redistribution}

Martin M. N. Schmitt, Line Fraemohs, Tilman M. Hackeng' Christian Weber and Rory R. Koenen

Atherosclerosis. 2014 Mar 25;234(2):254-264. 


\section{Abstract}

Background - Junctional adhesion molecule (JAM-) A is a transmembrane protein expressed in many cell types and maintains junctional integrity in endothelial cells. Upon inflammatory stimulation, JAM-A relocates to the apical surface and might thereby facilitate the recruitment of leukocytes.

Objective - Although inflammatory JAM-A redistribution is an established process, its exact role in the transmigration of mononuclear cells has not yet been characterized, particularly under atherogenic conditions.

Methods - By the use of RNA interference and genetic deletion, the role of JAM-A in the transmigration of T cells and monocytes through aortic endothelial cells was investigated. JAM-A-localization and subsequent mononuclear cell transmigration was explored during endothelial inflammation, induced by oxidized LDL or cytokines.

Results - RNA interference or genetic deletion of JAM-A in aortic endothelial cells resulted in a decreased transmigration of mononuclear cells. Treatment of the endothelial cells with oxLDL resulted in an increase of both permeability and apical JAM-A presentation, as shown by bead adhesion and confocal microscopy experiments. Redistribution of JAM-A resulted in an increased leukocyte transmigration, which could be inhibited with antibodies against JAM-A or by lovastatin-treatment, but not with the peroxisome proliferator activated receptor gamma-agonist pioglitazone.

Conclusions - This study demonstrates that redistribution of JAM-A in endothelial cells after stimulation with atherogenic oxidized lipoproteins results in increased transmigration of mononuclear cells. This inflammatory dispersal of JAM-A could be counteracted with statins, revealing a novel aspect of their mechanism of action. 


\section{Introduction}

Junctional Adhesion Molecule A (JAM-A, F11 receptor, JAM-1) is a member of the immunoglobulin superfamily (Ig-SF) transmembrane adhesion molecules and is expressed on a large variety of cell types, notably leukocytes, platelets and vascular endothelial cells ${ }^{2}$. In endothelial and epithelial cells, JAM-A maintains the integrity of the tight junctions through homophilic interactions, thereby controlling vascular and epithelial permeability ${ }^{3}$. Under inflammatory conditions, JAM-A has been shown to relocate to the apical surface of endothelial cells, where it becomes available for homophilic interactions with JAM-A on blood cells and for heterophilic interactions with lymphocyte functional antigen-1 (LFA-1 $)^{4}, 5$. Thus, it may facilitate leukocyte adhesion and transendothelial migration ${ }^{6-9}$. Alternatively, JAM-A can be shed from the cell surface by metalloproteases and soluble JAM-A may modulate the actions of leukocytes distal from the site of inflammation ${ }^{10}$. Accordingly, elevated plasma levels of soluble JAM-A have been observed in individuals with coronary artery disease and strongly correlated with circulating levels of tumor necrosis factor- $\alpha$ $(\mathrm{TNF}-\alpha)^{11}$. In addition, increased expression of JAM-A was observed in early vascular lesions of hyperlipidemic mice and in specimen of human atherosclerotic plaques ${ }^{7,12}$ and is involved in vascular remodeling after wire injury ${ }^{13}$. Interestingly, the structurally and functionally related JAM-C is both upregulated and redistributed in endothelial cells after treatment with oxidized low-density lipoprotein (oxLDL), further indicating a role for JAM family members in atherosclerosis ${ }^{14}$. In a recent study we have demonstrated that endothelial JAM-A promotes atherogenic leukocyte recruitment under conditions of disturbed arterial flow, by redistributing from the endothelial junctions to the luminal side of the vessel wall ${ }^{15}$.

Similar to other members of the Ig-SF, JAM-A consists of 2 globular extracellular domains, a transmembrane region and a relatively short $\mathrm{N}$-terminus, which contains a type $\| \mathrm{PDZ}$ domain ${ }^{5,}{ }^{16}$. The first $\mathrm{V}_{\mathrm{H}}$-type extracellular domain mediates homophilic interactions of neighboring JAM-A molecules in cis, as well as homophilic interactions of JAM-A on nearby cells in trans $^{17}$. The second $\mathrm{C}_{2}$-type domain, closest to the plasma membrane, binds to the integrin LFA- $1^{8}$. A previous study revealed that binding of LFA-1 to domain 2 of JAM-A caused a destabilization of the homophilic interaction through domain $1^{18}$. Thus through LFA-1 binding, the tight junction barrier of JAM-A might be loosened, facilitating the advancement of leukocytes through the cellular junctions. The PDZ domain links JAM-A to a variety of intracellular proteins, notably zonula occludens 1 (ZO-1), which serve as anchors to the cytoskeleton and are components of the organizational tight junction scaffold $^{19,20}$. Stimulation of endothelial or epithelial cells with TNF- $\alpha$ and/or interferon- $\gamma$ (IFN- $\gamma$ ) resulted in an increase of JAM-A in the triton-X100 cell 
fraction, which is indicative of its dissociation from the cytoskeleton ${ }^{1,21}$ and being liberated from cytoskeletal restraints, JAM-A might be able to guide leukocytes to junctional transmigration sites ${ }^{22}$. However, it is still unclear how this cellular redistribution and dispersal of JAM-A influences the subsequent recruitment of inflammatory cells. Moreover, it is of interest to investigate whether a pharmacologic attenuation of endothelial inflammation would also have effects on endothelial distribution of JAM-A and its consequences on monocyte recruitment. 


\section{Methods}

\section{Reagents and cell culture}

Dharmacon ${ }^{\circledR}$ small interfering RNA (siRNA) pools targeting JAM-A or laminin and FITC-conjugated phalloidin were purchased at Thermo Scientific (Pittsburg, PA). Antibodies against mouse and human JAM-A were purchased at Hycult Biotech (Uden, Netherlands) and mAb TS1/22 against CD11a was isolated from hybridoma-conditioned medium. Fab fragments were generated by papain digestion of JAM-A antibodies (243 and 246) and of mAb TS1/22 $2^{22}$. Cytokines and chemokines were from Peprotech (Rocky Hill, NJ). Low-density lipoprotein (LDL) was prepared from freshly prepared human plasma by ultracentrifugation in a $\mathrm{KBr}$ density gradient and oxidized with $\mathrm{CuCl}_{2}$ as described ${ }^{23}$. Fusion protein of human IgG FC and JAM-A (JAM-A.FC) was isolated from stably transfected $\mathrm{CHO}$ supernatants ${ }^{7}$. All other reagents were purchased at Sigma-Aldrich (St. Louis, MO) and were of the highest purity available.

Peripheral blood mononuclear cells (PBMC) were isolated from fresh buffy coats by density gradient centrifugation. $T$ cells were isolated using magnetic beads (Life Technologies, Carlsbad, CA) and were cultured up to 48 hours in RPMI medium containing $10 \%$ fetal bovine serum and $25 \mathrm{ng} / \mathrm{ml}$ interleukin 2 . Mouse aortic endothelial cells (MAoECs) were isolated from $J A M-A^{-/}$and $J A M-A^{+/+}$apolipoprotein $E$-deficient $\left(A p o e^{-/}\right)$mice according to Kreisel et al. ${ }^{24}$ and maintained in RPMI 1640 containing 20\% FCS, 0.1\% 2-mercaptoethanol and $50 \mu \mathrm{g} / \mathrm{mL}$ endothelial cell growth supplement (BD Biosciences, Franklin Lakes, NJ). Human aortic endothelial cells (HAoEC) were purchased from Promocell (Heidelberg, Germany) and cultured in proprietary MV2 media. Blood and tissue donations by humans and animals, respectively, were approved by the local ethics boards of the RWTH, LMU and Maastricht universities and the local governments.

\section{Stimulation and transfection of endothelial cells}

HAoEC were untreated, treated with TNF- $\alpha(10 \mathrm{ng} / \mathrm{ml})$, without or with CCL2 $(100 \mathrm{ng} / \mathrm{mL})$ or CXCL12 $(500 \mathrm{ng} / \mathrm{mL})$, or transfected with siRNA using a nucleofector $^{T M}$ with a reagent kit for endothelial cells (Lonza, Basel, Switzerland). The cells were subsequently cultured in $5 \mu \mathrm{M}$ pore size Transwell ${ }^{\circledR}$ filters (Corning, Tewksbury, MA) or collagenized glass slides until confluency. MAoECs (JAM-A $A^{+/+} A p o e^{-/}$or $J A M-A^{-/} A p o e^{-/-}$) were grown on collagenized glass slides and were activated for at least $4 \mathrm{~h}$ with TNF- $\alpha$ $(25 \mathrm{ng} / \mathrm{ml})$. For some experiments, $J A M-A^{-/} A p o e^{-/}$MAoECs were transfected with siRNA or a pcDNA3-based expression vector containing a cDNA for human JAM-A using a nucleofector. Cells were analyzed by flow cytometry with 
proper gating and appropriate isotype controls on a FACSCalibur (BD Biosciences, Franklin Lakes, NJ).

\section{Transendothelial migration experiments}

Real time measurement - Human monocytes $\left(0.7 \times 10^{6} / \mathrm{ml}\right)$ or $\mathrm{T}$ cells $\left(0.5 \times 10^{6} / \mathrm{ml}\right)$ were untreated or treated with oxLDL $(10 \mu \mathrm{g} / \mathrm{ml}, 16 \mathrm{~h})$ and were applied on HAoEC or MAoECs untreated or treated with JAM-A.FC, JAM-A D1.Fc, JAM-A D2.Fc (all $15 \mu \mathrm{g} / \mathrm{mL}$ ) without or with LDL, oxLDL (both $10 \mu \mathrm{g} / \mathrm{ml}, 16 \mathrm{~h})$, TNF- $\alpha$ and IFN-y $(10 \mathrm{ng} / \mathrm{ml}$ and $20 \mathrm{ng} / \mathrm{ml}, 4 \mathrm{~h}$, respectively) or oxLDL plus JAM-A.Fc $(10 \mu \mathrm{g} / \mathrm{ml}, 15 \mathrm{~min})$ under shear stress $\left(1.5 \mathrm{dyn} / \mathrm{cm}^{2}\right)$ using a syringe pump (WPI, Berlin, Germany) in a laminar flow chamber for $5 \mathrm{~min}$ and flushed with assay medium for $2 \mathrm{~min}$. After flushing, time-lapse images were recorded $\left(\right.$ Cell $^{\mathrm{M}}$ system, Olympus, Tokyo, Japan). Leukocytes showing transmigration were counted and related to adherent cells.

Transwell $^{\circledR}$ assay - PBMC $\left(1 \times 10^{5}\right)$ were added in the filter inserts containing confluent HAoEC and were allowed to transmigrate towards CCL2 $(100 \mathrm{ng} / \mathrm{mL})$ or CXCL12 (500 ng/mL) to attract monocytes or T cells, respectively, for 90 min at $37^{\circ} \mathrm{C}$. The transmigrated leukocyte subtypes were gated and counted using flow cytometry.

\section{Fluorescent bead assay}

HAoEC were treated without or with LDL, oxLDL (both $10 \mu \mathrm{g} / \mathrm{ml}, 16 \mathrm{~h}$ ) or TNF- $\alpha$ and IFN-y (10 ng/ml and $20 \mathrm{ng} / \mathrm{ml}$ respectively, $4 \mathrm{~h}$ ) in the absence or presence of cytochalasin D, jasplakinolide (both $50 \mathrm{nM}, 24 \mathrm{~h}$ ), lovastatin or pioglitazone (both $1 \mu \mathrm{M}, 24 \mathrm{~h}$ preincubation) and were subsequently incubated with fluorescent microbeads $(\sim 1 \mu \mathrm{m}$ diameter) coupled to JAM-A antibodies (clone 246) or IgG control for $30 \mathrm{~min}$. Nuclei were stained with HOECHST 33342. After washing, bright field and fluorescent images were recorded.

\section{Cell permeability assay}

Confluent HAoEC grown in a Transwell $^{\circledR}$ filter system were treated without or with LDL, oxLDL (both $10 \mu \mathrm{g} / \mathrm{ml}, 16 \mathrm{~h}$ ), TNF- $\alpha$ and IFN- $\gamma(10 \mathrm{ng} / \mathrm{ml}$ and $20 \mathrm{ng} / \mathrm{ml}, 4 \mathrm{~h}$, respectively), thrombin $(1 \mathrm{U} / \mathrm{ml}, 4 \mathrm{~h})$ or histamine $(50 \mu \mathrm{M}, 4 \mathrm{~h})$. After washing, a solution of $70 \mathrm{kDa}$ dextran coupled to FITC $(0.5 \mathrm{mg} / \mathrm{ml}$ in HBSS) was subjected to the filter insert for 90 minutes at $37^{\circ} \mathrm{C}$. Subsequently, fluorescence intensity in the bottom well was measured and normalized to untreated control.

\section{Co-Immunoprecipitation and Western blotting}

Co-Immunoprecipitation and Western blotting was performed as described ${ }^{20}$. Briefly, HAoEC were treated without or with oxLDL $(10 \mu \mathrm{g} / \mathrm{ml}, 16 \mathrm{~h})$ or TNF-a 
and IFN-y (10 ng/ml and $20 \mathrm{ng} / \mathrm{ml}$ respectively, $4 \mathrm{~h}$ ) and subjected to lysis buffer on ice for 30 minutes $(50 \mathrm{mM}$ Tris $\mathrm{HCl} \mathrm{pH} 8.0,150 \mathrm{mM} \mathrm{NaCl}, 2 \%$ Triton$\mathrm{X} 100$, protease inhibitor cocktail). Lysates were incubated overnight with total 2 $\mu \mathrm{g}$ anti-JAM-A antibody (clone mAb F11) following to antibody capture with magnetic beads coupled to Protein-G (Miltenyi, Bergisch Gladbach, Germany). Immunocomplexes were purified using MACS $\mu$-columns (Miltenyi, Bergisch Gladbach, Germany) and subsequently precipitated with SDS-loading buffer. After Western blotting ZO-1 protein was detected using a polyclonal antibody against ZO-1 (Hycult Biotech, Uden, Netherlands).

\section{Confocal microscopy}

HAoEC were treated without or with oxLDL $(10 \mu \mathrm{g} / \mathrm{ml}, 16 \mathrm{~h})$ or TNF- $\alpha$ and IFN- $\gamma$ (10 ng/ml and $20 \mathrm{ng} / \mathrm{ml}, 4 \mathrm{~h}$, respectively) in the absence or presence of cytochalasin D, jasplakinolide (both $50 \mathrm{nM}, 24 \mathrm{~h}$ ), lovastatin or pioglitazone (both $1 \mu \mathrm{M}, 24 \mathrm{~h})$ and stained with an anti-JAM-A antibody $(10 \mu \mathrm{g} / \mathrm{ml}, 2 \mathrm{~h}$, clone mAb F11) followed by secondary antibody staining (anti-mouse IgG Alexa 594, $1 \mu \mathrm{g} / \mathrm{ml}, 1 \mathrm{~h}$ ). Subsequently, cells were permeabilized and incubated with FITC-coupled phalloidin $(1 \mu \mathrm{g} / \mathrm{ml}, 1 \mathrm{~h})$. Finally, cells were visualized using a Leica SP5MP microscope set in confocal mode.

\section{Statistical analysis}

Statistical analysis was performed using Prism 6.0 (GraphPad Software). Means of 2 groups were compared by 2-tailed, unpaired Student's t-test or non-parametric Mann-Whitney $U$ test. Means of more than 2 groups were tested by 1-way ANOVA with Tukey's or Bonferroni's post-test or nonparametric Kruskal-Wallis test with Dunn's post test, where applicable. Differences with $P<0.05$ were considered as statistically significant. 


\section{Results}

\section{Endothelial JAM-A mediates transendothelial migration of mononuclear cells}

In order to further characterize the role of endothelial JAM-A in the transendothelial migration of $T$ cells and monocytes, its expression in HAoEC was attenuated by transfection with specific siRNA and appropriate controls. This resulted in an approximately 50\% decrease of JAM-A surface expression, compared to the control siRNA (Fig. 1A). Interestingly, a decreased JAM-A expression also diminished $\mathrm{T}$ cell and monocyte transmigration towards CXCL12 or CCL2, respectively (Figure 1B,C). A similar, albeit slight, reduction in transmigration was observed when human $\mathrm{T}$ cells were allowed to

A

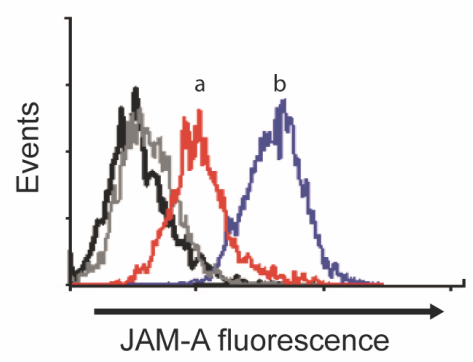

C

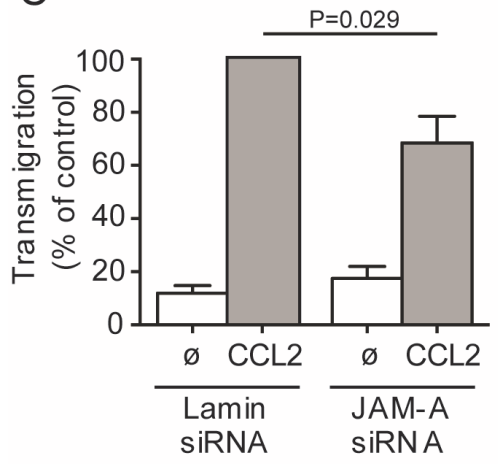

B
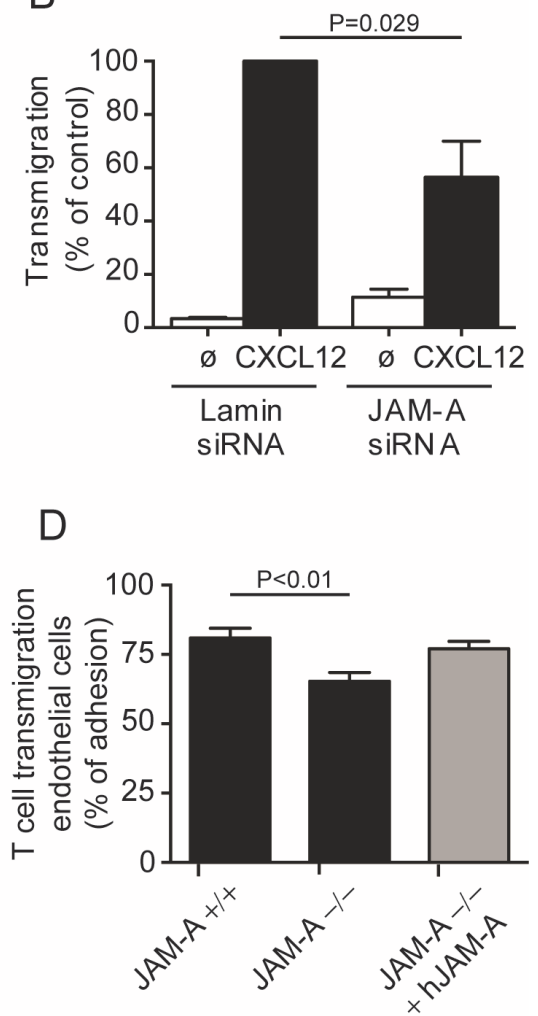

Figure 1: Endothelial JAM-A mediates transendothelial migration of mononuclear cells.

FACS histograms of JAM-A expression before (b) or after (a) transfection with siRNA and isotype (grey trace) and unstained (black trace) HAoEC $(\mathbf{A})$. Transmigration of T cells towards CXCL12 (B) or of monocytes towards CCL2 (C) through HAoEC transfected with lamin or JAM-A siRNA $(n=4)$.

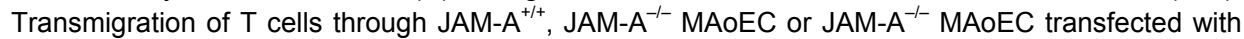
human JAM-A ( $n=7-14)(D)$. 
transmigrate over TNF- $\alpha$-activated JAM-A-deficient mouse aortic endothelial cells, compared to wild type endothelial cells (Fig. 1D). Reconstitution of these $\mathrm{JAM}^{-\mathrm{A}^{--}}$endothelial cells with human JAM-A restored the transmigration of T cells (Fig. 1D).

Oxidized LDL increases endothelial permeability and induces cytoskeletal rearrangement as well as JAM-A redistribution.

The involvement of JAM-A in the transendothelial migration of monocytes and T cells through aortic endothelial cells raised the question whether JAM-A could play a role in the recruitment of mononuclear cells under atherogenic conditions. As a model, endothelial cells were treated with oxLDL. In the presence of oxLDL, the permeability of HAoEC monolayers was increased almost to the extent of that observed with potent agents e.g. histamine, thrombin and TNF- $\alpha / / F N-\gamma$, while native LDL did not affect permeability (Fig. 2A). To investigate if treatment with oxLDL causes a redistribution of JAM-A on the endothelial surface, a fluorescent bead assay was used. Due to steric effects, junctionally located JAM-A is unavailable for binding to the antibody-coupled beads, making this assay specific for apically located JAM-A. Treatment with TNF- $\alpha / \mathrm{IFN}-\gamma$, an established trigger for JAM-A redistribution, increased the amount of surface-bound beads (Fig. 2B). Unlike native LDL, oxLDL also caused a notable increase in cellular bead count, indicating JAM-A redistribution under atherogenic conditions. Confocal microscopy of JAM-A and actin filaments in HAoEC under quiescent conditions revealed a predominantly junctional pattern of JAM-A staining and directed actin fibers without colocalization (Fig. 2C), while stimulation with TNF- $\alpha / \mathrm{IFN}-\gamma$ resulted in an increase of apical JAM-A localization and elongated cellular actin yet no notable colocalization (Fig. 2D). After stimulation with oxLDL, a considerable amount of JAM-A was located outside of the junctions. Interestingly, focal JAM-A staining was also observed that robustly colocalized with accumulations of actin fibers, indicating that JAM-A might form clusters that facilitate leukocyte recruitment (Fig. 2E). Immunoprecipitation of JAM-A revealed that treatment of HAoEC with oxLDL increased its association with the junctionally located cytoskeletal anchor protein ZO-1 (Fig. 2F), indicating an increased connection of JAM-A to the cytoskeleton. Destabilization of filamentous actin by cytochalasin $D$ resulted in an increased amount of beads bound to the surface of the HAoEC and a pronounced apical localization of JAM-A (Suppl. Figure 1A,B). Inhibition of actin depolymerization by jasplakinolide on the other hand also resulted in an increased bead binding, possibly due to the formation of focal JAM-A and actin accumulations, similar as observed after oxLDL treatment (Suppl. Figure 1A,C). 
A

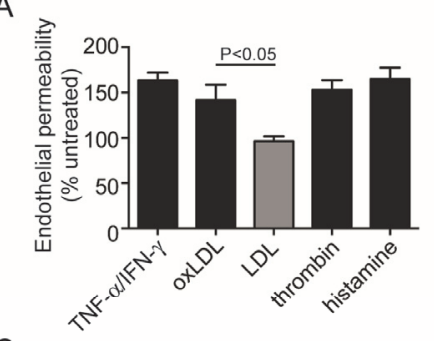

C
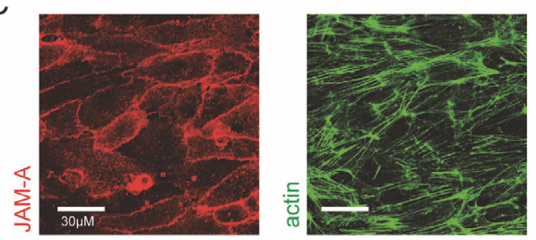

D
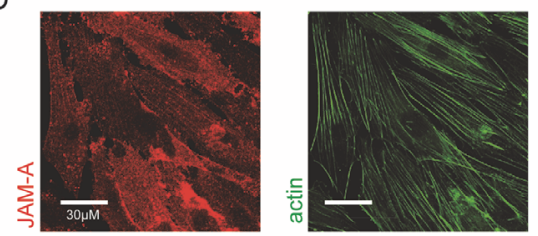

E
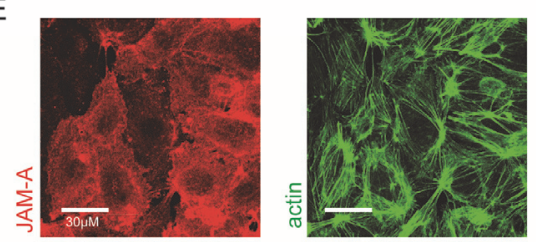

F

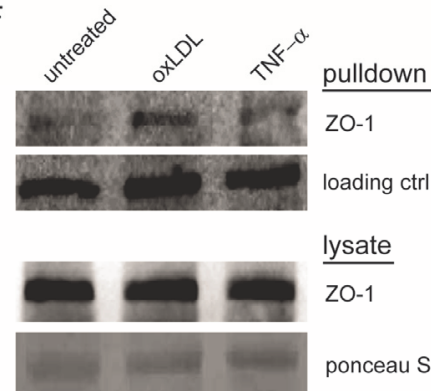

B
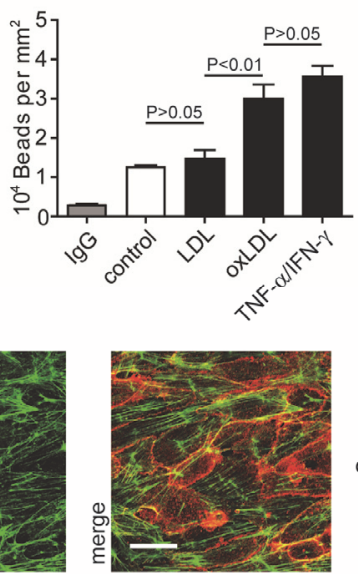

control

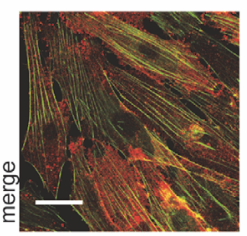

TNF- $\alpha / \mathrm{IFN}-\gamma$

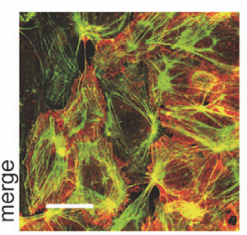

oxLDL

Figure 2: OxLDL increases endothelial permeability and causes endothelial JAM-A redistribution.

Endothelial permeability expressed as percentage of untreated controls of HAoEC after treatment with TNF-a/IFN-y, oxLDL, LDL, thrombin or histamine $(n=8)(A)$. Adhesion of control IgG or anti-JAM-A antibody-coupled fluorescent beads to HAoEC after treatment with LDL, oxLDL or TNF- $\alpha /$ IFN- $\gamma(n=5-12)(B)$. Confocal micrographs of HAoEC after staining for JAM-A (red) or actin (green) under control conditions (C) or after treatment with TNF- $\alpha / I F N-\gamma$ (D) or oxLDL (E). Scale bars: $30 \mu \mathrm{m}$. Co-immunoprecipitation of JAM-A with specific ZO-1-antibodies from HAoEC under quiescent conditions or after activation with TNF- $\alpha / I F N-\gamma$ or oxLDL (F). 
Oxidized LDL increases transendothelial migration of mononuclear cells.

Under conditions of flow stasis, treatment of HAoEC with oxLDL, but not with native LDL, significantly increased the transmigration of both monocytes and T cells, albeit to a lower extent as after TNF- $\alpha$ /IFN- $\gamma$ stimulation (Fig. 3A-F). The oxLDL-induced increase in transendothelial migration was effectively reversed by treatment of endothelial cells with JAM-A.Fc, whereas this did not influence diapedesis after LDL-treatment (Fig. 3A,D). Incubation of the mononuclear cells with oxLDL did not increase transmigration, confirming the specific role of endothelial JAM-A in this process (Fig. 3A,D). To address the roles of the extracellular domains of JAM-A and to rule out any unspecific Fc-receptor-mediated effects, HAoEC were treated with blocking Fab fragments against domain 1 or domain 2 of JAM-A, or the mononuclear cells with a blocking Fab against CD11a prior to transmigration over oxLDL or TNF- $\alpha / I F N-\gamma$ stimulated HAoEC. Both extracellular domains appeared to be involved in the transmigration of monocytes and $\mathrm{T}$ cells after stimulation with either oxLDL or TNF- $\alpha / \mathrm{IFN}-\gamma$, with an over $50 \%$ reduction of transmigration events in the presence of blocking Fabs (Fig. 3B,C and 3E,F). 
A

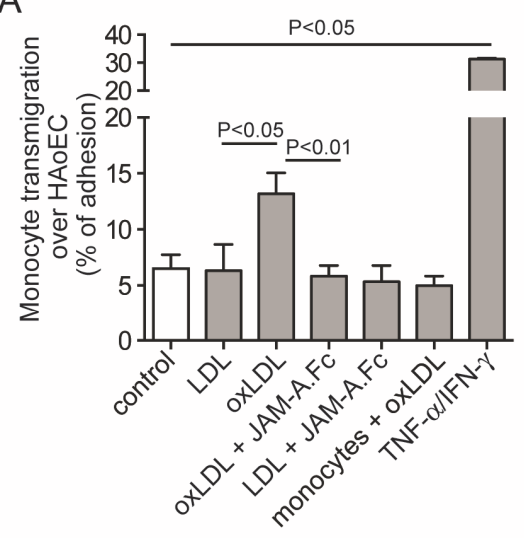

C
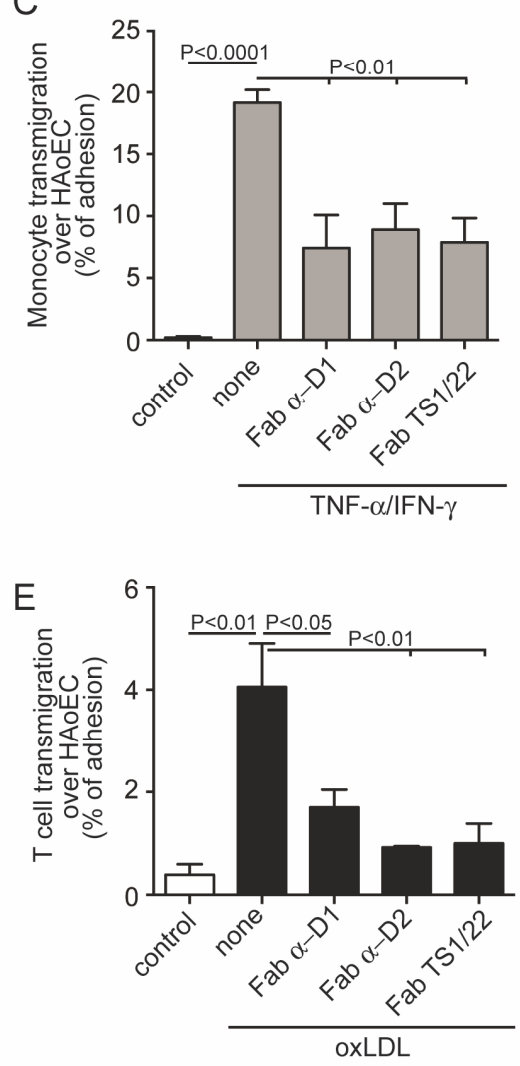

B

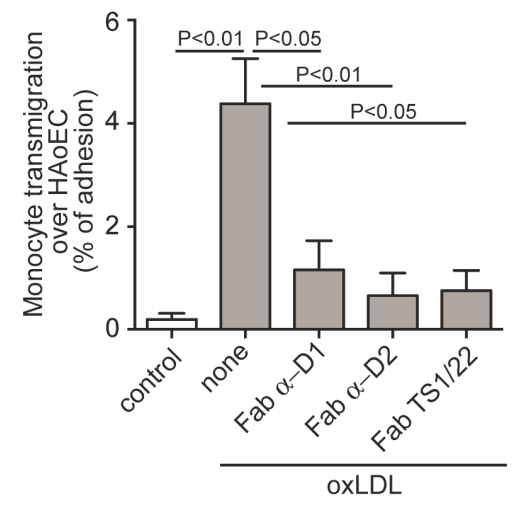

$\mathrm{D}$
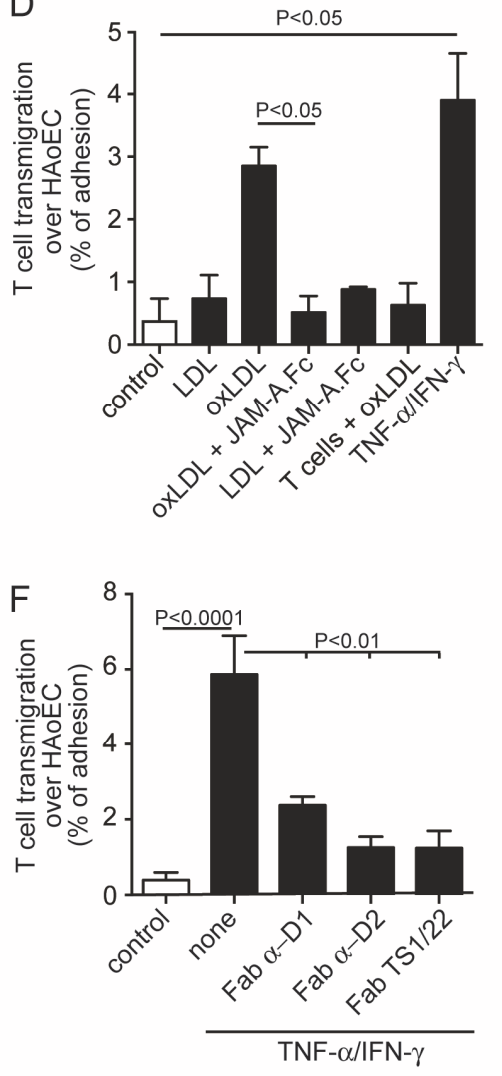

Figure 3: OxLDL-treatment induces transendothelial migration of mononuclear cells.

Transendothelial migration of monocytes (A-C) or T cells (D-F) through HAoEC under the indicated conditions ( $n=3-6)$. 
Anti-inflammatory treatment attenuates JAM-A redistribution and mononuclear cell transmigration.

Since atherogenic conditions caused a re-localization of endothelial JAM-A with an accompanying increase in mononuclear cell transmigration, we were interested whether these effects could be counteracted by the action of 2 classes of established therapeutics for the treatment of cardiovascular disease. From the class of the 3-hydroxy-3-methylglutaryl-coenzyme A reductase inhibitors (statins), the active compound lovastatin was chosen. Pre-treatment of the HAoEC with lovastatin for 24 hours lowered baseline adhesion of anti-JAM-A-coupled beads and prevented bead adhesion after stimulation with oxLDL or TNF- $\alpha /$ IFN-y (Fig. 4A). This observation was supported by confocal microscopy, where lovastatin prevented the relocalization of JAM-A after inflammatory stimulation, leaving the majority of JAM-A localized in the cell-cell contacts (Fig. 4B-D). In addition, lovastatin treatment of HAoEC almost completely abrogated the oxLDL-induced transmigration of both monocytes and $\mathrm{T}$ cells and strongly $(>50 \%)$ reduced the transmigration of monocytes after TNF- $\alpha / \mathrm{IFN}-\gamma-$ stimulation, while leaving that of $\mathrm{T}$ cells unaffected (Fig. 4E, F). This indicates that the prevention of JAM-A-mediated leukocyte recruitment might be one of the anti-inflammatory actions of statins. In contrast to statins, the peroxisome proliferator activated receptor gamma (PPAR $\gamma$ ) agonist pioglitazone was unable to prevent the oxLDL- and cytokine-induced redistribution of JAM-A (Fig. 5A-D) and prevented the transmigration of monocytes, but not of $T$ cells, through HAoEC only after TNF- $\alpha$ /IFN- $\gamma$-stimulation (Fig. 5E,F). Thus, PPAR $\gamma$-activation does not counteract oxLDL-induced endothelial activation, at least at the level of JAM-A redistribution and leukocyte recruitment. 
A

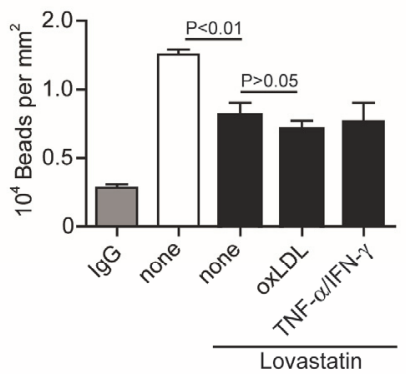

B
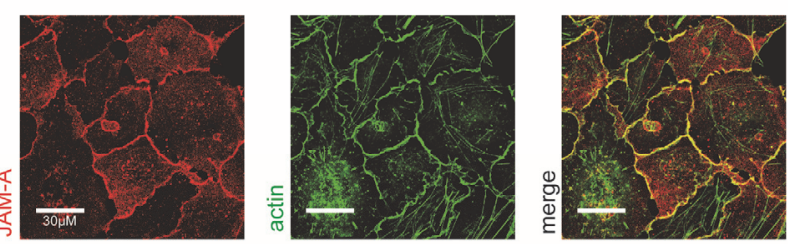

Lovastatin

C
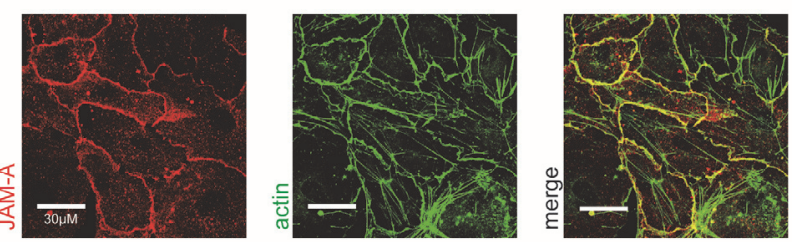

Lovastatin +

oxLDL

D
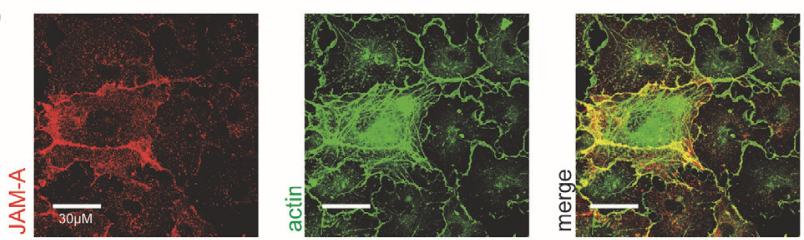

Lovastatin +

TNF- $\alpha /$ IFN- $\gamma$
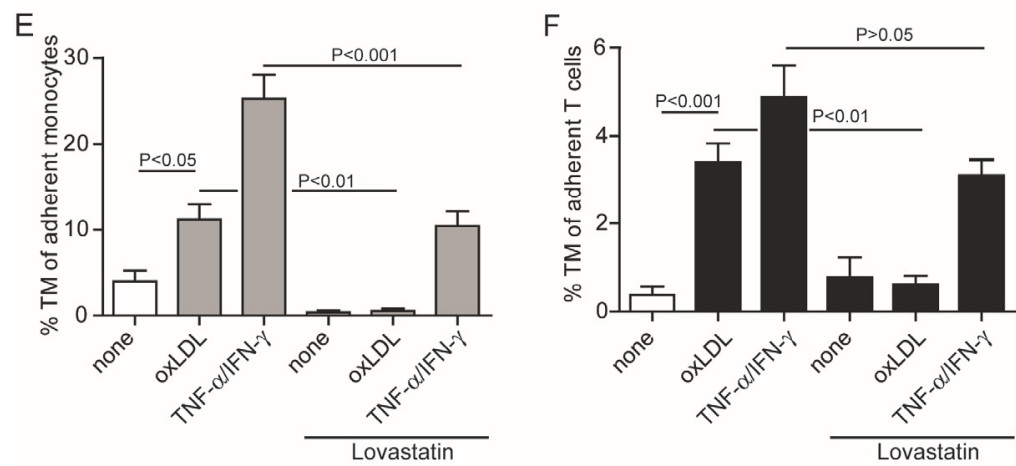

Figure 4: Lovastatin counteracts inflammatory JAM-A redistribution and diapedesis.

Adhesion of control IgG or anti-JAM-A antibody-coupled fluorescent beads to HAoEC after treatment without or with oxLDL or TNF- $\alpha /$ IFN- $y$ in the absence or presence of lovastatin $(n=3-4)$ (A). Confocal micrographs of HAoEC after staining for JAM-A (red) or actin (green) after treatment with lovastatin without (B) or with oxLDL (C) or TNF-a/IFN-Y (D). Scale bars: $30 \mu \mathrm{m}$. Transendothelial migration of monocytes $(E)$ or $T$ cells $(\mathbf{F})$ through HAoEC after treatment without or with oxLDL or TNF- $\alpha /$ IFN- $y$ in the absence or presence of lovastatin $(n=3-10)$. 
A
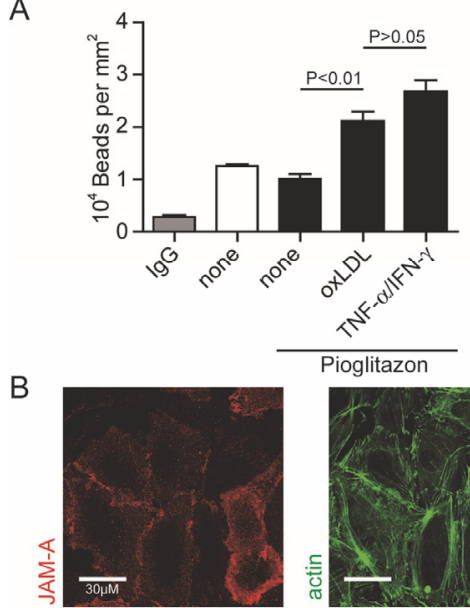

Pioglitazon

C
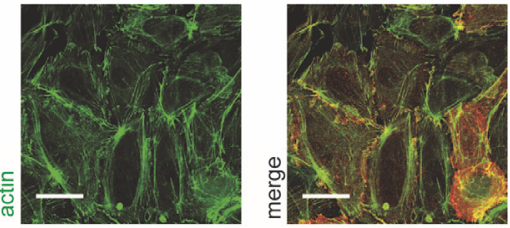

Pioglitazon
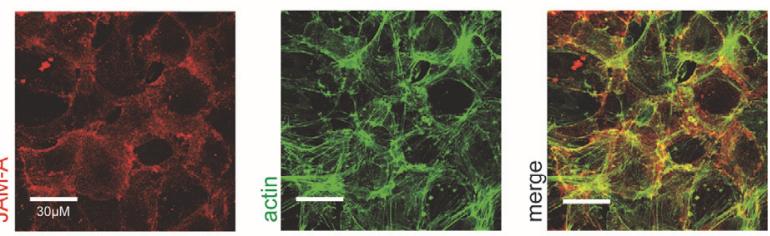

Pioglitazon +

oxLDL

D
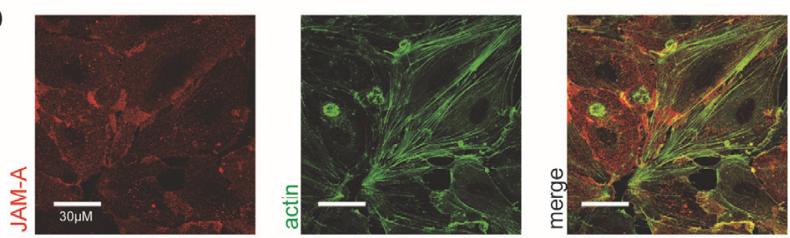

Pioglitazon +

TNF- $\alpha /$ IFN- $\gamma$
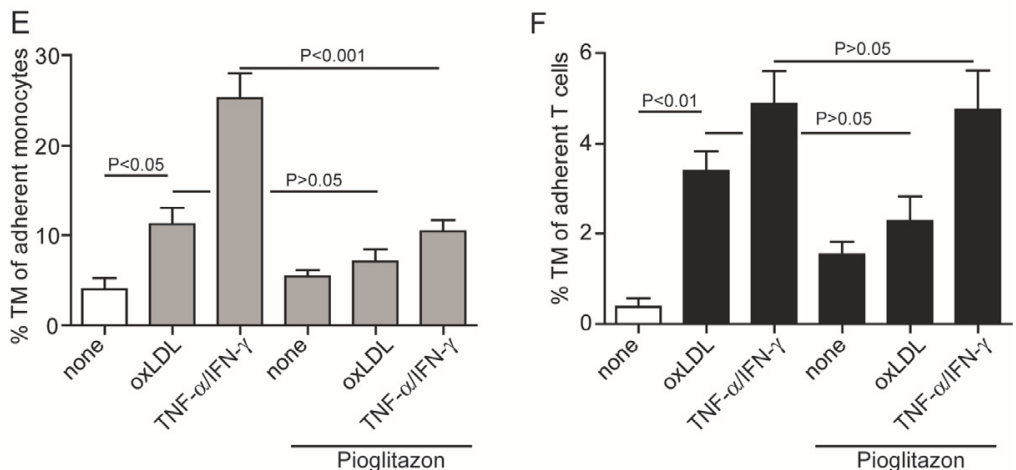

Figure 5: Effects of pioglitazone on JAM-A localization and diapedesis.

Adhesion of control IgG or anti-JAM-A antibody-coupled fluorescent beads to HAoEC after treatment without or with oxLDL or TNF- $\alpha / / F N-y$ in the absence or presence of pioglitazone $(n=3-4)$ (A). Confocal micrographs of HAoEC after staining for JAM-A (red) or actin (green) after treatment with pioglitazone without (B) or with oxLDL (C) or TNF- $\alpha / / F N-y$ (D). Scale bars: $30 \mu \mathrm{m}$. Transendothelial migration of monocytes $(E)$ or $T$ cells $(\mathbf{F})$ through HAoEC after treatment without or with oxLDL or TNF- $\alpha / \mathrm{IFN}-\gamma$ in the absence or presence of pioglitazone $(n=3-10)$. 


\section{Discussion}

In this study, we have demonstrated that rearrangement of endothelial JAM-A facilitates the transmigration of mononuclear cells under atherogenic conditions. It is well established that JAM-A redistributes from the endothelial junctions to the surface of the cells. Already in the 1990s, Ozaki and colleagues demonstrated that a potent inflammatory stimulus, such as a combination of TNF- $\alpha$ and IFN- $\gamma$ caused junctional JAM-A to become dispersed in endothelial cells ${ }^{4}$. Through the determination of triton-X100 soluble and insoluble fractions in later studies, this dispersal was attributed to a disconnection of JAM-A from the cytoskeleton ${ }^{1,21}$. However, our microscopy observations of arterial endothelial cells suggest that JAM-A and filamentous actin are generally not colocalized, neither under quiescent conditions nor after stimulation with TNF- $\alpha$ and IFN- $\gamma$, speaking against a connection of JAM-A with the cytoskeleton under these conditions. This might appear to conflict with the previous observations from Bruewer et al. and Martinez-Estrada and colleagues. Yet in both studies, a large pool of triton-X100-soluble JAM-A was observed also under quiescent conditions, which decreased further after stimulation with cytokines ${ }^{1,21}$. Thus, JAM-A might have an alternative cytoplasmic anchorage that modulates its cellular localization.

Interestingly, treatment with oxLDL resulted in a notable colocalization of JAM-A with actin fibers in focal cytoplasmic arrangements and showed an increased association with the cytoskeletal anchor ZO-1, compared with quiescent and cytokine-treated cells. Thus, JAM-A might actively associate with the cytoskeleton under atherogenic conditions, yet might also move out of the junctions, causing the junctional JAM-A staining to become more diffuse. Interestingly, both after treatment of the endothelial cells with oxLDL or cytokines, the permeability rose, the junctional localization of JAM-A decreased and JAM-A became available to fluorescent beads coupled with a specific antibody. Thus, inflammatory activation of endothelial cells does lead to an increased availability of JAM-A. This availability was reflected by an increased transendothelial migration of both monocytes and $T$ cells. Accordingly, a downregulation of JAM-A expression led to a decreased transmigration of mononuclear cells and reconstitution of $\mathrm{JAM}^{-\mathrm{A}^{--}}$murine endothelial cells with JAM-A restored $T$ cell diapedesis, highlighting the important role of endothelial JAM-A in leukocyte transmigration. A recent study revealed that stimulation of human umbilical endothelial cells (HUVEC) with TNF- $\alpha$ and IFN- $\gamma$ resulted in an increased concentration of JAM-A near the intercellular junctions ${ }^{22}$. Hence, JAM-A might guide mononuclear cells to transmigration sites on activated endothelium, similar as what was shown for ICAM- $1^{25}$.

In a previous study by Woodfin and colleagues, the important role of endothelial JAM-A in transmigration was demonstrated and the function of 
JAM-A appeared to depend on the inflammatory stimulus ${ }^{6}$. This finding is supported by our observations that oxLDL and TNF- $\alpha$ and IFN- $\gamma$ differentially influence endothelial JAM-A localization. The authors could further demonstrate that neutrophils showed incomplete transmigration in the absence of JAM- $\mathrm{A}^{6}$, a finding that was corroborated by our recent study, showing that this phenomenon specifically occurred in JAM-A-deficient leukocytes, but not in endothelial cells lacking JAM-A ${ }^{15}$. Since JAM-A can undergo both homophilic and heterophilic interactions ${ }^{5}$, the question about the counterligand for JAM-A remained open. By using specific Fab-fragments, an involvement of both the first or second extracellular domains of JAM-A in the transmigration of T cells and monocytes could be demonstrated. From this observation, the presently known counterligands for JAM-A can be inferred, since extracellular domain 1 is involved in interactions with JAM-A and the second domain mediates binding to LFA- $1^{8,26}$. It is conceivable that both homo- and heterophilic interactions are involved in the complex molecular process of transmigration, yet this notion is subject to future investigation and would add a further dimension to the celland stimulus-specific roles of JAM-A in transmigration.

Since inflammatory cell recruitment is a key driving force in atherogenesis, a role for JAM-A in plaque formation was hypothesized over a decade $\mathrm{ago}^{27}$. Subsequent work revealed an upregulation of JAM-A in atherosclerotic specimen from mice and humans ${ }^{7,12}$ and levels of soluble JAM-A were increased in patients with atherosclerosis and hypertension, compared to healthy individuals ${ }^{11,28}$. Recently, JAM-A was found to be upregulated in the brains of hypertensive rats and also in vein specimen of humans with hypertension ${ }^{29}$. Although these studies strongly hinted towards a role for JAM-A in cardiovascular disease, a direct causative role for JAM-A remained undefined. This might be explained by our recent observations in hyperlipidemic mice with a somatic deficiency of JAM-A, which showed no differences in plaque formation compared with JAM-A-positive mice ${ }^{15}$, indicating that JAM-A-deficiency might affect different cell types in a differential manner. This notion was supported by specific genetic deletion of endothelial JAM-A, which significantly delayed lesion progression due to a decreased diapedesis of mononuclear cells. The role of endothelial JAM-A during atherogenesis could thus be perceived as a guiding beacon, since conditions of aberrant flow, such as occurring in predilection sites for atherosclerosis led to a dispersal of endothelial JAM-A, in turn leading to an increased influx of monocytes $^{15}$. The observation that oxLDL increases the transmigration of both $T$ cells and monocytes over HAoEC in a JAM-A-dependent manner further supports a role of this adhesion molecule in atherosclerosis. Given the antiinflammatory effects of statins and PPAR $\gamma$-agonists and their benefit for cardiovascular diseases ${ }^{30}$, we were interested whether treatment of the endothelial cells with such compounds could revert the inflammatory 
redistribution of JAM-A. Treatment with lovastatin effectively counteracted the oxLDL-induced dispersal of JAM-A on HAoEC and reduced transendothelial migration of mononuclear cells to background levels. Given the role of JAM-A in atherosclerotic disease, the counteraction of vascular JAM-A rearrangement might be a novel functional aspect of statins, besides their established lipid-lowering activity. Interestingly treatment with pioglitazone, which also exerts anti-inflammatory effects, neither reduced JAM-A redistribution nor the subsequent transmigration of mononuclear cells, indicating a minor involvement of PPAR $\gamma$ in these JAM-A-related processes.

In conclusion, this study demonstrates that redistribution of JAM-A in endothelial cells after stimulation with atherogenic oxidized lipoproteins results in increased transmigration of mononuclear cells. This inflammatory dispersal of JAM-A could be counteracted with statins, revealing a novel aspect of their mechanism of action. 


\section{Supplementary Figure}

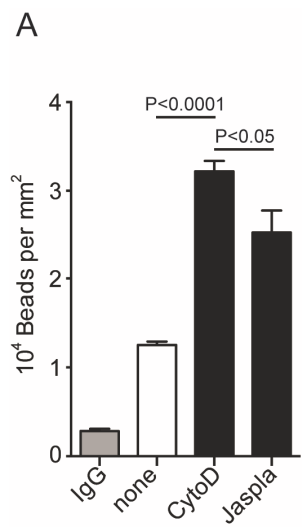

B
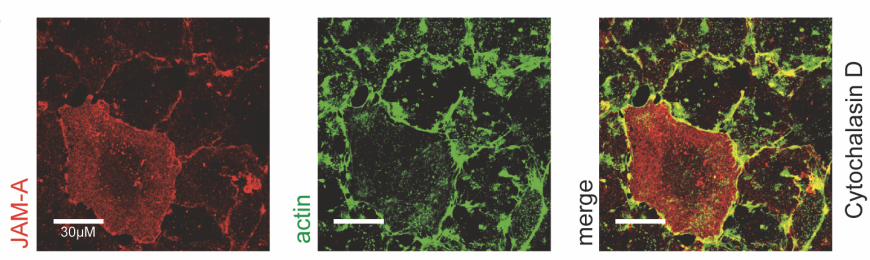

C
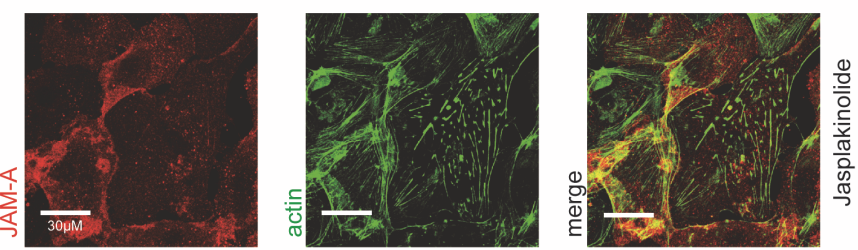

Supplementary figure 1: Role of cytoskeletal integrity on the cellular localization of JAM-A.

Adhesion of control IgG or anti-JAM-A antibody-coupled fluorescent beads to HAoEC after treatment with cytochalasin $D$ or jasplakinolide $(n=5-13)(A)$. Confocal micrographs of HAoEC after staining for JAM-A (red) or actin (green) after treatment with cytochalasin $D(B)$ or jasplakinolide (C).

Scale bars: $30 \mu \mathrm{m}$. 


\section{References}

1. Martinez-Estrada OM, Manzi L, Tonetti P, Dejana E, Bazzoni G. Opposite effects of tumor necrosis factor and soluble fibronectin on junctional adhesion molecule-a in endothelial cells. Am. J. Physiol. Lung Cell. Mol. Physiol. 2005;288:L1081-1088

2. Bazzoni G, Dejana E. Endothelial cell-to-cell junctions: Molecular organization and role in vascular homeostasis. Physiol. Rev. 2004;84:869-901

3. Laukoetter MG, Nava P, Lee WY, Severson EA, Capaldo CT, Babbin BA, Williams IR, Koval M, Peatman E, Campbell JA, Dermody TS, Nusrat A, Parkos CA. Jam-a regulates permeability and inflammation in the intestine in vivo. J. Exp. Med. 2007;204:3067-3076

4. Ozaki H, Ishii K, Horiuchi H, Arai H, Kawamoto T, Okawa K, Iwamatsu A, Kita T. Combined treatment of tnf-alpha and ifn-gamma causes redistribution of junctional adhesion molecule in human endothelial cells. J. Immunol. 1999;163:553-557

5. Weber C, Fraemohs L, Dejana E. The role of junctional adhesion molecules in vascular inflammation. Nat. Rev. Immunol. 2007;7:467-477

6. Woodfin A, Reichel CA, Khandoga A, Corada M, Voisin MB, Scheiermann C, Haskard DO, Dejana E, Krombach F, Nourshargh S. Jam-a mediates neutrophil transmigration in a stimulus-specific manner in vivo: Evidence for sequential roles for jam-a and pecam-1 in neutrophil transmigration. Blood. 2007;110:1848-1856

7. Ostermann G, Fraemohs L, Baltus T, Schober A, Lietz M, Zernecke A, Liehn EA, Weber C. Involvement of jam-a in mononuclear cell recruitment on inflamed or atherosclerotic endothelium: Inhibition by soluble jam-a. Arterioscler. Thromb. Vasc. Biol. 2005;25:729735

8. Ostermann G, Weber KS, Zernecke A, Schroder A, Weber C. Jam-1 is a ligand of the beta(2) integrin Ifa-1 involved in transendothelial migration of leukocytes. Nat. Immunol. 2002;3:151-158

9. Cera MR, Fabbri M, Molendini C, Corada M, Orsenigo F, Rehberg M, Reichel CA, Krombach F, Pardi R, Dejana E. Jam-a promotes neutrophil chemotaxis by controlling integrin internalization and recycling. J. Cell Sci. 2009;122:268-277

10. Koenen RR, Pruessmeyer J, Soehnlein O, Fraemohs L, Zernecke A, Schwarz N, Reiss K, Sarabi A, Lindbom L, Hackeng TM, Weber C, Ludwig A. Regulated release and functional modulation of junctional adhesion molecule a by disintegrin metalloproteinases. Blood. 2009;113:4799-4809

11. Cavusoglu E, Kornecki E, Sobocka MB, Babinska A, Ehrlich YH, Chopra V, Yanamadala S, Ruwende C, Salifu MO, Clark LT, Eng C, Pinsky DJ, Marmur JD. Association of plasma levels of f11 receptor/junctional adhesion molecule-a (f11r/jam-a) with human atherosclerosis. J. Am. Coll. Cardiol. 2007;50:1768-1776

12. Babinska A, Azari BM, Salifu MO, Liu R, Jiang XC, Sobocka MB, Boo D, Al Khoury G, Deitch JS, Marmur JD, Ehrlich YH, Kornecki E. The f11 receptor (f11r/jam-a) in atherothrombosis: Overexpression of $\mathrm{f} 11 \mathrm{r}$ in atherosclerotic plaques. Thromb. Haemost. 2007;97:272-281

13. Zernecke A, Liehn EA, Fraemohs L, von Hundelshausen P, Koenen RR, Corada M, Dejana E, Weber C. Importance of junctional adhesion molecule-a for neointimal lesion formation and infiltration in atherosclerosis-prone mice. Arterioscler. Thromb. Vasc. Biol. 2006;26:e10-13

14. Keiper T, Al-Fakhri N, Chavakis E, Athanasopoulos AN, Isermann B, Herzog S, Saffrich R, Hersemeyer K, Bohle RM, Haendeler J, Preissner KT, Santoso S, Chavakis T. The role of junctional adhesion molecule-c (jam-c) in oxidized Idl-mediated leukocyte recruitment. FASEB J. 2005;19:2078-2080

15. Schmitt MM, Megens RT, Zernecke A, Bidzhekov K, van den Akker NM, Rademakers T, van Zandvoort MA, Hackeng TM, Koenen RR, Weber C. Endothelial jam-a guides monocytes into flow-dependent predilection sites of atherosclerosis. Circulation. 2013

16. Bazzoni G. The jam family of junctional adhesion molecules. Curr. Opin. Cell Biol. 2003;15:525-530

17. Kostrewa D, Brockhaus M, D'Arcy A, Dale GE, Nelboeck P, Schmid G, Mueller F, Bazzoni G, Dejana E, Bartfai T, Winkler FK, Hennig M. X-ray structure of junctional adhesion molecule: Structural basis for homophilic adhesion via a novel dimerization motif. EMBO J. $2001 ; 20: 4391-4398$ 
18. Wojcikiewicz EP, Koenen RR, Fraemohs L, Minkiewicz J, Azad H, Weber C, Moy VT. Lfa1 binding destabilizes the jam-a homophilic interaction during leukocyte transmigration. Biophys. J. 2009;96:285-293

19. Bazzoni G, Martinez-Estrada OM, Orsenigo F, Cordenonsi M, Citi S, Dejana E. Interaction of junctional adhesion molecule with the tight junction components zo-1, cingulin, and occludin. J. Biol. Chem. 2000;275:20520-20526

20. Ebnet K, Schulz CU, Meyer Zu Brickwedde MK, Pendl GG, Vestweber D. Junctional adhesion molecule interacts with the pdz domain-containing proteins af- 6 and zo-1. J. Biol. Chem. 2000;275:27979-27988

21. Bruewer M, Luegering A, Kucharzik T, Parkos CA, Madara JL, Hopkins AM, Nusrat A. Proinflammatory cytokines disrupt epithelial barrier function by apoptosis-independent mechanisms. J. Immunol. 2003;171:6164-6172

22. Jaczewska J, Abdulreda MH, Yau CY, Schmitt MM, Schubert I, Berggren PO, Weber C, Koenen RR, Moy VT, Wojcikiewicz EP. Tnf-alpha and ifn-gamma promote lymphocyte adhesion to endothelial junctional regions facilitating transendothelial migration. $\mathrm{J}$. Leukoc. Biol. 2013

23. Groeneweg M, Vergouwe MN, Scheffer PG, Vermue HP, Sollewijn Gelpke MD, Sijbers AM, Leitinger N, Hofker MH, de Winther MP. Modification of Idl with oxidized 1-palmitoyl2-arachidonoyl-sn-glycero-3-phosphorylcholine (oxpapc) results in a novel form of minimally modified Idl that modulates gene expression in macrophages. Biochim. Biophys. Acta. 2008;1781:336-343

24. Kreisel D, Krupnick AS, Szeto WY, Popma SH, Sankaran D, Krasinskas AM, Amin KM, Rosengard BR. A simple method for culturing mouse vascular endothelium. J. Immunol. Methods. 2001;254:31-45

25. Schenkel AR, Mamdouh Z, Muller WA. Locomotion of monocytes on endothelium is a critical step during extravasation. Nat. Immunol. 2004;5:393-400

26. Fraemohs L, Koenen RR, Ostermann G, Heinemann B, Weber C. The functional interaction of the beta 2 integrin lymphocyte function-associated antigen-1 with junctional adhesion molecule-a is mediated by the i domain. J. Immunol. 2004;173:6259-6264

27. Babinska A, Kedees MH, Athar H, Ahmed T, Batuman O, Ehrlich $\mathrm{YH}$, Hussain MM, Kornecki E. F11-receptor (f11r/jam) mediates platelet adhesion to endothelial cells: Role in inflammatory thrombosis. Thromb. Haemost. 2002;88:843-850

28. Ong KL, Leung RY, Babinska A, Salifu MO, Ehrlich YH, Kornecki E, Wong LY, Tso AW, Cherny SS, Sham PC, Lam TH, Lam KS, Cheung BM. Elevated plasma level of soluble f11 receptor/junctional adhesion molecule-a (f11r/jam-a) in hypertension. Am. J. Hypertens. 2009;22:500-505

29. Xu H, Oliveira-Sales EB, McBride F, Liu B, Hewinson J, Toward M, Hendy EB, Graham D, Dominiczak AF, Giannotta M, Waki H, Ascione R, Paton JF, Kasparov S. Upregulation of junctional adhesion molecule-a is a putative prognostic marker of hypertension. Cardiovasc. Res. 2012;96:552-560

30. Weber C, Noels $\mathrm{H}$. Atherosclerosis: Current pathogenesis and therapeutic options. Nat. Med. 2011;17:1410-1422 
In chapter 2 and 3, we provided evidence for endothelial JAM-A re-localization and its subsequent result on leukocyte recruitment under atherogenic conditions. In chapter 2, we showed an increase of apical JAM-A under atherogenic conditions as well as a focal clustering of apical JAM-A ex vivo. In chapter 3 , we verified those results by performing in vitro immuno-fluorescence staining and expanded them by further mechanistical details. In order to detect the exact site of endothelial JAM-A re-localization and to determine its consequence on mononuclear cell recruitment, a follow-up study resolving endothelial JAM-A localization with higher accuracy is desirable.

Additional to the results presented in this thesis, preceding studies were able to provide evidence for JAM-A re-localization to the apical area of endothelial cells under inflammatory conditions, representing a chronic modality $^{1,2}$, as well as rapid JAM-A re-localization after transient leukocyte adhesion $^{3,4}$.

With the following chapter 4 , we further investigated the effect of JAM-A re-localization under inflammatory conditions observed in chapter 2 and 3. We therefore examined the effect of cytokine-triggered JAM-A relocalization on junctional $\mathrm{T}$ cell transendothelial migration. By performing single cell force spectroscopy and atomic force microscopy assisted homophilic JAMA adhesion mapping of endothelial cells we endeavored to obtain more precise information on JAM-A location after inflammatory stimulation. 
Contribution to the manuscript (chapter 4):

Martin Schmitt designed, conducted and evaluated transmigration assays, which are essential for the conclusion of this study. Additionally, Martin Schmitt prepared Supplemental movie 1, showing junctional transendothelial migration of a monocyte, which crucially contributes to authors' assumptions. Furthermore, Martin Schmitt wrote part of the manuscript. 


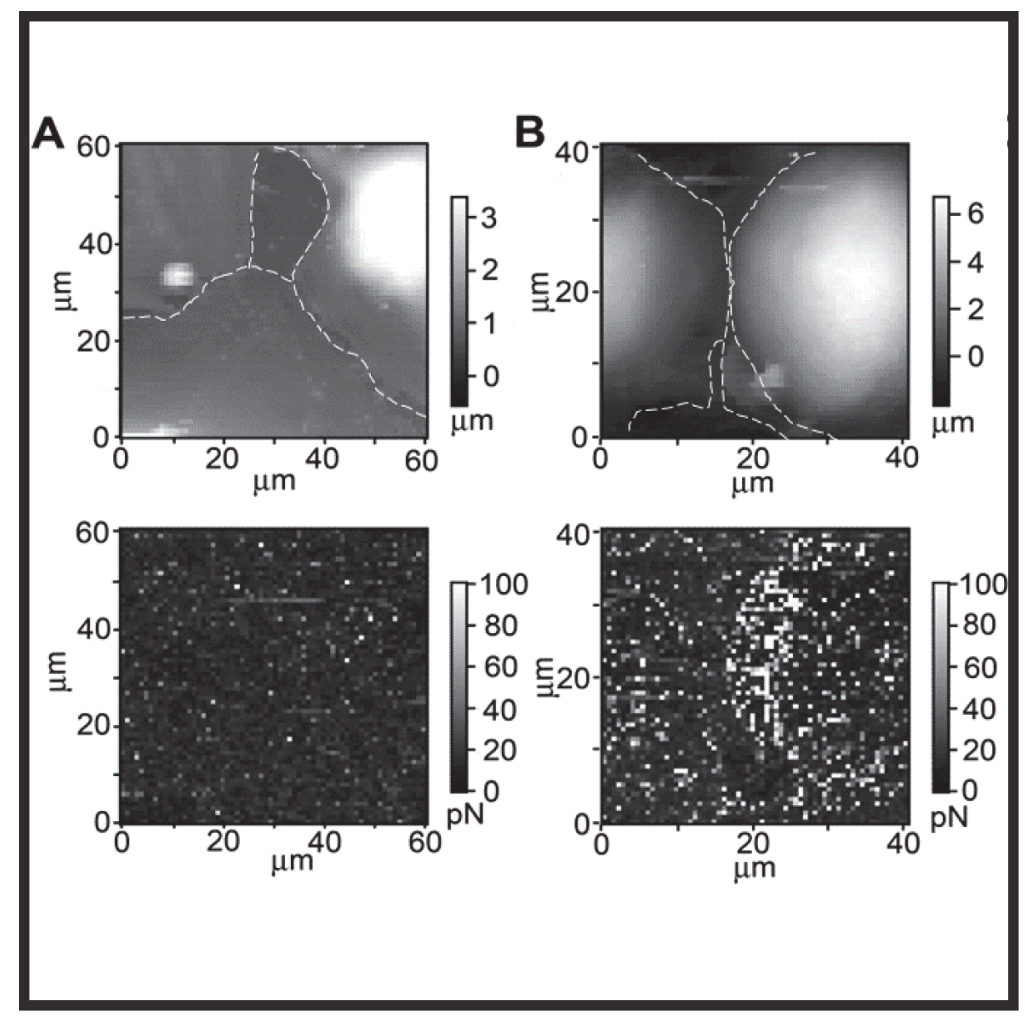

Chapter 4 


\section{TNF- $\alpha$ and IFN- $\gamma$ promote lymphocyte adhesion to endothelial junctional regions facilitating transendothelial migration}

Justyna Jaczewska, Midhat H. Abdulreda, Chi Y. Yau, Martin M. Schmitt, Irene Schubert, Per-Olof Berggren, Christian Weber, Rory R. Koenen, Vincent T. Moy and Ewa P. Wojcikiewicz

J Leukoc Biol. 2014 Feb;95(2):265-74. 


\begin{abstract}
Inflammatory conditions induce redistribution of junctional adhesion receptors toward the apical regions of endothelial cells promoting lymphocyte transendothelial migration (TEM). Much of the molecular structures of TEM have been revealed, however, the biophysical mechanisms underlying this process remain to be fully elucidated. Here, we used immunofluorescence microscopy and atomic force microscopy (AFM) to study endothelial distribution of adhesion molecules upon lymphocyte activation and transmigration. Our immunofluorescence results revealed redistribution of both JAM-A and PECAM-1, but not ICAM-1 or VCAM-1, toward the apical junctional regions of HUVECs following a 6 hour stimulation with TNF- $\alpha$ and IFN- $\gamma$ Consistently, our single cell force spectroscopy (SCFS) studies revealed that Jurkat cell adhesion to stimulated HUVEC monolayers was significantly greater in junctional regions. Enhanced adhesion was mostly mediated by JAM-A receptors. Further AFM adhesion mapping of the homophilic JAM-A/JAM-A interaction on the surfaces of HUVECs revealed a greater number of JAM-A receptors available for binding along junctional regions after TNF- $\alpha$ and IFN- $\gamma$ stimulation. Our data reveal for the first time that adhesion "hot spots" of JAM-A receptors are involved in initiating lymphocyte TEM under inflammatory conditions.
\end{abstract}




\section{Introduction}

Inflammation leads to recruitment of leukocytes from the circulation into injured tissues. This process involves leukocyte adhesion to the endothelium and subsequent transendothelial migration (TEM) into the interstitial space. Initial leukocyte capture by the endothelium is mediated by interaction of glycosylated ligands and the very-late antigen-4 (VLA-4) on the leukocyte surface with selectins and the vascular adhesion molecule-1 (VCAM-1), respectively, in the vascular wall $^{5,6}$. Subsequently leukocytes undergo firm adhesion mediated by integrin interaction with members of the immunoglobulin superfamily ${ }^{7}$. This is particularly enhanced under inflammatory conditions where interaction of $\alpha_{L} \beta_{2}$ or leukocyte function associated antigen-1 (LFA-1) with intercellular adhesion molecule-1 (ICAM-1) play a primary role during firm adhesion ${ }^{8}$. The arrested leukocyte then transmigrates through the endothelium to the underlying connective tissue employing paracellular or transcellular $\mathrm{TEM}^{9,10}$. Paracellular TEM occurs between two adjacent endothelial cells, while transcellular TEM occurs through the endothelial cell.

This work addresses the predominant paracellular pathway mediated by junctional adhesion receptors. The endothelial junctions consist of the tight junctions and the more permeable adherens junctions ${ }^{11,12}$. The integrity of these junctions is maintained via homophilic interactions of adhesion receptors between adjacent endothelial cells. These junctional receptors are linked to intracellular partners that mediate cytoskeletal anchorage and stabilize the junction. Junctional Adhesion Molecules (JAMs) maintain the integrity of tight junctions. Adherens junctions are stabilized by vascular endothelial (VE)-cadherins, which are associated with the actin cytoskeleton via catenins, platelet endothelial cellular adhesion molecule-1 (PECAM-1, CD31) and CD99.

The molecular processes associated with transmigration are complex as they involve binding events between leukocytes and endothelial cells. The migrating leukocyte encounters a number of different adhesion complexes in the endothelial junction that have to be disrupted. An important early event in transmigration is LFA-1 binding to JAM- ${ }^{13}$. JAM-A is a $32 \mathrm{kD}$ immunoglobulin superfamily receptor consisting of two domains, domain 1 (D1) capable of binding to other JAM-A receptors and domain 2 (D2) capable of binding to LFA- ${ }^{13-15}$. LFA-1/JAM-A interaction is essential in initiating TEM. It has been hypothesized that a trimeric complex forms between LFA-1 and junctional JAM-A/JAM-A. Indeed, the binding of lymphocyte LFA-1 to junctional JAM-A/JAM-A complex has been shown to weaken the JAM-A homophilic interaction and thus potentially facilitating cell entry into the junction ${ }^{3,13,16-18}$. Further migration of leukocytes through the junction involves two other adhesion receptors, PECAM-1 and CD99, 19, 20. PECAM-1 is also member of the immunoglobulin superfamily and consists of six Ig domains ${ }^{21}$. In vitro and in vivo 
studies have shown that homophilic PECAM-1 interaction between junctional endothelial cells and transmigrating leukocytes via D1 has been shown to play essential role in progression of $\mathrm{TEM}^{9,19,22,23,24}$.

The next step in the transmigration process involves CD99 receptor. CD99 is a $32 \mathrm{kD}$ transmembrane protein expressed on the surface of leukocytes and endothelial cells resulting in homophilic binding of leukocytes to junctional endothelial cells ${ }^{20}$. The last step allows leukocytes to migrate across the subendothelial basal lamina out of the junction into the interstitial space. This is achieved through heterophilic interaction of domain 6 of junctional PECAM-1 with integrin $\alpha_{v} \beta_{3}$ receptors on the leukocyte surface ${ }^{25,26}$. A recent study confirmed that adhesion molecules do act in sequence to facilitate leukocyte TEM by demonstrating that neutrophil TEM following IL-1 $\beta$ treatment was mediated by ICAM-2, JAM-A and PECAM-1, respectively ${ }^{27}$.

Transmigration of leukocytes is enhanced under inflammatory conditions induced experimentally through TNF- $\alpha$ and IFN- $\gamma$ injection in vivo ${ }^{28}$. TNF- $\alpha$ and IFN- $\gamma$ treatment leads to a number of changes in the endothelium that affect leukocyte binding. While endothelial surface expression of selectins, ICAM-1, and VCAM-1 has been shown to increase upon endothelium activation, PECAM-1 and JAM-A are thought to redistribute to different regions of the cells possibly through diffusion in the plasma membrane and/or transient internalization and re-expression at different sites $^{1,12,29-33}$. Overall, TNF- $\alpha$ and IFN- $\gamma$ stimulation has been shown to promote leukocyte adhesion and TEM in various experimental models ${ }^{28,34-37}$. These in vitro and in vivo studies suggested a modest to substantial increase in TEM, the extent of which seems to depend on stimulation time, with reduced effects for treatments exceeding 18 hours. Cytokine stimulation also was shown to promote endothelial cytoskeletal changes and increased endothelial permeability ${ }^{29,34,38,39}$. While these studies have provided us with insight into the molecular players of TEM and the impact of cytokine treatment on leukocyte trafficking, the biophysical mechanisms mediating TEM have not been fully elucidated. Although we know that cytokine treatment enhances leukocyte endothelial adhesion, the preferred regions for adhesion of a single leukocyte to an endothelial cell have not been identified. This work employed Atomic Force Microscopy (AFM) to provide a molecular level glimpse of lymphocyte-endothelial cell interactions. We show for the first time that redistribution of key adhesion receptors to junctional "hot spots" enhance lymphocyte interaction with junctional regions of stimulated HUVEC monolayers and promote their transendothelial migration ${ }^{40-42}$. 


\section{Methods}

\section{Isolation of peripheral blood T cells}

Human venous blood was obtained from healthy volunteers according to ethical regulations. $\mathrm{CD}^{+} \mathrm{T}$ cells were directly purified from whole blood using Flowcomp ${ }^{\circledR}$ Human CD4 Dynabeads (Life Technologies, Carlsbad, CA) according to manufacturer's instructions. Flow cytometry analysis confirmed the purity of the isolated cells $(>90 \%)$. For the video transmigration experiment (see below), the T cells were cultured up to 48 hours in RPMI medium containing $10 \%$ fetal bovine serum and $25 \mathrm{ng} / \mathrm{ml}$ interleukin 2 in a humidified $\mathrm{CO}_{2}$ incubator at $37^{\circ} \mathrm{C}$.

\section{Transmigration of primary $T$ cells}

Human umbilical vein endothelial cells (HUVEC, PromoCell Heidelberg, Germany) were cultured in proprietary medium (PromoCell) until confluency in porous filter inserts $\left(5 \mu \mathrm{M}\right.$ pore size Transwell ${ }^{\circledR}$, Corning, NY) or $35 \mathrm{~mm}$ petridishes and activated for $6 \mathrm{~h}$ with TNF- $\alpha(10 \mathrm{ng} / \mathrm{ml})$ and INF- $\gamma(20 \mathrm{ng} / \mathrm{ml})$. After $6 \mathrm{~h}$ the cytokines were removed and the HUVECs were washed before isolated primary $\mathrm{CD}^{+} \mathrm{T}$ cells $\left(1 \times 10^{6} / \mathrm{ml}\right)$ were added in $100 \mu \mathrm{l}$ (Transwell assay) or $2 \mathrm{ml}$ (time lapse assay) RPMl1640 medium containing 1\% human albumin (Baxter, Deerfield, IL). Where applicable, blocking antibodies $(0.5 \mu \mathrm{g} / \mathrm{mL})$ against JAM-A $^{18}$, PECAM-1 (Santa Cruz Biotechnology, Santa Cruz, CA) or ICAM-1 (R\&D Systems, Minneapolis, MN) or Fab fragments $(10 \mu \mathrm{g} / \mathrm{ml})$ generated by papain digestion of JAM-A antibodies (243-246) and anti-LFA-1 mAb clone TS1/22 were added to the $T$ cell suspension and $T$ cells were subsequently allowed to transmigrate for $2 \mathrm{~h}$ in a humidified $\mathrm{CO}_{2}$ incubator at 37 ${ }^{\circ} \mathrm{C}$. The transmigrated $\mathrm{T}$ cells were identified and quantified by morphologic gating using flow cytometry (FACS Canto II, BD Biosciences, Franklin Lakes, $\mathrm{NJ}$ ). Time lapse recordings were made in $30 \mathrm{~s}$ intervals for $60 \mathrm{~min}$ at $37^{\circ} \mathrm{C}$ and at 10x magnification, using differential interference contrast (DIC) and a CCD camera on a TE 2000-E microscope (NIS Elements AR software, Nikon, Tokyo, Japan).

\section{Cells and cell culture}

Human T-leukemia Jurkat cell line was obtained from ATCC and maintained in RPMI 1640 medium supplemented with $10 \%$ FBS, $1 \%$ glutamine, $50 \mathrm{U} / \mathrm{ml}$ penicillin, and $50 \mu \mathrm{g} / \mathrm{ml}$ streptomycin in $5 \% \mathrm{CO} 2$ at $37^{\circ} \mathrm{C}$. HUVECs were purchased from Lonza Inc. and cultured in endothelial cell basal medium (EBM-2) supplemented with 2\% FBS, hydrocortisone, human fibroblast growth factor, VEGF, IGF-1, ascorbic acid, human epidermal growth factor, gentamicin-amphotericin, and heparin. HUVECs were plated on $35 \mathrm{~mm}$ tissue 
culture dishes (Becton-Dickinson; Franklin Lakes, NJ) coated with $25 \mu \mathrm{g} / \mathrm{ml}$ human fibronectin (overnight at $25^{\circ} \mathrm{C}$ ). To activate the HUVECs, confluent monolayers were stimulated with TNF- $\alpha(100 \mathrm{ng} / \mathrm{ml})$ and IFN- $\gamma(200 \mathrm{ng} / \mathrm{ml})$ for $6 \mathrm{~h}$ at $37^{\circ} \mathrm{C}, 5 \% \mathrm{CO}_{2}$.

\section{Immunofluorescence and analysis}

Immunofluorescence images were acquired on HUVEC monolayers cultured as described above with and without permeabilization to exclusively visualize extracellular receptors. Confluent HUVEC monolayers were fixed in $4 \%$ paraformaldehyde, washed three times with blocking solution in PBS, incubated at room temperature for $1 \mathrm{~h}$ with primary antibodies (anti-ICAM-1, anti-JAM-A, or anti-PECAM-1) followed by appropriate secondary antibodies. Finally, culture dishes were washed extensively with PBS to remove excess unbound antibodies and the cells were kept submerged in PBS until imaging. Fluorescence confocal imaging was performed using an upright Leica DMLFSA microscope with long distance water-dipping lenses (Leica HXC APO 20x 0.5W, $40 \mathrm{x} 0.8 \mathrm{~W})$. Z-stacks of confocal images were acquired with $0.5 \mu \mathrm{m}$ spacing and different zoom factors using the same acquisition parameters (e.g., laser power, gain, etc). Images were shown as maximum projections unless otherwise stated.

To measure changes in the distribution patterns of extracellular receptors on the surface of HUVECs after stimulation, we measured the volume of the immunostain of the different receptors based on fluorescence intensity and quantified the relative co-distribution of JAM-A with ICAM-1 or PECAM-1 receptors. The receptor co-distribution was calculated based on the "intersect" (i.e., overlap) values $\left(\mu \mathrm{m}^{3}\right)$ of the corresponding immunostains normalized to the volume of the analyzed $3 D$ images ${ }^{43,44}$. It should be noted that this analysis is an indirect measure of the co-distribution, not co-localization, of the surface receptors as the spatial resolution of our images precludes the latter. The images showed that ICAM-1 maintained relatively constant, diffuse distribution on HUVEC surface with and without stimulation. By contrast, there was evident change in the distribution pattern of JAM-A before and after stimulation; whereas, it had a diffuse distribution similar to that of ICAM-1 in unstimulated HUVECs, JAM-A was predominantly expressed on the periphery of stimulated cells. Although all images were obtained using the same acquisition parameters, we did not quantify expression levels of the different receptors based on fluorescence intensity of immunostains; instead, we opted for a conservative approach by using the co-distribution analysis to estimate changes in JAM-A and PECAM-1 distribution relative to that of ICAM-1, which remained relatively constant before and after stimulation. Therefore, given that JAM-A expression was predominantly at the periphery of stimulated HUVEC, an increase in the co-distribution (i.e., intersect) of JAM-A with ICAM-1 was 
interpreted as increased presence of JAM-A in the junctional regions. The analysis was performed automatically in Volocity (Perkin Elmer) based on fluorescence intensity using built-in proprietary algorithms with user feedback. Detection threshold was set to 3-5 standard deviations (SD) depending on the channel ${ }^{45}$. Data were derived from 4-8 images for each condition and presented as mean \pm standard error (SEM).

\section{Single cell force spectroscopy (SCFS) studies}

SCFS studies were carried out by attaching a single cell to an AFM cantilever (Brukernano). Cantilevers with nominal spring constant of $10 \mathrm{pN} / \mathrm{nm}$ were used in all experiments. Experimental spring constants were calculated using the method described by Hutter and Bechhoefer and ranged from 6 to $15 \mathrm{pN} / \mathrm{nm}^{46}$. Attaching the cell to an AFM cantilever tip was accomplished by Concanavalin-A (Con-A) mediated linkages as most cells have Con-A surface receptors $^{47}$. To prepare the Con-A functionalized cantilever, the cantilevers were soaked in acetone for $5 \mathrm{~min}$, UV-irradiated for $10 \mathrm{~min}$ and incubated in biotinamidocaproyl-labeled bovine serum albumin (biotin-BSA, $0.5 \mathrm{mg} / \mathrm{ml}$ in $100 \mathrm{mM} \mathrm{NaHCO}_{3}, \mathrm{pH}$ 8.6; Sigma) overnight at $37^{\circ} \mathrm{C}$. The cantilevers were then rinsed three times with PBS and incubated in streptavidin $(0.5 \mathrm{mg} / \mathrm{ml}$ in PBS; Pierce; Rockford, IL) for 10 min at room temperature. Unbound streptavidin was removed by thorough rinsing in PBS. The cantilevers were then incubated in biotinylated Con-A ( $0.2 \mathrm{mg} / \mathrm{ml}$ in PBS; Sigma) and rinsed again with PBS prior to use. A single cell was attached to the cantilever by positioning the end of the Con-A-functionalized cantilever above the center of the cell and carefully lowering it onto the cell for approximately $1 \mathrm{~s}$. When attached, the cell was positioned right behind the AFM tip of the cantilever ${ }^{48}$. Experiments were carried out by lowering the cantilever with the attached cell onto HUVEC monolayers. Measurements were acquired at a fixed rate of cantilever retraction $(5 \mu \mathrm{m} / \mathrm{s})$, applied force $(200 \mathrm{pN})$ and contact time $(2 \mathrm{~s})$. Data was analyzed using Igor Pro 6.0 software. Data are presented as mean \pm SEM.

\section{AFM Adhesion Mapping}

Experiments were performed using MFP3D-Bio AFM (Asylum Research, Santa Barbara, CA, USA). Unstimulated and TNF- $\alpha / \mathrm{IFN}-\gamma$ stimulated HUVEC in culture media were probed with recombinant human JAM-A functionalized cantilevers at $37^{\circ} \mathrm{C}$. Cantilevers were functionalized as described previously ${ }^{18}$. To prevent receptor redistribution during adhesion map acquisition, all HUVEC were fixed with $4 \%$ formaldehyde in PBS for $30 \mathrm{~min}$ at room temperature. Adhesive interactions were blocked with function blocking antibody directed against D1 of JAM-A (100 $\mu \mathrm{g} / \mathrm{ml}, 60 \mathrm{~min})$. Force-distance adhesion force scans were acquired at a constant velocity $(4 \mu \mathrm{m} / \mathrm{s})$ and a maximum applied force of $\sim 200 \mathrm{pN}$. Adhesion maps were obtained over a scanning region ranging from 
40-90 $\mu^{2}$ and were composed of up to 9000 force-distance curves acquired in a square pattern of 32-96 curves along each side of the square scanned area.

\section{Statistical analysis}

For statistical comparisons we used Student's t-test (to compare two samples) or one-way ANOVA (to compare multiple samples) followed by multiple comparison procedures with the Holm-Sidak method (SigmaStat; Systat, CA). Data were presented as means \pm SEM. Asterisks indicate $p$ value $<0.05$. 


\section{Results}

\section{Transmigration assay across HUVEC monolayer}

The effects of inflammation on transendothelial migration of lymphocytes were investigated. We conducted transendothelial migration assays of primary $\mathrm{CD}^{+}{ }^{+} \mathrm{T}$ cells across TNF- $\alpha$ and IFN- $\gamma$ stimulated $(6 \mathrm{~h})$ and unstimulated HUVEC monolayers. T cell TEM across the junctions of stimulated HUVEC was visualized using real time video microscopy as shown in supplementary video file 1 . The average number of migrating cells per $\mathrm{mm}^{2}$ increased significantly following HUVEC stimulation (Fig. 1AB). Blocking antibodies directed against JAM-A, PECAM-1, or ICAM-1 inhibited this increase down to the levels observed for unstimulated HUVEC (Fig.1A). Furthermore, anti-JAM-A Fab fragments were generated and used to block TEM. All JAM-A Fab fragments reduced TEM down to the level of untreated cells (Fig.1B).
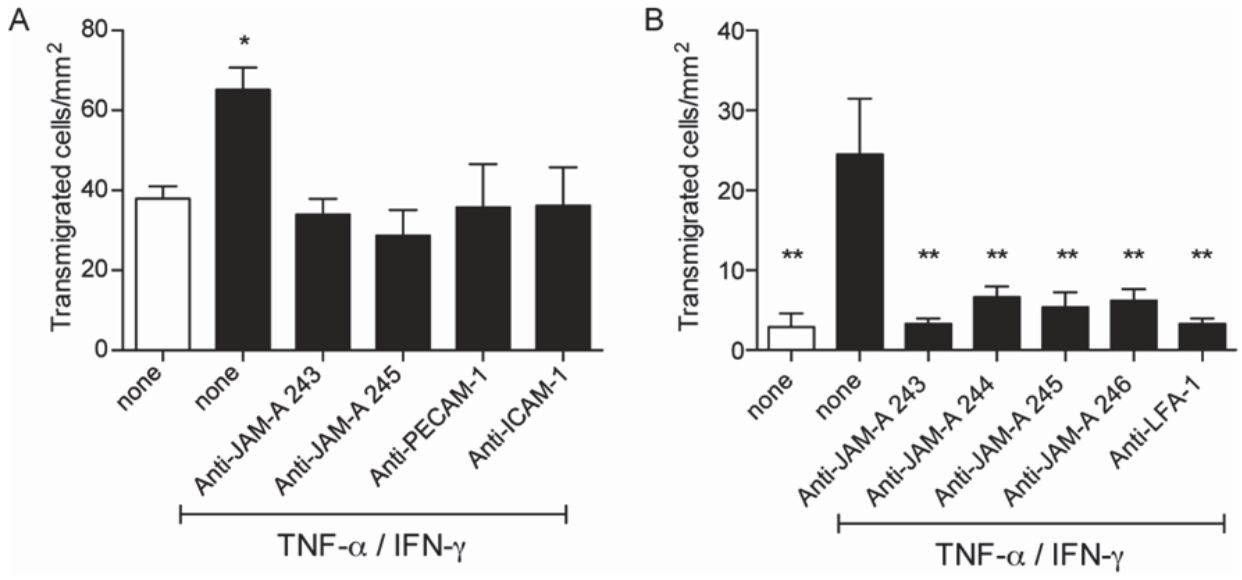

Figure 1: Transendothelial migration is enhanced following HUVEC stimulation. Transendothelial migration of $\mathrm{CD}^{+} \mathrm{T}$ cells was assayed across unstimulated (open bar) or TNF- $\alpha /$ IFN- $\gamma$-stimulated HUVEC (6 h, solid bars) by Transwell assay (A) or using real time video microscopy (B) at $37{ }^{\circ} \mathrm{C}$ and $5 \% \mathrm{CO}_{2}$. Stimulation of HUVEC with TNF- $\alpha / \mathrm{IFN}-\gamma$ enhanced migration significantly. (A) Blocking antibodies $(0.5 \mu \mathrm{g} / \mathrm{ml})$ or (B) Fab fragments $(10 \mu \mathrm{g} / \mathrm{ml})$ against JAM-A (243-246), PECAM-1, ICAM-1 and LFA-1 (TS1/22) significantly reduced migration. Data represent mean \pm SEM of at least 3 independent experiments. ${ }^{*} P<0.05$ vs. control. ${ }^{* *} P<0.001$ vs. stimulated HUVEC without antibody. 
Extracellular JAM-A and PECAM-1 receptors redistribute toward HUVEC junctions following TNF- $\alpha$ and IFN- $\gamma$ stimulation.

We next determined if receptor redistribution played a role in promoting lymphocyte TEM. We used immunofluorescence confocal imaging on HUVEC monolayers to determine the presence/distribution of adhesion receptors involved in mediating lymphocyte-endothelial adhesion. HUVEC monolayers were fixed with $4 \%$ PFA and immunostained for JAM-A, PECAM-1, or ICAM-1 without permeabilization. We also performed dual immunostaining for ICAM-1/JAM-A or PECAM-1/JAM-A. Control experiments with isotype antibodies confirmed immunostaining specificity. All studies were performed using both unstimulated and TNF- $\alpha /$ IFN- $\gamma$ stimulated HUVECs. Confocal images spanning the monolayers showed that all receptors were present on the HUVEC surface in both conditions (Fig. 2A; also see Movies 2 and 3 in the online supplemental material). While JAM-A, ICAM-1, and PECAM-1 were diffusely distributed on unstimulated cells, stimulation (6 h) with TNF- $\alpha$ and IFN- $\gamma$ resulted in evident redistribution of JAM-A and PECAM-1, but not ICAM-1, receptors to the junctional regions. We next quantified the relative codistribution of JAM-A with that of ICAM-1 or PECAM-1 on unstimulated or stimulated dual-stained HUVEC monolayers by measuring the "intersect" (i.e., overlap) of the corresponding immunostains (Fig. 2B) ${ }^{43,44}$. The nuclear stain (DAPI) was used as negative control in permeabilized monolayers. The intersect was used as an indirect measure of the relative co-distribution of the receptors to adjacent areas within the HUVEC membrane (see Methods). The intersect of ICAM-1 and JAM-A increased significantly following stimulation (6 h) (Fig.2B). Given that ICAM-1 surface expression did not appreciably change following stimulation (Fig. 2A) and that JAM-A appeared predominantly on the periphery of stimulated HUVECs, the relative increase in JAM-A distribution with ICAM-1 was interpreted as higher presence of JAM-A receptors in junctional regions. We performed similar analysis for PECAM-1 and JAM-A and found that PECAM-1 distribution did not differ from that of JAM-A before and after stimulation indicating that, similar to JAM-A, PECAM-1 expression was higher in junctional regions after TNF- $\alpha /$ IFN- $y$ treatment. 
A

A ICAM-1

JAM-A

PECAM-1
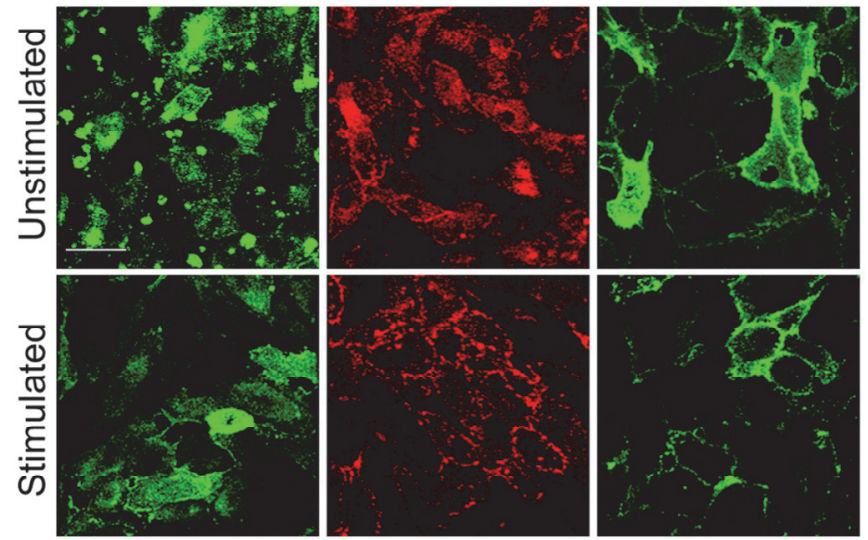

B ICAM-1/JAM-A

PECAM-1/JAM-A Unstimulated
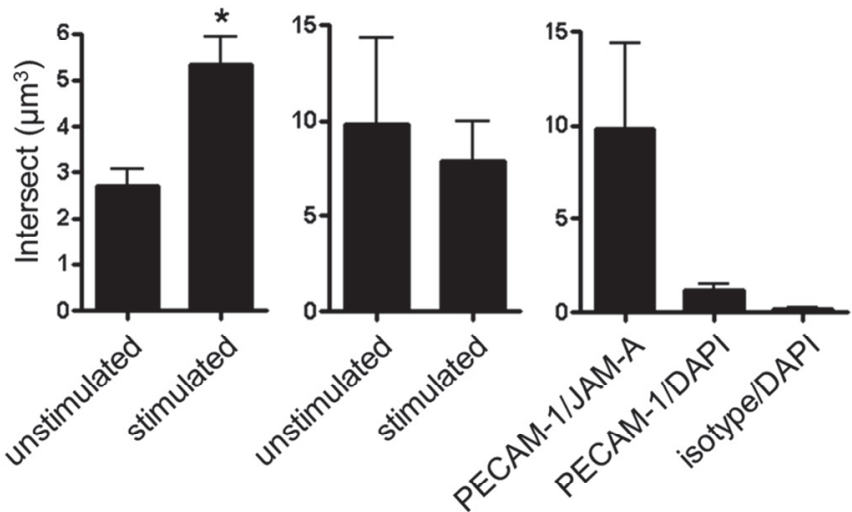

Figure 2: Adhesion receptor distribution on unstimulated and TNF- $\alpha / \mathrm{IFN}-\gamma$ stimulated HUVEC monolayers.

(A) Unpermeabilized cells were immunostained for extracellular adhesion receptors (ICAM-1, JAM-A, or PECAM-1). Unstimulated and stimulated HUVECs were imaged using confocal image $z$-stacks spanning the monolayers. Images are shown as maximum projections. Scale bar $=50 \mu \mathrm{m}$. Unstimulated HUVECs exhibited diffuse staining on the cell surface for all receptors. Following $6 \mathrm{~h}$ stimulation with TNF- $\alpha$ and IFN- $\gamma$, junctional staining for JAM-A and PECAM-1 receptors increased noticeably. (B) Intersect analysis in Volocity was used to quantify the relative co-distribution of JAM-A with that of ICAM-1 or PECAM-1. The results showed significantly increased co-distribution of JAM-A with ICAM-1 indicating increased expression of JAM-A in junctional regions on stimulated versus unstimulated HUVECs. No difference was observed for JAM-A/PECAM-1 indicating that PECAM-1 distributed in a similar pattern as JAM-A before and after HUVEC stimulation. Codistribution of PECAM-1 with the nuclear stain DAPI and of isotype antibody/DAPI served as controls. 
SCFS reveals enhanced adhesion of Jurkat to junctional regions of stimulated HUVEC

Motivated by our immunoimaging results, we performed SCFS studies between Jurkat cells and HUVEC monolayers cultured in Petri dishes as illustrated (Fig. 3 panel 1). The Jurkat cell was allowed to interact with either the HUVEC body or junctional region to determine if cell adhesion was enhanced at HUVEC junctional regions under inflammatory conditions. The Jurkat cell was attached to the AFM probe via Con-A-mediated linkages and lowered via the expansion of the piezoelectric translator onto the desired location on the HUVEC selected visually using the light microscope objective and camera located beneath the sample (Fig. 3). Following a $2 \mathrm{~s}$ contact with the HUVEC, the Jurkat cell was then retracted. This cycle was repeated up to 100 times for each cell assayed. Throughout the approach-retraction cycle, the AFM probe undergoes bending, leading to the deflection of a laser signal off the probe which is detected by the photodiode (Fig. 3). The result is a force-displacement record, or force scan.

A typical AFM force-displacement record of the interaction between a Jurkat cell and activated HUVEC monolayer is presented (Fig. 4A. top trace). This represents one adhesion-detachment cycle of the Jurkat from the HUVEC as it is moved in the $\mathrm{X}-\mathrm{Y}$ plane via the expansion and contraction of the piezoelectric translator (Fig. 3). The straight line represents zero force. Initially, as the Jurkat cell is lowered onto the HUVEC there is a slight increase in force (upward deflection along Y-axis), contact is achieved between the 2 cells and then the Jurkat cell is detached from the HUVEC. This typically results in stepwise rupture of adhesive contacts formed between the two cells as clearly seen in the second force-displacement record acquired on stimulated HUVEC depicted in Fig.4A. Each of these rupture events resulted in a rapid jump in force which correspond to the unbinding of one or more adhesive ligand-receptor bonds. The magnitudes of the force transitions are between 30 and $80 \mathrm{pN}$ and are consistent with the reported unbinding forces of individual selectin and integrin bonds ${ }^{47,49,50}$. 


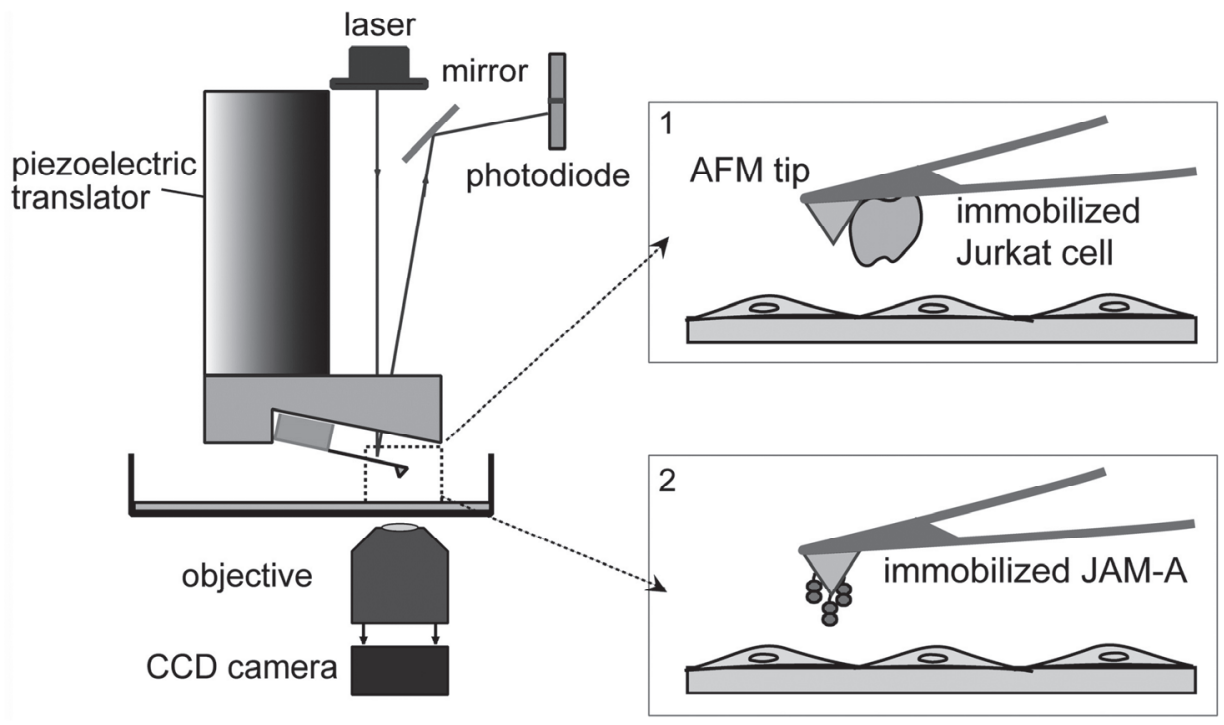

Figure 3: Experimental system to study cell-cell or protein-cell interactions.

A lymphocyte (Jurkat cell) was attached to the AFM silicon nitride probe via con-A linkages and lowered onto the HUVEC monolayer (panel 1). Alternately, JAM-A was cross-linked to the cantilever via 3-aminopropyl-triethoxysilane (panel 2). Cells were visualized via the objective and camera beneath the sample. The lymphocyte or JAM-A were lowered onto the HUVEC via the expansion of the piezoelectric translator (approach), allowed to make contact, and then the probe was retracted, breaking all contacts. A laser light was reflected off the probe onto a photodiode detector. The bending of the probe during the approach-retraction cycle resulted in laser deflection. These changes are detected by the photodiode and translated into a digital signal from which the force traces are derived.

The extent of the adhesive interaction was measured by calculating the work of de-adhesion, or the work required to pull and stretch the cell and disrupt all receptor-ligand interactions. This parameter is represented by the shaded region of the top two traces shown in Fig. 4. Our measurements revealed that Jurkat cell adhesion was equivalent to both HUVEC regions under unstimulated conditions (Fig. 4B). The work of de-adhesion required to detach a Jurkat cell from an unstimulated HUVEC was $1.38 \times 10^{-16} \pm 0.42 \mathrm{~J}$ at the HUVEC center and $1.60 \times 10^{-16} \pm 0.45 \mathrm{~J}$ at the HUVEC junction (Fig. 4B). Following a $6 \mathrm{~h}$ stimulation of HUVEC with TNF- $\alpha$ and IFN- $\gamma$, there was a significant increase in the measured work of de-adhesion at both the HUVEC center and junction as compared to that measured on unstimulated HUVEC (Fig. 4B) $(p<0.002$ for center, $p<0.001$ for junction). Interestingly, the most pronounced increase was observed at the junction, as evidenced by a significantly greater work of deadhesion represented by the filled gray region (Fig. 4A). The average measured work of de-adhesion required to detach a Jurkat cell from a stimulated HUVEC 
center was $3.09 \times 10^{-16} \pm 0.55 \mathrm{~J}$ and $7.03 \times 10^{-16} \pm 0.58 \mathrm{~J}$ at the HUVEC junction (Fig. 4B) $(p<0.001)$. This corresponds to a greater than 4 -fold increase in overall adhesion at junctional regions, suggesting greater number of receptors available for binding following stimulation (Fig. 2).

To determine the contribution of the various adhesion receptors toward mediating enhanced adhesion of Jurkat to TNF- $\alpha /$ IFN- $\gamma$-stimulated HUVEC, we carried out a series of experiments in the absence and presence of adhesion-blocking antibodies. We focused on the main receptors responsible for mediating firm adhesion of leukocytes to the endothelium, namely ICAM-1, and compared their contribution to that of JAM-A and PECAM-1 which are primarily responsible for leukocyte TEM (Fig. 4B). An antibody against ICAM-1 was used to block the LFA-1/ICAM-1 interaction as Jurkat cells express LFA-1. ICAM-1 blockade reduced adhesion by $\sim 25 \%$ at the HUVEC center $\left(2.32 \pm 0.41 \times 10^{-16} \mathrm{~J}\right)$ and $\sim 17 \%$ at the junction $\left(5.87 \pm 0.59 \times 10^{-16} \mathrm{~J}\right)$ as compared to untreated stimulated HUVEC ( $p=<0.005$ and $<0.003$, respectively). Thus, blocking key adhesion receptors for firm lymphocyte adhesion to the endothelium had a modest effect, particularly, at junctional regions. It is important to point out that this decrease in adhesion did not reveal large differences between the junction and the cell center. Two antibodies were used in conjunction to block all JAM-A interactions. One was directed against the second domain of JAM-A, thus blocking LFA-1/JAM-A heterophilic interactions, and the other directed against the first domain of JAM-A, blocking JAM-A homophilic interactions. Following the addition of both JAM-A antibodies, the measured work of de-adhesion was $1.92 \pm 0.87 \times 10^{-16} \mathrm{~J}$ at the HUVEC center and $0.82 \pm 0.06 \times 10^{-16} \mathrm{~J}$ at the junction. This is a $\sim 38 \%$ decrease in adhesion at the center and $\sim 88 \%$ at the HUVEC junction $(p=<0.003$ and $<0.001$, respectively). These results clearly indicate an important role for JAM-A interactions in lymphocyte adhesion to the endothelium and their recruitment into the endothelial junction under inflammatory conditions. Specifically, this indicates that JAM-A plays a more important role in mediating adhesion of lymphocytes in the junctional region than at the center of endothelial cells where ICAM-1 is more likely to be involved.

Finally, an antibody directed against PECAM-1 was then used to block the $\alpha_{v} \beta_{3} /$ PECAM- 1 interaction. PECAM- 1 blockade reduced adhesion by $23 \%$ at the center $\left(2.38 \pm 0.34 \times 10^{-16} \mathrm{~J}\right)$ and $33 \%$ at the junction $\left(4.7 \pm 0.40 \times 10^{-16} \mathrm{~J}\right)$ as compared to untreated stimulated HUVEC $(p=<0.005$ and $<0.002$, respectively). The decrease in adhesion was slightly larger at the junction as expected. However, the role of this interaction was not as pronounced compared to JAM-A consistent with the notion that PECAM-1 homophilic and heterophilic interactions are more significant in other cell types such as neutrophils. 


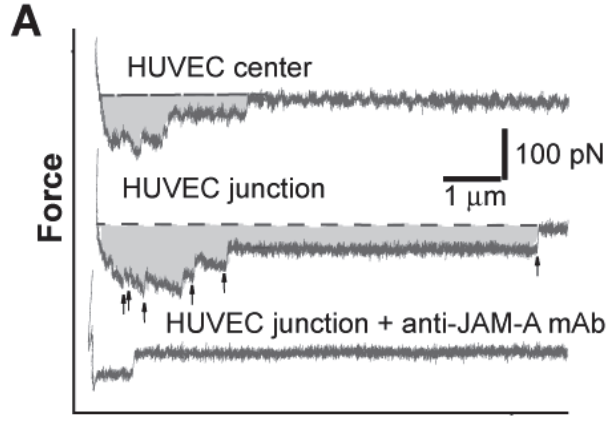

B

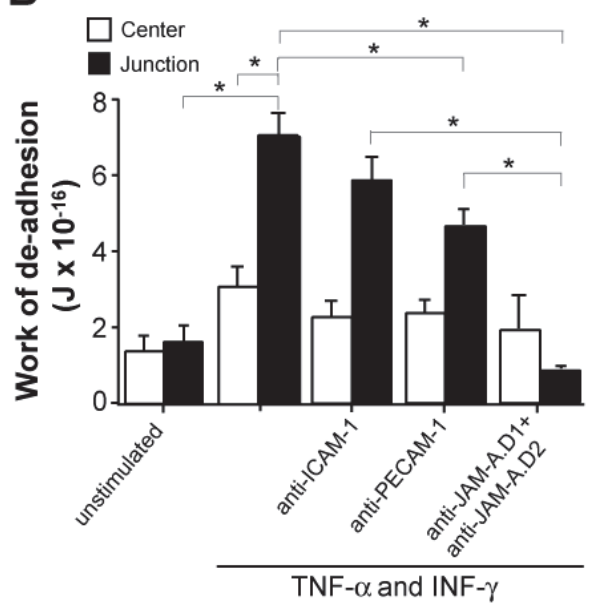

Figure 4: Measuring Jurkat-HUVEC interaction.

(A) Representative AFM force scans showing de-adhesion forces under different conditions. The work of de-adhesion required to disrupt adhesion of Jurkat to TNF- $\alpha / \mathrm{IFN}-\gamma$-stimulated HUVEC is shaded (top two traces). Force scans measured at the HUVEC center, junction, and in the presence of JAM-A-function-blocking antibodies directed D1 and D2 to block JAM-A/JAM-A and JAM-A/LFA-1 interactions are shown. Measurements were acquired with a compression force of $200 \mathrm{pN}, 2 \mathrm{~s}$ contact time and $5 \mu \mathrm{m} / \mathrm{s}$ cantilever retraction speed. Arrows in the second trace point to rupture events. Dashed line indicates zero force. Hundred force scans were acquired for each Jurkat cell measured. (B) Average work of de-adhesion of Jurkat cells measured on unstimulated or stimulated HUVEC monolayers. Measurements were conducted at the HUVEC junction (black bars) and center (gray bars). Blocking antibodies particularly against JAM-A reduced Jurkat adhesion to stimulated HUVEC $(p=<0.001$ for junction and $P=<0.003$ for center). Results for each condition represent over 500 AFM force scans acquired from at least five independent experiments and are presented as means \pm SEM. ${ }^{*} \mathrm{P}<0.005$.

\section{AFM adhesion maps of JAM-A reveal adhesion "hot spots" following HUVEC stimulation}

Since JAM-A was chiefly responsible for Jurkat cell adhesion to the endothelial junctional region, we postulated that JAM-A may form adhesion "hot spots" that facilitate recruitment of lymphocytes into junctional regions (Figs. 1, 2, 4). We therefore conducted detailed AFM adhesion mapping of JAM-A adhesion distribution on the HUVEC surface. This requires systematic acquisition of adhesion force scans on the HUVEC surface as illustrated in Fig. 5A. Each recorded force scan provides information regarding the magnitude of the measured JAM-A adhesive interaction and its specific location on the HUVEC surface in the $X-Y-Z$ planes (Fig. 5A). Measurements were acquired using purified JAM-A cross-linked to the cantilever tip as described in Methods (also see Fig. 4, panel 2). JAM-A was allowed to interact with the HUVEC surface with $1 \mu \mathrm{m}$ intervals along each line scan. At each point the functionalized probe was lowered onto the HUVEC to make contact with the HUVEC before it was subsequently withdrawn. This cycle is represented by the approach-retract 
traces shown in force scan 1 depicted in Fig. 5B. If an adhesive interaction is formed and disrupted a single rupture event is observed (Fig. 5B force scans 1 and 2) where a force jump of $\sim 60 \mathrm{pN}$ in the retraction traces was observed. If no adhesive interaction occurs, there is no jump in force (Fig 5B force scans 3 and 4). To generate adhesion maps, we repeated force measurements along line scans in predefined areas where each interaction was represented by a pixel per square (Fig. 5C, lower panel). Lighter pixels correspond to larger adhesive forces where as dark pixels represent no adhesion.

In addition to adhesion force measurements, these experiments simultaneously allow for the acquisition of topographical information about the probed cells. Topographical information is derived from the extent of expansion of the piezoelectric transducer which is used to lower the probe onto the substrate. Therefore, the piezoelectric transducer has to expand to a greater extent in order for the probe to reach lower regions of the cell edge as compared to higher regions located at the center of the cell. For example, force scan 4 is located at $\sim 1.8 \mu \mathrm{m}$, a lower position compared to force scan 1 $(\sim 3.8 \mu \mathrm{m})$ (Fig. 5B); the higher the point of contact, the lighter the region in the height map (Fig. 5C, top panel). Both maps shown in Fig. $5 \mathrm{C}$ are a magnified $12 \times 12 \mu \mathrm{m}$ region of the larger adhesion map shown in Fig. 6B.

A
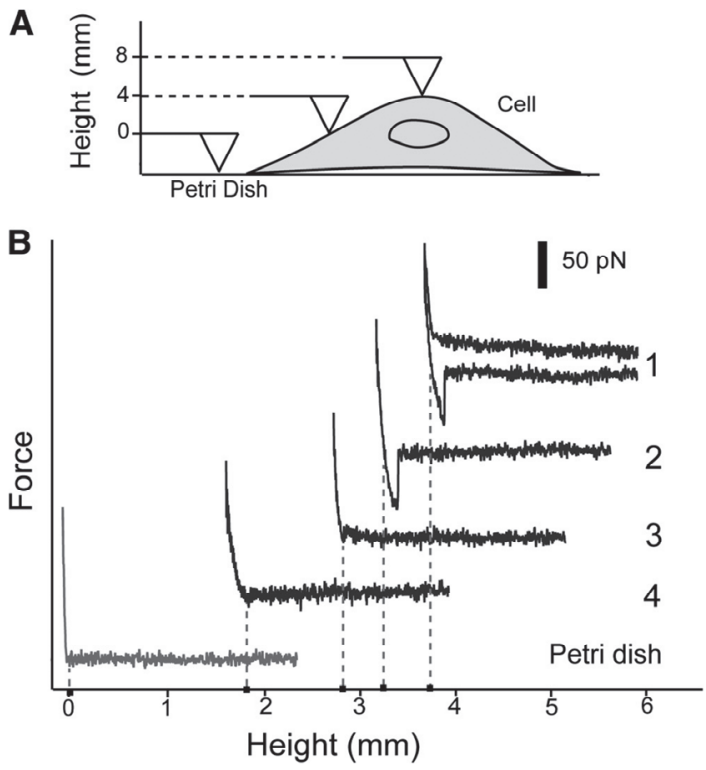

C

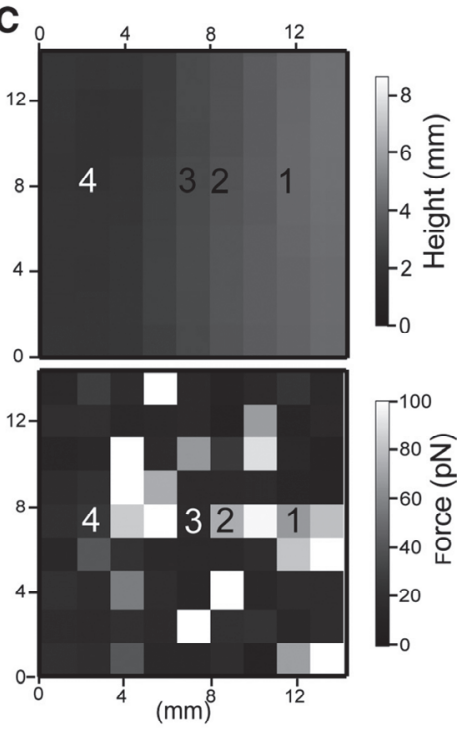

Figure 5: AFM adhesion map acquisition.

(A) Adhesion mapping entails systematically scanning the cell surface with a coated AFM cantilever tip. This allows height mapping of the cell in conjunction with adhesion measurement acquisition for specific points on the cell. (B) Representative force-displacement traces acquired with a JAM-A coated AFM probe at specific heights on a TNF- $\alpha$ and IFN- $\gamma$-stimulated HUVEC. (C) Detailed height and corresponding adhesion maps for a $12 \times 12 \mu \mathrm{m}$ region of TNF- $\alpha$ and IFN- $\gamma$-stimulated HUVEC. Locations and adhesion forces of the force scans shown in $\mathbf{B}$ are numbered 1-5 on both maps. 
Only adhesion maps acquired on stimulated HUVEC revealed JAM-A adhesion patterns. A height map image of a HUVEC monolayer and its corresponding adhesion map for unstimulated HUVECs acquired for a $60 \mu \mathrm{m}^{2}$ region is shown in Fig. 6A. Although a few white pixels indicating stronger JAM-A adhesive interactions in the $80-100 \mathrm{pN}$ range appeared sporadically, most of the map consisted of gray or black regions representing little or no JAM-A adhesive interactions. A $40 \mu^{2}$ height map of a HUVEC and the corresponding adhesion map for TNF- $\alpha / \mathrm{IFN}-\gamma$-stimulated HUVEC is depicted in Fig. 6B. The adhesion map of the stimulated HUVEC revealed greatly enhanced JAM-A adhesion as compared to unstimulated cells (Fig. 6A). In specific, JAM-A adhesive contacts were measured in the range of $80-100 \mathrm{pN}$, arranged in a semicircular pattern along the edge of the stimulated HUVEC. This "hot spot" is located between $15-25 \mu \mathrm{m}$ on the horizontal axis of the map and 10-35 $\mu \mathrm{m}$ on the vertical axis and is large enough to accommodate $T$ cell adhesion as the average $T$ cell diameter is $7 \mu \mathrm{m}$. Blockade of domains 1 and 2 of JAM-A eliminated all JAM-A interactions, and the adhesion map acquired on a $90 \mu \mathrm{m}^{2}$ region of the HUVEC monolayer was composed mostly of dark pixels (Fig. $6 \mathrm{C}$ ).
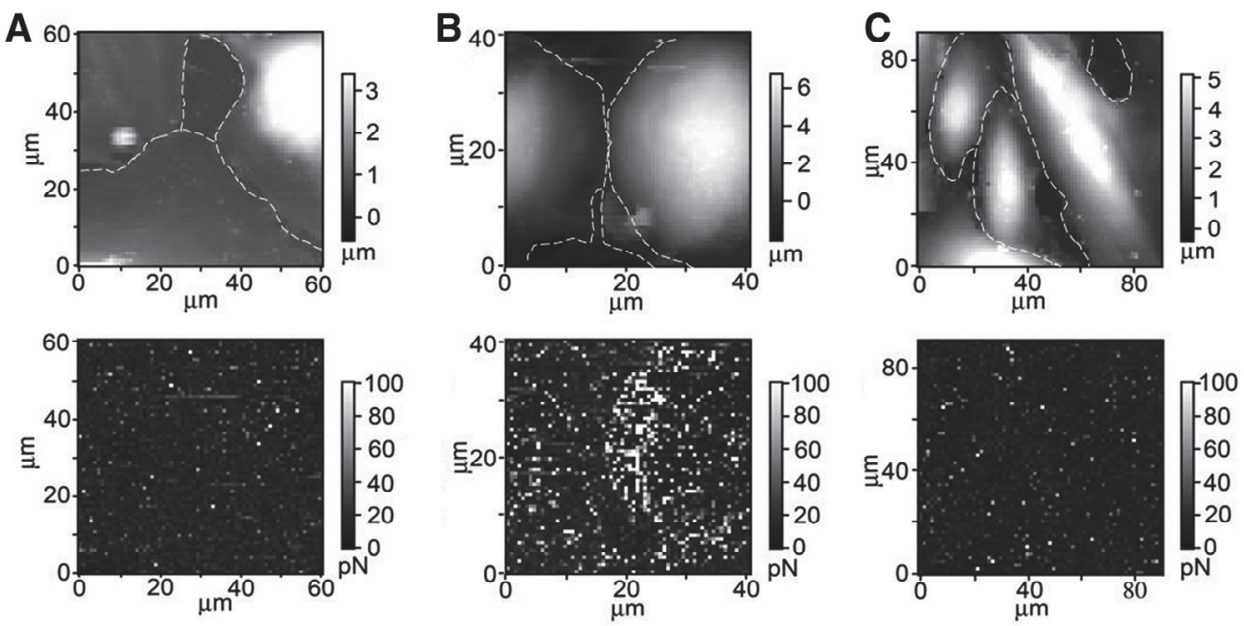

Figure 6: AFM adhesion maps of JAM-A-mediated adhesion to HUVEC.

Adhesion maps were acquired by scanning the HUVEC surface with a JAM-A coated AFM probe. Each adhesion map (bottom) is shown with the corresponding height map image (top) where the cells are outlined with dotted lines. White regions represent the greatest height and the highest force as shown. (A) Adhesion map of an unstimulated HUVEC monolayer. Note the lack of white pixels indicative of few strong adhesive contacts. (B) Adhesion map of a HUVEC monolayer stimulated for $6 \mathrm{~h}$ with TNF- $\alpha$ and IFN- $\gamma$. Note strong JAM-A adhesive contacts of $>80 \mathrm{pN}$ (white pixels) along the HUVEC junction (dashed lines). (C) Map of the same stimulated HUVEC monolayer acquired in B after addition of JAM-A function-blocking antibodies against D1 and D2. Note loss of adhesive contacts along the HUVEC junction. 


\section{Discussion}

Our results showed that a 6 hour TNF- $\alpha$ and IFN- $\gamma$-treatment promoted TEM of T cells across HUVEC monolayers. Moreover, our work shows, for the first time, that the underlying molecular mechanism for enhanced lymphocyte paracellular TEM is the development of JAM-A "hot spots" located near the HUVEC junctions that enhance lymphocyte junctional adhesion and facilitate their junctional recruitment.

Function-blocking antibodies directed against ICAM-1, JAM-A or PECAM-1 significantly diminished lymphocyte TEM after stimulation as assayed by transwell assays and real time video microscopy (Fig. 1 and Supplementary movie 1). Furthermore, we observed a redistribution of JAM-A and PECAM-1, but not ICAM-1, following a 6 hour TNF- $\alpha$ and IFN- $\gamma$ stimulation. The diffuse staining at the HUVEC center of both receptors was reduced and only junctional staining was observed following stimulation (Fig.2).

Our findings prompted us to investigate the potential role of receptor redistribution in lymphocyte junctional recruitment at the single cell level. In order for cells to be recruited into endothelial junctions they must first adhere more strongly to the endothelium as had been shown by others ${ }^{28,34-37}$. Our study is the first of its kind to determine the specific region on a single HUVEC cell where leukocyte binding is most likely to take place. We conducted SCFS measurements that revealed that lymphocyte adhesion was enhanced near HUVEC junctions following $6 \mathrm{~h}$ stimulation. A key feature of SCFS is that the adhesion of a single living cell is measured under applied force $(\sim 200 \mathrm{pN})$ simulating in vivo conditions where shear forces in the blood stream act on migrating leukocytes as they interact with the endothelium. During each force measurement, the lymphocyte is subjected to both pushing (approach toward substrate) and pulling (retraction) forces. The rate of probe retraction was kept constant $(\sim 5 \mu \mathrm{m} / \mathrm{s})$ as was the applied force and contact time based on our previous studies of leukocyte adhesion to HUVEC showing the impact of these parameters on the adhesion strength measured by detachment force and work of de-adhesion ${ }^{51,52}$. SCFS revealed that Jurkat cell adhesion to HUVEC junctional regions increased by $>4$ fold after a $6 \mathrm{~h}$ TNF- $\alpha$ and IFN- $\gamma$ stimulation. Blocking experiments also showed that JAM-A played the most significant role in enhancing adhesion at junctions of stimulated HUVEC. PECAM-1 blockade also had a significant yet lesser effect than JAM-A blockade on Jurkat cell adhesion likely due to low levels of integrin $\alpha_{v} \beta_{3}$, the binding partner of PECAM-1, on HUVECs. ICAM-1 was more prominent at mediating cell adhesion at the cell center as revealed by greater blockade in that HUVEC region. These findings are consistent with previous studies showing the important role of ICAM-1 in transcellular TEM ${ }^{10,53}$. 
It has been suggested by numerous studies that an adhesion receptor gradient is responsible for guiding lymphocytes to the junction. We further determined if such a JAM-A gradient was present on stimulated HUVEC by conducting AFM adhesion mapping to determine the availability of functional JAM-A adhesive contacts on the HUVEC surface with 1 micron resolution. Systematic adhesion mapping of the interaction of purified JAM-A with the surface of stimulated HUVEC monolayers following a $6 \mathrm{~h}$ TNF- $\alpha$ and IFN- $\gamma$-treatment revealed a large increase and markedly altered distribution profile of adhesive forces. The measured forces of the interaction of JAM-A with HUVEC surface ranged from $50 \mathrm{pN}$ to $100 \mathrm{pN}$, which is in the range of previously measured single bond forces of JAM-A/JAM-A interaction ${ }^{18}$. JAM-A can also form heterophilic interactions with LFA-1. However, the JAM-A/LFA-1 interaction is unlikely to have been involved as JAM-A/LFA-1 single bond forces are $>150 \mathrm{pN}$. The regions of functional JAM-A receptors were arranged in $\sim 10 \mu \mathrm{m}^{2}$ regions, an area sufficient in size to accommodate lymphocyte binding ${ }^{54}$. We term these regions of increased JAM-A receptors as adhesion "hot spots." Lymphocyte binding to a "hot spot" likely plays a key role in guiding it toward the junction. Indeed, our video microscopy observations suggest that such a process occurs, showing lymphocytes preferentially transmigrating at the endothelial cell contacts.

This is consistent with previous studies where effects of combined TNF- $\alpha$ and IFN- $\gamma$ treatment on leukocyte paracellular TEM were investigated under both static or flow conditions in vitro and in vivo. An in vivo study by Munro and colleagues conducted in the baboon reported that TNF- $\alpha$ and IFN- $\gamma$ treatment resulted in the upregulation of E-selectin and ICAM-1 and led to leukocyte accumulation at endothelial junctions as early as $6 \mathrm{~h}$ after combined TNF- $\alpha$ and IFN- $\gamma$ treatment ${ }^{28}$. Interestingly, E-selectin levels decreased at 24 hours. In addition, the Munro et al. study also revealed that the level of polymorphonuclear cells (PMN) accumulation peaked at 6-9 $\mathrm{h}$ following combined treatment and later decreased to lower levels. A later in vitro study by Shaw et al. revealed an increase in leukocyte adhesion and TEM under flow following TNF- $\alpha$ and IFN- $\gamma$ treatment with an observed increase in endothelial permeability ${ }^{34}$. These findings are consistent with a number of subsequent studies. For example, two studies by Mohan et al. described a notable increase in adhesion of T cells to HUVEC stimulated with TNF- $\alpha$ and IFN- $\gamma$ and an increase in migration and a study by Ancuta et al. revealed increased migration for CD16- monocytes ${ }^{36}$.

Our immunofluorescence images revealed a more diffuse staining of JAM-A and PECAM-1 on the HUVEC surface with receptors localizing toward the junctions. This is consistent with the adhesion receptor movement reported in other studies where receptors disappear after 24 hours. It is likely that receptors begin their movement toward the junctional regions and significant 
changes occur at the $6 \mathrm{~h}$ mark following TNF- $\alpha$ and IFN- $\gamma$ stimulation. Longer stimulation times allow the receptors to move into the junction and seemingly disappear from the confocal images ${ }^{1,55}$. Response to inflammation is a very dynamic process. We believe that receptor movement is never halted but rather likely continues in vivo. Perhaps adhesion "hot spots" first form to recruit cells to junctional regions. Subsequently, receptors continue their movement, potentially helping to drag the leukocytes into the junction. This idea is supported by numerous studies highlighting cytoskeletal alterations in stimulated endothelial cells. For example, Munro and coworkers compared TNF- $\alpha$ stimulation to cytochalasin-D treatment (a known disruptor of $f$-actin) ${ }^{28}$. Such disruption or rearrangement occuring in the actin cytoskeleton likely leads to the release of adhesion receptors anchoring to the cytoskeleton and allows for their greater mobility. Since confocal microscopy techniques continue to improve in resolution, future studies illustrating adhesion receptor distribution over a continuous time course in the context of lymphocyte TEM would greatly improve our understanding of this process.

We believe that TNF- $\alpha$ and IFN- $\gamma$ stimulation for $24 \mathrm{~h}$ or longer leads to different outcomes as compared to stimulation times less than $18 \mathrm{~h}$. At these longer stimulation times, lymphocytes may not adhere preferentially to the junctional region as receptors are no longer present there at greater levels as revealed by previous studies ${ }^{1,34}$. Shaw et al. do report enhanced adhesion to the endothelium but the results show the number of cells bound ${ }^{34}$. No information about preferential binding is available. However, the cytoskeletal changes that likely facilitate receptor rearrangement likely also promote increased endothelial permeability as observed by these authors where significant increases were seen. So, although receptor distribution at longer time points may not favor TEM, the increased junctional permeability does. Therefore, TEM is not reduced. Other studies employed an $18 \mathrm{~h}$ treatment with TNF- $\alpha$ and IFN- $\gamma$. All report an increase in leukocyte adhesion and TEM at this time point ${ }^{35,36,37}$.

In order for the body to effectively defend against pathogens, there has to be a significant enhancement in immune cell interactions with the endothelium. This is, for example, highlighted in the ICAM-1 and ICAM-2 receptors, where ICAM-2 is constitutively expressed on the endothelial surface and participates in immune surveillance. Meanwhile, ICAM-1 is greatly upregulated under inflammatory conditions to facilitate firm lymphocyte adhesion to the endothelium. It then makes sense, for TEM to be significantly increased in response to stimulation and for the process to be attenuated with time. As previously shown by Munro et al., receptor redistribution in response to cytokines is reversible and likely also varies for different cell types ${ }^{28}$. The receptors likely return to their original location and await a subsequent signal, the release of more cytokines. We propose that this process is cyclical. 
Together, our findings suggest that inflammation of the vascular wall leads to redistribution of JAM-A receptors toward endothelial junctions creating "hot spots" that promote lymphocyte binding and facilitate initiation of TEM. Further lymphocyte entry into the endothelial junction requires disrupting tight junctions which are maintained by homophilic JAM-A/JAM-A interactions on adjacent endothelial cells. LFA-1 is likely to play a critical role in this step ${ }^{13}$. We have shown previously that lymphocyte LFA-1 is capable of competing out JAM-A homodimers in the tight junctions leading to disruption of junctional integrity and, thus, facilitating lymphocyte egress further into the junction ${ }^{18}$. In summary, our findings indicate that JAM-A plays an important role in mediating lymphocyte recruitment to the endothelium and subsequent TEM under inflammatory conditions. 


\section{Supplemetary video files}

\section{Supplementary videos online}

Linked at:

\section{http://www.jleukbio.org/content/early/2013/09/25/jlb.0412205/suppl/DC1}

Movie 1: Transendothelial migration of T cells through stimulated HUVEC.

Transendothelial migration of CD4 ${ }^{+}$T cells over TNF- $\alpha /$ IFN- $\gamma$-stimulated HUVEC $(6 \mathrm{~h})$ was recorded using real time video microscopy in $30 \mathrm{~s}$ intervals at $37{ }^{\circ} \mathrm{C}$ and $5 \% \mathrm{CO}_{2}$. Two contiguous image sequences show a transmigrating $T$ cell (marked with $x$ ) at the intercellular junction of a HUVEC cell.

Movie 2: Movie of serial confocal z-sections of a HUVEC monolayer immunostained without permeabilization for ICAM-1 (green) and JAM-A (red) after 6 hour treatment with TNF- $\alpha$ /IFN- $\gamma$. The movie loops from top to bottom ( $0.5 \mu \mathrm{m}$ steps) of the monolayer showing individual ICAM- 1 and JAM-A as well as merged immunostains. ICAM-1 appears diffusely expressed through the HUVEC surface (center and junction), whereas JAM-A is predominantly evident along the junctional regions visible in the lower equatorial z-sections. Notice the change in overlap (yellow) between the ICAM-1 and JAM-A immunostains in the lower z-sections at the junctional regions.

Movie 3: Movie of serial confocal z-sections of a HUVEC monolayer immunostained without permeabilization for ICAM-1 (green) and JAM-A (red) without TNF- $\alpha$ /IFN- $\gamma$ stimulation.

The movie loops from top to bottom ( $0.5 \mu \mathrm{m}$ steps) of the monolayer showing individual ICAM- 1 and JAM-A as well as merged immunostains. Both ICAM-1 and JAM-A appear diffusely distributed on the HUVEC surface from the center (top) to the junctional regions (lower z-sections). 


\section{References}

1. Ozaki H, Ishii K, Horiuchi H, Arai H, Kawamoto T, Okawa K, Iwamatsu A, Kita T. Cutting edge: Combined treatment of tnf-alpha and ifn-gamma causes redistribution of junctional adhesion molecule in human endothelial cells. J Immunol. 1999;163:553-557

2. Martinez-Estrada OM, Manzi L, Tonetti P, Dejana E, Bazzoni G. Opposite effects of tumor necrosis factor and soluble fibronectin on junctional adhesion molecule-a in endothelial cells. American journal of physiology. Lung cellular and molecular physiology. 2005;288:L1081-1088

3. Shaw SK, Ma S, Kim MB, Rao RM, Hartman CU, Froio RM, Yang L, Jones T, Liu Y, Nusrat A, Parkos CA, Luscinskas FW. Coordinated redistribution of leukocyte Ifa-1 and endothelial cell icam-1 accompany neutrophil transmigration. The Journal of experimental medicine. 2004;200:1571-1580

4. Mamdouh Z, Mikhailov A, Muller WA. Transcellular migration of leukocytes is mediated by the endothelial lateral border recycling compartment. The Journal of experimental medicine. 2009;206:2795-2808

5. Springer TA. Adhesion receptors of the immune system. Nature. 1990;346:425-434

6. Springer TA. Traffic signals for lymphocyte recirculation and leukocyte emigration: The multistep paradigm. Cell. 1994;76:301-314

7. Schenkel AR, Mamdouh Z, Muller WA. Locomotion of monocytes on endothelium is a critical step during extravasation. Nature immunology. 2004;5:393-400

8. Dustin ML, Springer TA. Lymphocyte function-associated antigen-1 (Ifa-1) interaction with intercellular adhesion molecule-1 (icam-1) is one of at least three mechanisms for lymphocyte adhesion to cultured endothelial cells. J Cell Biol. 1988;107:321-331

9. Muller WA, Weigl SA, Deng X, Phillips DM. Pecam-1 is required for transendothelial migration of leukocytes. The Journal of experimental medicine. 1993;178:449-460

10. Carman CV, Springer TA. A transmigratory cup in leukocyte diapedesis both through individual vascular endothelial cells and between them. The Journal of cell biology. 2004; $167: 377-388$

11. Dejana E, Corada M, Lampugnani MG. Endothelial cell-to-cell junctions. Faseb J. 1995;9:910-918

12. Bazzoni G, Dejana E. Endothelial cell-to-cell junctions: Molecular organization and role in vascular homeostasis. Physiological reviews. 2004;84:869-901

13. Ostermann G, Weber KS, Zernecke A, Schroder A, Weber C. Jam-1 is a ligand of the beta(2) integrin Ifa-1 involved in transendothelial migration of leukocytes. Nat Immunol. 2002;3:151-158

14. Bazzoni G, Martinez-Estrada OM, Mueller F, Nelboeck P, Schmid G, Bartfai T, Dejana E, Brockhaus M. Homophilic interaction of junctional adhesion molecule. J Biol Chem. 2000;275:30970-30976

15. Naik UP, Naik MU, Eckfeld K, Martin-DeLeon P, Spychala J. Characterization and chromosomal localization of jam-1, a platelet receptor for a stimulatory monoclonal antibody. Journal of cell science. 2001;114:539-547

16. Weber C, Lu CF, Casasnovas JM, Springer TA. Role of alpha I beta 2 integrin avidity in transendothelial chemotaxis of mononuclear cells. J Immunol. 1997;159:3968-3975

17. Weber C, Fraemohs L, Dejana E. The role of junctional adhesion molecules in vascular inflammation. Nat Rev Immunol. 2007;7:467-477

18. Wojcikiewicz EP, Koenen RR, Fraemohs L, Minkiewicz J, Azad H, Weber C, Moy VT. Lfa1 binding destabilizes the jam-a homophilic interaction during leukocyte transmigration. Biophysical journal. 2009;96:285-293

19. Zocchi MR, Ferrero E, Leone BE, Rovere P, Bianchi E, Toninelli E, Pardi R. Cd31/pecam1-driven chemokine-independent transmigration of human $\mathrm{t}$ lymphocytes. European journal of immunology. 1996;26:759-767

20. Schenkel AR, Mamdouh Z, Chen X, Liebman RM, Muller WA. Cd99 plays a major role in the migration of monocytes through endothelial junctions. Nature immunology. 2002;3:143-150

21. Sun J, Paddock C, Shubert J, Zhang HB, Amin K, Newman PJ, Albelda SM. Contributions of the extracellular and cytoplasmic domains of platelet-endothelial cell adhesion molecule-1 (pecam-1/cd31) in regulating cell-cell localization. Journal of cell science. 2000;113 ( Pt 8):1459-1469 
22. Berman ME, Xie Y, Muller WA. Roles of platelet/endothelial cell adhesion molecule-1 (pecam-1, cd31) in natural killer cell transendothelial migration and beta 2 integrin activation. J Immunol. 1996;156:1515-1524

23. Thompson RD, Noble KE, Larbi KY, Dewar A, Duncan GS, Mak TW, Nourshargh S. Platelet-endothelial cell adhesion molecule-1 (pecam-1)-deficient mice demonstrate a transient and cytokine-specific role for pecam-1 in leukocyte migration through the perivascular basement membrane. Blood. 2001;97:1854-1860

24. Vaporciyan AA, DeLisser HM, Yan HC, Mendiguren, II, Thom SR, Jones ML, Ward PA, Albelda SM. Involvement of platelet-endothelial cell adhesion molecule-1 in neutrophil recruitment in vivo. Science. 1993;262:1580-1582

25. Buckley CD, Doyonnas R, Newton JP, Blystone SD, Brown EJ, Watt SM, Simmons DL. Identification of alpha $v$ beta 3 as a heterotypic ligand for cd31/pecam-1. Journal of cell science. 1996;109 ( Pt 2):437-445

26. Dangerfield J, Larbi KY, Huang MT, Dewar A, Nourshargh S. Pecam-1 (cd31) homophilic interaction up-regulates alpha6beta1 on transmigrated neutrophils in vivo and plays a functional role in the ability of alpha6 integrins to mediate leukocyte migration through the perivascular basement membrane. The Journal of experimental medicine. 2002;196:1201-1211

27. Woodfin A, Voisin MB, Imhof BA, Dejana E, Engelhardt B, Nourshargh S. Endothelial cell activation leads to neutrophil transmigration as supported by the sequential roles of icam2, jam-a, and pecam-1. Blood. 2009;113:6246-6257

28. Munro JM, Pober JS, Cotran RS. Tumor necrosis factor and interferon-gamma induce distinct patterns of endothelial activation and associated leukocyte accumulation in skin of papio anubis. The American journal of pathology. 1989;135:121-133

29. Romer LH, McLean NV, Yan HC, Daise M, Sun J, DeLisser HM. Ifn-gamma and tnf-alpha induce redistribution of pecam-1 (cd31) on human endothelial cells. $J$ Immunol. 1995;154:6582-6592

30. Mamdouh Z, Chen X, Pierini LM, Maxfield FR, Muller WA. Targeted recycling of pecam from endothelial surface-connected compartments during diapedesis. Nature. 2003;421:748-753

31. Dejana E. Endothelial cell-cell junctions: Happy together. Nature reviews. 2004;5:261-270

32. Iurlaro M, Demontis F, Corada M, Zanetta L, Drake C, Gariboldi M, Peiro S, Cano A, Navarro P, Cattelino A, Tognin S, Marchisio PC, Dejana E. Ve-cadherin expression and clustering maintain low levels of survivin in endothelial cells. The American journal of pathology. 2004;165:181-189

33. Thomas FC, Sheth B, Eckert JJ, Bazzoni G, Dejana E, Fleming TP. Contribution of jam-1 to epithelial differentiation and tight-junction biogenesis in the mouse preimplantation embryo. Journal of cell science. 2004;117:5599-5608

34. Shaw SK, Perkins BN, Lim YC, Liu Y, Nusrat A, Schnell FJ, Parkos CA, Luscinskas FW. Reduced expression of junctional adhesion molecule and platelet/endothelial cell adhesion molecule-1 (cd31) at human vascular endothelial junctions by cytokines tumor necrosis factor-alpha plus interferon-gamma does not reduce leukocyte transmigration under flow. Am J Pathol. 2001;159:2281-2291

35. Ancuta P, Moses A, Gabuzda D. Transendothelial migration of cd16+ monocytes in response to fractalkine under constitutive and inflammatory conditions. Immunobiology. 2004;209:11-20

36. Mohan K, Ding Z, Hanly J, Issekutz TB. Ifn-gamma-inducible t cell alpha chemoattractant is a potent stimulator of normal human blood $t$ lymphocyte transendothelial migration: Differential regulation by ifn-gamma and tnf-alpha. J Immunol. 2002;168:6420-6428

37. Mohan K, Pinto D, Issekutz TB. Identification of tissue transglutaminase as a novel molecule involved in human cd8+ $\mathrm{t}$ cell transendothelial migration. $\mathrm{J}$ Immunol. 2003;171:3179-3186

38. Szczygiel AM, Brzezinka G, Targosz-Korecka M, Chlopicki S, Szymonski M. Elasticity changes anti-correlate with no production for human endothelial cells stimulated with tnfalpha. Pflugers Arch.463:487-496

39. Targosz-Korecka M, Biedron R, Szczygiel AM, Brzezinka G, Szczerbinski J, Zuk A. Stiffness changes of tumor hep2 cells correlates with the inhibition and release of trailinduced apoptosis pathways. J Mol Recognit.25:299-308

40. Benoit M. Cell adhesion measured by force spectroscopy on living cells. Methods Cell Biol. 2002;68:91-114 
41. Benoit M, Gabriel D, Gerisch G, Gaub HE. Discrete interactions in cell adhesion measured by single-molecule force spectroscopy. Nat Cell Biol. 2000;2:313-317

42. Wojcikiewicz EP, Zhang X, Chen A, Moy VT. Contributions of molecular binding events and cellular compliance to the modulation of leukocyte adhesion. Journal of cell science. 2003;116:2531-2539

43. Abdulreda MH, Faleo G, Molano RD, Lopez-Cabezas M, Molina J, Tan Y, Echeverria OA, Zahr-Akrawi E, Rodriguez-Diaz R, Edlund PK, Leibiger I, Bayer AL, Perez V, Ricordi C, Caicedo A, Pileggi A, Berggren PO. High-resolution, noninvasive longitudinal live imaging of immune responses. Proceedings of the National Academy of Sciences of the United States of America. 2011;108:12863-12868

44. Rodriguez-Diaz R, Abdulreda MH, Formoso AL, Gans I, Ricordi C, Berggren PO, Caicedo A. Innervation patterns of autonomic axons in the human endocrine pancreas. Cell metabolism. 2011;14:45-54

45. Barlow AL, Macleod A, Noppen S, Sanderson J, Guerin CJ. Colocalization analysis in fluorescence micrographs: Verification of a more accurate calculation of pearson's correlation coefficient. Microsc Microanal.16:710-724

46. Hutter J, Bechhoefer J. Calibration of atomic force microscope tips. Rev.Sci. Instrum. 1993;64:1868-1873

47. Zhang X, Wojcikiewicz E, Moy VT. Force spectroscopy of the leukocyte functionassociated antigen-1/intercellular adhesion molecule-1 interaction. Biophysical journal. 2002;83:2270-2279

48. Zhang X, Chen A., Wojcikiewicz EP, Moy VT. Probing ligand-receptor interactions with atomic force microscopy. Protein-Protein Interactions: A Molecular Cloning Manual, Cold Spring Harbor Laboratory Press. 2002:241-254

49. Evans E. Probing the relation between force--lifetime--and chemistry in single molecular bonds. Annu Rev Biophys Biomol Struct. 2001;30:105-128

50. Tees DF, Waugh RE, Hammer DA. A microcantilever device to assess the effect of force on the lifetime of selectin-carbohydrate bonds. Biophysical journal. 2001;80:668-682

51. Zhang X, Chen A, De Leon D, Li H, Noiri E, Moy VT, Goligorsky MS. Atomic force microscopy measurement of leukocyte-endothelial interaction. Am J Physiol Heart Circ Physiol. 2004;286:H359-367

52. Zhang X, Wojcikiewicz EP, Moy VT. Dynamic adhesion of t lymphocytes to endothelial cells revealed by atomic force microscopy. Exp Biol Med (Maywood). 2006;231:13061312

53. Carman CV, Sage PT, Sciuto TE, de la Fuente MA, Geha RS, Ochs HD, Dvorak HF, Dvorak AM, Springer TA. Transcellular diapedesis is initiated by invasive podosomes. Immunity. 2007;26:784-797

54. Szczygiel AM, Brzezinka G, Targosz-Korecka M, Chlopicki S, Szymonski M. Elasticity changes anti-correlate with no production for human endothelial cells stimulated with tnfalpha. Pflugers Archiv : European journal of physiology. 2012;463:487-496

55. Rival Y, Del Maschio A, Rabiet MJ, Dejana E, Duperray A. Inhibition of platelet endothelial cell adhesion molecule- 1 synthesis and leukocyte transmigration in endothelial cells by the combined action of tnf-alpha and ifn-gamma. J Immunol. 1996;157:1233-1241 
In the preceding chapter 2 we were able to demonstrate different, even opposing, roles of JAM-A on atherosclerotic lesion formation in mice specifically deficient for endothelial and leukocytic JAM-A. Thus we showed that endothelial JAM-A displays atherogenic properties by increased availability at the luminal site of endothelial cells under hyperlipidemic and altered shear stress conditions, thereby increasing leukocyte adhesion and transmigration which aggravates atherosclerotic lesion formation. Leukocytic JAM-A played an atheroprotective role, likely by facilitating $\beta_{2}$-integrin internalization. Leukocytes lacking JAM-A showed a defect in de-adhesion expectedly mediated by enhanced integrin activity and availability. This defect in de-adhesion most likely inflicts damage on the endothelial cell lining, which finally led to enhanced atherosclerotic lesion formation. A JAM-A deficiency in all cell-types resulted in no significant changes in plaque formation and composition, leading to the assumption that also other JAM-A expressing cell-types like smooth muscle cells or mast cells also play a role in atherosclerotic lesion formation.

Another important cell-type carrying JAM-A are platelets. Besides their central role in hemostasis, it has been shown that platelets play a key-role in inflammation and atherosclerotic lesion formation. Platelets adhere at early atherosclerotic lesions ${ }^{1}$ and presumably deposit inflammatory chemokines like PF4 and RANTES at the glycosaminoglycans of endothelial cells ${ }^{2}$, thereby triggering leukocyte transmigration and atherosclerotic lesion formation ${ }^{3}$. Recently, it has been demonstrated that platelets lacking JAM-A showed enhanced reactivity as well as inhibited integrin $\alpha_{2 b} \beta_{3}$-mediated outside-in signaling ${ }^{4}$.

In chapter 5, we aimed to further expand our findings regarding a cellspecific role for JAM-A in atherosclerotic lesion formation. We generated a BI6 mouse with ApoE background specifically deficient for platelet JAM-A. As performed in chapter 2, we analyzed lesion formation, composition and stage, also at different time-points of high-fat diet, and we were able to propose molecular mechanisms underlying the observed results. As such, activity and adhesion assays as well as measurement of inflammatory parameter pointed towards a hyperreactive phenotype of platelets deficient for JAM-A. 
Contribution to the manuscript (chapter 5):

Martin Schmitt performed imaging crucially contributing to this study's conclusion. Furthermore, Martin Schmitt wrote part of the manuscript and added substantial improvement. 


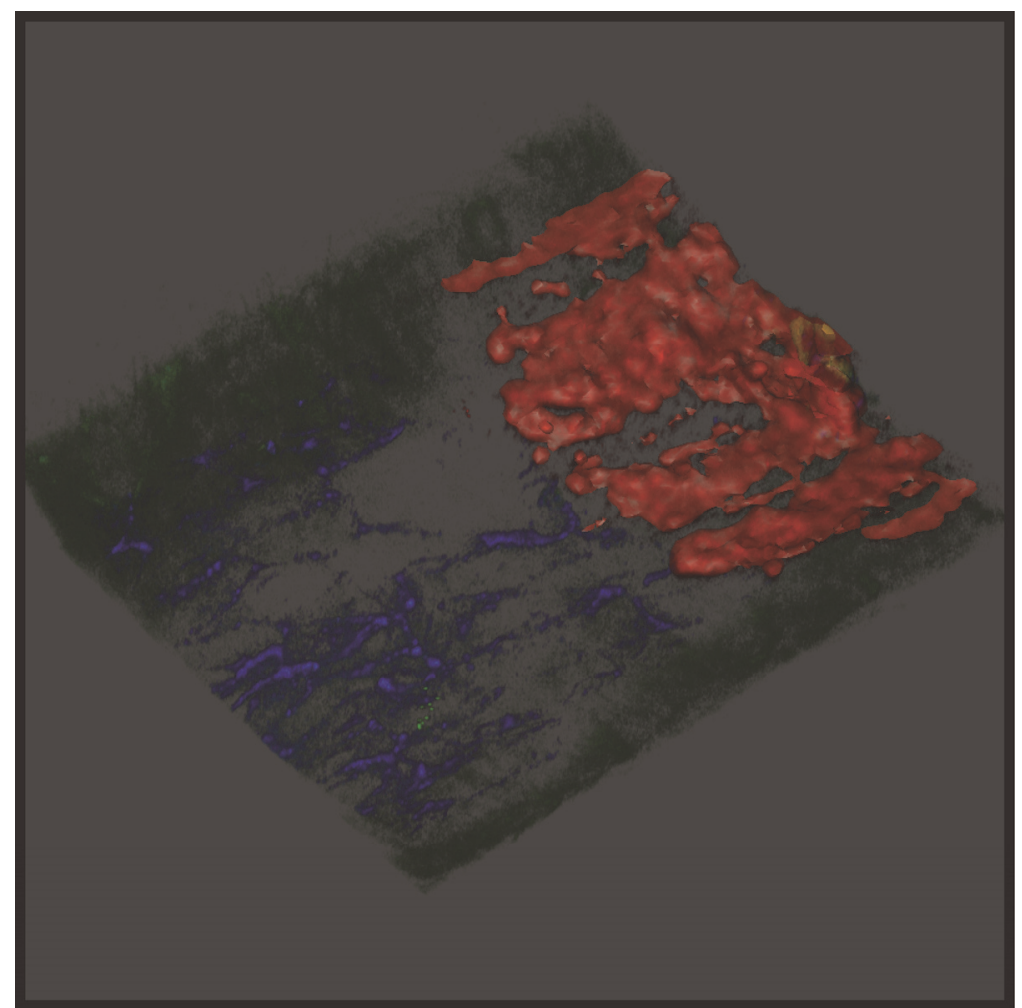

Chapter 5 


\section{Hyperreactivity of junctional adhesion molecule A-deficient platelets accelerates atherosclerosis in mice}

Ela Karshovska*, Zhen Zhao*, Martin M. Schmitt, Xavier Blanchet, Kiril Bidzhekov, Oliver Soehnlein, Philipp von Hundelshausen, Nadine J. Mattheij, Johan W.M. Heemskerk, Thomas A. Koeppel, Andreas Schober, Tilman, M. Hackeng, Christian Weber and Rory R. Koenen

*authors contribute equally 


\section{Abstract}

Background - Besides their essential role in hemostasis, platelets also have functions in inflammation. On platelets, junctional adhesion molecule (JAM-)A, is abundantly expressed. Recently, platelet-JAM-A was identified as an inhibitor of integrin $\alpha_{2 b} \beta_{3}$-mediated outside-in signaling and its absence in platelets resulted in hyperreactivity. In this study, this gain-of-function was specifically exploited to investigate the role of platelet hyperreactivity in plaque development.

Methods and Results - Mice with or without platelet-specific (tr)JAM-Adeficiency were crossed in an apolipoprotein e $\left(\mathrm{Apoe}^{--}\right)$background and fed a high-fat diet (HFD) for 2, 6, and 12 weeks. During flow, trJAM-A ${ }^{-/}$apoe $^{-/-}$ platelets showed increased collagen adhesion and $\alpha_{2 b} \beta_{3}$-integrin expression. After 12 weeks of diet at most, $\operatorname{trJAM}-\mathrm{A}^{-/} \mathrm{Apoe}^{-/-}$mice showed increased plaque formation in the aorta compared with trJAM-A $A^{+++}$Apoe $^{-/}$controls and these differences were most evident at early time points. After 2 weeks of HFD, the plaques of the trJAM- $\mathrm{A}^{-/-} \mathrm{Apoe}^{-/-}$animals showed increased macrophage, $\mathrm{T}$ cell and smooth muscle cell content. Interestingly, the plasma levels of chemokines CCL5 and CXCL4 were increased in the trJAM- ${ }^{-1-}$ Apoe $^{--}$mice and JAM-A-deficient platelets showed increased binding to monocytes and leukocytes. Finally, whole-blood perfusion experiments in vitro and intravital microscopy in vivo revealed increased adhesion of monocytes to the endothelium in blood of trJAM- $\mathrm{A}^{-/-} \mathrm{Apoe}^{-/-}$mice compared to controls.

Conclusions - Deletion of JAM-A causes a gain-of-function in platelets, with lower activation thresholds and increased inflammatory activities. This leads to an increase of plaque formation, particularly in early stages of the disease. 


\section{Introduction}

Blood platelets have an essential function in hemostasis, but also play an important role in immune and inflammatory processes ${ }^{5,6}$. Recent studies have highlighted platelets as key effectors in e.g. sepsis ${ }^{7}$, rheumatoid arthritis, experimental autoimmune encephalomyelitis ${ }^{9}$ and host defense during bacterial infection ${ }^{10}$. In addition, platelets spark vascular inflammatory processes and adhere to atherosclerotic predilection sites preceding plaque formation ${ }^{1}$. Platelets may also form a bridge between leukocytes and the injured or inflamed vessel wall ${ }^{11}$, promoting the extravasation of monocytes and neutrophils ${ }^{12}$ and the response to vascular injury ${ }^{13}$. Accordingly, infusion of activated platelets into hyperlipidemic mice accelerated atherosclerosis in a Pselectin- and CD40 ligand (CD40L)-dependent manner ${ }^{14,15}$.

Junctional adhesion molecule A (JAM-A, F11R) is a member of the immunoglobulin superfamily adhesion molecules and expressed on a large variety of cell types, including platelets, leukocytes and endothelial cells ${ }^{16}$. On leukocytes, it mediates cell migration by regulating integrin recycling and deadhesion ${ }^{17,}{ }^{18}$. On epi- and endothelial cells, JAM-A is a component of the tight junctions and regulates cell layer permeability through homophilic interactions ${ }^{19}$, ${ }^{20}$. Upon inflammatory stimulation of endothelial cells, JAM-A moves out of the intercellular contacts and is exposed on the apical surface, thereby becoming available for the interaction with blood cells ${ }^{21}$. Recently, we demonstrated that JAM-A plays a cell type-specific role in atherosclerotic plaque formation ${ }^{22}$. Whereas JAM-A on leukocytes protected against atherosclerosis, endothelial JAM-A promoted plaque formation by enhanced luminal availability under proatherosclerotic conditions, thus guiding monocytes to sites of plaque development ${ }^{22}$.

Although JAM-A was first identified in platelets ${ }^{23,24}$, its influence on platelet function remained poorly characterized. Earlier studies demonstrated phosphorylation of JAM-A upon platelet activation ${ }^{25}$ and its association with $\alpha_{2 b} \beta_{3}$-integrin ${ }^{26}$, yet no functional consequences for platelet function were reported. Recent work however identified JAM-A as an endogenous inhibitor of platelet function by attenuating c-Src-dependent outside-in signal transduction through $\alpha_{2 b} \beta_{3}$-integrin ${ }^{4,27}$. Deficiency of JAM-A in platelets resulted in increased aggregation in response to some platelet agonists and led to a prothrombotic phenotype in mice ${ }^{4}$.

The importance of platelets in the pathogenesis of atherosclerosis and the gain-of-function phenotype of JAM-A-deficient platelets prompted us to investigate the role of platelet hyperreactivity in the progression of atherosclerosis. Using mice with a platelet-specific deletion of the JAM-A gene, we demonstrate that loss of JAM-A on platelets leads to hyperreactivity and an acceleration of early-phase plaque formation. 


\section{Methods}

\section{Mouse models}

Mice carrying cre-recombinase under the control of the platelet factor 4 (PF4)promoter were a kind gift from Dr. R.C. Skoda, University Hospital Basel ${ }^{28}$ and were backcrossed in an apolipoprotein e (Apoe)-deficient background (C57BI/6). These mice were crossed with JAM-A ${ }^{\text {flox/flox }} \mathrm{Apoe}^{-/-}$mice $^{22}$ to obtain platelet-specific (tr)JAM-A ${ }^{-/-}$Apoe $^{-/-}$mice. Littermates not containing the PF4cre transgene were used as $\operatorname{trJAM}-\mathrm{A}^{+/+} \mathrm{Apoe}^{-/-}$controls. Specific gene deletion of JAM-A was confirmed by FACS and western blot analysis demonstrating

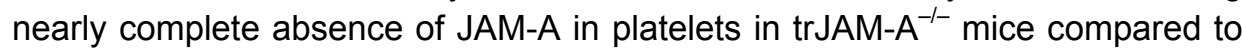
controls.

\section{Blood collection and analysis}

Mice were anesthetized with ketamine $(80 \mathrm{mg} / \mathrm{kg})$ and medetomidine $(0.3$ $\mathrm{mg} / \mathrm{kg}$ ) and blood was retro-orbitally collected into citrate-, EDTA- or hirudincoated tubes for flow cytometry-, cell counts and platelet function assessment (see below). Cell counts and mean platelet volume (MPV) were determined using an automated hematology analyzer (scil Animal Care, Viernheim, Germany).

\section{Plaque formation, quantification and histological analysis of atherosclerosis}

Plaque formation was induced in male/female 6-8-week old mice $(n=7-14)$ by feeding a high-fat diet (HFD, $21 \%$ fat, $19.5 \%$ casein, $0.15 \%$ cholesterol, ssniff, Soest, Germany) for 2, 6 and 12 weeks. Mice were anesthetized as described above and the heart and the whole aorta were excised after whole body in situ perfusion with $4 \%$ buffered formaldehyde (Carl Roth, Karlsruhe, Germany). After overnight fixation and adventitia removal, the aorta was longitudinally opened and stained en face with Oil-Red-O to visualize the lipid deposition. The plaque area was calculated as percentage of the Oil-Red- $\mathrm{O}^{+}$stained area by dividing the whole aortic area. After paraffin-embedding and cutting into 4- $\mu \mathrm{m}$ transverse sections, aortic root samples were assessed for atherosclerotic plaque size after staining with Elastica van Gieson (EVG) (Baacklab, Schwerin, Germany). The plaque area was quantified as percentage of plaque area of all three aortic valves divided to the area of the internal lumen. Adjacent sections were used for evaluating plaque cellular content by immunofluorescence staining for macrophages, $\mathrm{CD}^{+} \mathrm{T}$ cells and smooth muscle cells (SMCs). Briefly, after heat-induced antigen retrieval (Dako, Hamburg, Germany) and blocking of unspecific protein binding (goat- and sheep sera, Sigma Aldrich, St. Louis, MO) aortic root samples were reacted with anti-MAC-2 (Cedarlane Labs, Burlington, Canada), anti-CD3 and anti-aSMA antibodies (both Dako), 
respectively. Nuclei were counterstained with DAPI (Vector Laboratories, Burlingame, CA). For immunofluorescence staining on platelets, cells were isolated as described ${ }^{15}$, fixed with $4 \%$ formaldehyde, permeabilized with saponin (BD Biosciences, Franklin Lakes, NJ) and incubated with anti-CXCL4 and anti-CCL5 antibodies (both R\&D Systems, Minneapolis, MN). Finally, the primary antibodies were detected (visualized) after incubation with DyLight $@$ 488, -550 and $-650-$ conjugated secondary antibodies (all Abcam, Cambridge, UK). Images were recorded with a DM 6000B fluorescence microscope (Leica, Solms, Germany), connected to a monochrome digital camera (DFC 365FX) for the fluorescent images and DFC425C camera for the EVG-stained aortic root pictures. MAC-2-, CD3- and aSMA cells were manually quantified as positive cells per plaque area. Stages of atherosclerotic lesions were determined by evaluation of EVG-stained aortic roots ${ }^{29}$. All animal experiments were approved by local authorities (Regierung von Oberbayern, Munich, Germany) to comply with German animal protection law.

\section{Platelet isolation and activity measurement}

Platelets were isolated and washed by centrifugation as described ${ }^{15}$. Platelet aggregation in response to adenosine diphosphate (ADP), thrombin, or collagen (Loxo $\mathrm{GmbH}$, Dossenheim, Germany) was assessed in mouse whole blood within 2 hours after isolation by multiple electrode aggregometry technology using a Multiplate ${ }^{\circledR}$ platelet analyzer according to manufacturer's instructions (Roche Diagnostics, Mannheim, Germany) ${ }^{30}$.

\section{Thrombus formation on collagen under flow}

Platelet adhesion onto fibrillar collagen under shear flow was performed essentially as described ${ }^{15,31}$. Briefly, mouse blood collected into D-phenylalanylL-prolyl-L-arginine chloromethylketone (PPACK) was perfused over collagen type I-coated coverslips in a transparent parallel-plate perfusion chamber at a shear rate of $1000 \mathrm{~s}^{-1}$ for 4 minutes. To assess $\alpha_{2 b} \beta_{3}$-integrin activation, phosphatidyl serine binding and platelet granule secretion, thrombi formed on the collagen surface were post-stained with fluorescently labeled anti-JON/A PE-conjugated (Emfret, Würzburg, Germany), anti-annexin A5 Alexa Fluor ${ }^{\circledR}$ 647-conjugated (Life Technologies, Carlsbad, CA) and anti-CD62P (P-Selectin) FITC-conjugated (Emfret) antibodies, respectively. Phase contrast and fluorescence images were recorded using an EVOS-FL digital microscope (Life Technologies). Finally, surface area coverage of adherent platelets and fluorescence over multiple microscopic fields was analyzed using Metamorph 5.0.0 software (MDS Analytical Technologies). 


\section{Western blotting}

For immunoblotting, isolated platelets and harvested arteries after whole body perfusion with ice-cold phosphate-buffered saline solution (PBS, Sigma Aldrich) were homogenized as described ${ }^{32}$. Briefly, protein extracts were obtained from homogenates after incubation in lysis buffer containing protease inhibitors and detergents $^{32}$, following centrifugation at $8,000 \mathrm{~g}$ for $1 \mathrm{~min}$. Supernatants were analyzed for immunoblotting. Protein concentrations were determined (Bio-Rad protein assay, Bio-Rad). Equal amounts of protein (10 to $30 \mu \mathrm{g}$ ) were separated by $10 \%$ SDS-PAGE and transferred to nitrocellulose membranes. Ponceau $\mathrm{S}$ staining served as loading control. The membranes were reacted with antimouse JAM-A antibody (AbSerotec, Düsseldorf, Germany) followed by incubation with peroxidase-conjugated secondary antibody (Santa Cruz Biotech, Santa Cruz, CA) and detected with chemiluminescence reagent (Thermo Fischer Scientific, Waltham, MA).

\section{Plasma lipid and chemokine determination}

Concentrations of chemokines CXCL4 and CCL5 were measured in plasma from mice fed a HFD for 2, 6 and 12 weeks using Enzyme-linked immunosorbent assays (ELISA) kits (both R\&D Systems, Minneapolis). Total cholesterol and triglycerides concentrations were analyzed using the enzymatic colorimetric method (Cholesterol-CHOD-PAP kit and Triglycerides-GPO-PAP kit, both Roche Diagnostics) according to the manufacturer's instructions.

\section{Flow cytometry}

Platelets were isolated and washed by centrifugation as described ${ }^{15}$ followed by labeling with anti-JAM-A AlexaFluor®488-conjugated (AbSerotec) and antiCD41 PE-conjugated (BD Pharmingen) antibodies.

For platelet-leukocyte interactions, platelets were isolated as described above and activated with $0.5 \mathrm{U} / \mathrm{ml}$ thrombin. Leukocytes were obtained from the sediments (pellets) after platelet centrifugation and lysis of erythrocytes and added to the activated platelets for $20 \mathrm{~min}$ at $37^{\circ} \mathrm{C}$. Finally, cells were stained with anti-CD41 PE-conjugated (BD Pharmingen), anti-CD11b FITC-conjugated (eBioscience, San Diego, CA) and anti-Ly6G APC-conjugated (eBioscience) antibodies. JAM-A expression on platelets and platelet-leukocytes interactions were measured by flow cytometry (FACSCantoll, BD Biosciences) and analyzed by FlowJo v.10 software (Tree Star Inc., Ashland, OR).

\section{Quantitative real-time PCR}

For RNA analysis, total RNA was isolated from mouse aortae after 2 and 12 weeks after HFD and reverse transcribed into cDNA using Mo-MLV RT (Life Technologies). q-PCR was performed using TaqMan Gene Expression Master 
Mix and real time specific primers (Life Technologies). All reactions were run on a $7900 \mathrm{HT}$ thermocycler (Life Technologies). The expression levels of the target CXCR3 (Mm99999054_s1); IFNY (Mm99999071_m1); TNFa (Mm00443260_g1) were quantified by the ratio to 18S RNA (4319413E) levels.

Platelet and leukocyte adhesion assays

In vitro adhesion assay

SV-40-large T antigen-immortalized mouse endothelial cell (mECs) monolayers were challenged with TNFa $(10 \mathrm{ng} / \mathrm{ml})$ for 4 hours. Freshly isolated leukocytes and platelets were suspended in HBSS containing $0.5 \%$ human albumin and 10 $\mathrm{mM}$ HEPES at $1 \times 10^{6}$ leukocytes $/ \mathrm{ml}$ and $1 \times 10^{8}$ platelets $/ \mathrm{ml}$. The blood cells were then labeled with CD45 Alexa Fluor $® 488$-conjugated (Bio-Rad, Hercules, $\mathrm{CA}$ ) and CD41 PE-conjugated (BD Pharmingen). Immediately prior to perfusion, $0.5 \mathrm{U} / \mathrm{ml}$ thrombin and $1 \mathrm{mM} \mathrm{CaCl} 2$ and $\mathrm{MgCl}_{2}$ was added to the platelets and leukocytes at $37^{\circ} \mathrm{C}$. The endothelial cells were assembled as a lower wall into a custom-made flow chamber and platelets were perfused for $20 \mathrm{~min}$, followed by leukocytes for $5 \mathrm{~min}$ and additional washing of non-adherent cells (all at wall shear stress of $1.5 \mathrm{dyne} / \mathrm{cm}^{2}$ ). Digital pictures were recorded with Leica DM 6000B fluorescence microscope, connected to a digital camera (Leica DFC $365 \mathrm{FX}$ ) and quantified as percentage surface coverage of all cells or platelets/leukocytes over multiple microscopic fields using ImageJ software.

In vivo adhesion assay

Intravital microscopy was performed to visualize leukocyte-endothelium interactions along the atherosclerotic carotid artery. Mice were fed a HFD for 4 weeks, anesthetized as described above and the right jugular vein was cannulated with polyethylene tubing for intravenous administration of antiCD11b eFluor ${ }^{\circledR 650 N C}$-conjugated and anti-Ly6G PE-conjugated antibodies (both eBioscience). The left carotid artery was exposed and the firm arrest of the labeled leukocytes was captured by epifluorescence microscopy (Olympus BX51 10x saline-immersion objective) and recorded using a digital camera (Hamamatsu EM-CCD, C9100) as described ${ }^{33}$. Olympus cell ${ }^{R}$ software (Olympus, Shinjuku, Japan) was used for image acquisition and quantification. Leukocytes were considered adherent when no rolling was observed for more than $30 \mathrm{sec}$.

\section{Two-photon laser scanning microscopy}

For two-photon laser scanning microscopy (TPLSM) mice were fed a HFD for 2 weeks and carotid arteries were carefully harvested, mounted in custom-made perfusion chambers and incubated at physiological pressure of $60 \mathrm{mmHg}$. To detect endothelial JAM-A (eJAM-A), vessels were intraluminally incubated with 


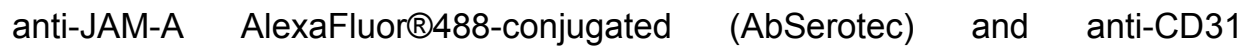
efluor ${ }^{4} 40$ (eBioscience) antibodies for 1 hour ${ }^{22}$. TPLSM imaging was performed using a Leica SP5MP system with a pulsed Ti:Sapphire laser tuned at $800 \mathrm{~nm}$ and a 20×NA1.00 water immersion objectives. Fluorescent signals were captured using 3 photo-multiplier tubes: $400-440 \mathrm{~nm}$ for second-harmonic generation (SHG); 460-490 nm (eFluor® 450) and 510-560 nm (Alexa Fluor $\AA^{488)}$ ). Z-stacks were acquired at $0.1 \mathrm{~Hz}$ over time including two-fold line averaging; FOV $=240 \mu \mathrm{m}^{2}$ (voxel: $0.24 \times 0.24 \times 1.00 \mu \mathrm{m}^{3}$ ). All pictures were processed using LAS software (Leica) and Image Pro v7.0 software (Media Cybernetics, Rockville, MD) ${ }^{22}$.

\section{Statistical Analysis}

Statistical analysis was performed using Prism 6.0 (GraphPad Software, La Jolla, CA). Means were compared between 2 groups by 2-tailed, unpaired or paired Student's t-test, without or with Welch correction or among more than 2 groups by 1-way ANOVA with Tukey's post-test or Kruskal-Wallis test with Dunn's post-test, as indicated. Differences with $\mathrm{P}<0.05$ were considered as statistically significant. Each experiment was independently repeated at least 3 times. 


\section{Results}

\section{Deficiency in platelet-JAM-A results in hyperreactivity}

Previous studies have shown that genetic deletion of JAM-A results in platelet hyperreactivity ${ }^{4}, 27$, yet the functional consequences for the progression of atherosclerosis have not been investigated. For this, we implemented plateletspecific JAM-A knock out (trJAM- $A^{-1}$ ) mice and compared them to their control littermates $\left(\operatorname{trJAM}-\mathrm{A}^{+/+}\right)$. Genetic deletion of JAM-A in platelets of trJAM-A ${ }^{-/}$ mice was confirmed by western blotting (Fig. 1A), immunofluorescence staining (Suppl. Fig. 1A) and flow cytometry (Suppl. Fig. 1B). Importantly, JAM-A expression on leukocytes (Suppl. Fig. 1C), endothelial JAM-A (eJAM-A) (Suppl. Fig. 2) and JAM-A in smooth muscle cells (SMCs) (data not shown) was not affected. This was additionally confirmed by whole vessel homogenates from aorta and A. carotis (Suppl. Fig. 1D). In addition, JAM-A deficiency did neither affect the platelet count, nor the volume or the counts of other blood cell populations (Suppl. Table 1).

To recapitulate the previous observations ${ }^{4,27}$, we examined in vitro platelet aggregation upon activation. JAM-A-deletion resulted in enhanced responsiveness to different agonists such as ADP, thrombin and collagen, (Fig. $1 \mathrm{~B}-\mathrm{F})$, supporting the role of JAM-A as an endogenous platelet function inhibitor.

A

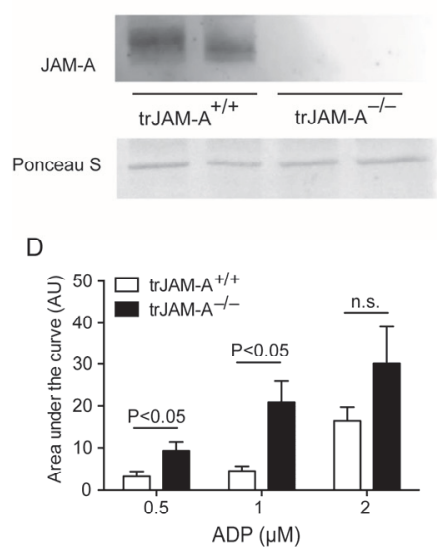

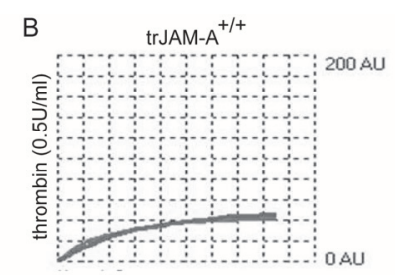
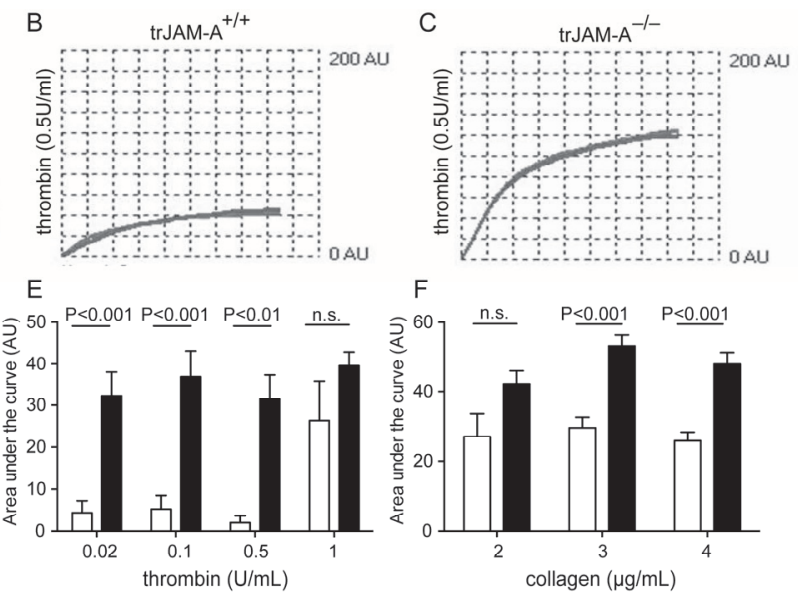

$\mathrm{F}$

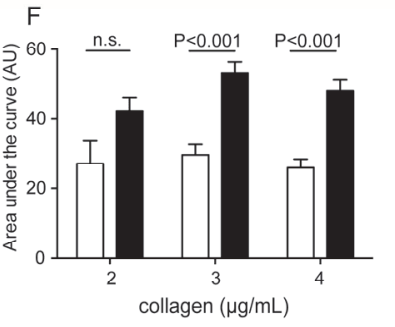

Figure 1: Hyperreactivity of platelets in trJAM-A ${ }^{-1-}$ mice.

Absence of JAM-A on platelets was confirmed by western blotting. Ponceau $S$ served as a loading control (A). Representative images of thrombin activation $(0.5 \mathrm{U} / \mathrm{mL})$ in $\operatorname{trJAM}-\mathrm{A}^{+++}(B)$ and $\operatorname{trJAM}-\mathrm{A}^{-1-}$ (C) platelets are shown. Aggregation of trJAM- $\mathrm{A}^{+/+}$and $\operatorname{trJAM}-\mathrm{A}^{-/-}$platelets by ADP (D), thrombin $(E)$ and collagen $(F)$ are depicted in aggregation units $(A U)$. Data represent mean \pm SEM $(n=8-15)$ and all $P$ values were calculated by ANOVA with Bonferroni's post test. 


\section{Absence of JAM-A promotes thrombus formation}

As JAM-A-deficient mice showed a prothrombotic phenotype ${ }^{4}$, blood from trJAM-A ${ }^{-/}$Apoe $^{-/}$and trJAM-A ${ }^{+/+}$Apoe $^{-/-}$mice was compared to determine the specific role of JAM-A on platelet in flow-dependent thrombus formation on a thrombogenic surface. Perfusion at high shear rates over fibrillar collagen induced the formation of platelet aggregates, which was markedly enhanced for trJAM-A ${ }^{-1-}$ Apoe $^{-l-}$ platelets (Fig. 2A,D,G). In addition, post-staining with the JON/A antibody, specific for the activated conformation of $\alpha_{2 b} \beta_{3}$-integrin, showed increased coverage of activated $\alpha_{2 b} \beta_{3}$-integrin-carrying platelets from trJAM-A ${ }^{-/}$Apoe $^{-/-}$mice (Fig. 2B,E,H). Remarkably, JAM-A ${ }^{-/-}$platelets revealed constant JON/A signal throughout the cell-aggregates, whereas JAM-A ${ }^{+/+}$ platelets only showed JON/A staining at the aggregates' border. Under the same conditions, little procoagulant surface (annexin A5 binding) was observed and no differences were present between platelets from $\operatorname{trJAM}-\mathrm{A}^{-/} \mathrm{Apoe}^{-/-}$mice and controls (Fig. $2 \mathrm{C}, \mathrm{F}, \mathrm{I})$. Taken together, these results suggest that genetic ablation of JAM-A on platelets results in increased platelet reactivity accompanied with enhanced integrin activation.

\section{Platelet-specific JAM-A-deficiency accelerates early-stage atherosclerosis}

To investigate the role of JAM-A on platelets during the progression of atherosclerosis, trJAM-A ${ }^{+/+}$Apoe $^{-/-}$and trJAM-A ${ }^{-/-}$Apoe $^{-/-}$mice were fed a HFD for 2, 6 and 12 weeks. Of note, in early stages of atherosclerosis (2 weeks HFD) platelet JAM-A deficiency resulted in a significantly increased lesion area in the aortic root and in the whole aorta (Fig. 3A,B,C,F). At an intermediate time point (6 weeks HFD), whole-aortic plaque area was still significantly increased in $\operatorname{trJAM}-\mathrm{A}^{-/} \mathrm{Apoe}^{-/-}$mice compared with controls (Fig. 3D), whereas an increased plaque area was no longer observed in the aortic roots (Fig. 3G). Similar results were obtained after 12 weeks HFD, where a lack of JAM-A on platelets led to in increased lesional area only in the whole aorta (Fig. 3A,E), but not in the aortic root (Fig. 3B,H). No differences were detected in the platelet count, the size, or in other blood cell populations at any time point during HFD (Suppl. Table 1). In addition, no significant changes were detected in plasma levels of cholesterol or triglycerides in absence of JAM-A on platelets during atherosclerosis development (Suppl. Table 2). These observations strongly suggest an atheroprotective role of platelet JAM-A, particularly in early stages of atherosclerosis. The vascular expression of JAM-A was unaffected at this time point (Suppl. Fig. 2). 

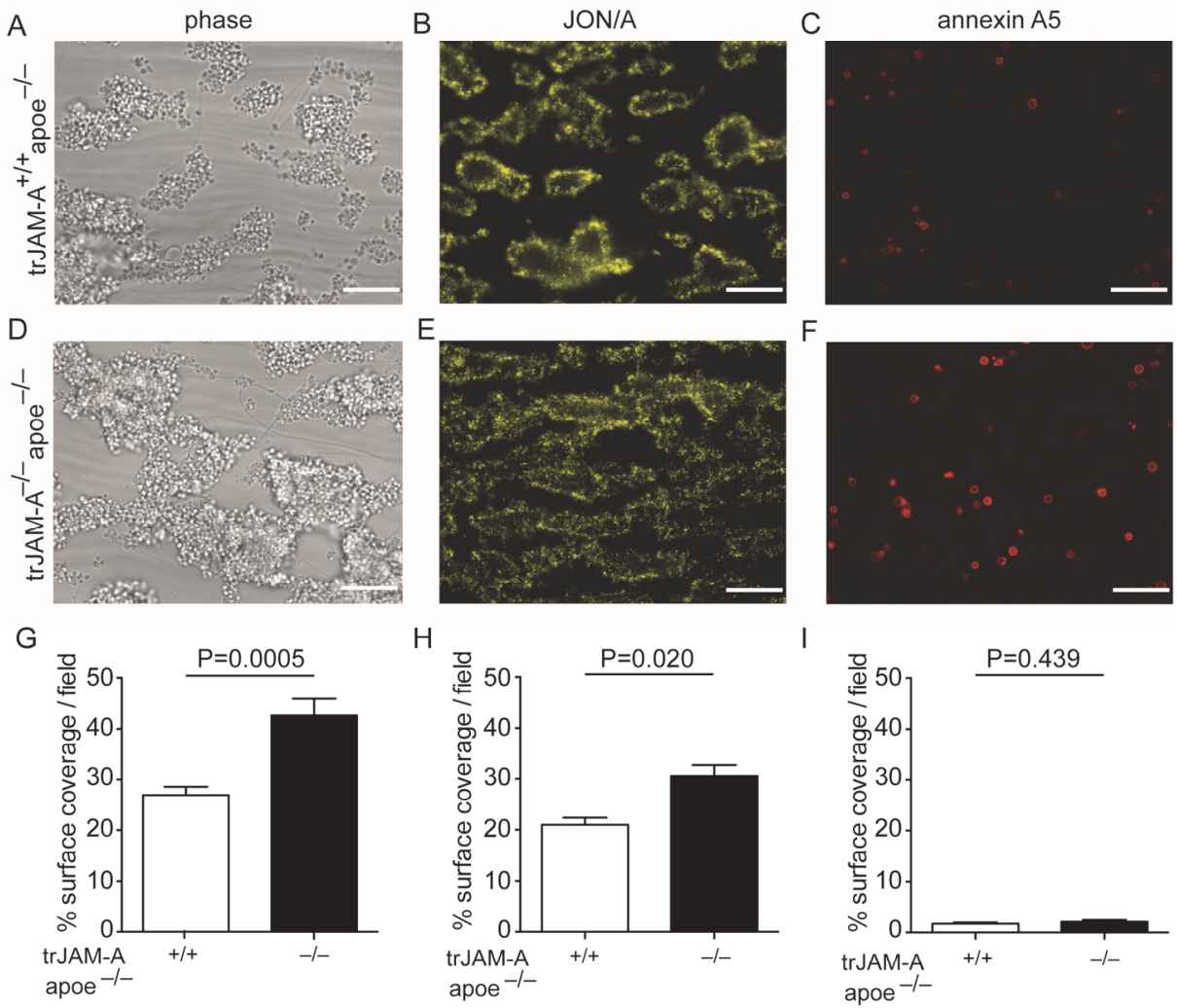

Figure 2: Platelet aggregation on collagen under flow conditions.

Whole blood from trJAM-A ${ }^{+/+}$Apoe $^{-/-}(\mathbf{A}-\mathbf{C})$ and trJAM-A ${ }^{-/-}$Apoe $^{-/-}$(D-F) mice was perfused over collagen type I and platelet aggregation or fluorescence was quantified as $\%$ surface area coverage per analyzed field (G-I). Expression of activated $\alpha_{2 b} \beta_{3}$-integrin or negatively charged phospholipids was quantified after staining with JON/A $(\mathbf{B}, \mathbf{E})$ or anti-annexin A5 antibodies $(\mathbf{C}, \mathbf{F})$. Scale bar= 20 $\mu \mathrm{m}$. Data represent mean \pm SEM $(n=6-8)$ and all $P$ values were calculated by Student's t-test.

\section{Absence of JAM-A on platelets accelerates lesional infiltration of mononuclear cells}

Quantification of plaque composition in the aortic root revealed that the lesional MAC- $2^{+}$macrophage content in early stages ( 2 weeks HFD) was significantly increased in trJAM- $\mathrm{A}^{-/-}$Apoe $^{-/-}$mice, compared with control littermates (Fig. $4 A, D)$. In contrast, at intermediate (6 weeks HFD) (data not shown) or advanced time points (12 weeks HFD), the macrophage content did not differ in $\operatorname{trJAM-A^{-/-}}$ Apoe $^{-/-}$mice versus trJAM-A ${ }^{+/+}$Apoe $^{-/-}$controls (Fig. 4A,G). Of note, absence of platelet JAM-A markedly augmented infiltration of the $\mathrm{CD}^{+}$T-cells in early stages (Fig. 4B,E), whereas trJAM-A-deletion did not influence $T$ cell content at intermediate (data not shown) and in late time points (Fig. 4B,H). Moreover, as 
A
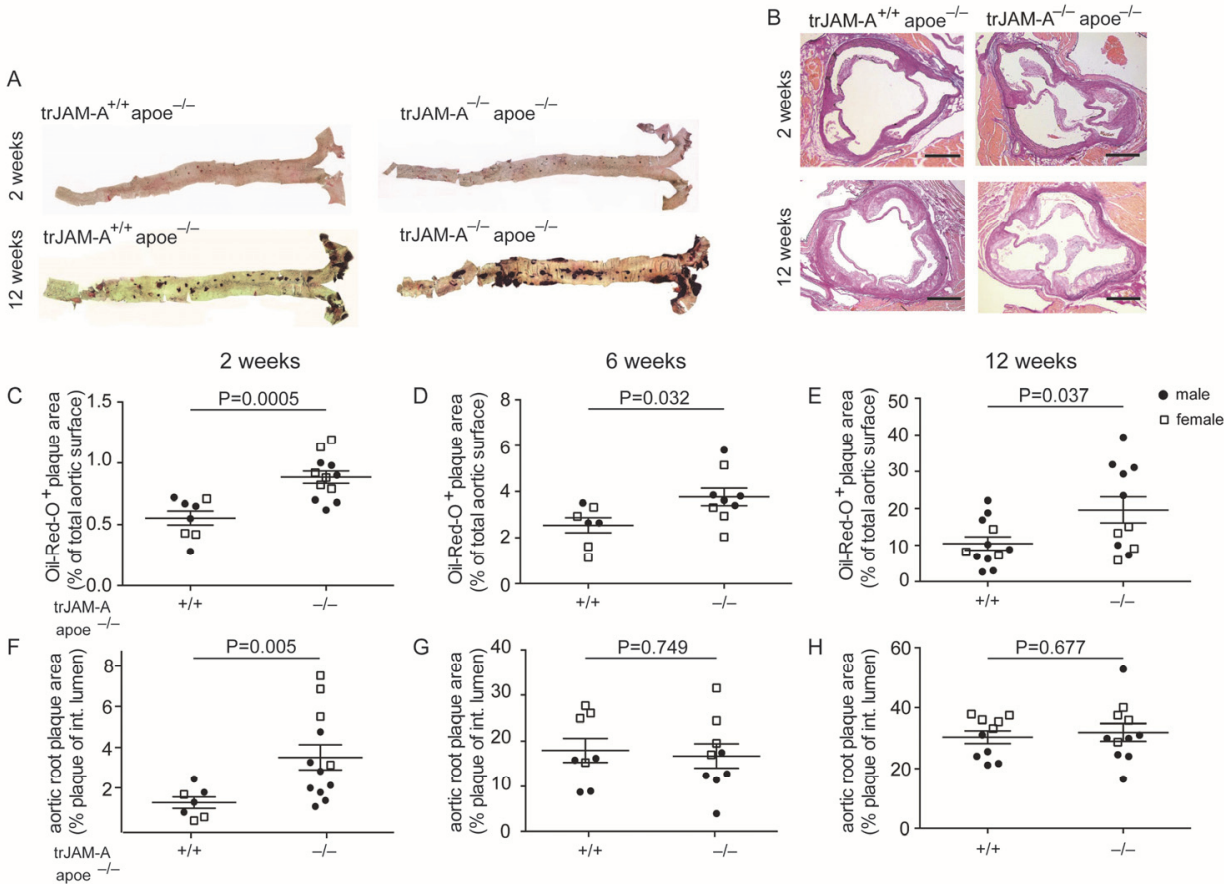

Figure 3: Specific role of JAM-A on platelets during atherogenesis.

$\operatorname{trJAM}-\mathrm{A}^{+/+} \mathrm{Apoe}^{-/-}$and trJAM-A ${ }^{-/} \mathrm{Apoe}^{-/-}$mice were fed a high-fat diet (HFD) for 2 weeks (A-C, F), 6 weeks $(\mathbf{D}, \mathbf{G})$ and 12 weeks $(\mathbf{A}, \mathbf{B}, \mathbf{E}, \mathbf{H})$, as indicated. Representative pictures display the atherosclerotic areas in aortic roots $(\mathbf{A})$ and in whole aortae $(\mathbf{B})$ of $\operatorname{trJAM}-\mathrm{A}^{+/+} \mathrm{Apoe}^{-/-}$and $\operatorname{trJAM}-\mathrm{A}^{-1-}$ Apoe $^{-l-}$ mice after 2 weeks and 12 weeks HFD, as indicated. Scale bar $=500 \mu m$. Lesional areas were quantified in the whole aorta after Oil-Red-O staining (B-E) and in the aortic roots after EVGstaining $(\mathbf{A}, \mathbf{F}-\mathbf{H})$. Data represent mean \pm SEM $(n=7-12)$ and all $P$ values were calculated by Student's t-test.

compared to control mice, platelet JAM-A-deficiency strongly increased $\alpha-S M A^{+}$ smooth muscle cell (SMC) content at the early time point (Fig. 4C,F) and neither had effect on SMC at intermediate (data not shown) nor at late time points (Fig. $4 \mathrm{C}, \mathrm{I})$. In line with these findings, an evaluation of the plaque phenotype in aortic roots revealed that JAM-A deficiency on platelets resulted in more advanced plaque phenotypes, compared to controls (Fig. 4M).

In addition, investigations on mRNA level in atherosclerotic aortae in mice fed for 2 and 12 weeks HFD showed that deletion of JAM-A on platelets significantly increased the aortic expression of chemokine receptor CXCR3 (Fig. $4 \mathrm{~J}$ ), a marker for helper and effector $\mathrm{T}$ cells and of the inflammatory cytokines IFNy (Fig. 4K) and TNFa (Fig. 4L), after 2 weeks but not after 12 weeks of HFD. Thus, platelets may differentially modulate the inflammatory lesion phenotype and the atherosclerotic plaque stage. 

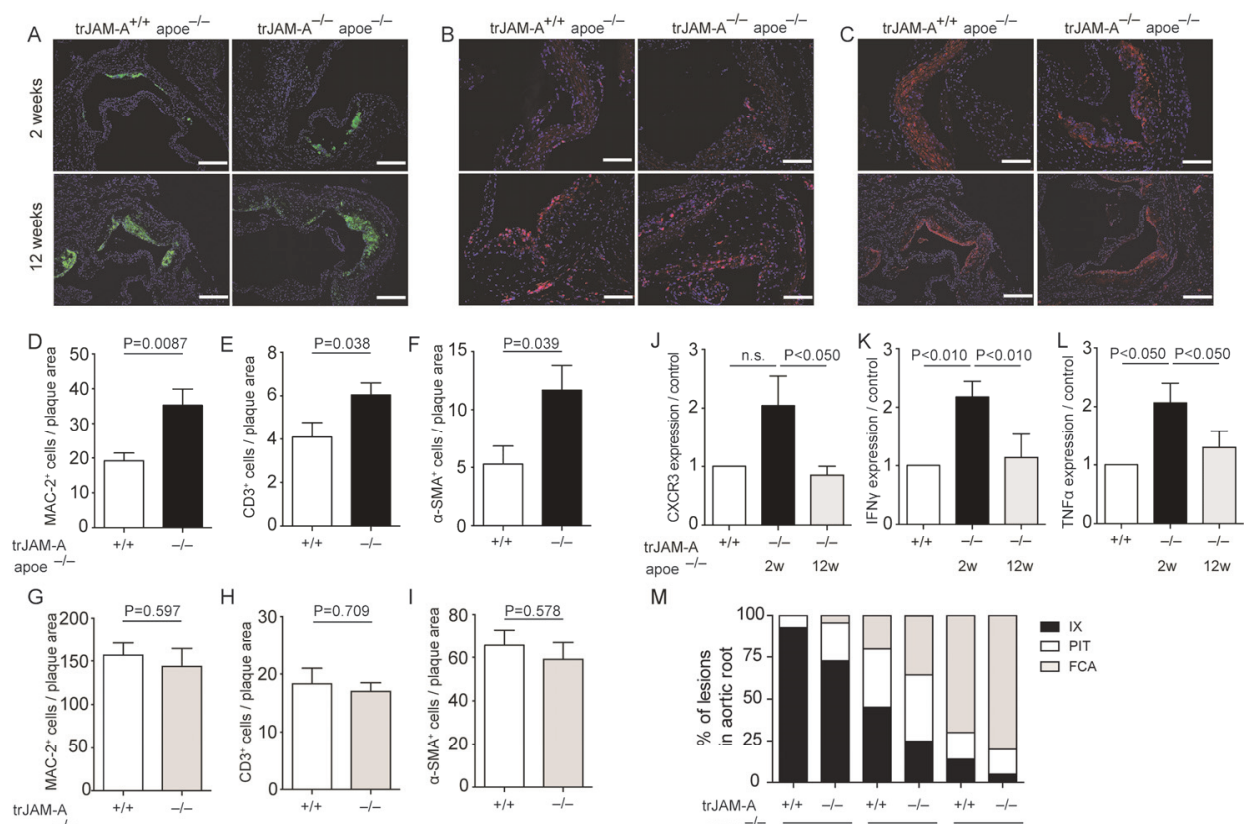

M

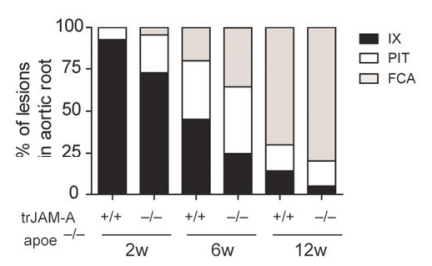

Figure 4: Atherosclerotic lesion phenotype in trJAM-A $\mathrm{A}^{-1-} \mathrm{Apoe}^{-1-}$ mice.

Representative pictures of MAC-2 (A, green), CD3 (B, red) and aSMA (C, red) -stained aortic roots, 2 weeks (upper panel) and 12 weeks (lower panel) from $\operatorname{trJAM}-\mathrm{A}^{+/+} \mathrm{Apoe}^{-/-}$and $\operatorname{trJAM}-\mathrm{A}^{-1-} \mathrm{Apoe}^{-{ }^{-}}$ mice, as indicated. Nuclei were stained with DAPI (blue). Scale bar $=200 \mu \mathrm{m}(\mathbf{A}, \mathbf{C})$, scale bar $=100 \mu \mathrm{m}$ (B). The plaque content of MAC-2 ${ }^{+}$macrophages $(\mathbf{D}, \mathbf{G}), \mathrm{CD}^{+} \mathrm{T}$ cells $(\mathrm{E}, \mathrm{H})$ and $\mathrm{SMCs}(\mathbf{F}, \mathbf{I})$ in aortic root lesions was quantified after 2 weeks (D-F) and 12 weeks HFD (G-I). cDNA expression of CXCR3 (J), IFN- $\gamma(\mathbf{K})$ and TNF- $\alpha(\mathbf{L})$ in whole aorta from trJAM-A $A^{+/+}$Apoe $^{-/-}$mice and trJAM-A ${ }^{-/-}$ $\mathrm{Apoe}^{-/-}$mice after 2 weeks and 12 weeks HFD is expressed as ratio between target gene expression and 18S RNA. The lesions were phenotypically characterized according to stage (M). IX: intimal xanthoma, PIT: pathologic intimal thickening, FCA: fibrous cap atheroma. Data represent mean \pm SEM $(n=7-12)$ and $P$ values were calculated by Student's t-test (D-I) or ANOVA with Tukey's post test (J-L).

\section{Deficiency of JAM-A leads to increased release of chemokines from platelets}

Platelets store many inflammatory proteins in their a-granules and they can release chemokines e.g. platelet factor-4 (PF4, CXCL4) and RANTES (CCL5) upon activation, leading to increased recruitment of mononuclear cells to the inflamed vessel wall ${ }^{3,34}$. Therefore, we investigated whether the deletion of platelet JAM-A might have an influence on the secretion of chemokines during the course of atherosclerosis. Interestingly, CXCL4 and CCL5 immunofluorescence intensities were reduced in platelets isolated from trJAM$\mathrm{A}^{-/-} \mathrm{Apoe}^{-/-}$mice compared with those from trJAM- $\mathrm{A}^{++}$Apoe $^{-/}$mice after 12 weeks and 2 weeks HFD, respectively (Fig. 5A,B). In addition, absence of JAM- 
A on platelets incrementally increased the levels of circulating CXCL4 after 2, 6 and 12 weeks of HFD (Fig. 5C). Similarly, CCL5 levels were markedly.
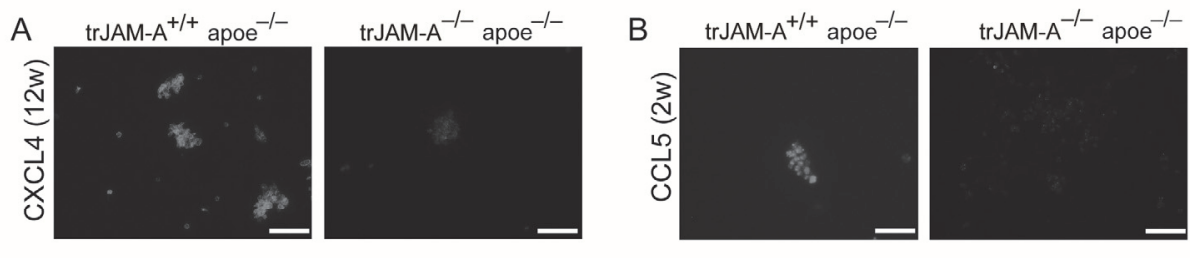

C

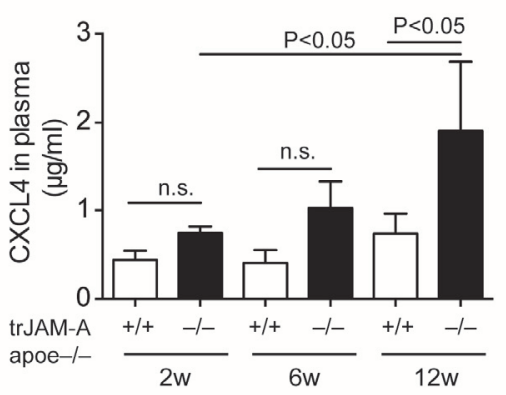

D

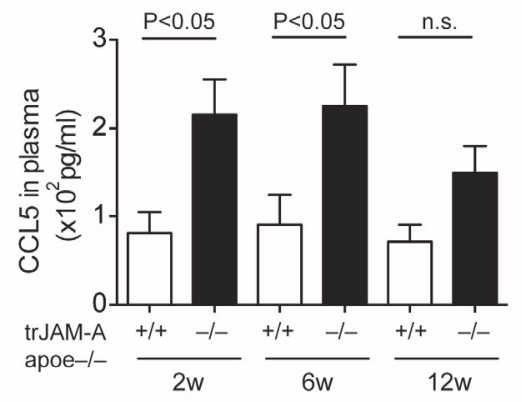

E

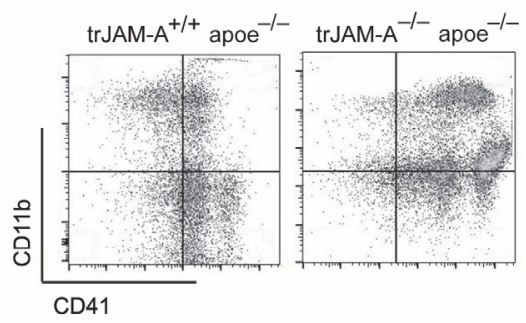

G
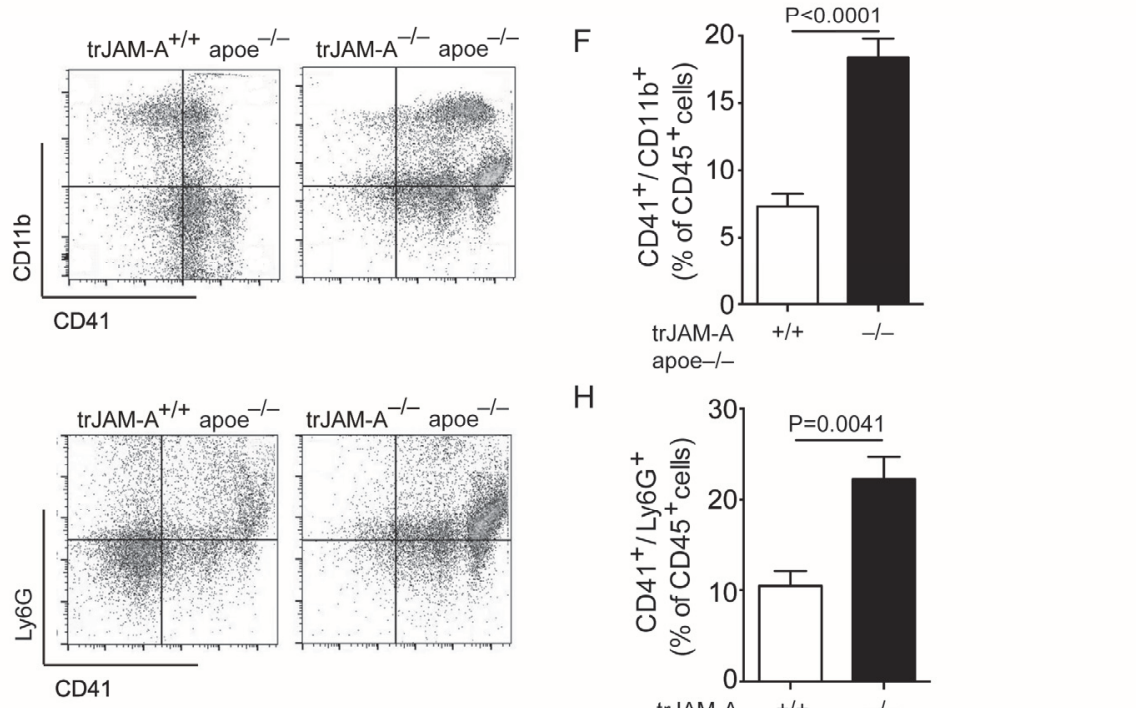

$\mathrm{H}$

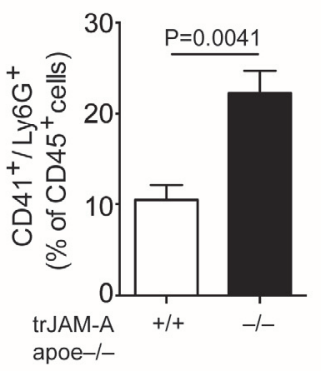

Figure 5: Role of trJAM-A in platelet release and platelet-leukocyte interactions. Representative images of CXCL4 (A) and CCL5 (B) staining in platelets after 12 weeks (A) and 2 weeks HFD (B). Scale bar=20 $\mu \mathrm{m}$. Chemokine levels of CXCL4 (C) and CCL5 (D) in plasma from trJAM-A ${ }^{+/+}$Apoe $^{-/-}$and trJAM-A ${ }^{-/}$Apoe $^{-/-}$mice fed a HFD for 2 weeks, 6 weeks and 12 weeks and without HFD (w/o HFD). Thrombin-activated platelets and leukocytes were incubated and plateletmonocytes aggregates $\left(\mathrm{CD} 41^{+} / \mathrm{CD} 11 \mathrm{~b}^{+}\right) \quad(\mathbf{E}, \mathbf{F})$ and platelet-neutrophil $\left(\mathrm{CD} 41^{+} / \mathrm{Ly} 6 \mathrm{G}^{+}\right) \quad(\mathbf{G}, \mathbf{H})$ complexes were analyzed by flow cytometry as a percentage of all CD45+ cells. Data represent mean \pm SEM $(n=7-14)$ and all $P$ values were calculated by by ANOVA with Bonferroni's post test $(\mathbf{B}, \mathbf{D})$ or Student's t-test $(\mathbf{F}, \mathbf{H})$. 
enhanced in plasma from trJAM- $\mathrm{A}^{-1-} \mathrm{Apoe}^{-/-}$mice compared to controls in the early and intermediate time points of the HFD (Fig.5D), indicative of increased chemokine release by JAM-A-deficient platelets.

\section{JAM-A-deficient platelets show an increased interaction with leukocytes}

Activated platelets have been described to form complexes with leukocytes ${ }^{14,35}$, which might be relevant during acute coronary events ${ }^{36,37}$. To investigate whether JAM-A-deficiency might lead to increased interactions with leukocytes, activated platelets isolated from trJAM-A ${ }^{-1-} \mathrm{Apoe}^{-/-}$mice were incubated with leukocytes. Indeed, JAM-A-deficient platelets formed significantly more plateletmonocyte (Fig.5E,F) and platelet-neutrophil (Fig. 5G,H) aggregation than platelets from trJAM-A ${ }^{+/+}$Apoe $^{-/-}$mice, suggesting that JAM-A-deficient platelets might more effectively augment monocyte recruitment to sites of endothelial inflammation.

\section{Leukocyte adhesion is enhanced in the absence of JAM-A on platelets}

Platelets are able to form a bridge between monocytes and endothelial cells during inflammation ${ }^{11}$. To assess the contribution of JAM-A to platelet and leukocyte adhesion to endothelial cells, we performed both in vitro and in vivo assays. Thrombin-activated platelets from $\operatorname{trJAM}-\mathrm{A}^{--} \mathrm{Apoe}^{-/-}$mice were perfused over mouse endothelial monolayers challenged with TNF- $\alpha$, followed by perfusion of activated leukocytes from the same mouse genotype. A significantly increased cell surface coverage with both platelets and leukocytes (Fig. 6A,B left), only platelets (Fig. 6A,B middle) or leukocytes adherent on the platelets (Fig. 6A,B right) was observed in trJAM-A ${ }^{-1-} \mathrm{Apoe}^{-/}$mice compared with the control group.

In addition, intravital microscopy performed along the atherosclerotic $A$. carotis supported these observations. Flow-resistant monocyte-endothelium interactions in trJAM- $\mathrm{A}^{--} \mathrm{Apoe}^{-/}$mice were significantly more pronounced than in trJAM-A ${ }^{+/+} \mathrm{Apoe}^{-/-}$mice (Fig. 6C,D left), whereas neutrophil adhesion in trJAM- ${ }^{-1-}$ mice showed a non-significant tendency to an increase (Fig. 6D right). These results indicate that platelet hyperreactivity due to JAM-Adeficiency might result in increased platelet-monocyte interactions which in turn facilitates monocyte recruitment to the vessel wall during atherogenesis. 


\section{CHAPTER 5}

A
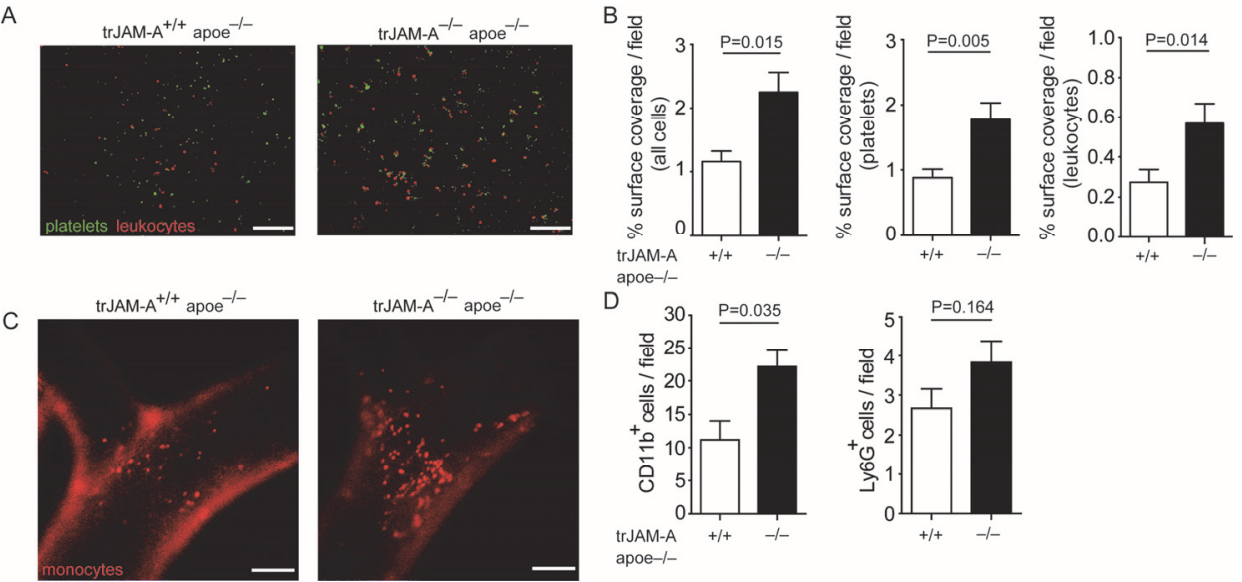

$$
\text { apoe-l- }
$$

D $30 \quad \mathrm{P}=0.035$
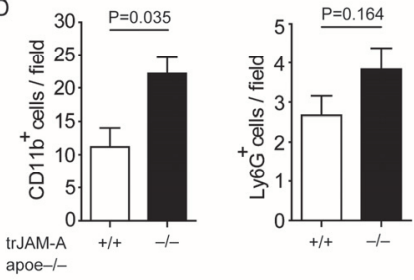

Figure 6: Role of JAM-A on platelets in leukocyte recruitment.

Representative images displaying adherent platelets (green) and leukocytes (red) in vitro (A) and of adherent monocytes (red) in vivo (C) are shown. Scale bar=100 $\mu \mathrm{m}(\mathbf{A}, \mathbf{C})$. Adherent $\mathrm{CD} 45^{+}$ leukocytes (B, right), $\mathrm{CD} 41^{+}$platelets (B, middle) or platelets and leukocytes aggregates (B, left panel) were analyzed on TNFa-activated mECs as cell surface coverage (\%) in the presence or absence of JAM-A on platelets. Firm arrest of $C D 11 b^{+}$monocytes (D, left) and $\mathrm{Ly} 6 \mathrm{G}^{+}$neutrophils (D, right) was assessed in atherosclerotic $A$. carotis in vivo using intravital microscopy and presented as number of adherent cells per visual field. Data represent mean \pm SEM $(n=6)$ and all $P$ values were calculated by Student's t-test. 


\section{Discussion}

It is well established that platelets play a decisive role in the clinical precipitation and recurrence of cardiovascular disease (CVD), and antiplatelet drugs are widely used in the after-care and prevention of individuals who suffered, or are at risk of, a cardiovascular event ${ }^{38}$. However, it is less known that platelets can also initiate and propagate vascular inflammation, which may ultimately lead to the development of atherosclerotic plaques ${ }^{5,6}$. In both cases, platelet hyperreactivity might contribute to an increased risk of CVD, by initiating endothelial dysfunction and propagating vascular inflammation, and through lower aggregation thresholds, aiding to the occurrence or recurrence of ischemic events due to vascular occlusion. Increased platelet reactivity in combination with resistance to antiplatelet therapy is known to pose an enhanced risk for CVD in patients with e.g. diabetes or hypertension ${ }^{39,40}$. In this respect, an increase of both the inflammatory as well as the hemostatic functions of platelets might play an underlying role, but experimental evidence for this notion is scarce.

Deficiency of JAM-A was shown to increase the response of platelets to various agonists in recent studies by Naik and coworkers ${ }^{4,27}$. Additionally, lack of trJAM-A led to shortened bleeding times and increased platelet aggregation in response to collagen, ADP and PAR-4 agonists, without leading to increased activation of $\alpha_{2 b} \beta_{3}$-integrin. Our findings support these observations and we have also demonstrated increased adhesiveness and aggregation of JAM-Adeficient platelets to immobilized collagen under flow. In addition, unlike negatively charged phospholipids, active $\alpha_{2 b} \beta_{3}$-integrin was abundantly expressed on these shear-resistant platelet aggregates from both trJAM- $A^{-/}$ $\mathrm{Apoe}^{-/-}$and trJAM-A ${ }^{+/+} \mathrm{Apoe}^{-/-}$mice, although platelets from trJAM-A ${ }^{-/-} \mathrm{Apoe}^{-/-}$ mice did show more active $\alpha_{2 b} \beta_{3}$-integrin staining, rather due to a higher surface coverage than to higher integrin activity on an individual platelet. This appears to be in concordance with the previously postulated notion that JAM-Adeficiency does not influence $\alpha_{2 b} \beta_{3}$-integrin activation ${ }^{27}$.

The current mechanistic model of how JAM-A regulates platelet activation is that tyrosine-phosphorylated JAM-A is associated with $\alpha_{2 b} \beta_{3^{-}}$ integrin in resting platelets ${ }^{27}$. In this state, $\alpha_{2 b} \beta_{3}$-integrin is bound to inactive, tyrosine-phosphorylated c-Src. Phosphorylated JAM-A was found to recruit $\mathrm{CSK}$, an inhibitor of c-Src to the $\alpha_{2 b} \beta_{3}$-integrin-c-Src complex, thereby maintaining $\mathrm{c}-\mathrm{Src}$ (and $\alpha_{2 b} \beta_{3}$ ) in an inactive state. Upon platelet activation, JAMA is rapidly dephosphorylated causing CSK and JAM-A to dissociate from $\alpha_{2 b} \beta_{3}$, enabling c-Src-mediated $\alpha_{2 b} \beta_{3}$-integrin activation. Because JAM-dissociation from $\alpha_{2 b} \beta_{3}$ was observed both after agonist-induced inside-out signaling as well as ligand-induced outside-in signaling, it is unclear whether the regulatory function of JAM-A is restricted to the attenuation of outside-in signaling. Since 
platelet activation involves an intricate sequence of instantaneous enzymatic steps along with autocrine communication, the resulting cascade of events ultimately leads to a variety of responses e.g. aggregation, shape change, integrin activation and vesicle release. Thus, it is challenging to pinpoint the regulatory effects of JAM-A solely on outside-in signaling. As a whole, the findings by Naik et al., combined with those in our study highlight JAM-A as an $\alpha_{2 b} \beta_{3}$ integrin-associated negative regulator of platelet activation and aggregation.

In trJAM-A ${ }^{-/}$Apoe $^{-/}$mice, we found decreased granular staining of the chemokines CCL5 and CXCL4 in platelets and increased plasma levels of these chemokines during the course of a high-fat diet. Thus, we postulate that the decreased activation threshold of JAM-A-deficient platelets results in a continuous low-level release of $\alpha$-granule contents, leading to increased circulating chemokine concentrations. These chemokines might also be more effectively deposited onto the vessel walls of the $\operatorname{trJAM}-\mathrm{A}^{-/} \mathrm{Apoe}^{-/}$mice, resulting in increased recruitment of mononuclear cells to developing plaques. This might explain the increased content of $T$ cells, macrophages and the elevated pro-inflammatory cytokine expression levels, particularly in the lesions of $\operatorname{trJAM}-\mathrm{A}^{-/-} \mathrm{Apoe}^{-/-}$mice at early time-points. Previous studies have highlighted a role for platelets and their secretion products particularly in early phases of plaque development ${ }^{1,41}$. In this respect, it is interesting that the effects of platelet-specific JAM-A-deficiency declined at later time points during the high-fat diet, particularly in the aortic root. This also supports the notion that platelets mainly propel early-phase plaque development, which preferentially occurs under conditions of disturbed flow, as occurring in the aorta near the heart valves. As plaque progression occurs, other determinants might dominate and platelet-specific effects become secondary.

Activated platelets avidly bind to leukocytes and uncontrolled platelet activation might lead to increased levels of circulating platelet-leukocyte complexes e.g. during acute cardiovascular events ${ }^{36,37}$. Since platelets have been shown to actively recruit mononuclear cells to the vessel wall ${ }^{11,42,43}$, it is conceivable that increased platelet-leukocyte aggregation in $\operatorname{trJAM}-\mathrm{A}^{-/-} \mathrm{Apoe}^{-/-}$ mice might also contribute to plaque development.

Taken together, JAM-A plays a crucial role in controlling platelet reactivity. Uncontrolled platelet reactivity might lead to continuous low-level activation of circulating platelets, due to a decreased stimulation threshold. Since activated platelets exacerbate atherosclerosis, hyperreactive JAM-A-deficient platelets might both initiate and accelerate early plaque formation. This study thus highlights the detrimental role of activated platelets in preclinical phases of CVD and adds another fundamental facet to the role of JAM-A in vascular disease. 


\section{Supplementary Figures}
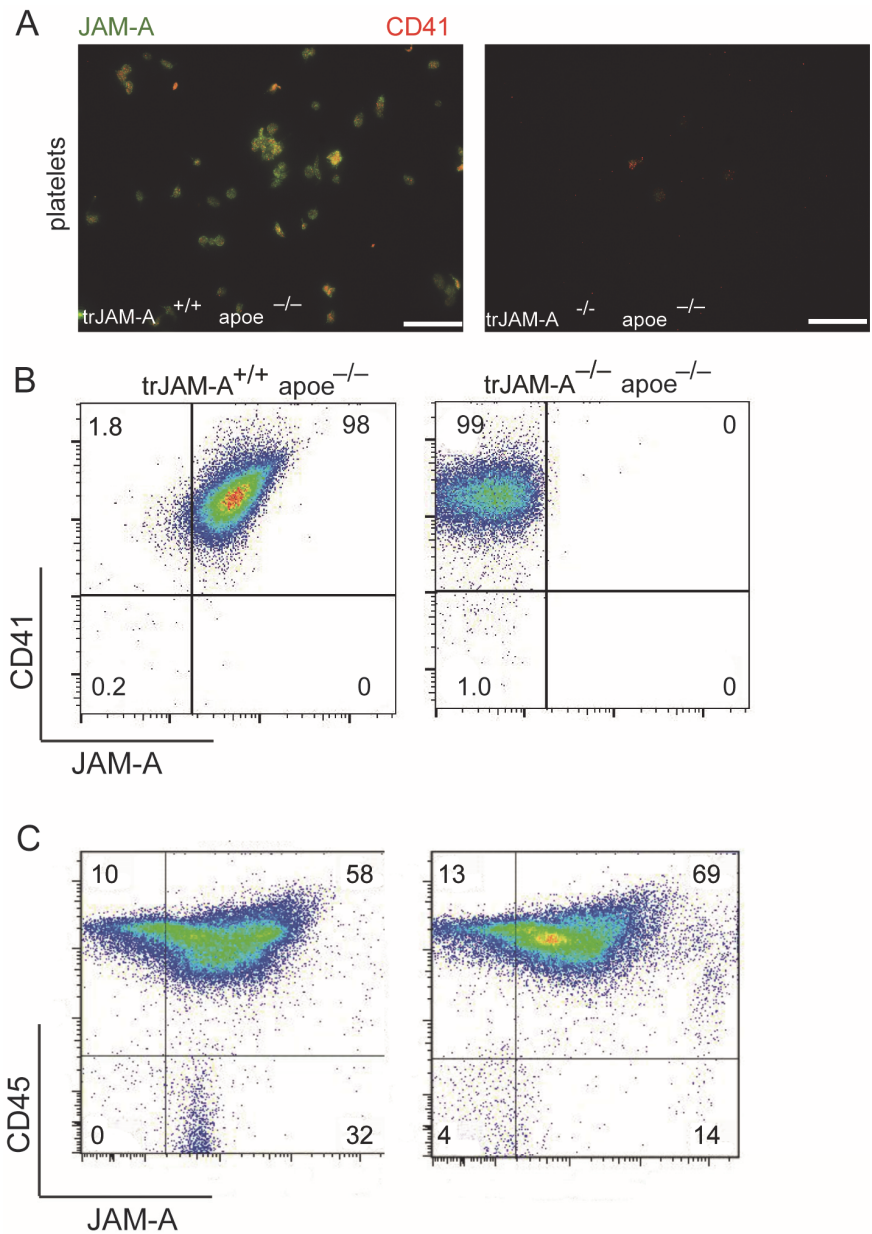

D

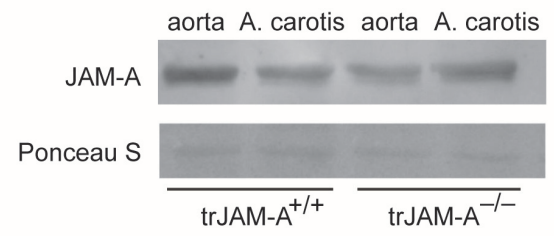

Supplementary Figure 1: JAM-A deletion on platelets and cell-specific JAM-A expression in trJAM-A ${ }^{-1-}$ Apoe $^{-1-}$ mice

JAM-A was stained on isolated platelets (A, JAM-A: green, CD41: red). Scale bar=20 $\mu$ m. JAM-A expression on platelets (B) and leukocytes (C) was measured by flow cytometry. Upper right quadrants depict the percentage of platelet (B) and leukocyte (C) JAM-A expression in trJAM-A ${ }^{+/+}$ Apoe $^{-/}$and trJAM-A ${ }^{-1-}$ Apoe $^{-/-}$mice, as indicated. Western blot experiments in homogenates from aortae and $A$. carotis from trJAM-A $A^{-/-}$Apoe $^{-/-}$and trJAM-A ${ }^{+/+}$mice $A p o e^{-/-}$(D). Ponceau S staining served as a loading control. Representative picture express 3 independent experiments. 

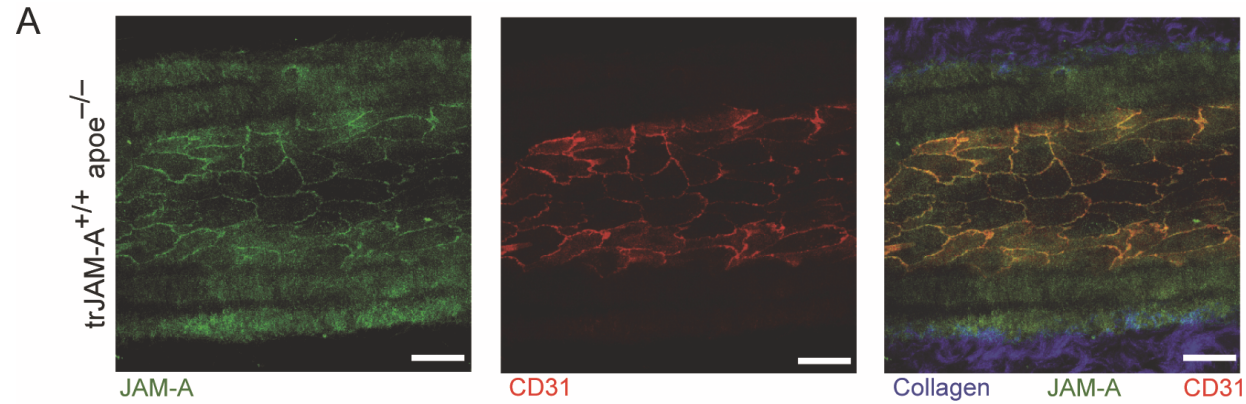

B
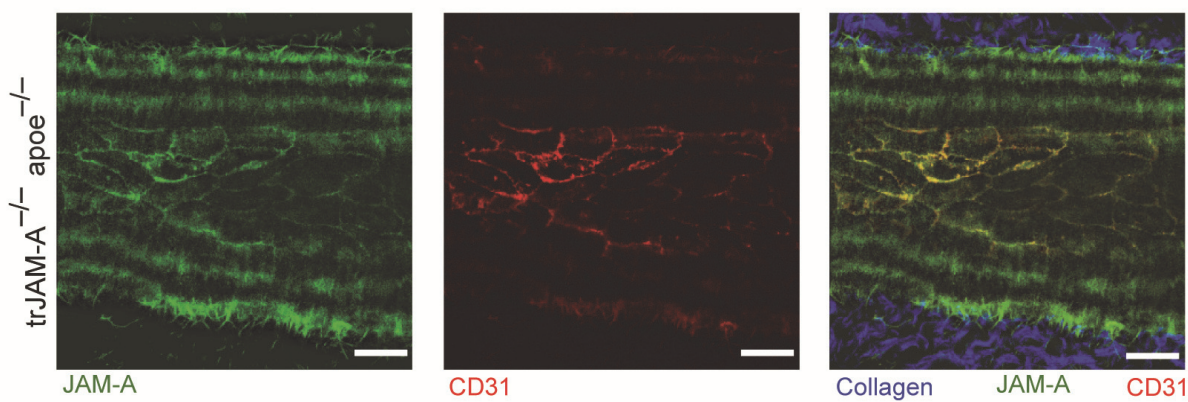

Supplementary Figure 2: Endothelial JAM-A expression in platelet-deficient JAM-A mice Endothelial JAM-A (A,B, merged, right) was stained in A. carotis from $\operatorname{trJAM-A^{+/+}} \mathrm{Apoe}^{-/-}(\mathbf{A})$ and trJAM-A ${ }^{-1-}$ Apoe $^{--}$(B) mice fed a HFD for 2 weeks. JAM-A: green (A, B left), CD31: red (A,B, middle), collagen: blue (autofluorescence). Scale bar= $20 \mu \mathrm{m}$. 


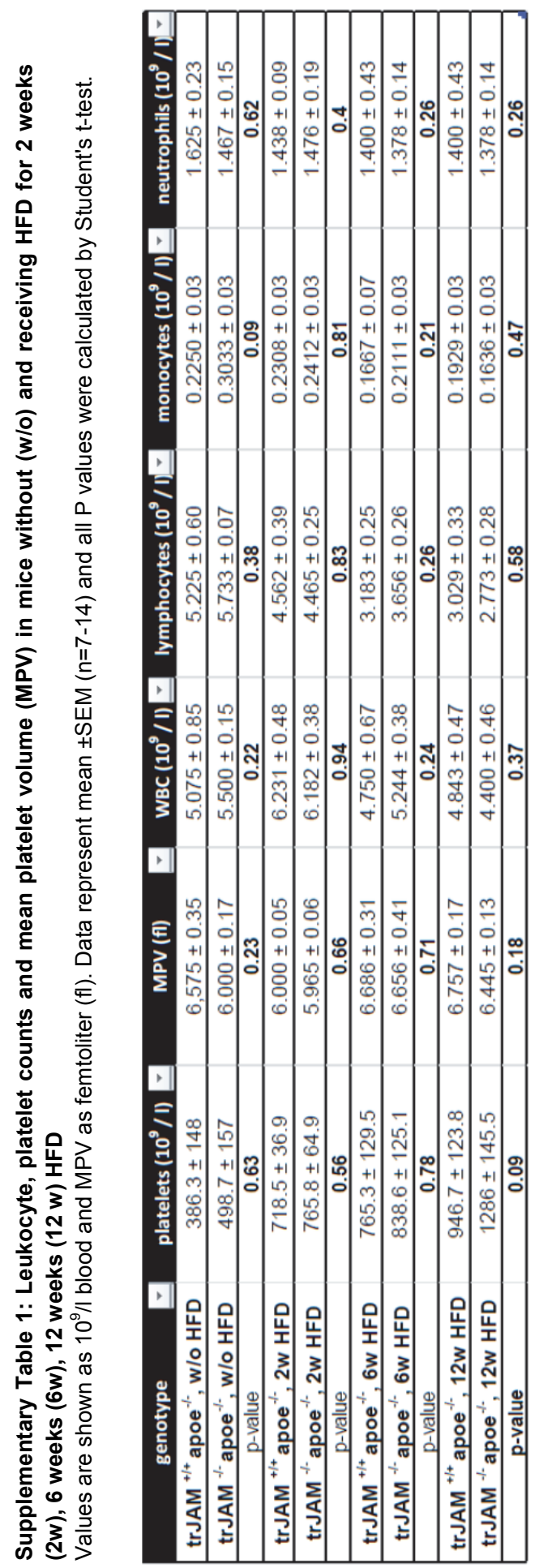


Supplementary Table 2: Plasma cholesterol- and triglyceride levels in mice receiving HFD for 2 weeks (2w), 6 weeks (6w) and 12 weeks (12 w) HFD

Values are expressed as $\mathrm{mg} / \mathrm{dl}$. Data represent mean \pm SEM $(n=7-13)$ and all $P$ values were calculated by Student's t-test.

\begin{tabular}{|c|c|c|}
\hline genotype & cholesterol $(\mathrm{mg} / \mathrm{dl})=$ & triglycerides (mg/dl) \\
\hline $\operatorname{trJAM}^{+/+}$apoe $^{-l-}, 2$ w HFD & $983.8 \pm 131.5$ & $164.2 \pm 40.9$ \\
\hline trJAM $^{-1-}$ apoe ${ }^{-1-}, 2$ w HFD & $1105 \pm 124.5$ & $140.8 \pm 20.5$ \\
\hline $\mathrm{p}$-value & 0.51 & 0.62 \\
\hline trJAM +/+ apoe ${ }^{-l-}, 6$ w HFD & $918.1 \pm 132.1$ & $164.6 \pm 31.5$ \\
\hline $\operatorname{trJAM}^{-/-}$apoe $^{-1-}, 6$ w HFD & $950.5 \pm 161.3$ & $183.8 \pm 48.8$ \\
\hline p-value & 0.88 & 0.96 \\
\hline $\operatorname{trJAM}+/+$ apoe ${ }^{-1-}, 12$ w HFD & $1222 \pm 121.3$ & $178.1 \pm 26.5$ \\
\hline trJAM ${ }^{-1-}$ apoe $^{-/-}, 12$ w HFD & $1349 \pm 145.9$ & $222.2 \pm 30.5$ \\
\hline $\mathrm{p}$-value & 0.51 & 0.29 \\
\hline
\end{tabular}




\section{References}

1. Massberg S, Brand K, Gruner S, Page S, Muller E, Muller I, Bergmeier W, Richter T, Lorenz M, Konrad I, Nieswandt B, Gawaz M. A critical role of platelet adhesion in the initiation of atherosclerotic lesion formation. The Journal of experimental medicine. 2002;196:887-896

2. von Hundelshausen $P$, Koenen RR, Sack M, Mause SF, Adriaens W, Proudfoot AE, Hackeng TM, Weber C. Heterophilic interactions of platelet factor 4 and rantes promote monocyte arrest on endothelium. Blood. 2005;105:924-930

3. Koenen RR, von Hundelshausen P, Nesmelova IV, Zernecke A, Liehn EA, Sarabi A, Kramp BK, Piccinini AM, Paludan SR, Kowalska MA, Kungl AJ, Hackeng TM, Mayo KH, Weber C. Disrupting functional interactions between platelet chemokines inhibits atherosclerosis in hyperlipidemic mice. Nature medicine. 2009;15:97-103

4. Naik MU, Stalker TJ, Brass LF, Naik UP. Jam-a protects from thrombosis by suppressing integrin alphaiibbeta3-dependent outside-in signaling in platelets. Blood. 2012;119:33523360

5. Rondina MT, Weyrich AS, Zimmerman GA. Platelets as cellular effectors of inflammation in vascular diseases. Circ. Res. 2013;112:1506-1519

6. Projahn D, Koenen RR. Platelets: Key players in vascular inflammation. J. Leukoc. Biol. 2012;92:1167-1175

7. Clark SR, Ma AC, Tavener SA, McDonald B, Goodarzi Z, Kelly MM, Patel KD, Chakrabarti S, McAvoy E, Sinclair GD, Keys EM, Allen-Vercoe E, Devinney R, Doig CJ, Green FH, Kubes P. Platelet ttr4 activates neutrophil extracellular traps to ensnare bacteria in septic blood. Nat. Med. 2007;13:463-469

8. Boilard E, Nigrovic PA, Larabee K, Watts GF, Coblyn JS, Weinblatt ME, Massarotti EM, Remold-O'Donnell E, Farndale RW, Ware J, Lee DM. Platelets amplify inflammation in arthritis via collagen-dependent microparticle production. Science. 2010;327:580-583

9. Langer HF, Choi EY, Zhou H, Schleicher R, Chung KJ, Tang Z, Gobel K, Bdeir K, Chatzigeorgiou A, Wong C, Bhatia S, Kruhlak MJ, Rose JW, Burns JB, Hill KE, Qu H, Zhang Y, Lehrmann E, Becker KG, Wang Y, Simon DI, Nieswandt B, Lambris JD, Li X, Meuth SG, Kubes P, Chavakis T. Platelets contribute to the pathogenesis of experimental autoimmune encephalomyelitis. Circ. Res. 2012;110:1202-1210

10. Wong $\mathrm{CH}$, Jenne CN, Petri B, Chrobok NL, Kubes P. Nucleation of platelets with bloodborne pathogens on kupffer cells precedes other innate immunity and contributes to bacterial clearance. Nat. Immunol. 2013;14:785-792

11. Kuckleburg CJ, Yates CM, Kalia N, Zhao Y, Nash GB, Watson SP, Rainger GE. Endothelial cell-borne platelet bridges selectively recruit monocytes in human and mouse models of vascular inflammation. Cardiovasc. Res. 2011;91:134-141

12. Ghasemzadeh M, Kaplan ZS, Alwis I, Schoenwaelder SM, Ashworth KJ, Westein E, Hosseini E, Salem HH, Slattery R, McColl SR, Hickey MJ, Ruggeri ZM, Yuan Y, Jackson $\mathrm{SP}$. The cxcr1/2 ligand nap-2 promotes directed intravascular leukocyte migration through platelet thrombi. Blood. 2013;121:4555-4566

13. Wang Y, Sakuma M, Chen Z, Ustinov V, Shi C, Croce K, Zago AC, Lopez J, Andre P, Plow E, Simon DI. Leukocyte engagement of platelet glycoprotein ibalpha via the integrin mac-1 is critical for the biological response to vascular injury. Circulation. 2005;112:29933000

14. Huo Y, Schober A, Forlow SB, Smith DF, Hyman MC, Jung S, Littman DR, Weber C, Ley K. Circulating activated platelets exacerbate atherosclerosis in mice deficient in apolipoprotein e. Nat. Med. 2003;9:61-67

15. Lievens D, Zernecke A, Seijkens T, Soehnlein O, Beckers L, Munnix IC, Wijnands E, Goossens P, van Kruchten R, Thevissen L, Boon L, Flavell RA, Noelle RJ, Gerdes N, Biessen EA, Daemen MJ, Heemskerk JW, Weber C, Lutgens E. Platelet cd40I mediates thrombotic and inflammatory processes in atherosclerosis. Blood. 2010

16. Weber C, Fraemohs L, Dejana E. The role of junctional adhesion molecules in vascular inflammation. Nat. Rev. Immunol. 2007;7:467-477

17. Corada M, Chimenti S, Cera MR, Vinci M, Salio M, Fiordaliso F, De Angelis N, Villa A, Bossi M, Staszewsky LI, Vecchi A, Parazzoli D, Motoike T, Latini R, Dejana E. Junctional adhesion molecule-a-deficient polymorphonuclear cells show reduced diapedesis in peritonitis and heart ischemia-reperfusion injury. Proc. Natl. Acad. Sci. U. S. A. 2005;102:10634-10639 
18. Cera MR, Fabbri M, Molendini C, Corada M, Orsenigo F, Rehberg M, Reichel CA, Krombach F, Pardi R, Dejana E. Jam-a promotes neutrophil chemotaxis by controlling integrin internalization and recycling. J. Cell Sci. 2009;122:268-277

19. Liang TW, DeMarco RA, Mrsny RJ, Gurney A, Gray A, Hooley J, Aaron HL, Huang A, Klassen T, Tumas DB, Fong S. Characterization of hujam: Evidence for involvement in cell-cell contact and tight junction regulation. Am. J. Physiol. Cell Physiol. 2000;279:C1733-1743

20. Bazzoni G. Endothelial tight junctions: Permeable barriers of the vessel wall. Thromb. Haemost. 2006;95:36-42

21. Martinez-Estrada OM, Manzi L, Tonetti P, Dejana E, Bazzoni G. Opposite effects of tumor necrosis factor and soluble fibronectin on junctional adhesion molecule-a in endothelial cells. Am. J. Physiol. Lung Cell. Mol. Physiol. 2005;288:L1081-1088

22. Schmitt MM, Megens RT, Zernecke A, Bidzhekov K, van den Akker NM, Rademakers T, van Zandvoort MA, Hackeng TM, Koenen RR, Weber C. Endothelial junctional adhesion molecule-a guides monocytes into flow-dependent predilection sites of atherosclerosis. Circulation. 2014;129:66-76

23. Kornecki E, Walkowiak B, Naik UP, Ehrlich YH. Activation of human platelets by a stimulatory monoclonal antibody. J. Biol. Chem. 1990;265:10042-10048

24. Sobocka MB, Sobocki T, Banerjee P, Weiss C, Rushbrook JI, Norin AJ, Hartwig J, Salifu MO, Markell MS, Babinska A, Ehrlich YH, Kornecki E. Cloning of the human platelet f11 receptor: A cell adhesion molecule member of the immunoglobulin superfamily involved in platelet aggregation. Blood. 2000;95:2600-2609

25. Ozaki H, Ishii K, Arai H, Horiuchi H, Kawamoto T, Suzuki H, Kita T. Junctional adhesion molecule (jam) is phosphorylated by protein kinase c upon platelet activation. Biochem. Biophys. Res. Commun. 2000;276:873-878

26. Sobocka MB, Sobocki T, Babinska A, Hartwig JH, Li M, Ehrlich YH, Kornecki E. Signaling pathways of the $\mathrm{f11}$ receptor (f11r; a.K.A. Jam-1, jam-a) in human platelets: F11r dimerization, phosphorylation and complex formation with the integrin gpiiia. Journal of receptor and signal transduction research. 2004;24:85-105

27. Naik MU, Caplan JL, Naik UP. Junctional adhesion molecule-a suppresses platelet integrin alphaiibbeta3 signaling by recruiting csk to the integrin-c-src complex. Blood. 2013

28. Tiedt R, Schomber T, Hao-Shen H, Skoda RC. Pf4-cre transgenic mice allow the generation of lineage-restricted gene knockouts for studying megakaryocyte and platelet function in vivo. Blood. 2007;109:1503-1506

29. Virmani R, Kolodgie FD, Burke AP, Farb A, Schwartz SM. Lessons from sudden coronary death: A comprehensive morphological classification scheme for atherosclerotic lesions. Arterioscler. Thromb. Vasc. Biol. 2000;20:1262-1275

30. Wurtz M, Hvas AM, Christensen KH, Rubak P, Kristensen SD, Grove EL. Rapid evaluation of platelet function using the multiplate(r) analyzer. Platelets. 2013

31. Mattheij NJ, Gilio K, van Kruchten R, Jobe SM, Wieschhaus AJ, Chishti AH, Collins P, Heemskerk JW, Cosemans JM. Dual mechanism of integrin alphaiibbeta3 closure in procoagulant platelets. J. Biol. Chem. 2013;288:13325-13336

32. Karshovska E, Zernecke A, Sevilmis G, Millet A, Hristov M, Cohen CD, Schmid H, Krotz F, Sohn HY, Klauss V, Weber C, Schober A. Expression of hif-1alpha in injured arteries controls sdf-1alpha mediated neointima formation in apolipoprotein e deficient mice. Arterioscler. Thromb. Vasc. Biol. 2007;27:2540-2547

33. Soehnlein O, Drechsler M, Doring Y, Lievens D, Hartwig H, Kemmerich K, Ortega-Gomez A, Mandl M, Vijayan S, Projahn D, Garlichs CD, Koenen RR, Hristov M, Lutgens E, Zernecke A, Weber $C$. Distinct functions of chemokine receptor axes in the atherogenic mobilization and recruitment of classical monocytes. EMBO Mol. Med. 2013;5:471-481

34. Karshovska E, Weber C, von Hundelshausen P. Platelet chemokines in health and disease. Thromb. Haemost. 2013;110:894-902

35. Postea O, Vasina EM, Cauwenberghs S, Projahn D, Liehn EA, Lievens D, Theelen W, Kramp BK, Butoi ED, Soehnlein O, Heemskerk JW, Ludwig A, Weber C, Koenen RR. Contribution of platelet cx3cr1 to platelet-monocyte complex formation and vascular recruitment during hyperlipidemia. Arterioscler. Thromb. Vasc. Biol. 2012;32:1186-1193

36. Ott I, Neumann FJ, Gawaz M, Schmitt M, Schomig A. Increased neutrophil-platelet adhesion in patients with unstable angina. Circulation. 1996;94:1239-1246

37. Sarma J, Laan CA, Alam S, Jha A, Fox KA, Dransfield I. Increased platelet binding to circulating monocytes in acute coronary syndromes. Circulation. 2002;105:2166-2171 
38. Angiolillo DJ. The evolution of antiplatelet therapy in the treatment of acute coronary syndromes: From aspirin to the present day. Drugs. 2012;72:2087-2116

39. Gasparyan AY, Watson T, Lip GY. The role of aspirin in cardiovascular prevention: Implications of aspirin resistance. J. Am. Coll. Cardiol. 2008;51:1829-1843

40. Colwell JA, Nesto RW. The platelet in diabetes: Focus on prevention of ischemic events. Diabetes Care. 2003;26:2181-2188

41. Drechsler M, Megens RT, van Zandvoort M, Weber C, Soehnlein O. Hyperlipidemiatriggered neutrophilia promotes early atherosclerosis. Circulation. 2010;122:1837-1845

42. da Costa Martins P, van den Berk N, Ulfman LH, Koenderman L, Hordijk PL, Zwaginga JJ. Platelet-monocyte complexes support monocyte adhesion to endothelium by enhancing secondary tethering and cluster formation. Arterioscler. Thromb. Vasc. Biol. 2004;24:193-199

43. Spectre G, Zhu L, Ersoy M, Hjemdahl P, Savion N, Varon D, Li N. Platelets selectively enhance lymphocyte adhesion on subendothelial matrix under arterial flow conditions. Thromb. Haemost. 2012;108:328-337 


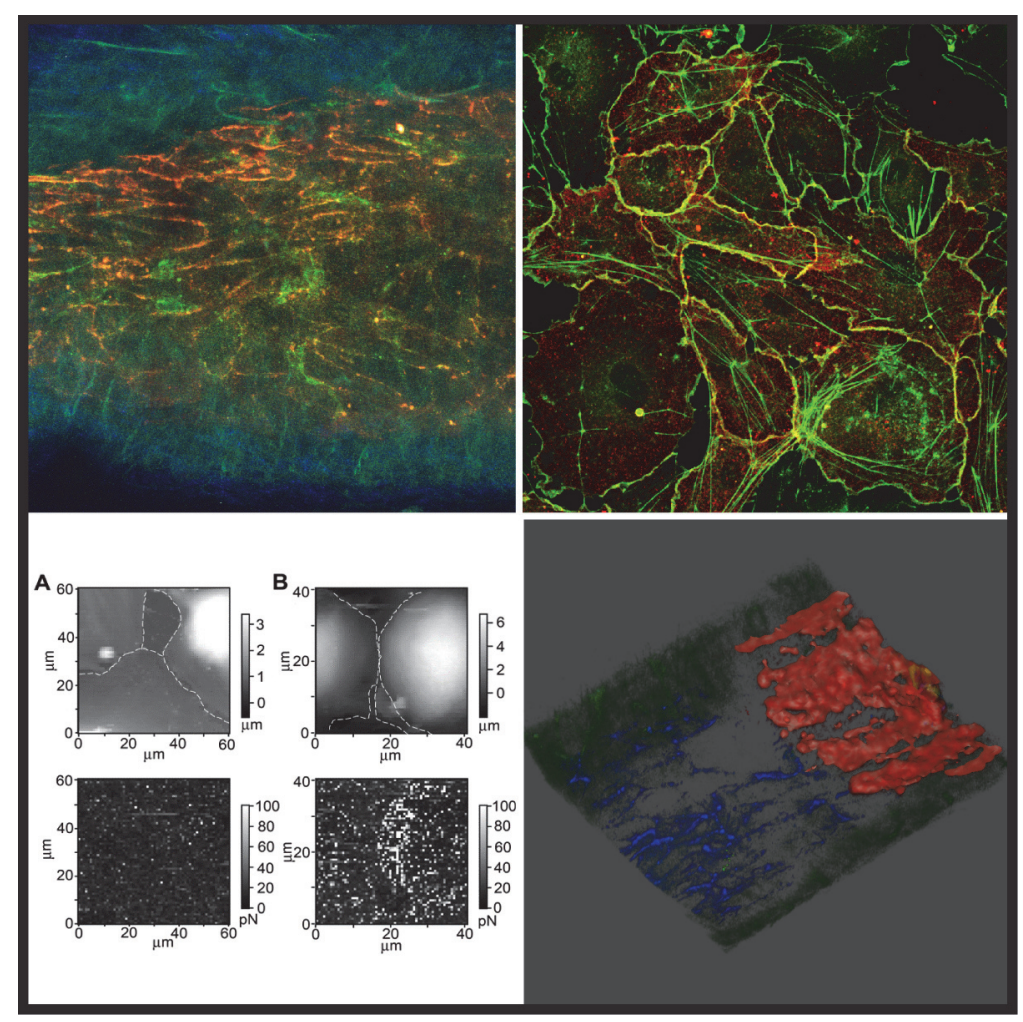

\section{Chapter 6}


General Discussion 
Presently, atherosclerosis constitutes one of the leading causes for patients suffering morbidity and death around the world with no expected changes in frequency the next decades ${ }^{1,2}$. A lot of efforts to find powerful therapeutic targets had been taken already, but the range of useful drugs is still comparably limited regarding the broad causalities of this multifaceted disease. Still plenty of crucial cellular and molecular mechanisms facilitating atherosclerosis are not understood completely. As atherosclerosis is a chronic inflammation of the vessel wall, leukocyte - endothelial cell interaction is one of the determining factors for atherosclerotic lesion formation. Thus, investigating mechanisms underlying leukocyte recruitment is important for development of novel therapeutic strategies as they still are not explored to a satisfying degree. One of the involved adhesion molecules, at which attention had be drawn to already years ago, is JAM-A. Over the years a rag rug of roles for JAM-A expressed by differing cell types in different inflammatory setups was generated. For example the role of JAM-A in injury models of liver ${ }^{3}$, carotid artery ${ }^{4}$ and heart ${ }^{5}$ had been investigated, sometimes with contrary results ${ }^{6-9}$, but a conclusive study directly comparing the role of JAM-A from differing cellular origin on atherogenesis is still missing.

With this study, we aimed to unravel the influence of the adhesion molecule JAM-A expressed from different cell types on atherosclerotic lesion formation and progression. Meanwhile, identified new concepts of leukocyte extravasation and were able to verify established ones. In detail, we found that:

1. JAM-A from differing cellular origin exerts diverse effects on atherogenesis

2. Whereas somatic deficiency has no effect, endothelial JAM-A deficiency reduces plaque formation via decreasing leukocyte recruitment

3. Leukocytes deficient for JAM-A lack active transmigratory capacity and damage the vessel wall, thus enhancing plaque formation

4. Endothelial JAM-A is more abundant on the cell surface under hyperlipidemic and altered shear stress conditions

5. Normal flow conditions exert atheroprotective function by reducing JAM-A expression via increased miR-145 levels

6. Lovastatin completely abolishes oxidized LDL-mediated JAM-A re-localization and increase in leukocyte infiltration 
7. Adhesion "hot spots" of JAM-A molecules are involved in initiating leukocyte infiltration under inflammatory conditions

8. Platelets deficient for JAM-A show a hyperreactive phenotype enhancing secondary adhesion of leukocytes, thus aggravating lesion formation

\section{Cell-specific function of JAM-A in atherosclerosis}

For the first time, we were able to demonstrate opposing functions of JAM-A from different cellular origins in one comprehensive study (chapter 2, chapter 5). Precisely, endothelial JAM-A facilitates leukocyte recruitment and thus atherosclerotic lesion formation via its increased accessibility to bypassing leukocytes under inflammatory and altered shear stress conditions. In contrast, JAM-A on leukocytes and platelets display atheroprotective properties, mainly because deficiency of JAM-A leads to extension of integrin activity with increased leukocyte adhesion or defective de-adhesion as consequence.

Not many molecular players orchestrating the adhesion cascade are known to be expressed by several cell types like leukocytes, endothelial cells and platelets. Another adhesion molecule being closely related to JAM-A and expressed by diverse cell types is JAM-C. A comprehensive study regarding possible alternating functions of JAM-C from differing cellular origin in atherosclerotic lesion formation is missing, making a comparative discussion to JAM-A difficult, but single studies performed in different inflammatory models provide initial evidence. Thus, endothelial JAM-C had been discovered to act rather as a "gate-keeper" than facilitating transendothelial migration like JAM-A does. JAM-C tightly seals junctions of big vessels for already transmigrated leukocytes, thereby inhibiting re-transmigrated leukocytes from inflicting secondary organ damage by increased reactive oxygen species production ${ }^{10,11}$. Recently, Donate and colleagues were able to show a reduction of lymphocyte infiltration into secondary lymphatic organs subsequent to leukocytic JAM-C antibody-facilitated blockade. In detail, treatment of B cells with anti-JAM-C antibodies reduced migration of JAM-C-expressing $B$ cells into spleen and lymph nodes ${ }^{12}$. Comparable to genetic deletion of JAM-A in mice, a systemic blockade of JAM-C using antibodies resulted in decreased neo-intima formation after wire-injury experiments of the murine carotid artery, ${ }^{4,13}$ and in reduced accumulation of leukocytes in alveoli during acute pulmonary inflammation in mice ${ }^{14,15}$. Additionally comparable to JAM-A deficiency, inhibition of systemic JAM-C using soluble JAM-C resulted in a reduction of transmigrated neutrophils in a model of acute thioglycollate-induced peritonitis ${ }^{5,16}$. 
Endothelial JAM-A facilitates leukocyte infiltration through relocalization under inflammatory or altered shear stress conditions

Some debate with contrary results regarding endothelial JAM-A as a mediator for leukocyte infiltration under inflammatory conditions was held in the past $^{3,4,7,9}$. Here we provide definite evidence for endothelial JAM-A-mediated leukocyte recruitment by using mice deficient for endothelial JAM-A, blocking antibodies and rescue experiments (chapter 2, chapter 3 ). The main reason why endothelial JAM-A exerts atherogenic properties is its re-localization triggered by cytokines, oxidized LDL or low/oscillatory shear stress (chapter $\mathbf{2}$, chapter 4). In an inflammatory setting, leukocytes adhere at endothelial cells of post-capillary venules under rather low shear forces compared to high shear in the arterial system. It is highly likely that, additional to selectins, further molecular interactions are needed to overcome the higher shear rates found in the artery and to facilitate adhesion of leukocytes to endothelial cells, e.g. hetero- and homophilic interactions of luminal JAM-A. Thus, JAM-A relocalization enables additional leukocyte adhesion to the endothelium. In detail, we were able to show a clustered re-localization of JAM-A on the apical endothelial cell site (chapter 2) together with an accumulation of JAM-A not in but near the junctions to build "hot-spots" of transmigration (chapter 4). Concomitant to those results another study showed a chemokine triggered and macropinocytosis driven functional JAM-A re-localization in brain endothelial cells ${ }^{17}$. Intriguingly, further work demonstrated no observable rapid re-localization of JAM-A compared to LFA-1 and ICAM-1 re-localization on TNF- $\alpha-$ stimulated HUVECs after neutrophil adherence ${ }^{7}$. This might point to another mechanism for JAM-A re-localization, which occurs soon after leukocyte adhesion compared to the mechanism triggered by prolonged inflammatory setups like hyperlipidemia and altered shear stress described by us. In another work by Mamdouh and colleagues, JAM-A was identified as part of the so-called "lateral border recycling compartments", a patch of junctional membrane also consistent of CD31 and CD99, which tends to re-localize to "invest" adherent leukocytes ${ }^{9}$. Comparable to the former study, this mechanism of re-localization again should be accounted to a more rapid, cell adhesiontriggered phenomenon and might explain the observed differences to our chronic model basing on comparably long-term exposure to atherogenic factors. Additionally, the authors claimed that JAM-A blocking antibodies do not change transmigration capacities neither on the para- nor on the transcellular route. Observed differences to our results might originate in their aim to discriminate between para- and transcellular leukocyte transmigration, which demanded an experimental setup far from physiologic conditions and thus not necessarily representing the physiological role of JAM-A in leukocyte transmigration. 


\section{Atheroprotective function of high and laminar shear stress via shear receptive miR-145}

Many preceding studies were able to indicate an atheroprotective function for high and laminar shear stress, also regarding shear stress regulated miR levels ${ }^{18-23}$. Recently, another adhesion molecule named PECAM-1 was found to regulate atherosclerotic plaque formation in a cell- and site-specific manner ${ }^{24}$. PECAM-1 on bone marrow cells displayed pro-atherogenic properties regardless of the hemodynamic situation, whereas endothelial PECAM-1 increased macrophage infiltration in areas of low and oscillatory shear stress but was atheroprotective in regions of high and laminar shear stress. Here, we were able to extend those results with findings for JAM-A, as a correlative decrease of miR-145 with shear stress enhanced JAM-A expression. Therefore, comparable to increased JAM-A expression under hyperlipidemic conditions, more functional JAM-A was available in predilection sites under conditions of low and oscillatory shear stress for proatherogenic facilitation of leukocyte transmigration (chapter 2).

\section{Enhanced integrin activity on leukocytes or platelets with JAM-A deficiency}

An initially surprising increase in adhesion of JAM-A deficient leukocytes to endothelial cells paved the way in understanding the increased lesion formation in leukocytic JAM-A deficient mice (chapter 2). A recent study found a co-distribution of JAM-A with $\beta_{1}$ integrins in neutrophils causing their collaborative internalization, which was inhibited when JAM-A was lacking ${ }^{25}$. This decreased the transmigratory capacity of leukocytes. We found that a JAM-A deficiency-mediated prolonged activity of $\beta_{2}$ integrins caused a defect in de-adhesion from their receptor ICAM-1 (chapter 2). Likely, JAM-A deficient leukocytes displaying defective de-adhesion and being captured at the endothelium or in between endothelium and basement membrane might inflict enough damage to endothelial cell integrity to facilitate secondary influx of atherogenic cells or compounds. In platelets JAM-A is a negative regulator of $\alpha_{2 b} \beta_{3}$ integrin ${ }^{26,27}$. The $\alpha_{2 b} \beta_{3}$ integrin is known to facilitate platelet/endothelial cell interactions ${ }^{28}$ and $a \alpha_{2 b} \beta_{3}$ integrin-antagonist treatment of whole blood resulted in decreased platelet/monocyte and platelet/neutrophil interactions ${ }^{29}$. Concomitantly, we were able to show that deficiency of platelet JAM-A introduced platelet hyperreactivity with lower activation thresholds and increased platelet/leukocyte interaction via enhanced $\alpha_{2 b} \beta_{3}$ integrin activity. Besides the increase plasma-levels of atherogenic chemokines like CCL5 and CXCL4, these enhanced platelet/leukocyte interactions likely aggravated the atherosclerotic lesion formation observed (chapter 5). 


\section{Lovastatin, but not pioglitazone treatment abolishes oxidized LDL- induced JAM-A re-localization and leukocyte infiltration}

With this study we were able to expand the knowledge on the atheroprotective effects of the HMG-CoA-reductase inhibitor lovastatin with another aspect. Here we demonstrate the complete reduction of oxidized LDL as well as TNF- $\alpha /$ IFN$\gamma$-induced functional re-localization of endothelial JAM-A by lovastatin treatment. Moreover, leukocyte transmigration rates enhanced by oxidized LDL as well as TNF- $\alpha / \mathrm{IFN}-\gamma$ treatment were completely abolished after co-treatment with lovastatin (chapter 3). Parallel to an enhanced junctional localization of JAM-A after lovastatin treatment, immunofluorescence analysis of actin organization revealed a reduction of stress fibers in endothelial cells incubated with lovastatin. (chapter 3). Concomitant to that, a previous study demonstrated lovastatin-mediated alterations in cytoskeleton organization with consequences on adhesion, motility and proteolysis of mammary carcinoma cells ${ }^{30}$. Besides a steric hindrance of JAM-A re-localization facilitated by actin reorganization and tight JAM-A/actin interactions, which might likely be the cause for the lovastatinmediated inhibition of TNF- $\alpha /$ IFN- $\gamma$-facilitated JAM-A re-localization and leukocyte infiltration, statins also exerts important effects on lectin-like oxidized low density lipoprotein receptor (LOX)-1. As shown recently, statins protect vascular endothelium against effects of oxidized LDL through impairment of LOX-1 receptor function ${ }^{31}$. Together with findings that LOX-1 activation plays an important role in oxidized LDL-induced expression of adhesion molecules ${ }^{32}$ one could easily conclude that statins also inhibit leukocyte infiltration via reducing oxidized LDL mediated adhesion molecule expression. Finally, statins were shown to be capable of inhibiting lymphocyte homing to murine peripheral lymph nodes in vivo ${ }^{33}$.

The peroxisome proliferator-activated receptor- $\gamma$ agonist pioglitazone did not establish any effects on oxidized LDL as well as TNF- $\alpha /$ IFN- $\gamma$ induced JAM-A re-localization and leukocyte infiltration, although previous studies provided reliable evidence for that. For example, pioglitazone reduced neutrophil infiltration in a model of LPS induced acute lung injury ${ }^{34}$. Moreover, pioglitazone reduced intracellular super-oxide radical generation and subsequently the expression of LOX-1 and monocyte adhesion in human endothelial cells ${ }^{35}$. Additionally, pioglitazone had been shown to inhibit TNF- $\alpha$-induced LOX-1 expression in bovine endothelial cells ${ }^{36}$. Why pioglitazone did not affect oxidized LDL and TNF- $\alpha /$ IFN- $\gamma$ induced JAM-A re-localization and leukocyte infiltration in our model is still to be elucidated. 


\section{Concluding remarks and future perspectives}

With this thesis, for the first time we unraveled opposing contributions of JAM-A harbored by differing cell types to atherosclerotic lesion formation.

We could prove that endothelial JAM-A propagates atherogenic conditions in Apoe-deficient mice by regulating leukocyte infiltration, in contrast to leukocytic and platelet JAM-A, which mediate regular integrin internalization and contribute thus to normal leukocyte and platelet (de)-adhesion.

Another main novelty also adds more details to the atheroprotective function of high and laminar shear stress, namely the regulation of JAM-A expression by shear-receptive miR-145.

Last but not least, our results pointed out a novel atheroprotective effect of lovastatin by completely blocking oxidized LDL- and cytokine-induced increase of JAM-A re-localization and leukocyte infiltration.

Having deciphered the different engagements of JAM-A, specifically targeting endothelial JAM-A likely by miR-145 intervention could present a promising and valuable therapy for preventing atherosclerotic lesion formation in early and late stages. Additionally, re-localized endothelial JAM-A might be useful in order to identify upcoming atherosclerotic lesions, likely via JAM-A antibody coupled microbubbles detected by non-invasive ultrasound.

In general we believe that this work thoroughly illustrates the necessity for investigating crucial proteins in different context e.g. cellular, circadian or trigger-based. Deeper understanding of those issues would lead to better and safer drug development. 


\section{References}

1. Go AS, Mozaffarian D, Roger VL, Benjamin EJ, Berry JD, Borden WB, Bravata DM, Dai S, Ford ES, Fox CS, Franco S, Fullerton HJ, Gillespie C, Hailpern SM, Heit JA, Howard VJ, Huffman MD, Kissela BM, Kittner SJ, Lackland DT, Lichtman JH, Lisabeth LD, Magid D, Marcus GM, Marelli A, Matchar DB, McGuire DK, Mohler ER, Moy CS, Mussolino ME, Nichol G, Paynter NP, Schreiner PJ, Sorlie PD, Stein J, Turan TN, Virani SS, Wong ND, Woo D, Turner MB. Executive summary: Heart disease and stroke statistics--2013 update: A report from the american heart association. Circulation. 2013;127:143-152

2. Sanz J, Moreno PR, Fuster V. The year in atherothrombosis. Journal of the American College of Cardiology. 2013;62:1131-1143

3. Khandoga A, Kessler JS, Meissner H, Hanschen M, Corada M, Motoike T, Enders G, Dejana E, Krombach F. Junctional adhesion molecule-a deficiency increases hepatic ischemia-reperfusion injury despite reduction of neutrophil transendothelial migration. Blood. 2005;106:725-733

4. Zernecke A, Liehn EA, Fraemohs L, von Hundelshausen P, Koenen RR, Corada M, Dejana E, Weber C. Importance of junctional adhesion molecule-a for neointimal lesion formation and infiltration in atherosclerosis-prone mice. Arteriosclerosis, thrombosis, and vascular biology. 2006;26:e10-13

5. Corada M, Chimenti S, Cera MR, Vinci M, Salio M, Fiordaliso F, De Angelis N, Villa A, Bossi M, Staszewsky LI, Vecchi A, Parazzoli D, Motoike T, Latini R, Dejana E. Junctional adhesion molecule-a-deficient polymorphonuclear cells show reduced diapedesis in peritonitis and heart ischemia-reperfusion injury. Proc Natl Acad Sci U S A. 2005;102:10634-10639

6. Shaw SK, Perkins BN, Lim YC, Liu Y, Nusrat A, Schnell FJ, Parkos CA, Luscinskas FW. Reduced expression of junctional adhesion molecule and platelet/endothelial cell adhesion molecule-1 (cd31) at human vascular endothelial junctions by cytokines tumor necrosis factor-alpha plus interferon-gamma does not reduce leukocyte transmigration under flow. Am J Pathol. 2001;159:2281-2291

7. Shaw SK, Ma S, Kim MB, Rao RM, Hartman CU, Froio RM, Yang L, Jones T, Liu Y, Nusrat A, Parkos CA, Luscinskas FW. Coordinated redistribution of leukocyte Ifa-1 and endothelial cell icam-1 accompany neutrophil transmigration. The Journal of experimental medicine. 2004;200:1571-1580

8. Woodfin A, Reichel CA, Khandoga A, Corada M, Voisin MB, Scheiermann C, Haskard DO, Dejana E, Krombach F, Nourshargh S. Jam-a mediates neutrophil transmigration in a stimulus-specific manner in vivo: Evidence for sequential roles for jam-a and pecam-1 in neutrophil transmigration. Blood. 2007;110:1848-1856

9. Mamdouh Z, Mikhailov A, Muller WA. Transcellular migration of leukocytes is mediated by the endothelial lateral border recycling compartment. The Journal of experimental medicine. 2009;206:2795-2808

10. Bradfield PF, Scheiermann C, Nourshargh S, Ody C, Luscinskas FW, Rainger GE, Nash GB, Miljkovic-Licina M, Aurrand-Lions M, Imhof BA. Jam-c regulates unidirectional monocyte transendothelial migration in inflammation. Blood. 2007;110:2545-2555

11. Woodfin A, Voisin MB, Beyrau M, Colom B, Caille D, Diapouli FM, Nash GB, Chavakis T, Albelda SM, Rainger GE, Meda P, Imhof BA, Nourshargh S. The junctional adhesion molecule jam-c regulates polarized transendothelial migration of neutrophils in vivo. Nature immunology. 2011;12:761-769

12. Donate C, Ody C, McKee T, Ruault-Jungblut S, Fischer N, Ropraz P, Imhof BA, Matthes $\mathrm{T}$. Homing of human $\mathrm{b}$ cells to lymphoid organs and b-cell lymphoma engraftment are controlled by cell adhesion molecule jam-c. Cancer research. 2013;73:640-651

13. Shagdarsuren E, Djalali-Talab Y, Aurrand-Lions M, Bidzhekov K, Liehn EA, Imhof BA, Weber C, Zernecke A. Importance of junctional adhesion molecule-c for neointimal hyperplasia and monocyte recruitment in atherosclerosis-prone mice-brief report. Arteriosclerosis, thrombosis, and vascular biology. 2009;29:1161-1163

14. Lakshmi SP, Reddy AT, Naik MU, Naik UP, Reddy RC. Effects of jam-a deficiency or blocking antibodies on neutrophil migration and lung injury in a murine model of ali. American journal of physiology. Lung cellular and molecular physiology. 2012;303:L758766 
15. Aurrand-Lions M, Lamagna C, Dangerfield JP, Wang S, Herrera P, Nourshargh S, Imhof BA. Junctional adhesion molecule-c regulates the early influx of leukocytes into tissues during inflammation. J Immunol. 2005;174:6406-6415

16. Chavakis T, Keiper T, Matz-Westphal R, Hersemeyer K, Sachs UJ, Nawroth PP, Preissner KT, Santoso S. The junctional adhesion molecule-c promotes neutrophil transendothelial migration in vitro and in vivo. The Journal of biological chemistry. 2004;279:55602-55608

17. Stamatovic SM, Sladojevic N, Keep RF, Andjelkovic AV. Relocalization of junctional adhesion molecule a during inflammatory stimulation of brain endothelial cells. Molecular and cellular biology. 2012;32:3414-3427

18. Berk BC, Min W, Yan C, Surapisitchat J, Liu Y, Hoefen R. Atheroprotective mechanisms activated by fluid shear stress in endothelial cells. Drug news \& perspectives. 2002;15:133-139

19. Pan S. Molecular mechanisms responsible for the atheroprotective effects of laminar shear stress. Antioxidants \& redox signaling. 2009;11:1669-1682

20. Pfenniger A, Wong C, Sutter E, Cuhlmann S, Dunoyer-Geindre S, Mach F, Horrevoets AJ, Evans PC, Krams R, Kwak BR. Shear stress modulates the expression of the atheroprotective protein cx37 in endothelial cells. Journal of molecular and cellular cardiology. 2012;53:299-309

21. Melchior B, Frangos JA. Distinctive subcellular akt-1 responses to shear stress in endothelial cells. Journal of cellular biochemistry. 2013

22. Neth P, Nazari-Jahantigh M, Schober A, Weber C. Micrornas in flow-dependent vascular remodelling. Cardiovascular research. 2013;99:294-303

23. Hergenreider E, Heydt S, Treguer K, Boettger T, Horrevoets AJ, Zeiher AM, Scheffer MP, Frangakis AS, Yin X, Mayr M, Braun T, Urbich C, Boon RA, Dimmeler S. Atheroprotective communication between endothelial cells and smooth muscle cells through mirnas. Nat Cell Biol. 2012;14:249-256

24. Harrison M, Smith E, Ross E, Krams R, Segers D, Buckley CD, Nash GB, Rainger GE. The role of platelet-endothelial cell adhesion molecule-1 in atheroma formation varies depending on the site-specific hemodynamic environment. Arteriosclerosis, thrombosis, and vascular biology. 2013;33:694-701

25. Cera MR, Fabbri M, Molendini C, Corada M, Orsenigo F, Rehberg M, Reichel CA, Krombach F, Pardi R, Dejana E. Jam-a promotes neutrophil chemotaxis by controlling integrin internalization and recycling. J Cell Sci. 2009;122:268-277

26. Naik MU, Stalker TJ, Brass LF, Naik UP. Jam-a protects from thrombosis by suppressing integrin alphaiibbeta3-dependent outside-in signaling in platelets. Blood. 2012;119:33523360

27. Naik MU, Caplan JL, Naik UP. Junctional adhesion molecule-a suppresses platelet integrin alphaiibbeta3 signaling by recruiting csk to the integrin-c-src complex. Blood. 2013

28. Massberg S, Brand K, Gruner S, Page S, Muller E, Muller I, Bergmeier W, Richter T, Lorenz M, Konrad I, Nieswandt B, Gawaz M. A critical role of platelet adhesion in the initiation of atherosclerotic lesion formation. The Journal of experimental medicine. 2002;196:887-896

29. Sanderson HM, Fox SC, Robbins RA, Losche W, Spangenberg P, Heptinstall S. Role of gpiib-iiia in platelet-monocyte and platelet-neutrophil conjugate formation in whole blood. Platelets. 1998;9:245-250

30. Farina HG, Bublik DR, Alonso DF, Gomez DE. Lovastatin alters cytoskeleton organization and inhibits experimental metastasis of mammary carcinoma cells. Clinical \& experimental metastasis. 2002;19:551-559

31. Matarazzo S, Quitadamo MC, Mango R, Ciccone S, Novelli G, Biocca S. Cholesterollowering drugs inhibit lectin-like oxidized low-density lipoprotein-1 receptor function by membrane raft disruption. Molecular pharmacology. 2012;82:246-254

32. Li D, Chen H, Romeo F, Sawamura T, Saldeen T, Mehta JL. Statins modulate oxidized low-density lipoprotein-mediated adhesion molecule expression in human coronary artery endothelial cells: Role of lox-1. The Journal of pharmacology and experimental therapeutics. 2002;302:601-605

33. Schramm R, Menger MD, Harder Y, Schmits R, Adam O, Weitz-Schmidt G, Schafers HJ. Statins inhibit lymphocyte homing to peripheral lymph nodes. Immunology. 2007;120:315324 
34. Grommes J, Morgelin M, Soehnlein O. Pioglitazone attenuates endotoxin-induced acute lung injury by reducing neutrophil recruitment. The European respiratory journal. 2012;40:416-423

35. Mehta JL, Hu B, Chen J, Li D. Pioglitazone inhibits lox-1 expression in human coronary artery endothelial cells by reducing intracellular superoxide radical generation. Arteriosclerosis, thrombosis, and vascular biology. 2003;23:2203-2208

36. Chiba Y, Ogita T, Ando K, Fujita T. Ppargamma ligands inhibit tnf-alpha-induced lox-1 expression in cultured endothelial cells. Biochemical and biophysical research communications. 2001;286:541-546 
GENERAL DISCUSSION 


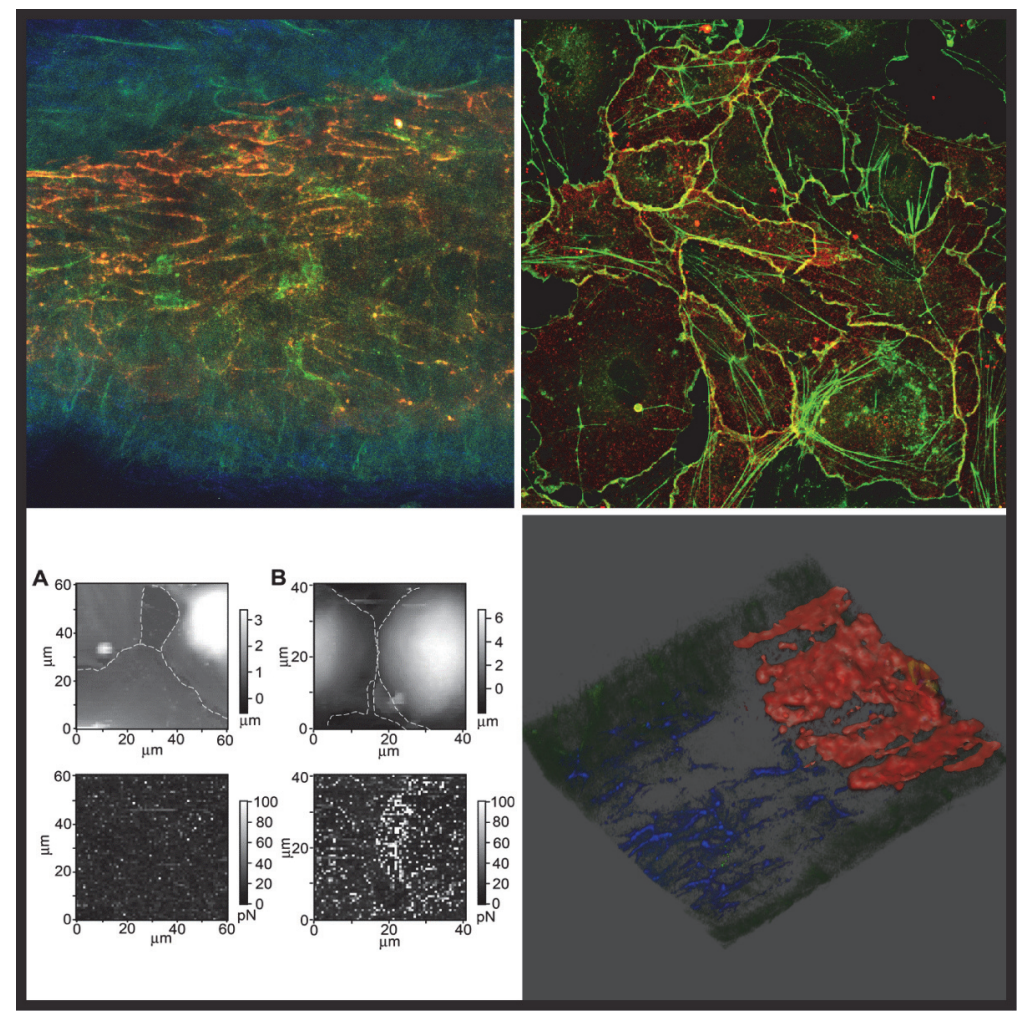

\section{Summary/Zusammenfassung/ Samenvatting}


Summary 
Worldwide, cardiovascular diseases are the leading source of patients suffering tremendous reduction in life quality until premature death. Fighting those widely spread diseases is one of the most challenging tasks of our generation. Their multi-factorial nature allows on the one hand a broad spectrum of potential therapeutics, but on the other hand being tightly linked to the body's immune system, therapeutic drugs need to be highly specific without causing undesirable side-effects.

The most abundant cardiovascular diseases are acute myocardial infarction and stroke, which are typically instigated by stenosis of arteries as a result of rupture of advanced atherosclerotic lesions.

Atherosclerosis is a progressive and chronic disease, induced by constituents of the immune system. It is characterized by accumulation of lipids, immune cells and fibrous components in the arterial wall at predilection sites comprising altered shear stress conditions. At these sites, hyperlipidemiatriggered excess uptake of LDL-cholesterol into the vessel wall occurs and oxidation as well as acetylation of those lipids take place with subsequent activation of endothelial cells. Enhanced monocyte influx enabled by endothelial cell activation finally leads to greater prevalence of highly lipid-laden foam cells, which were macrophages differentiated from monocytes taking up oxidized LDL (oxLDL). Foam cells secrete factors contributing to a persistent inflammatory response in the vessel wall, augmenting the influx of additional monocytes and other inflammatory cell types like T cells and granulocytes. Chronic occurrence of inflammation finally leads to development of advanced atherosclerotic lesions with a necrotic core being covered by a fibrous cap. Destabilization of the fibrous cap through proteases, but also erosion and cell death will advance the plaque stage to an instable plaque phenotype. Upon plaque rupture, prothrombotic factors of the necrotic core will trigger coagulation and thrombus formation causing acute myocardial infarction or stroke.

Recruitment of leukocytes is an important prerequisite for atherosclerotic lesion formation. A lot of efforts had been taken to elucidate the mechanisms and molecular effectors playing a role in leukocyte recruitment. From a plurality of studies a multi-step cascade evolved, called the Leukocyte Adhesion Cascade, which however is still not studied completely.

The beginning of the Leukocyte Adhesion Cascade comprises selectin and PSGL-1-mediated leukocyte tethering to and rolling on the endothelial cell layer, followed by integrin and adhesion molecule interaction-mediated firm adhesion and transmigration along a chemokine gradient. One of those molecular players orchestrating leukocyte adhesion and transmigration is Junctional Adhesion Molecule (JAM)-A. Several studies demonstrated (sometimes even contrary) roles for JAM-A in various inflammatory disease models, but a comprehensive study identifying the roles of JAM-A harbored by different cell types regarding atherosclerotic lesion formation is still missing (chapter 1). 
Therefore, the hypothesis of this thesis is that JAM-A from differing cellular origin might exert different effects on leukocyte recruitment and thus on atherogenesis, a phenomenon being of fundamental interest not only in basic science but also in drug development. Additionally, exact localization of endothelial JAM-A under inflammatory conditions would add key information to the underlying mechanisms.

In chapter 2, we were able to demonstrate atherogenic functions of endothelial JAM-A by showing decreased atherosclerotic lesion formation in mice deficient for endothelial JAM-A. In contrast, an increased lesion formation was observed in mice with leukocytic JAM-A deficiency, suggesting an atheroprotective role of leukocytic JAM-A. In transmigration assays in vitro and in vivo, deficiency of endothelial JAM-A resulted in decreased leukocyte transmigration rates contrary to deficiency of leukocytic JAM-A, which induced defect de-adhesion likely due to prolonged $\beta_{2}$-integrin activity caused by absence of JAM-A-mediated integrin internalization, thereby damaging endothelial cell lining. Moreover we provided evidence that endothelial JAM-A re-localizes to apical cell site in a focal manner after treatment with cytokines or oxLDL as well as in areas of disturbed flow, thereby increasing leukocyte adhesion and transmigration. Additionally we could demonstrate an atheroprotective role of high and laminar shear stress via robust miR-145 copy synthesis, inhibiting endothelial JAM-A expression.

In order to explore the mechanisms of endothelial JAM-A re-localization more deeply (chapter 3), immuno-fluorescence based detection of JAM-A and actin revealed an increase of actin expression additional to actin re-localization and increased JAM-A/actin co-localization likely facilitated by enhanced ZO-1/JAM-A interaction after oxLDL treatment. Moreover, additional transmigration assays expanded preceding results by ruling out any $\mathrm{Fc}$-based artifacts while blocking JAM-A with antibodies. Thus using anti-JAM-A Fab fragments resulted in decreased leukocyte recruitment after cytokine or oxLDL treatment. Furthermore, we were able to expand the knowledge of atheroprotective properties of the cholesterol-lowering drug lovastatin by abolishment of functional JAM-A re-localization after cytokine as well as oxLDL treatment of endothelial cells likely via junctional actin stabilization and oxLDL receptor LOX-1 expression reduction.

In a subsequent study described in chapter 4 , we sought to further elucidate re-localization of JAM-A and its effect on leukocyte recruitment. By applying atomic force microscopy, we were able to show for the first time that the underlying molecular mechanism for enhanced $T$ cell paracellular recruitment is the development of JAM-A "hot spots", comparable to JAM-A re-localization shown in chapter 2 and 3 . Those focal accumulations located near the endothelial cell-cell contacts enhance $T$ cell junctional adhesion and facilitate their junctional recruitment. 
Finally in chapter 5 , we provide significant findings regarding JAM-A deficiency in thrombocytes and its outcome on atherosclerotic lesion formation. In detail, thrombotic JAM-A (trJAM-A) deficiency led to hyperreactivity and lowered activation thresholds for activators like ADP, thrombin and collagen, resulting in increased adherence and aggregation. More important, a rise of inflammatory cytokine (TNF- $\alpha$ and IFN- - ) levels was present and chemokine levels (CXCL4 and CCL5) were enhanced in mice specifically lacking trJAM-A. Additionally, we found higher platelet-leukocyte interaction triggered by trJAM-A deficiency. Those factors finally resulted in enhanced atherosclerotic lesion formation, which was most pronounced in the early phase.

In chapter 6, the results described in this thesis and their potential use in drug and diagnostic marker development were discussed and put into perspective. In conclusion, this thesis provides novel insights into JAM-A's contribution in atherosclerotic lesion formation regarding cellular origin, leukocyte infiltration mechanism and potential interference. 
Zusammenfassung 
Herz- und Gefäßkrankheiten sind der häufigste Grund für starke Einschränkungen in der Lebensqualität bis hin zum Tod von Patienten weltweit. Der Kampf gegen diese weit verbreiteten Krankheiten ist eine der größten Herausforderungen unserer Zeit. Zwar erlauben Herz- und Gefäßkrankheiten auf Grund ihrer mannigfaltigen Kausalitäten auch ein großes Repertoire an verschiedenen Wirkstoffen, doch die enge Verbindung vom Immunsystem zu Herz- und Gefäßkrankheiten erlauben nur Therapien, die absolut frei von Nebenwirkung sind.

Die wichtigsten Herz- und Gefäßkrankheiten stellen akutes Herzversagen und Schlaganfall dar, welche typischer Weise durch Stenose von arteriellen Gefäßen als Resultat eines Aufbruchs fortgeschrittener atherosklerotischer Läsionen ausgelöst werden.

Atherosklerose ist eine chronisch progressive Krankheit, ausgelöst von Bestandteilen des Immunsystems. Sie wird durch die Anhäufung von Lipiden, Immunzellen und fibrotischem Material in der Gefäßwand von sogenannten „predilection sites”, welche veränderte Scherflussraten aufweisen, charakterisiert. An diesen „predilection sites“ kommt es, ausgelöst durch eine Hyperlipidämie, zur erhöhten Aufnahme von LDL-Cholesterin in die Gefäßwand. Eine oxidative Veränderung des LDLs hat weiterhin eine von oxidierten LDL (oxLDL) induzierte Aktivierung von Endothelzellen zur Folge. Eine durch Aktivierung der Endothelzellschicht ermöglichte erhöhte Rekrutierung von Monozyten wiederum führt $\mathrm{zu}$ einem gesteigerten Vorkommen von Schaumzellen, deren Inhalt hauptsächlich oxidierte Lipide darstellen. Eine langanhaltende Entzündung der Gefäßwand wird von Schaumzellen sezernierten Faktoren ausgelöst, was eine erhöhte Rekrutierung von weiteren Immunzellen wie $\mathrm{T}$ Zellen und Granulozyten bewirkt. Die chronische Entzündung der Gefäßwand führt letztendlich zur Entwicklung von fortgeschrittenen atherosklerotischen Läsionen, charakterisiert durch einen Kern nekrotischer Zellen überlagert von einer Kappe aus fibrotischem Material. Durch Protease-vermittelter Destabilisierung der fibrotischen Kappe, sowie durch zusätzlicher Nekrose und Erosion der Läsion wird diese instabil. Nach Aufbruch der instabilen Läsion gelangen prothrombotische Faktoren aus dem nekrotischen Kern in die Blutzirkulation, was eine Koagulation des Blutes bewirkt. Dies hat einen Verschluss und damit einen akuten Herzinfarkt oder Hirnschlag zur Folge.

Für das Entstehen atherosklerotischer Läsionen ist die Rekrutierung von Leukozyten eminent wichtig. Viele Anstrengungen wurden bis jetzt unternommen, um Mechanismen und molekulare Effektoren der LeukozytenRekrutierung zu identifizieren. Daraus konnte ein heutzutage allgemeingültiger Mechanismus abgeleitet werden, die sogenannte Leukozyten Adhäsions Kaskade, deren Gesamtbild trotz aller Bemühungen noch nicht vollständig ist.

Der Anfang der Leukozyten Adhäsions Kaskade stellt ein Selektin und PSGL-1 vermitteltes loses Anheften und Rollen von Leukozyten an und über die 
Endothelzellschicht dar, gefolgt von der festen Adhäsion und transendothelialen Migration der Leukozyten durch Integrin und Adhäsionsmolekül vermittelter Interaktion entlang eines Chemokingradienten. Ein wichtiges Molekül, welches Leukozyten-Adhäsion und -Transmigration vermittelt, ist das Junktionale Adhäsionsmolekül (JAM)-A. Mehrere Studien zeigen einen (teilweise sogar entgegengesetzten) Einfluss von JAM-A auf verschiedene Modelle entzündlicher Krankheiten, doch eine Studie bezüglich der Identifikation der einzelnen zellspezifischen Rollen von JAM-A auf atherosklerotischer Läsionsbildung fehlt bis heute (Kapitel 1).

Deswegen lautet die Hypothese dieser Arbeit, dass JAM-A exprimiert durch unterschiedliche Zelltypen diverse Effekte auf die LeukozytenRekrutierung und damit auf die Entstehung atherosklerotischer Läsionen ausübt. Das Wissen um unterschiedliche Funktionen ist nicht nur von fundamentalem Interesse für die Grundlagenforschung, sondern auch für die Wirkstoffentwicklung. Zusätzlich trägt eine exakte Lokalisierung von endothelialen JAM-A unter entzündlichen Bedingungen zum Verständnis des zugrundeliegenden Mechanismus der Leukozyten-Rekrutierung bei.

In Kapitel 2 beschreiben wir eine atherogene Funktion von endothelialen JAM-A durch verminderte Läsionsbildung und LeukozytenRekrutierung bei Abwesenheit dieses Proteins im Kontrast zu der atheroprotektiven Funktion von leukozytärem JAM-A beschrieben durch erhöhte Läsionsbildung und Leukozyten-Rekrutierung in Mäusen mit JAM-A ${ }^{-1-}$ Leukozyten. In vitro und in vivo Transmigrations-Versuche mit Endothelzellen defizient für JAM-A bestätigten die verminderte Rekrutierung gegensätzlich zur Defizienz von leukozytärem JAM-A, was zu einer gestörten $\beta_{2}$-Integrin vermittelten De-Adhäsion und damit zur Verletzung der endothelialen Integrität führt. Darüber hinaus konnten wir zeigen, dass eine erhöhte LeukozytenRekrutierung in Zuge von Behandlungen mit oxLDL oder Zytokinen oder in Bereichen mit veränderten Scherflussraten durch eine lokale Umverteilung von endothelialen JAM-A zur apikalen Endothelzelloberfläche vermittelt wird. Weiterhin erforschten wir einen weiteren atheroprotektiven Mechanismus von hohen und laminaren Scherflussraten. Diese bewirken eine starke Erhöhung der miR-145 Synthese, welche wiederum die Expression von endothelialen JAM-A inhibiert.

Um den zugrundeliegenden Mechanismus der endothelialen JAM-A Umverteilung weiter zu erforschen konnten wir durch Immunfluoreszenzbasierte Detektion von JAM-A und Aktin belegen, dass eine Behandlung mit oxLDL erstens eine Erhöhung der Aktin-Expression, zweitens eine Aktin-Umverteilung und drittens eine erhöhte JAM-A/Aktin Ko-Lokalisation, vermittelt durch stärkere ZO-1/JAM-A Interaktion, bewirkt (Kapitel 3). Darüber hinaus erweitern wir die vorherigen Ergebnisse der LeukozytenTransmigrationsversuche nach Antikörper-vermittelter JAM-A Blockade um eine 
Erniedrigung der oxLDL und Zytokin getriggerten Leukozyten-Rekrutierung nach Blockade mit anti-JAM-A Fab-Fragmenten. Dies zeigt, dass eventuelle Fc-basierte Artefakte während einer Antikörper-vermittelten Blockade von JAM-A hier keine Rolle spielen. Um Informationen über eine pharmakologische Beeinflussbarkeit der JAM-A Funktionen zu erhalten wurde mitunter Lovastatin in Lokalisations- und Transmigrations-Studien eingesetzt. Hierbei konnten wir zeigen, dass Lovastatin als atheroprotektiven Effekt nicht nur Einfluss auf den Cholesterinspiegel hat, sondern auch die oxLDL und Zytokine getriggerte endotheliale JAM-A Umverteilung sowie die Leukozyten-Rekrutierung hemmt.

In einer weiterführenden Studie betrachteten wir genauer die JAM-A Umverteilung und ihren Einfluss auf die Leukozyten-Rekrutierung (Kapitel 4). Mit Hilfe der "atomic force“ Mikroskopie konnten wir zum ersten Mal beweisen, dass der zugrundeliegende Mechanismus für erhöhte T Zell Rekrutierung die Entwicklung von endothelialen JAM-A "hot-spots" darstellt. Diese lokalen Akkumulationen von JAM-A Molekülen nahe aber nicht in den Zell-Zellkontakten zeigen eine vergleichbare Struktur wie die JAM-A Umverteilung aus Kapitel 2 und 3 und sind für eine erhöhte T Zell Adhäsion und Rekrutierung entlang der Zell-Zellkontakte eminent wichtig.

Die in Kapitel 5 dargestellten Ergebnisse verweisen auf eine wichtige Rolle von thrombozytärem JAM-A (trJAM-A) in der atherosklerotischen Läsionsbildung. So konnten wir zeigen, dass trJAM-A-Defizienz für eine Hyperreaktivität der Thrombozyten mit erniedrigter Aktivierungsschwelle für ADP, Thrombin und Kollagen verantwortlich war, was folglich zu erhöhter Thrombozyten-Adhärenz und Aggregation führte. Weiterhin waren höhere Level inflammatorischer Zytokine (TNF- $\alpha$ und IFN- $y$ ) und Chemokine (CXCL4 und CCL5) in Mäusen mit spezifischer trJAM-A Defizienz detektierbar. Darüber hinaus fanden wir eine erhöhte Thrombozyten-Leukozyten-Interaktion. Diese Faktoren resultierten letztendlich in einer Erhöhung der atherosklerotischen Läsionsbildung, die besonders im frühen Stadion ausgeprägt war.

Mit Kapitel 6 diskutieren wir die in Kapitel 2 bis 5 dargestellten Ergebnisse und nehmen Bezug zu einer potenziellen Nutzung von JAM-A in der Entwicklung von diagnostischen Markern und neuen Wirkstoffklassen. Zusammenfassend bietet diese Arbeit neuartige Erkenntnisse zur Rolle von JAM-A exprimiert von verschiedenen Zelltypen in der atherosklerotischen Läsionsbildung einhergehend mit Leukozyten-Rekrutierung sowie deren Mechanismus und Intervention. 
Samenvatting 
Wereldwijd zijn hart- en vaatziekten de oorzaak van een sterk verminderde levenskwaliteit en vroegtijdig overlijden. Het bestrijden van deze ziekten is dan ook een van de grootste uitdaging van deze tijd. De multifactoriële aard van deze ziekten biedt vele mogelijkheden voor therapeutische interventie, maar tegelijker zullen, gezien de sterke link met het immuunsysteem, potentiële geneesmiddelen erg specifiek moeten zijn, om het veroorzaken van onwenselijke bijwerkingen te voorkomen.

De meest voorkomende hart- en vaatzieken zijn hart- en herseninfarcten, die voornamelijk veroorzaakt worden door vernauwing van slagaders als gevolg van ruptuur van vergevorderde atherosclerotische laesies.

Atherosclerose, ook wel bekend als aderverkalking, is een progressieve chronische ziekte, die wordt gekarakteriseerd door een opeenhoping van vetten, ontstekingscellen en vezelachtig materiaal in de bloedvatwand van slagaders. Atherosclerose ontstaat op plekken van veranderde bloedstroomprofielen, waar LDL-cholesterol de vaatwand kan binnendringen, geoxideerd of geacetyleerd kan worden en vervolgens leidt tot activatie van endotheelcellen. Ten gevolge hiervan zullen monocyten de vaatwand binnengaan, differentiëren tot macrofagen onder invloed van het geoxideerde LDL (oxLDL), en verder ontwikkelen tot met vet gevulde schuimcellen. Deze schuimcellen scheiden stoffen uit die zorgen voor een aanhoudende ontstekingsreactie, gekenmerkt door influx van meer monocyten, maar ook ontstekingscellen als T-cellen en granulocyten. De chronische inflammatoire reactie zorgt op termijn voor de ontwikkeling van een vergevorderde atherosclerotische laesie met een necrotische kern omgeven door een fibreus kapsel. Destabilisatie van dit kapsel door proteolytische enzymen, erosie en celdood leiden tot een instabiele laesie. Wanneer een dergelijke instabiele laesie scheurt, komen pro-thrombotische factoren van de necrotische kern in contact met het bloed, hetgeen leidt tot vorming van een bloedstolsel met een hart- of herseninfarct tot gevolg.

Rekrutering van leukocyten is een vereiste in de ontwikkeling van atherosclerose. $\mathrm{Er}$ is reeds veel onderzoek gedaan om de onderliggende moleculaire mechanismen die hierbij een rol spelen te ontrafelen. Uit voorgaand onderzoek is gebleken dat een meerstaps proces gekomen dat bekend staat als de leukocyt adhesie cascade een belangrijke rol speelt, hoewel dit proces nog niet volledig begrepen is.

De leukocyt adhesie cascade start met selectine- en PSGL-1afhankelijke binding van leukocyten aan en het rollen van deze leukocyten over het endotheel. Vervolgens zorgt interactie van integrines en adhesiemoleculen voor binding van leukocyten aan het endotheel, hetgeen gevolgd wordt transmigratie van de leukocyt over de endotheelcellaag naar een chemokinegradiënt. Een belangrijke factor die betrokken is bij de adhesie en transmigratie van leukocyten is Junctional Adhesion Molecule (JAM)-A. Voorgaand onderzoek heeft aangetoond dat JAM-A een rol heeft in modellen van 
verschillende inflammatoire ziektes, alhoewel de resultaten van deze studies soms tegenovergestelde resultaten laten zien, en er nog geen duidelijkheid over is over de rol van JAM-A in de verschillende celtypes die een rol spelen in atherosclerose (hoofdstuk 1).

Daarom is de hypothese van dit proefschrift dat JAM-A in verschillende celtypes verschillende effecten heeft op rekrutering van leukocyten en de ontwikkeling van atherosclerose, hetgeen ook van belang is voor de ontwikkeling van therapeutische interventies. Bovendien zal het bepalen van de lokalisatie van endotheliaal JAM-A tijdens inflammatoire condities belangrijke informatie verschaffen over de onderliggende moleculaire mechanismen.

In hoofdstuk 2 konden we aantonen dat JAM-A op het endotheel een pro-atherogene functie heeft. Door gebruik te maken van muizen die geen endotheliaal JAM-A hebben, kon een verminderde atherosclerotische laesievorming worden gedemonstreerd. Muizen met een deficiëntie voor JAM-A op leukocyten, lieten het tegenovergestelde zien, hetgeen wijst op een beschermende rol van JAM-A op leukocyten in de ontwikkeling van atherosclerose. Hierbij lieten in vitro en in vivo transmigratie-studies zien dat deficiëntie voor JAM-A op het endotheel resulteerde in een verminderde transmigratie van leukocyten. Daarentegen leidde het ontbreken van JAM-A op leukocyten tot een verstoorde de-adhesie van de leukocyten en beschadiging van het endotheel, waarschijnlijk veroorzaakt door versterkte $\beta_{2}$-integrine activatie als gevolg van de afwezigheid van JAM-A afhankelijke internalisatie van integrines. Verder konden we aantonen dat endotheliaal JAM-A focaal geherdistribueerd wordt naar het apicale membraan, zowel na stimulatie met cytokines of oxLDL, als ook op plaatsen van verstoorde flow. Hierdoor wordt adhesie en transmigratie van leukocyten versterkt. Ook kon worden aangetoond dat hoge en laminaire flow tegen de vorming van atherosclerose beschermt door middel van verhoogde aanmaak van miR-145 die de expressie van endotheliaal JAM-A vermindert.

In hoofdstuk 3 hebben we bestudeerd welke mechanismen betrokken zijn bij herdistributie van endotheliaal JAM-A na stimulatie met oxLDL. Op basis van immunofluorescente detectie van JAM-A en actine hebben we aangetoond dat na oxLDL-stimulatie niet alleen actine-herdistributie plaatsvindt, maar dat ook de expressie van actine werd verhoogd. Ook was er een sterkere colokalisatie van JAM-A/actine, waarschijnlijk ten gevolge van de sterkere interactie tussen JAM-A en ZO-1 na behandeling met oxLDL. Bovendien konden we aantonen dat de effecten van behandeling met anti-JAM-A antilichamen op leukocyte-transmigratie die we voorheen beschreven hadden specifiek het gevolg waren van het anti-JAM-A Fab fragment van het antilichaam. Gebruik van enkel deze fragmenten, in plaats van het volledige antilichaam, resulteerde ook in verminderde rekrutering van leukocyten na behandeling met cytokines en oxLDL. Verder hebben we ook meer inzichten verkregen in de beschermende werking van het cholesterol-verlagende middel 
lovastatine, en zagen we dat lovastatine de herdistributie van JAM-A na oxLDLof cytokine-stimulatie verhinderde. Dit was waarschijnlijk het gevolg van stabilisatie van actine in de celjuncties en een verminderde expressie van de oxLDL-receptor LOX-1.

Vervolgens hebben we ook getracht meer inzicht te krijgen in het effect van herdistributie van JAM-A op rekrutering van leukocyten (hoofdstuk 4). Door middel van atomic force microscopie konden we aantonen dat voor paracellulaire rekrutering van T-cellen de vorming van JAM-A hotspots noodzakelijk was, vergelijkbaar met de herdistributie van JAM-A die we reeds beschreven hadden in hoofdstuk 2 en 3 . Deze hotspots waren met name gelokaliseerd bij de endotheliale cel-cel-contacten, en versterkten de adhesie van de T-cellen, die nodig is om rekrutering te bewerkstelligen.

Aansluitend hebben we in hoofdstuk 5 de rol onderzocht van deficiëntie van JAM-A op bloedplaatjes en de invloed hiervan op de vorming van atherosclerotische laesies. Hier bleek dat deficiëntie van JAM-A op bloedplaatjes (trJAM-A) leidde tot hyperreactiviteit van bloedplaatjes en een verlaagde activatiedrempel voor ADP, thrombine en collageen, hetgeen resulteerde in een versterkte adhesie en aggregatie van de bloedplaatjes. Bovendien toonden trJAM-A-deficiënte muizen een verhoogde expressie van pro-inflammatoire cytokines (TNF- $\alpha$ en IFN- $\gamma$ ) en chemokines (CXCL4 en CCL5), en waren er meer interacties tussen bloedplaatjes en leukocyten. Samen zorgden deze factoren voor een versterkte vorming van atherosclerotische laesies, met name in de vroege fase van de laesieontwikkeling.

In hoofdstuk 6 werden tot slot de resultaten beschreven in dit proefschrift en de implicaties hiervan bediscussieerd en in perspectief geplaatst en werden de mogelijkheden voor het gebruik van JAM-A als diagnostische of therapeutische target besproken. In conclusie geeft dit proefschrift nieuwe inzichten in de rol van JAM-A in de ontwikkeling van atherosclerose, met name met betrekking tot de cel-type specifieke rol van JAM-A, de mechanismen de betrokken zijn bij rekrutering van leukocyten en potentiële interventies. 


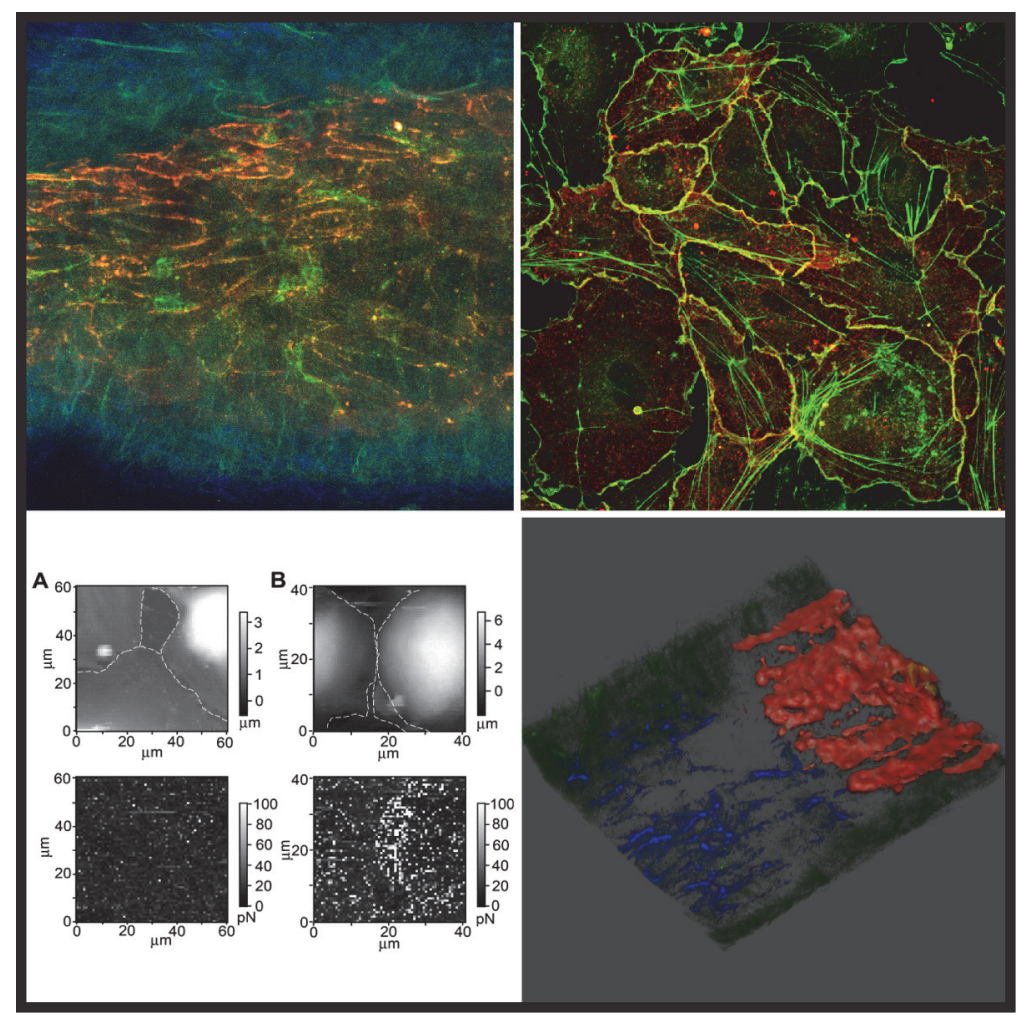




\section{Curriculum Vitae}




\section{Personal details}

Name

Date of birth

Place of birth

Nationality

\section{Education}

Oct. 2013 until now

Oct. 2012 - Sept. 2013

Apr. 2009 - Sept. 2012

Oct. 2003 - Mar. 2009

Apr. 2002
Martin Schmitt

Mai $5^{\text {th }}, 1983$

Düren, Germany

German

Fellowship at the Institute for Cardiovascular Prevention (IPEK), Ludwigs-MaximiliansUniversity, Munich, Germany

PhD-student of the Sonderforschungsbereich 914 (SFB 914): "Trafficking of Immune Cells in Inflammation, Development and Disease", Institute for Cardiovascular Prevention (IPEK), LudwigsMaximilians-University, Munich, Germany

PhD-student in the Euregional Cardiovascular Research Training Group (EUCAR) 'Arterial Remodeling'; RWTH Aachen, Germany and Maastricht University, The Netherlands

Academic studies of Biology (Diploma degree) with the focus on Neurobiology, Microbiology, Genetics and Bioprocess Engineering; concluded with the grade "very good $(1,1)$ " at the RWTH Aachen, Germany

Graduation with Abitur at the grammar school in Düren, Germany

\section{Presentation at scientific conferences}

Jan. 2014

Oct. 2013

Mar. 2013

Jun. 2012
Bernd R. Binder Memorial Lecture, VBM 2014, Vienna

SFB 914 retreat, Menaggio, Italy

Focus on Microscopy Conference, Maastricht, The Netherlands

$17^{\text {th }}$ International Vascular Biology Meeting, Wiesbaden, Germany 
Mar. 2012

Oct. 2010

Sept. 2010

Jun. 2010

May 2010

Feb. 2010

Sept. 2009
Cardiovascular Network Retreat, Castle Rauischholzhausen, Gießen, Germany

$1^{\text {st }}$ Annual Symposium of the Graduate-School "EuCAR" (GRK 1508), Castel Rahe, Aachen, Germany

9th World Congress for Microcirculation, Paris, France Annual meeting of the "Gesellschaft für Mikrozirkulation und Vaskuläre Biologie" (GfMVB), Berlin, Germany

Annual I'MCARIM weekend organized by the Cardiovascular School for Medicine (CARIM), Maastricht, The Netherlands

$1^{\text {st }}$ Joint Meeting GTH and NVTH, Nürnberg, Germany $5^{\text {th }}$ European Meeting on Vascular Biology and Medicine, Marseilles, France

Bernd R. Binder Publication Prize, VBM 2014, Vienna

Jan. 2014

10. 2012 - 09. $2013 \quad$ Fellowship SFB 914 (DFG)

04. 2009 - 09. $2012 \quad$ Fellowship IRTG 1508 (DFG)

Oct. 2011
GfMVB Travel Award for the CBCS/ESC Summer School on Cardiovascular Sciences

\section{Additional scientific activities}

2013, reviewer for Arteriosclerosis, Thrombosis, and Vascular Biology 


\section{List of Publications}

Schmitt M.M., Megens R.T., Zernecke A., Bidzhekov K., van den Akker N.M., Rademakers T., van Zandvoort M.A., Hackeng T.M., Koenen R.R., Weber C. JAM-A guides monocytes into flow-dependent predilection sites of atherosclerosis. Circ. 2014 Jan 7;129(1):66-76.

Schmitt M.M., Fraemohs L., Hackeng T.M., Weber C., Koenen R.R. Atherogenic mononuclear cell recruitment is facilitated by oxidized lipoproteininduced endothelial junctional adhesion molecule-A redistribution. Atheroscl. 2014 Mar 25;234(2):254-264.

Jaczewska J., Abdulreda M.H., Yau C.Y., Schmitt M.M., Schubert I., Berggren P.O., Weber C., Koenen R.R., Moy V.T., Wojcikiewicz E.P. TNF- $\alpha$ and IFN-Y promote lymphocyte adhesion to endothelial junctional regions facilitating transendothelial migration. J Leukoc Biol. 2014; 95, 265-74.

Karshovska E., Zhao Z., Schmitt M.M., Blanchet X., Bidzhekov K., Soehnlein O., von Hundelshausen P., Mattheij N.J., Heemskerk J.W.M., Koeppel T.A., Schober A., Hackeng T.M., Weber C., Koenen R.R. Hyperreactivity of junctional adhesion molecule A-deficient platelets accelerates atherosclerosis in hyperlipidemic mice. Submitted

Asare Y., Schmitt M., Bernhagen J. The vascular biology of macrophage migration inhibitory factor (MIF). Expression and effects in inflammation, atherogenesis and angiogenesis. Thromb. Haemost. 2013; 109, 391-398.

Van de Vijver P., Schmitt M., Suylen D., Scheer L., Thomassen M.C., Schurgers L.J., Griffin J.H., Koenen R.R., Hackeng T.M. Incorporation of disulfide containing protein modules into multivalent antigenic conjugates: generation of antibodies against the thrombin-sensitive region of murine protein S. J. AM. Chem. Soc. 2012; 134, 19318-19321.

Herrmann M., Schäfer C., Heiss A., Gräber S., Kinkeldey A., Büscher A., Schmitt M.M., Bornemann J., Nimmerjahn F., Herrmann M., Helming L., Gordon S., Jahnen-Dechent W. Clearance of fetuin-A-containing calciprotein particles is mediated by scavenger receptor-A. Circ. Res. 2012; 11, 575-584. 


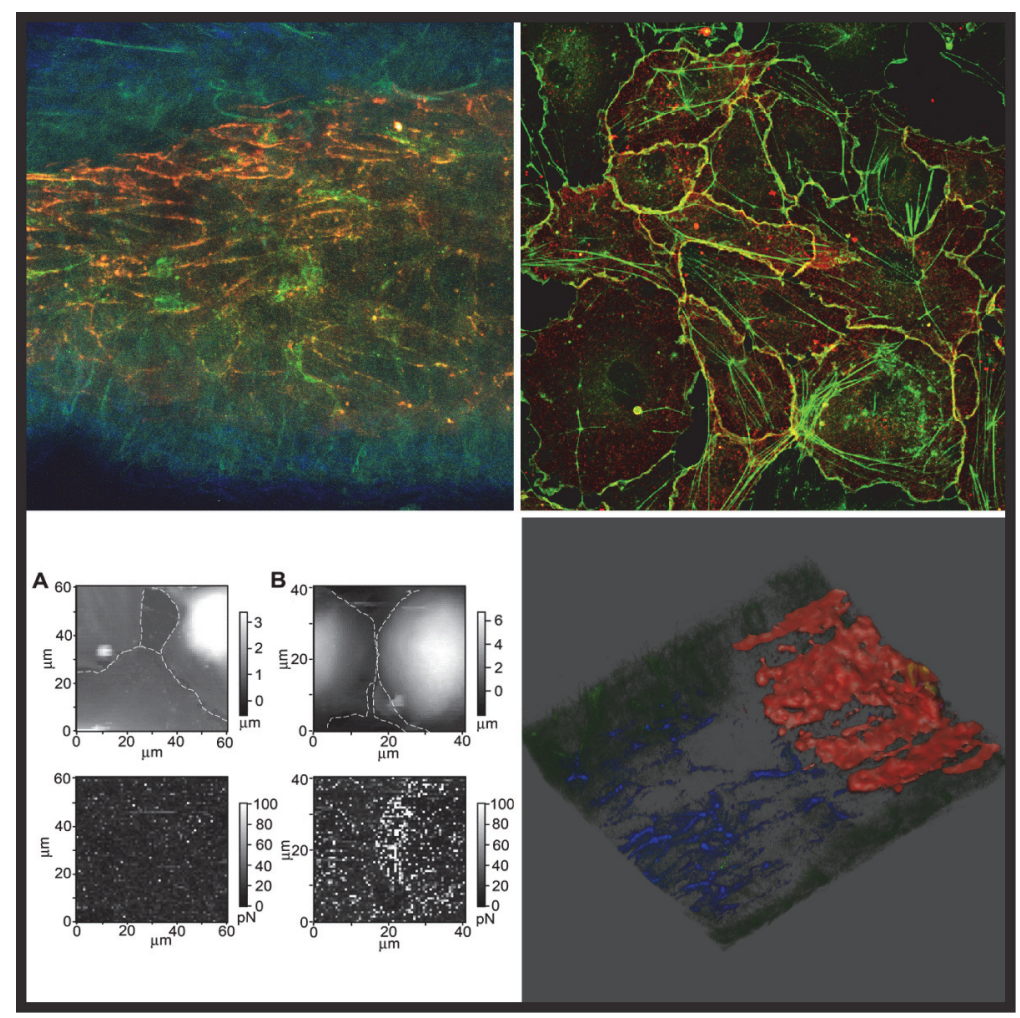


List of

abbreviations 


$\begin{array}{ll}\text { ADP } & \text { Adenosine diphosphate } \\ \text { AF-6 } & \text { ALL-1 fusion partner from chromosome 6 } \\ \text { AFM } & \text { Atomic force microscopy } \\ \text { ALE } & \text { Alanine - leucine - glutamic acid } \\ \text { Apoe } & \text { Apolipoprotein E } \\ \text { ASIP } & \text { Atypical PKC isotype specific interacting protein } \\ \text { BM } & \text { Bone marrow } \\ \text { CAM } & \text { Cell adhesion molecule } \\ \text { CAR } & \text { Coxsackie and adenovirus receptor } \\ \text { CASK } & \text { Calcium/calmodulin-dependent serine protein kinase } \\ \text { CCD } & \text { Charged-coupled device } \\ \text { CDNA } & \text { Copy DNA } \\ \text { CFSE } & \text { Carboxyfluorescein succinimidyl ester } \\ \text { CHO } & \text { Chinese hamster ovary cell } \\ \text { Con-A } & \text { Concanavalin-A } \\ \text { CSK } & \text { COOH-terminal Srk kinase } \\ \text { CVD } & \text { Cardiovascular disease } \\ \text { DAPI } & \text { 4,6-Diamidin-2-phenylindol } \\ \text { Dlg } & \text { Disks large gene } \\ \text { EBM-2 } & \text { Endothelial cell basal medium-2 } \\ \text { EC } & \text { Endothelial cell } \\ \text { ELISA } & \text { Enzyme-linked immunoabsorbent assay } \\ \text { ERM } & \text { Ezrin - radixin - moesin } \\ \text { ESAM } & \text { Endothelial cell-selective adhesion molecule } \\ \text { ESL-1 } & \text { E-selectin ligand-1 } \\ \text { EVG } & \text { Elastica-van-Gieson } \\ \text { FACS } & \text { Fluorescence-activated cell sorting } \\ \text { FCS } & \text { Fetal calf serum } \\ \text { FITC } & \text { Fluorescein isothiocyanate } \\ \text { fMLP } & \text { Formyl-methionyl-leucyl-phenylalanine } \\ \text { FOV } & \text { Field of view } \\ \text { GAG } & \text { Glycosaminoglycan } \\ \text { GAPDH } & \text { Glyceraldehyde 3-phosphate dehydrogenase } \\ \text { GEF } & \text { Guanine-nucleotide-exchange factor } \\ \text { GEF-2 } & \text { Guanine nucleotide exchange factor-2 } \\ \text { GPCR } & \text { G-protein coupled receptor } \\ \text { GTPase } & \text { Guanosine triphosphate hydrolase } \\ \text { HAoEC } & \text { Human aortic endothelial cell } \\ \text { HFD } & \text { High fat diet } \\ \text { HMG-CoA } & \text { 3-hydroxy-3-methyl-glutaryl-Coenzyme A } \\ \text { HUVEC } & \text { Human umbilical vene endothelial cell } \\ \text { I/R } & \text { Ischemic/reperfusion } \\ \text { ICAM-1 } & \text { Intercellular adhesion molecule-1 } \\ & \end{array}$




$\begin{array}{ll}\text { ICAM-2 } & \text { Intercellular adhesion molecule-2 } \\ \text { IFN- } \gamma & \text { Interferon- } \gamma \\ \text { IGF-1 } & \text { Insuline-like growth factor-1 } \\ \text { IgG } & \text { Immunoglobulin G } \\ \text { Ig-Sf } & \text { Immunoglobulin superfamily } \\ \text { IL-1 } & \text { Interleukin-1 } \\ \text { IL-1beta } & \text { Interleukin-1 } \beta \\ \text { IL-6 } & \text { Interleukin-6 } \\ \text { JAM } & \text { Junctional adhesion molecule } \\ \text { KBr } & \text { Potassium bromide } \\ \text { KLF-2 } & \text { Kruppel like factor-2 } \\ \text { LDL } & \text { Low density lipoprotein } \\ \text { LFA-1 } & \text { Lymphocyte function-associated antigen-1 } \\ \text { LOX-1 } & \text { Lectin-like oxidized low density lipoprotein receptor-1 } \\ \text { LTB } & \text { Leukotrien B } \\ \text { MAC-1 } & \text { Macrophage 1 antigen-1 } \\ \text { MADCAM-1 } & \text { Mucosal vascular addressin cell-adhesion molecule-1 } \\ \text { MAGI-1 } & \text { Membrane associated guanylate kinase-1 } \\ \text { MAOEC } & \text { Mouse aortic endothelial cell } \\ \text { MAPK } & \text { p38 mitogen-activated protein kinase } \\ \text { MCP-1 } & \text { Monocyte chemotactic protein-1 } \\ \text { mEC } & \text { Mouse endothelial cell } \\ \text { MiR } & \text { Micro RNA } \\ \text { MMP } & \text { Matrix-metallo protease } \\ \text { MPLSM } & \text { Multi photon laser scanning microscopy } \\ \text { MPV } & \text { Mean platelet volume } \\ \text { mRNA } & \text { Messenger RNA } \\ \text { MUPP-1 } & \text { Multi-PDZ domain protein 1 } \\ \text { NaCl } & \text { Natrium chloride } \\ \text { PAR-4 } & \text { Protease-activated receptor-4 } \\ \text { PBMC } & \text { Peripheral blood mononuclear cells } \\ \text { PBS } & \text { Phosphate buffered saline } \\ \text { PCR } & \text { Polymerase chain reaction } \\ \text { PDZ } & \text { PSD-95 - DLG - ZO-1 } \\ \text { PECAM-1 } & \text { Platelet-endothelial cell adhesion molecule-1 } \\ \text { PF4 } & \text { Platelet factor 4 } \\ \text { PFA } & \text { Paraformaldehyde } \\ \text { PKC } & \text { Phosphokinase C } \\ \text { PMN } & \text { Polymorphonuclear cell } \\ \text { PMT } & \text { Photo-multiplier tube } \\ \text { PPAR- } \gamma & \text { Peroxisome proliferator-activated receptor- } \gamma \\ \text { PSD-95 } & \text { Postsynaptic density protein-95 } \\ & \end{array}$




$\begin{array}{ll}\text { PSGL-1 } & \text { Platelet-selectin glycoprotein ligand-1 } \\ \text { RANTES } & \text { Regulated on activation normal T cell expressed and } \\ & \text { secreted } \\ \text { RAS } & \text { Rat sarcoma } \\ \text { RHO } & \text { RAS homologue } \\ \text { RIE } & \text { Arginine - isoleucine - glutamic acid } \\ \text { RVE } & \text { Arginine - valine - glutamic acid } \\ \text { SCFS } & \text { Single cell force spectroscopy } \\ \text { SHG } & \text { Second harmonic generation } \\ \text { SiRNA } & \text { Small interfering RNA } \\ \text { SMA } & \text { Smooth muscle cell actin } \\ \text { SMC } & \text { Smooth muscle cell } \\ \text { SVEC } & \text { Simian Virus 40 large T antigen-transfected mouse } \\ & \text { endothelial cells } \\ \text { TEM } & \text { Transendothelial migration } \\ \text { TJ } & \text { Tight junction } \\ \text { TNF- } \alpha & \text { Tumor necrosis factor- } \alpha \\ \text { TPLSM } & \text { Two photon laser scanning microscopy } \\ \text { Tris HCl } & \text { Tris(hydroxymethyl)aminomethane hydrochloride } \\ \text { VCAM-1 } & \text { Vascular cell-adhesion molecule-1 } \\ \text { Ve-Cad } & \text { Vascular-endothelial cell cadherin } \\ \text { VEGF } & \text { Vascular endothelial growth factor } \\ \text { VLA-4 } & \text { Very late antigen-4 } \\ \text { VLV } & \text { Valine - leucine - valine } \\ \text { ZO-1 } & \text { Zonula occludens-1 }\end{array}$


LIST OF ABBREVIATIONS 


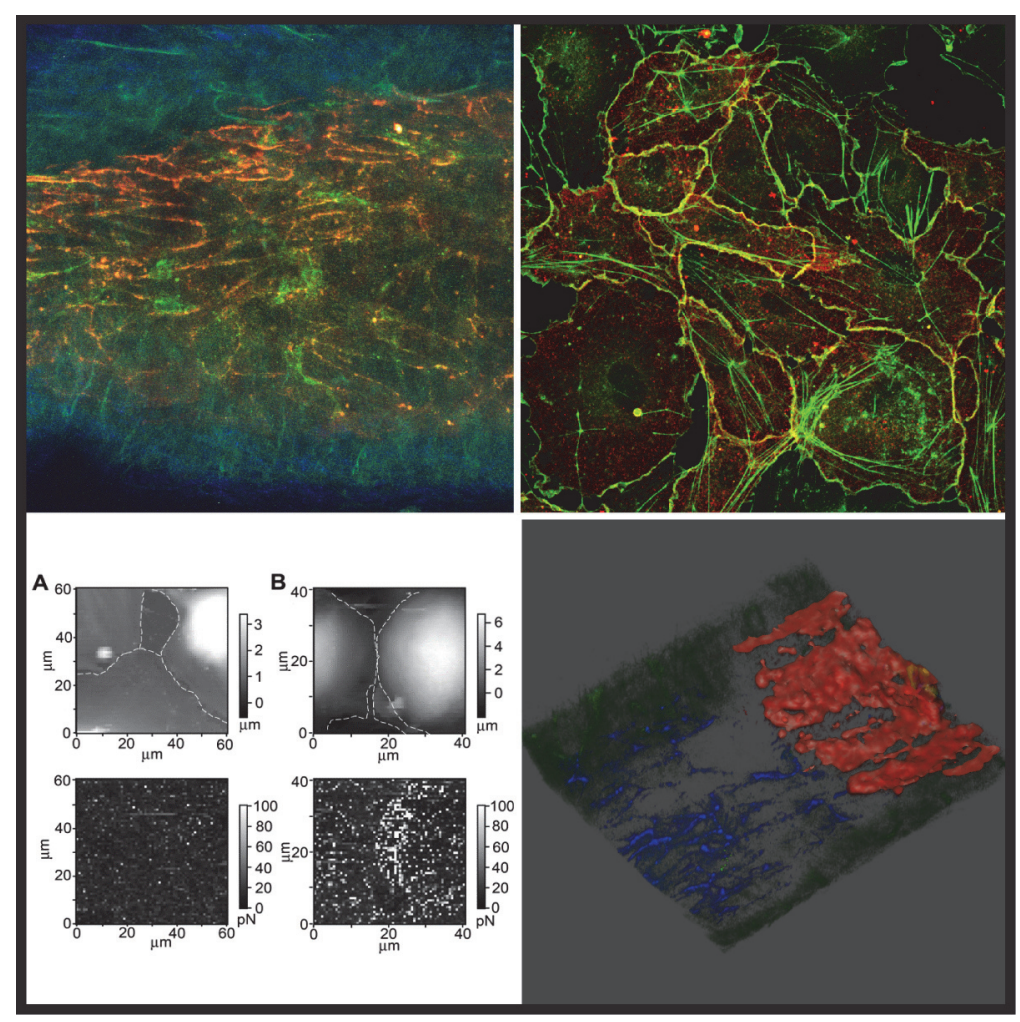


Acknowledgement/ Danksagung 
Nach nun etwa 5 Jahren Promotionszeit ist es endlich soweit diese Arbeit, frei nach Johann Wolfgang von Goethe, für beendet zu erklären. So prägte er eines der wahrscheinlich meist verwendeten Zitate für Dissertationen: „So eine Arbeit wird eigentlich nie fertig, man muss sie für fertig erklären, wenn man nach der Zeit und den Umständen das Möglichste getan hat". So bleiben gewiss noch weitere interessante Details im JAM-A Universum bezüglich dessen Rolle bei der Atherosklerosebildung zu entdecken.

Doch auf dem Weg zur „Fertigstellung“ dieser Arbeit gab es viele Menschen, denen ich zu tiefem Dank verpflichtet bin. Diese Menschen haben mich durch viele oder sogar alle Höhen und Tiefen begleitet und mit dafür gesorgt, dass diese Arbeit überhaupt in dieser Form zustande gekommen ist. Ich hoffe ich kann in diesem Teil jede Kollegin und jeden Kollegen angemessen würdigen.

Geschätzter Prof. Dr. Rory Koenen, lieber Rory. Obwohl es nun etwa 6,5 Jahre her ist, dass wir uns kennen gelernt haben (erster Laborbucheintrag: 12.06.2007), kann ich mich noch ganz gut an unser erstes Treffen erinnern. Ich kam als Student zu dir um mich für einen HiWi-Job beim IMCAR zu bewerben. Du trugst noch lustige bunte Hemden, hattest längere Haare und erzähltest sehr enthusiastisch von FACS (Zellen faxen???) und von einem Protein, das wir bestimmt schon in den Vorlesungen behandelt hätten (JAM-A???). Zum Glück hattest du dich damals nicht von meinem fragenden Gesicht abschrecken lassen, weil die nachfolgenden Jahre als HiWi, Diplomand und Doktorand für mich sehr lehr- und für uns sehr erfolgreich waren. Mit dir machte ich meine ersten Erfahrungen in praktischer Molekularbiologie und bis hin zur Arbeit an den letzten Veröffentlichungen war auf dich immer Verlass. Stets hattest du guten Rat für mich und gabst mir viele Freiheiten um meinen eigenen Arbeits"Stil" zu entwickeln. Dafür möchte ich mich sehr herzlich bei dir bedanken, und ich hoffe, dass wir noch weiterhin einige Projekte zusammen bearbeiten können.

Geschätzter Prof. Dr. Christian Weber, lieber Christian. Am gleichen Tag als ich zum Bewerbungsgespräch bei Rory war kamst du zur Begrüßung kurz vorbei, wobei wohl die brennendste Frage war, ob ich Fußball spiele. Seitdem haben wir schon einige Duell gegeneinander auf dem Platz ausgefochten, aber auch zusammen Titel geholt (z.B. den RWTH-Hallen Cup 2010). Ebenso abseits des Platzes waren wir zusammen erfolgreich, so gabst du dem JAM-A Projekt nochmal den letzten push und hast es damit nochmal einen wichtigen Schritt nach vorne gebracht. Als erster EuCAR-Chef hattest du immer ein offenes Ohr für mich und ich wusste, dass so wichtige Dinge wie zum Beispiel Finanzierungen bei dir nie ein Thema waren. Wie von Rory konnte ich auch von dir viele für Wissenschaftler unverzichtbare Dinge lernen. Nicht nur dein Engagement auf dem Platz, sondern auch in wissenschaftlichen Dingen weiß 
ich sehr zu schätzen. Vielen herzlichen Dank für die gute Zusammenarbeit und auf die nächsten Tore und Paper!

Honored Prof. Dr. Tilman Hackeng, dear Tilman. You were my Maastricht supervisor of the EuCAR project and later on together with Jürgen head of the program. As such, you struggled a lot to launch the Aachen-Maastricht Joint Degree. Additionally, you also took lots of efforts for my personal promotion. For all that and much more I am very grateful. We often had a good laugh and good exchange of thoughts. I guess you get that a lot but I think you are a splendid fellow, never reluctant to slap my back. So, Tilman, thanks a lot for everything you helped me with.

Geschätzter Prof. Dr. Jürgen Bernhagen, lieber Jürgen. Nach einiger Zeit hattest du den Vorsitz des deutschen Zweigs des EuCARs übernommen, und spätestens dann durfte ich als Studentensprecher deine Hilfsbereitschaft und deinen Optimismus kennen lernen. Du warst auch immer offen für neue Ideen, auch wenn sie leider in der angedachten Form nicht zustande kamen, wie zum Beispiel die EuCAR special edition. Darüber hinaus hast du mich und meine EuCAR Kollegen ständig unterstützt, auch auf dem Weg zum AachenMaastricht Joint Degree, der anfänglich ein wenig holprig zu sein schien. Besten Dank dafür.

Geschätzter Prof. Dr. Marc Spehr, lieber Marc. Auch wenn wir uns in etwa nur jedes halbe Jahr gesehen haben fand ich trotzdem die Atmosphäre und die flachen Hierarchien bei euch immer sehr entspannend. Gerne bin ich auch, nach kurzer Einweisung von dir, zur Auswertung von TPLSM Bildern zu euch gekommen. Wenn es für mich nicht das IMCAR geworden wäre, hätte ich mich bestimmt auch bei euch beworben. Auch standen wir vor langer Zeit einmal zusammen mit Prof. Wagner, Philipp, Lutz und Julius auf dem Fußballplatz. Auf jeden Fall danke ich dir herzlich für deine Betreuung meiner Arbeit und für deine Hilfe und die wertvollen Kommentaren zu meinem Projekt.

Honored Prof. Dr. Marc van Zandvoort, dear Marc. For me being (or wanting to be) a two-photon guy talking to you about the whole topic was always very precious, or even by just listening to you I did learn a lot for example about Mister Manders. Moreover I think you are one of those persons with indestructible optimism, which was also quite inspiring for me. Your humor, as part of your positive character, was often very compelling but also sometimes rather sobering. For your valuable advice, the nice conversations and cheering me up, Grazie tante!

Dear Mr. Mullet, dear Remco. If it wasn't for Rory I guess you would be the person from whom I learn the most practical thinks, and for sure you are regarding TPLSM and the flow-chamber model. I guess this peculiar thing made 
the difference for my former and maybe for my future work. Just for this I am deeply indebted to you. But I am also very grateful for all the hours we spent sitting and waiting for the next scan. I really liked the talks, not only the scientific ones, for me they are quiet rememberable. So, I really owe you some, maybe a nice german Schnitzel?

Lieber Michael. An dieser Stelle auch vielen Dank für deine Unterstützung am Aachener two-photon, für die netten Unterhaltungen und für deine spontane Hilfe und Rückendeckung als ich als Neu-Münchener trotzdem euer Mikroskop eine ganze Woche belegt habe. Natürlich war dies alles nichts im Vergleich zu dem einen riesigen Gefallen, den du mir sogar ohne Nachfrage erwiesen hast. Ich glaube nicht nur ich bin dir dafür und deine direkte Art sehr sehr dankbar.

Liebe Frau Mayer. Auch Innen gebührt ein wirklich großes und herzliches Dankeschön. Nicht nur Ihre Arbeit haben Sie mit einer Raffinesse und Umsichtigkeit erledigt, die Ihres gleichen sucht, auch Ihre herzliche und zuvorkommende Art war stets ein Anker für mich. Christian prägte einmal den respektvollen Begriff "Autopilot Mayer", ich würde so weit gehen und sagen, dass dies nicht ganz der Realität entspricht. Einen Autopilot muss man vorher noch aktivieren, doch meist hatten Sie schon Lösungen bei der Hand ohne das Problem vollständig gehört zu haben. Nochmals vielen lieben Dank, ich bin wirklich froh meine ersten Schritte in der wissenschaftlichen Welt mit Ihnen gemacht zu haben.

Liebe AG Koenen, lieber Ali, liebe Birgit, liebe Sabine, liebe Delia. Ich kann mich noch gut an meinen ersten Schreibplatz erinnern, der genau zwischen Alis und Birgits lag. Ich fühlte mich ein wenig wie am London Heathrow Airport, weil mir die ganze Zeit Worte um die Ohren flogen ;-). Aber nachdem ich meine erste Schüchternheit abgelegt hatte merkte ich schnell, dass es ja doch ganz witzig an diesem Flughafen ist. Bei euch allen muss ich mich für die lustigen Gespräche im Labor bedanken, die einen die Inkubations- und ZentrifugationsZeiten versüßt haben. Auch vielen Dank für die anfängliche Geduld, die ihr mit mir hattet, wenn ich mal wieder kleine Fragen zu WB, PCR oder cloning hatte.

Wo ich gerade bei Geduld bin; liebe Aachener TA crew, liebe Sabine, liebe Roya, liebe Melanie, liebe Steffi, liebe Sandra, liebe Susanne, lieber Leon. Bei euch allen muss ich mich sehr für eure Unterstützung und für die tolle Arbeit bedanken, die ihr die Jahre über für mich oder mit mir erledigt habt. Sabine, vielen Dank für deine Einweisungen in Zellkultur, WB und PCR, vor allem auch für die netten Gespräche und Abende mit guten Essen bei dir in Aachen. Roya, man sagt die Lauteste hat nicht immer gleich recht, vielleicht bist du da die Ausnahme ;-). Vielen Dank für deine Hilfe mit den Färbungen und für deine gute Laune. Mel und Steffi, euch gebührt auch ein großes Dankeschön für eure Hilfe 
bei den Präparationen und Schnitten. Sandra, vielen Dank für deine Unterstützung bei der Tierhaltung und den Bestellungen. TVs sind, aus gutem Grund, in vielen Dingen nicht trivial, doch mit deiner Hilfe hat alles gut geklappt. Susanne, wenn es Fragen zum FACSen gab konnte ich damit immer zu dir, vielen Dank für deine Hilfe. Und last but not least Leon, der auch jederzeit hilfsbereit war und mir mit seinen Anekdoten aus dem Leben den Altag verschönert hat. Ohne euch alle hätte es wohl nicht so gut funktioniert, Herzlichen Dank!!!

Liebe 3 Engel für Martin, liebe Patti, liebe Sakine, liebe Wendy. Schon zu meinen Aachener Zeiten ward ihr stets für mich da und habt mir geholfen, wenn es um die Tierzucht ging. Alleine dafür bin ich schon sehr dankbar. Eine Herausforderung wurde es aber, als ich nach München ging und ihr dann fast alleine die Geschicke von 1-2 Linien gelenkt habt. Durch eure Unterstützung aber war dies gar nicht mehr so chaotisch, was ich sehr zu schätzen weiß. Vielen Dank für eure Hilfe!

Liebe Ela. Wir lernten uns als AG Koenen Mitglieder erst in München kennen. Was ich sah war eine tatkräftige und energische Frau, die auch ein JAM-A Projekt bearbeitete. Glücklicherweise kamen dann auch Kooperationen zu Stande. Auch der Austausch mit dir war immer belebend. Vielen lieben Dank für die gute Zusammenarbeit.

Was wäre die Doktorandenzeit ohne gute und mitunter trinkfeste Kollegen? Lieber Ali, liebe Biggi, liebe Helene, lieber Holgor, lieber Maik, liebe Patti, lieber Santosh, liebe Svenja, liebe Yve. Ich denke ohne euch wäre die Zeit bedeutend weniger schön gewesen. So erinnere ich mich noch heute gerne an den Pizza Battle (und andere Koch-Events) und den Casino Besuch zurück und an all die Abende, an denen wir unser karges Gehalt der Kiste oder dem Domkeller kampflos überlassen haben. Ali und Helene, The Aachener wird immer einen Platz bei mir finden. Patti, vielen Dank für deine herzliche und positiv verrückte Art, auch für deine seelische und moralische Unterstützung. Witzig waren auch die letzten Karnevalsfeiern zusammen mit Mr. Croc, hoffe nächstes Mal feiern wir dann "Fassenacht“ zusammen. Holgor, auch unvergesslich: HSV gegen Bremen, Oktoberfestzeit, Schweden, Iren und der "Scherbentanz". Es war eine wirklich schöne Zeit mit euch, und wenn sich die meisten in alle Himmelsrichtungen verstreut haben und man sich nicht mehr so häufig sieht, werde ich euch umso lieber dort besuchen. Mahalo, Bedankt und Dankscheen.

Liebe Maastrichter Bande, lieber Timo, lieber David, liebe Anette. Ich bin sehr froh euch kennen gelernt zu haben und die Partys und Fußball-Abende fand ich echt klasse. Timo, ich hatte bis dato noch nie einen Holländer mit so viel Würde aus einer Aachener Kneipe voll mit Deutschlandfans nach einem 1:2 der 
Holländer gegen Deutschland (EM 2012) schreiten sehen ;-). Auch deine Anteilnahme nach dem deutschen 1:2 im Halbfinale gegen Italien war echt, oder? Anette, vielen lieben Dank für deine Hilfe beim Zurechtfinden im Aachen/Maastrichter Promotionsregularien-Dschungel. David, vielen Dank, dass du mich in die Sonntags-Kick Gruppe aufgenommen hast. Es machte immer sehr viel Spaß. Doch das unbestrittene Highlight: RaR, Metallica, Tribüne, Gänsehaut.

Lieber Timo, zum zweiten. Man kann mit dir nicht nur hervorragend feiern, auch über das Imagen haben wir schnell einen Draht zueinander gefunden. Die daraus resultierende Coop hat ja auch uns beiden was gebracht ;-). Doch nicht nur dafür, auch für deine Hilfe bei formalen Dingen dieser Arbeit bin ich dir sehr dankbar.

La Familia Gerdes, lieber Norbert, lieber Holgor, lieber Tobi, liebe Geli, liebe Sigrid, lieber Dirk, lieber Karl Otto, liebe Chrissy. In München angekommen fühlte ich mich eher heimatlos, da die AG Koenen leider sehr verstreut war. Ihr hattet mich schnell aufgenommen, und schon bald waren die Mittagspausen wieder richtig lustig. Vielen Dank dafür und auch vielen Dank für die netten Abende die da waren und noch kommen mögen.

Meine lieben Eltern, liebe Ingrid, lieber Klaus. Bis jetzt fiel mir das Schreiben der Danksagung relativ leicht, für euren Teil ist das anders. Wohl nicht, weil es mir schwer fällt Dinge zu benennen, wofür ich euch dankbar bin, sondern eher weil ich nicht genau weiß, wo ich anfangen soll. Auch besteht die Gefahr schon tausendfach geschriebenes zu wiederholen. Ich versuche es trotzdem: Nun ist ja schon einige Zeit vergangen, dass es mich nach Aachen und dann nach München verschlagen hatte und ich euch nicht mehr auf der Tasche liege. Doch eure Unterstützung und Fürsorge war nie gebrochen. Egal ob es in München eine Küche aufzubauen gab oder ein großes Fest viel Vorbereitung benötigte, gerne habt ihr den langen Weg auf euch genommen um für mich da zu sein. Ich denke, dass dies das beste Symbol für eure stete Bereitschaft ist große Strapazen auf euch zu nehmen um mir zu helfen. Dafür gebührt euch mein größter Dank!

Martin 
ACKNOWLEDGEMENT 